UNIVERSIDADE DE SÃO PAULO

FACULDADE DE ZOOTECNIA E ENGENHARIA DE ALIMENTOS

FERNANDO DE OLIVEIRA BUSSIMAN

Estudo de associação genômica ampla para as diferenças genéticas entre as marchas batida e picada em equinos Mangalarga Marchador 
Estudo de associação genômica ampla para as diferenças genéticas entre as marchas batida e picada em equinos Mangalarga Marchador

\section{Versão Corrigida}

Dissertação apresentada à Faculdade de Zootecnia e Engenharia de Alimentos da Universidade de São Paulo, como parte dos requisitos para a obtenção do Título de Mestre em Ciências.

Área de Concentração: Qualidade e Produtividade Animal

Orientador: Prof. Dr. Júlio César de Carvalho Balieiro

Coorientador: Prof. Dr. Rogério Abdallah Curi 
Ficha catalográfica elaborada pelo Serviço de Biblioteca e Informação, FZEA/USP, com os dados fornecidos pelo(a) autor(a)

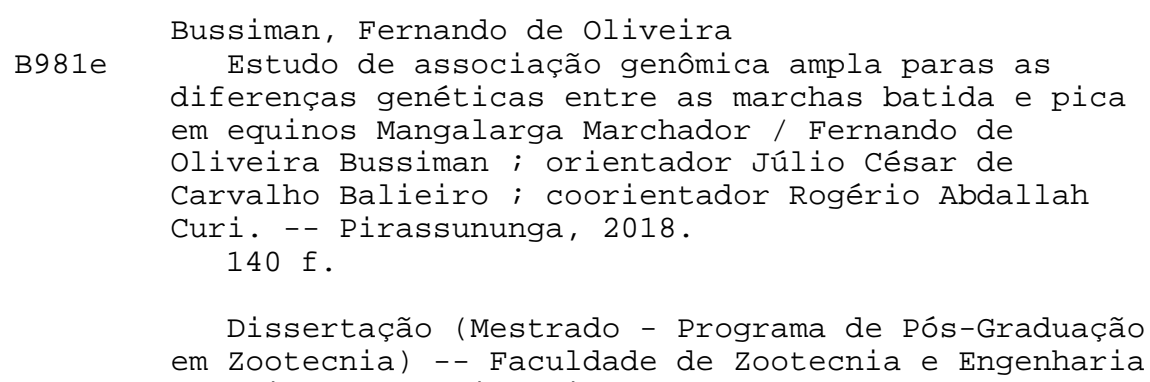

1. GWAS. 2. Marcadores Moleculares. 3.

Melhoramento Genético. 4. DMRT3. 5. RORB. I.

Balieiro, Júlio César de Carvalho, orient. II.

Curi, Rogério Abdallah, coorient. III. Título. 


\section{FERNANDO DE OLIVEIRA BUSSIMAN}

\section{Estudo de associação genômica ampla para as diferenças genéticas entre as marchas batida e picada em equinos Mangalarga Marchador}

Dissertação apresentada à Faculdade de Zootecnia e Engenharia de Alimentos da Universidade de São Paulo, como parte dos requisitos para a obtenção do Título de Mestre em Ciências.

Área de Concentração: Qualidade e Produtividade Animal

Data de aprovação: $\underline{13} / \underline{12 /} \underline{2018}$.

Banca Examinadora:

Prof.(a) Dr.(a) Júlio César de Carvalho Balieiro

Instituição Faculdade de Medicina Veterinária e Zootecnia - FMVZ/USP

Presidente da Banca Examinadora

Prof.(a) Dr.(a) Rachel Santos Bueno Carvalho

Instituição Faculdade de Zootecnia e Engenharia de Alimentos - FZEA/USP

Prof.(a) Dr.(a) Ricardo Vieira Ventura

Instituição Faculdade de Medicina Veterinária e Zootecnia - FMVZ/USP

Prof.(a) Dr.(a) Fernanda Nascimento de Godoi

Instituição Universidade Federal Rural do Rio de Janeiro - UFRRJ 


\section{DEDICATORIA}

À minha eterna "Mulher de Quarenta", Claudete Cândia de Oliveira, a melhor "pãe" do mundo, que sempre me mostrou a fibra; a dignidade e o caráter que uma pessoa hígida deve ter!

Ao meu avô, Claudio Cândido de Oliveira, exemplo de moral e fibra, que sempre me ensinou ao longo de toda sua vida, guiando-me na retidão e mostrando-me que com empenho, dedicação e esmero tudo é possível.

À minha avó, Neusa Felisberto de Oliveira, exemplo de mulher; guerreira por natureza; que conduz a família até hoje como nossa matriarca, que sempre me aconselha e "puxa a orelha"! 


\section{AGRADECIMENTOS}

A Deus porque Ele é bom e justa é sua misericórdia!

À minha família, exemplos primeiros que tive na vida, dos quais sem o apoio, a compreensão e alguns "puxões de orelha", jamais chegaria onde cheguei. Meu muito obrigado a todos vocês!

Ao Prof. Dr. Júlio César de Carvalho Balieiro pela orientação, por ser meu exemplo de pesquisador e me mostrar sempre o Norte para o conhecimento, afinal "alguém tem que comprar sua loucura, professor".

Ao Prof. Dr. Rogério Abdallah Curi pela oportunidade e por confiar em meu trabalho, me mostrando sempre que com zelo e cuidado os resultados são certeiros.

Ao Prof. Dr. José Bento Sterman Ferraz quem primeiro me mostrou o mundo do melhoramento e contribuiu para despertar em mim o interesse que levo comigo pela pesquisa.

Ao Prof. Dr. Joanir Pereira Eler pelas ricas conversas, pela experiência trocada e por sempre me aconselhar acerca da modelagem mais correta, afinal "precisamos ver esse modelo com calma".

Ao Prof. Dr. Ricardo Vieira Ventura que me guiou os passos pelos caminhos da assombrosa imputação e me auxiliou na interpretação de vários resultados, sempre pronto a dizer um "não, é issae" ao final de qualquer conversa, meu sincero muito obrigado pela ajuda professor.

Ao Prof. Dr. Van Raden que me auxiliou no processo de imputação, verificando não somente meus scripts, mas também meus resultados: "a great thank to you professor!".

À minha amiga Elisângela Chicaroni Mattos, "chefe do GMAB” quem deu suporte para todas as análises e vários conselhos, meu muito obrigado Li.

À minha amiga/irmã/mãe Bárbara ABREU SILVA, obrigado por aguentar minhas rabugice e insegurança. Obrigado por me dar abrigo e um teto sem nem pensar duas vezes! Mas, para além disso, obrigado por ser meu apoio, meu pontapé e minha conselheira de todas as horas (sem falar da melhor motorista de fuga!); você foi uma das peças fundamentais deste mestrado.

À minha amiga Bruna Aparecida dos Santos, parceira de coleta de dados, com quem compartilhei bons momentos durante toda a fase "experimental" deste estudo, muito obrigado por segurar a barra nos momentos mais difíceis e por conduzir brilhantemente todas as análises no laboratório quando eu não pude ajudar! 
Ao casal 20 Karen e Maria Camila, por sempre me hospedarem, aturarem meu toque, compartilharem momentos e serem as melhores "amigas na gringa", meu muito obrigado!

Ao amigo Gerardo Cornélio Mamani Mamani Mamani Mamani etc. etc. etc... que me ajudou muito nessa empreitada genômica, sempre me instigando e auxiliando no uso do Plink, meu muito obrigado, nossas conversas e seus ensinamentos levarei sempre comigo.

À amiga Laís Grigoletto que sempre suportou minhas “pausas estratégicas” e meus pedidos de "posso ligar o ar?", muito obrigado por toda a discussão e ajuda neste tempo.

À minha "filha" Bruna Folegatti Santana, que sempre estava pronta para dizer "Fer você consegue" quando eu mais precisava, obrigado pelo apoio, pela amizade, pelas trocas de scripts e por me ajudar sempre que possível no que eu precisasse.

Ao meu "pai” Bruno Casali Sarzi, quem foi responsável por me fazer pensar e repensar estruturas várias vezes, me mostrando como pensar “como um computador". Meu muito obrigado, pela parceria e pela amizade.

Ao meu amigo Felipe Eguti de Carvalho, com quem compartilhei histórias e risadas ao longo de minha estadia no GMAB/FZEA-USP, muito obrigado pela confiança, parceria e amizade.

À minha amiga Marisa Xavier Manço, que sempre esteve disposta a me ajudar, meu muito obrigado.

Ao amigo Bruno da Costa Perez que ajudou a solidificar os resultados deste trabalho e contribuiu para sua execução, principalmente traduzindo meus artigos o que muito economizou-me a bolsa.

Aos amigos do GMA/FZEA-USP que me ajudaram muito seja com conselhos e sugestões, seja suportando meus ataques de desespero quando alguma análise dava errado.

A todos que direta ou indiretamente contribuíram para minha formação pessoal e acadêmica, meu muito obrigado!

À Faculdade de Zootecnia e Engenharia de Alimentos (FZEA/USP) e a Faculdade de Medicina Veterinária e Zootecnia (FMVZ/UNESP) por terem amparado minha pesquisa estruturalmente viabilizando a conclusão deste mestrado.

À Fundação de Amparo à Pesquisa do Estado de São Paulo (FAPESP) pela bolsa (Processo No: 2016/17834-0) e pelo auxílio (Processo No 16/19081-9) que viabilizaram o desenvolvimento desta pesquisa, sem os quais este trabalho não seria possível. O presente trabalho foi realizado com o apoio da Coordenação de Aperfeiçoamento de Pessoal de Nível Superior - Brasil (CAPES) - Código de Financiamento 001. 
"If you only do what you can do, you'll never be more than you are, now..."

(Mestre Shifu)

"As the area of our knowledge grows, so too does the perimeter of our ignorance."

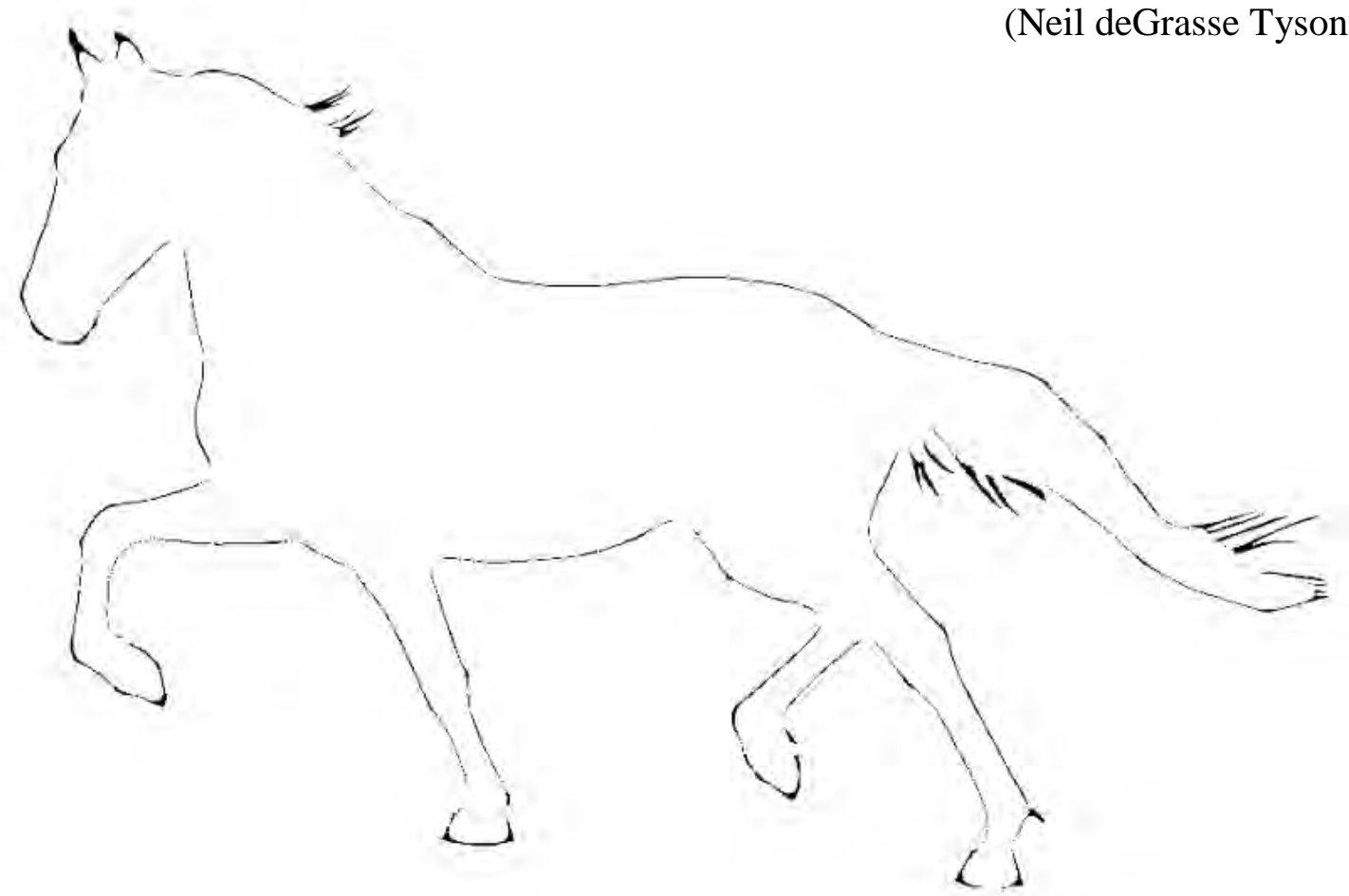




\section{RESUMO}

BUSSIMAN, F. O. Estudo de associação genômica ampla para as diferenças genéticas entre as marchas batida e picada em equinos Mangalarga Marchador. 2018. $140 \mathrm{f}$. Dissertação (Mestrado) - Faculdade de Zootecnia e Engenharia de Alimentos, Universidade de São Paulo, Pirassununga, 2018.

O gene DMRT3 tem sido descrito como o principal gene a atuar na determinação da marcha em diversas raças equinas. O alelo A do SNP 23:g.22999655C>A do DMRT3 foi apontado como responsável por essa característica. Na raça brasileira Mangalarga Marchador, a qual apresenta dois padrões de marcha com características bem definidas, os genótipos AA e CA vem sendo associados à marcha picada e o genótipo $\mathrm{CC}$ à marcha batida. $\mathrm{O}$ objetivo geral do presente prospectar regiões genômicas associadas às marchas batida e picada em equinos Mangalarga Marchador. Foram utilizados 1.230 dados fenotípicos sobre o tipo de andamento (marcha batida $\mathrm{N}=1.006$; marcha picada $\mathrm{N}=227$ ) e, considerando a totalidade da genealogia conhecida para cada animal, 3172 animais no pedigree. Primeiramente foram testadas estratégias de modelagem para esta característica a fim de determinar os efeitos a serem considerados no modelo, bem como a melhor forma de inclusão (efeito fixo ou aleatório). Posteriormente, foi estudada a relação entre as frequências alélicas e genotípicas do gene DMRT3 com os padrões de parentesco e endogamia de acordo com cada tipo de marcha. Um estudo de associação genômica ampla em passo único (considerando informações de animais genotipados e nãogenotipados simultaneamente) foi conduzido para verificar regiões genômicas, polimorfismos de nucleotídeo único e genes relacionados com a determinação do tipo de marcha em cavalos Mangalarga Marchador. Vinte e dois polimorfismos de nucleotídeo único localizados nos cromossomos 4(N = 5), 6 (2), 16 (1), 23 (11), 26 (1) e 29 (2), foram responsáveis por 42,43\% da variância genética aditiva. Foram associados ao tipo de marcha 69 genes, mas cerca de 39 não estavam anotados em equinos. Foi conduzido um blast a fim de recuperar a função mais provável destes genes. Foram encontradas oito vias metabólicas associadas ao tipo de marcha. Os principais genes envolvidos estavam relacionados à percepção de estímulos externos, metabolismo energético-oxidativo, sistema imune e aprendizado e ritmo da locomoção. Não foi possível identificar a(s) variante(s) causal(ais) do tipo de marcha, contudo este estudo foi o primeiro e verificar que a possível determinação genética do tipo de marcha em cavalos Mangalarga Marchador passa por diferenças em níveis metabólicos que garantem a adaptação dos animais ao tipo de andamento.

Palavras-chave: GWAS. Marcadores moleculares. Melhoramento genético. DMRT3. ROR $\beta$. 


\begin{abstract}
BUSSIMAN, F. O. Genome-wide association study for the genetic differences between marcha batida and marcha picada gaits in Mangalarga Marchador equine. 2018. $140 \mathrm{f}$. M.Sc. Dissertation - Faculdade de Zootecnia e Engenharia de Alimentos, Universidade de São Paulo, Pirassununga, 2018.

The DMRT3 gene has been described as the main gene to act in gait determination in several equine breeds. The allele A of the SNP 23:g.22999655C>A of DMRT3 gene was identified as responsible for this trait. In the Brazilian Mangalarga Marchador breed, which presents two gait patterns with characteristics well defined, the AA and CA genotypes have been associated with marcha picada gait and CC genotype with marcha batida gait. The general aim of this study was to prospect genomic regions associated with marcha batida and marcha picada gaits in Mangalarga Marchador equines. 1,230 phenotypic data were used on the type of gait (marcha batida $\mathrm{N}=1.006$; marcha picada $\mathrm{N}=227$ ) and, considering the totality of known genealogy for each animal, 3,172 animals in the pedigree. Firstly, modelling strategies were tested for this trait in order to determine the effects to be considered in the model, as well as the best form of inclusion (fixed or random effect). Based on the best modelling strategy to be used, the relationship between the allelic and genotypic frequencies of the DMRT3 gene with kinship and inbreeding patterns was studied according to each type of gait. A single-step wide genomic association study (considering information from both genotyped and non-genotyped animals simultaneously) was conducted to verify genomic regions, single nucleotide polymorphisms and genes related to determination of gait type in Mangalarga Marchador horses. Twenty two single nucleotide polymorphisms located on chromosomes $4(\mathrm{~N}=5), 6(2), 16(1), 23$ (11), 26 (1) and 29 (2) were responsible for $42.43 \%$ of the additive genetic variance. 69 genes were associated with gait type, but about 39 were not annotated in horses. A blast was conducted in order to recover the most likely function of these genes. Eight metabolic pathways were found associated with gait type and the main genes involved were related to the perception of external stimuli, energy-oxidative metabolism, immune system and learning and rhythm of locomotion. It was not possible to identify the causal variant(s) of the type of gait; however, this study was the first and to verify that the possible genetic determination of gait type in Mangalarga Marchador horses goes through differences in the metabolic levels that guarantee the adaptation of the animals to the type of gait.
\end{abstract}

Keywords: GWAS. Molecular Markers. Animal breeding. DMRT3. ROR $\beta$. 


\section{SUMÁRIO}

\begin{tabular}{|c|c|}
\hline 1 & [NTRODUÇẼ \\
\hline 1.1 & Hipótese \\
\hline 1.2 & 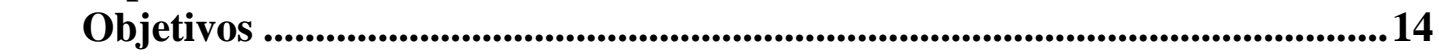 \\
\hline 1.2 .1 & 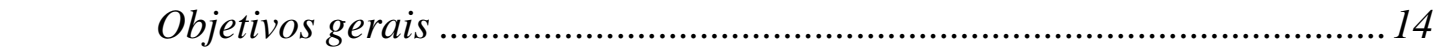 \\
\hline 1.2 .2 & 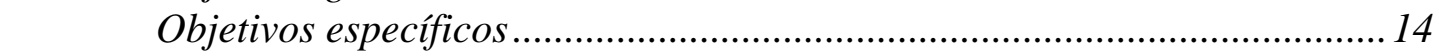 \\
\hline 1.3 & 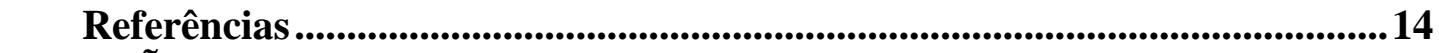 \\
\hline 2 & REVISÃO DE LITERATURA \\
\hline 2.1 & Uma curta história do cavalo \\
\hline 2.2 & Agronegócio do Cavalo \\
\hline 2.3 & Andamentos do Cavalo \\
\hline 2.3 .1 & 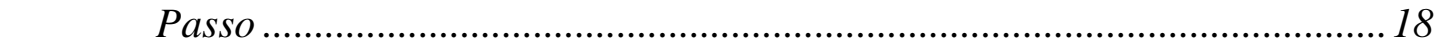 \\
\hline 2.3.2 & Trote ...... \\
\hline 2.3.3 & Cânter e Galope... \\
\hline 2.3.4 & Andadura.............. \\
\hline 2.3 .5 & A marcha. \\
\hline 2.3.5.1 & Marcha Batida. \\
\hline 2.3.5.2 & Marcha Picada .... \\
\hline 2.3.5.3 & Marcha de Centro . \\
\hline 2.3.5.4 & Marcha Trotada.... \\
\hline 2.3.5.5 & 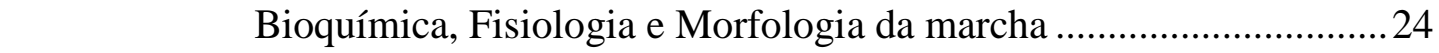 \\
\hline 2.4 & O cavalo Mangalarga Marchador ….........................................................................26 \\
\hline 2.5 & Genética do andamento em equinos \\
\hline 2.6 & Polimorfismos de nucleotídeo único (SNP) ......................................................28 \\
\hline 2.7 & 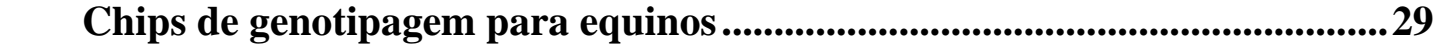 \\
\hline 2.8 & Estudos de associação genômica ampla (GWAS) ..........................................30 \\
\hline 2.9 & Estrutura populacional nos estudos de associação genômica ampla .............31 \\
\hline 2.10 & 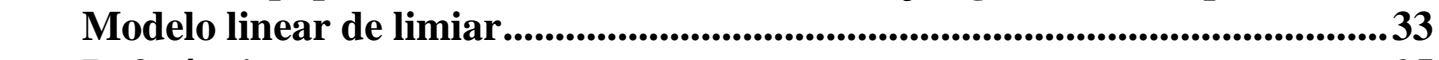 \\
\hline 2.11 & 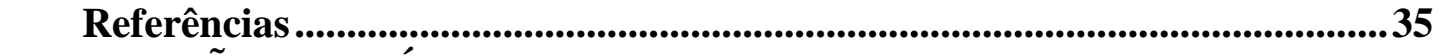 \\
\hline
\end{tabular}

AVALIAÇÃO GENÉTICA DO TIPO DE MARCHA EM CAVALOS MANGALARGA MARCHADOR: COMPARAÇÃO DE MODELOS NA PRESENÇA DE EFEITOS FIXOS COM VARIÂNCIA NULA .........................45

Material e Métodos......................................................................................................... 47

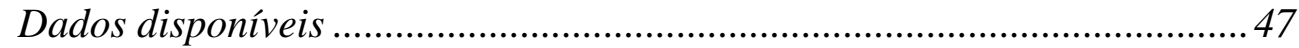

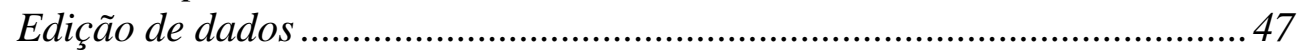

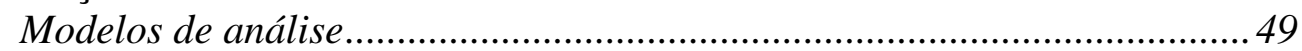

Estimação dos parâmetros genéticos.......................................................50

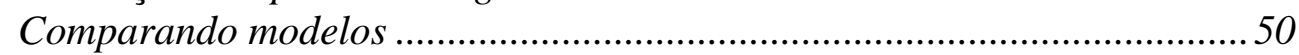

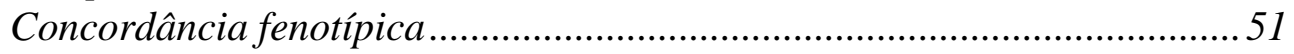

Resultados ........................................................................................51

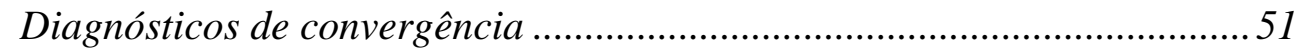

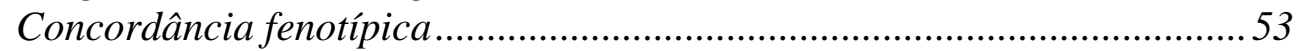

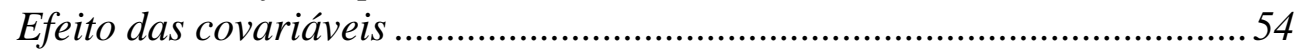

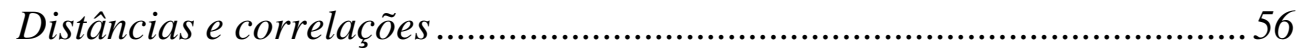

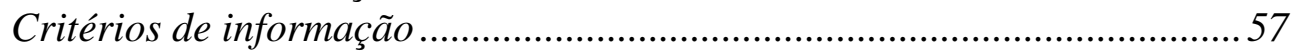

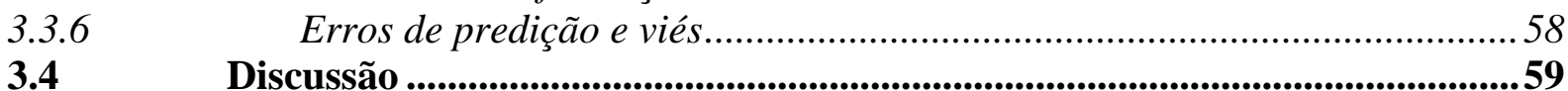




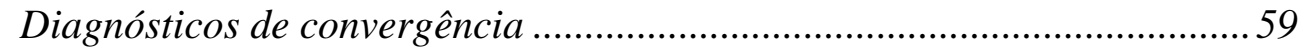

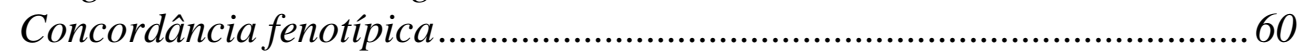

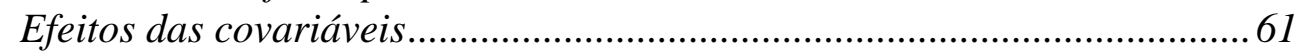

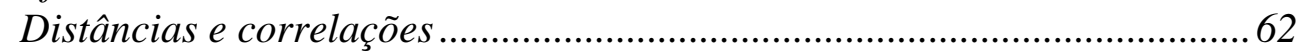

Critérios de informação ..............................................................................63

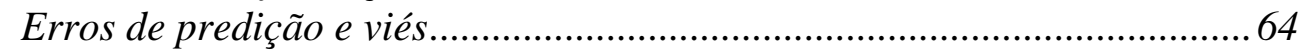

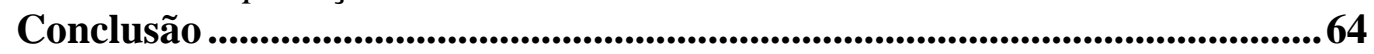

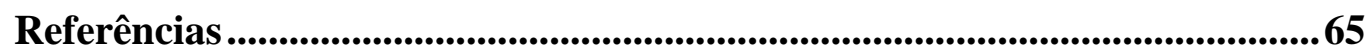

FREQUENCIAS ALÉLICAS E GENOTÍPICAS DO GENE DMRT3 NA RAÇA

DE CAVALOS BRASILEIRA MANGALARGA MARCHADOR E SUA ASSOCIAÇÃO COM OS TIPOS DE MARCHA ...............................................68

Introdução.....................................................................................................69

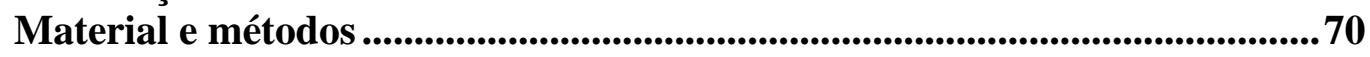

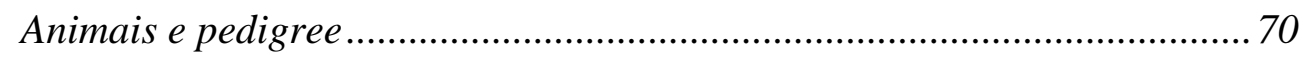

Determinação do tipo de marcha............................................................. 71

Parentesco, endogamia e frequências alélicas ......................................... 72

Efeito do DMRT3 …................................................................................ 72

Resultados .....................................................................................................74

Parentesco, endogamia e frequência alélica ............................................. 74

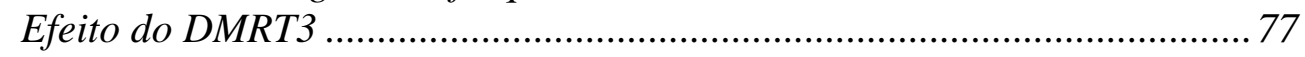

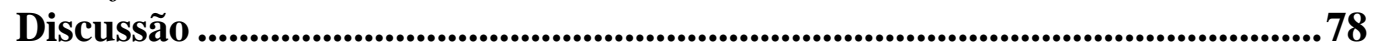

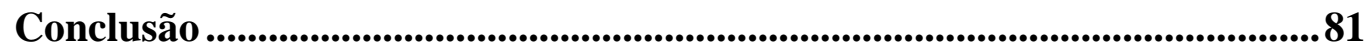

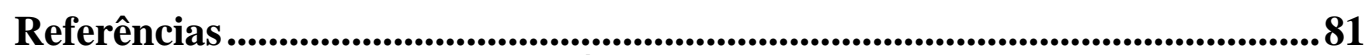

ESTUDO DE ASSOCIAÇÃO GENÔMICA AMPLA: ENTENDENDO A BASE

GENÉTICA DO TIPO DE MARCHA EM CAVALOS BRASILEIROS

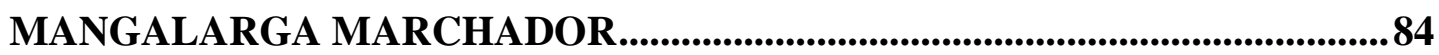

Introdução.......................................................................................................88

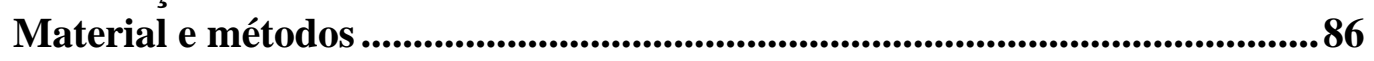

Coleta de sangue, extração de DNA e genotipagem de SNPs .....................86

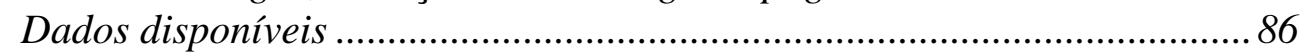

Imputação de genótipo e controle de qualidade ......................................... 87

Estudo de associação genômica ampla e capacidade de previsão.............. 88

Anotação de genes e enriquecimento funcional .......................................... 90

Resultados ..................................................................................................................90

Imputação, estratificação populacional e representação de pedigree ........ 90

Componentes de variância ........................................................................... 92

Associação genômica ampla e análise funcional......................................... 93

Habilidade de predição fenotípica ............................................................... 96

Discussão ......................................................................................................................997

Representação do pedigree, estratificação da população e imputação ...... 97

Componentes de variância ........................................................................ 98

Associação genômica ampla e análise funcional....................................... 99

Habilidade de predição fenotípica .............................................................. 103

Conclusão ............................................................................................................104

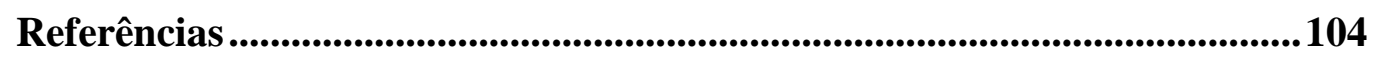

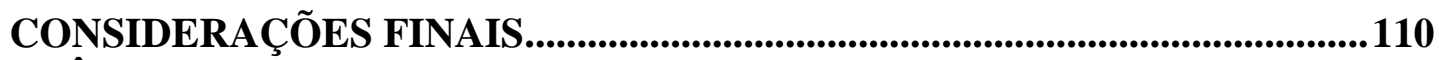

APÊNDICE A - Gráficos de convergência ..............................................................112

APÊNDICE B - Resultados de Imputação ........................................................113

APÊNDICE C - Genes encontrados e enriquecimento funcional ...........................115

APÊNDICE D - Vias metabólicas associadas ao tipo de marcha .......................122 
APÊNDICE E - Resultados da habilidade de predição fenotípica

APÊNDICE F - Outros genes possivelmente envolvidos na determinação do tipo de marcha.

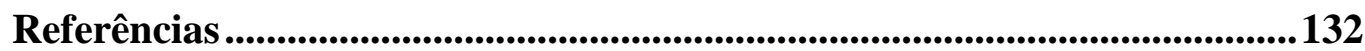
APÊNDICE G - Marcadores em possível desequilíbrio de ligação com o gene DMRT3. 135

APÊNDICE H - Interação entre as vias metabólicas encontradas 136 APÊNDICE I - Haplótipos em torno dos SNPs que explicaram mais de $1 \%$ da variância genética aditiva 


\section{INTRODUÇÃO}

A população mundial de equídeos é estimada em 113 milhões de cabeças, das quais cerca de 58 milhões são equinos (ALMEIDA; SILVA, 2010; FAO, 2017). Petersen et al. (2013a, 2013b) afirmam que os equinos, além de importância econômica, possuem importância como animais de transporte, trabalho e lazer. Deste montante de animais, cerca de $57 \%$ encontram-se nas Américas (ALMEIDA; SILVA, 2010), o que evidencia a importância da equideocultura neste continente.

O rebanho nacional de equinos conta com cerca de 5,5 milhões de cabeças (BRASIL, 2016; IBGE, 2015), o que coloca o Brasil em 4º lugar na classificação dos maiores rebanhos equinos do mundo. Segundo Araújo (2013) o Brasil possui, reconhecidas pelo Ministério da Agricultura, cerca de 12 raças de equídeos, sendo 6 dessas de animais marchadores. Dentre as várias raças criadas no Brasil, o destaque, em números, é para o Mangalarga Marchador, seguido do Nordestino e do Quarto de Milha (BRASIL, 2016).

Segundo Coelho e Oliveira (2008), a equideocultura brasileira movimenta alto volume de recursos e sua maior importância se dá nos âmbitos de manejo da pecuária de corte, principalmente devido aos avanços na genética dos animais. Segundo a CNA (2004) o rebanho equino acompanha o rebanho bovino, apresentando uma correlação entre as quantidades de animais de 0,74 .

Os equinos desempenham diversas funções, em diferentes atividades. Seu uso vai desde o militar, até o lazer, passando pela lida com animais de produção e esporte, o que mostra a contribuição decisiva dos cavalos para as demais criações (KIST et al., 2017). O complexo agronegócio do cavalo no Brasil, movimenta anualmente mais de R 7 bilhões e emprega mais de 3 milhões de pessoas, possuindo, portanto, importância não só econômica, mas social (LIMA; SHIROTA; BARROS, 2006).

Muitos estudos vêm sendo desenvolvidos utilizando biotecnologias na experimentação com equinos (OLIVEIRA, 2010). A descoberta de genes responsáveis pelo andamento marchado nestes animais e a busca de seus mecanismos de controle têm sido amplamente difundidas (ANDERSSON et al., 2012; PATTERSON; STAIGER; BROOKS, 2015; PROMEROVÁ et al., 2014).

Estudo recente conduzido por Fonseca et al. (2017), revelou diferenciação genética entre as marchas batida e picada em equinos da raça Mangalarga Marchador, ou seja, que a marcha batida apresenta controle poligênico, diferentemente da marcha picada. Entretanto, 
devido às condições experimentais, estes autores não conseguiram identificar com precisão as regiões cromossômicas e genes responsáveis por tal fenótipo.

Diferentemente das outras espécies, na maioria dos casos, um cavalo não é vendido pelo seu peso; pela sua precocidade sexual; pela sua produção diária de carne, leite ou ovos; pela qualidade dos pelos de suas crina e cauda... Um cavalo é vendido pelo seu andamento, em outras palavras, ele vale o que ele faz! Um cavalo de corridas é vendido pela maneira que corre, o que nem sempre está relacionado com pódio; um cavalo de trabalho é vendido pela qualidade de seu trabalho e assim por diante.

É fácil perceber, portanto, que o desempenho "esportivo" de um cavalo é o seu valor econômico. Desta forma, tão melhor seja um animal em uma dada modalidade, maior será seu valor. Com a marcha não é diferente, cavalos marchadores tem seu valor na qualidade e no conforto de sua marcha, seja ela de qualquer tipo. Prática comum entre as associações de criadores, os animais são avaliados sempre dentro do seu tipo de marcha, assim, o tipo de marcha em si não torna um animal mais, ou menos, valioso.

Uma outra variável, por vezes particular dos cavalos marchadores, que influencia na precificação dos animais é o regionalismo. Tal fato pode ser evidenciado pela quantidade de animais de um dado tipo de marcha ser maior do que o outro tipo em uma certa região, por exemplo: existe uma preferência no Sudeste por animais de marcha batida, já no Nordeste é a marcha picada que caiu no gosto dos proprietários.

Fruto dessa preferência muitos são os animais que tem seu andamento natural mudado para agradar o gosto de seu proprietário, o que causa muitos problemas ao animal, principalmente para as articulações, uma vez que a morfologia está relacionada ao tipo de marcha (SANTIAGO et al., 2014). Desta forma, conhecer regiões genômicas relacionadas a determinação do tipo de marcha além de auxiliar na seleção dos animais, caso seja de interesse das associações de criadores, pode ajudar a determinar precocemente qual a marcha do animal, evitando-se mudanças e, antecipando vendas.

\subsection{Hipótese}

O tipo de marcha em cavalos Mangalarga Marchador é uma característica com alta herdabilidade e controle poligênico. 


\subsection{Objetivos}

\subsubsection{Objetivos gerais}

Com base no exposto e considerando a escassez de informações genômicas referentes a raça Mangalarga Marchador, o presente trabalho visa a prospecção de regiões genômicas às marchas batida e picada em equinos desta raça.

\subsubsection{Objetivos específicos}

1. aplicar diferentes estratégias em modelos de limiar que poderiam ser usadas para analisar o tipo de andamento em cavalos Mangalarga Marchador sob um modelo animal, considerando os efeitos fixos com variância nula, para avaliações genéticas e futuras predições genômicas;

2. avaliar a relação entre o gene DMRT3 e o tipo de marcha de cavalos Mangalarga Marchador, bem como verificar dos padrões de parentesco e endogamia de acordo com o fenótipo observado;

3. realizar um estudo de associação genômica ampla em passo único (ssGWAS - WANG et al., 2012) para prospectar regiões genômicas, polimorfismos de nucleotídeo único (SNPs) e genes relacionados com o tipo de marcha

4. caracterizar a arquitetura genética desta característica, assim como, investigar a capacidade de predição pelos SNPs significativos, na raça de cavalos Mangalarga Marchador.

\subsection{Referências}

ALMEIDA, F. Q.; SILVA, V. P. Progresso científico em equideocultura na 1a década do século XXI. Revista Brasileira de Zootecnia, Viçosa, v. 39, n. supl. especial, p. 119-129, 2010.

ANDERSSON, L. S. et al. Mutations in DMRT3 affect locomotion in horses and spinal circuit function in mice. Nature, London, v. 488, n. 7413, p. 642-646, 2012.

ARAÚJO, N. Cavalos marchadores brasileiros. Globo Rural, Rio de Janeiro, 2013. Disponível em: <https://globoplay.globo.com/v/2328452/>. Acesso em: 10 mar. 2018.

BRASIL. Ministério da Agricultura Pecuária e Abastecimento - MAPA. Revisão do estudo do complexo do agronegócio do cavalo. Brasília-DF: MAPA, 2016. 
CONFEDERAÇÃO DA AGRICULTURA E PECUÁRIA DO BRASIL - CNA. Estudo do complexo do agronegócio cavalo. Coletânea Estudos Gleba, Brasília, v. 1, n. 39, p. 1-68, 2004.

COELHO, E. G. A.; OLIVEIRA, D. A.A. DE. Testes genéticos na eqüideocultura. Revista Brasileira de Zootecnia, Viçosa, v. 37, n. supl. especial, p. 202-205, 2008.

FOOD AND AGRICULTURE ORGANIZATION OF THE UNITED NATIONS - FAO. FAOSTAT. Disponível em: <http://www.fao.org/faostat/en/\#home>. Acesso em: 7 mar. 2018.

FONSECA, M. G. et al. A Genome-wide association study reveals differences in the genetic mechanism of control of the two gait patterns of the Brazilian Mangalarga Marchador Breed. Journal of Equine Veterinary Science, Maryland Heights, v. 53, p. 64-67, 2017.

INSTITUTO BRASILEIRO DE GEOGRAFIA E ESTATÍSTICA - IBGE. Sistema IBGE de Recuperação Automática - SIDRA. 2015.

LIMA, R. A. D. S.; SHIROTA, R.; BARROS, G. S. D. C. Estudo do complexo do agronegócio cavalo. Piracicaba: CEPEA/ESALQ/USP, 2006.

OLIVEIRA, A. E. T. Genotipagem da imunoglobulina G, em éguas das raças Campolina e Mangalarga Marchador, na Zona da Mata de Pernambuco. 2010. 43 f. Dissertação (Mestrado) - Universidade Federal Rural de Pernambuco, Recife, 2010.

PATTERSON, L.; STAIGER, E. A.; BROOKS, S. A. DMRT3 is associated with gait type in Mangalarga Marchador horses, but does not control gait ability. Animal Genetics, Chichester, v. 46, n. 2, p. 213-215, 2015.

PETERSEN, J. L. et al. Genome-wide analysis reveals selection for important traits in domestic horse breeds. PLoS Genetics, San Francisco, v. 9, n. 1, $2013 a$.

PETERSEN, J. L. et al. Genetic diversity in the modern horse illustrated from genome-wide SNP data. PLoS ONE, San Francisco, v. 8, n. 1, 2013 b.

PROMEROVÁ, M. et al. Worldwide frequency distribution of the "Gait keeper" mutation in the DMRT3 gene. Animal Genetics, Chichester, v. 45, n. 2, p. 274-282, 2014.

SANTIAGO, J. M. et al. Comparação entre as medidas morfométricas de equinos mangalarga marchador de marcha batida e marcha picada. Arquivo Brasileiro de Medicina Veterinaria e Zootecnia, Belo Horizonte, v. 66, n. 2, p. 635-639, 2014. 


\section{REVISÃO DE LITERATURA}

\subsection{Uma curta história do cavalo}

A domesticação do cavalo se deu por volta de 5,5 a 6 milhões de anos atrás (SCHUBERT et al., 2014; WARMUTH et al., 2012) e o surgimento da equitação, carruagens e cavalaria militar, transformou drasticamente a sociedade. Essa domesticação teve impacto não só econômico, mas social (KELENKA, 2009), uma vez que os cavalos proveram não somente leite e carne, mas tornaram possível a conquista e desenvolvimento de impérios nômades (OUTRAM et al., 2009).

Os cavalos permanecem como meio de transporte e fonte de proteína animal, mas durante a Idade Média adquiriram maior importância, atuando como responsáveis diretos, pela assim chamada, "Revolução Industrial da Idade Média". O cavalo foi empregado em várias tarefas, o que levou a um grande desenvolvimento dos meios de produção e processamento de produtos. Todavia, o homem tenha tido em mente sempre a melhoria dos animais, tal fato levou a um grande aumento da força de tração dos animais, que durante a Idade Média chega a 5,5 toneladas por parelha (PERNOUD, 1997). Desde sua domesticação o cavalo esteve diretamente envolvido com a história da humanidade, servindo como transporte, força motriz e atuando como montaria em batalhas (RIBEIRO, 1988).

O cavalo passa a representar um status entre a nobreza feudal, que era a única classe com poder econômico suficiente para manter cavaleiros montados a seu serviço (PERNOUD, 1997). Passa-se então a ser criada uma relação entre força, riqueza e liberdade e a figura do cavalo. Após a adoção do arado tracionado por cavalos, durante a Idade Média, os meios de plantio e produção começam a ser aprimorados e, após essa fase, os cavalos permanecem como meios de transporte e fins agropecuários (pastoreio e tração), ou como montaria/tração militar (primeira e segunda guerras mundiais, respectivamente).

Quando os automóveis foram inventados, o cavalo perdeu espaço como transporte, mas encontrou terreno fértil no esporte. Caça e Turfe, que eram populares apenas entre apostadores, começam a representar nobreza e atrair mais investimentos. Este processo culmina com a criação de grupos de animais mais especializados para cada modalidade equestre. Tais grupos passam a ser chamados de raças e, atualmente, várias são as raças selecionadas, até mesmo, para um andamento mais confortável (ANDERSSON et al., 2012; PATTERSON; STAIGER; BROOKS, 2015). 


\subsection{Agronegócio do Cavalo}

Com 5,8 milhões de equídeos (IBGE, 2015) a quantia de dinheiro movimentada pelo seguimento é de R \$ 16,15 bilhões (BRASIL, 2016). Em termos de empregos gerados, são cerca de 6 milhões de pessoas empregadas direta ou indiretamente na atividade (MAPA, 2016). De acordo com a FAO (2017) este rebanho é expressivo em nível mundial; o Brasil possui o $5^{\circ}$ maior rebanho equino do mundo e o terceiro entre as Américas. Somados, cavalos, asininos e muares, são cerca de 8 milhões de cabeças, que movimentam R \$ 7,3 bilhões por ano, apenas para atividades antes da porteira (criação de animais) (BRASIL, 2016; CNA, 2004; LIMA; SHIROTA; BARROS, 2006).

De acordo com Lima, Shirota e Barros (2006), devido ao número de empregos gerados, o cavalo tem importância não somente econômica, mas social. Existem cerca de 30 segmentos envolvidos com o agronegócio do cavalo, desde a produção de insumos até a destinação final e, o número total de empregos, diretos e indiretos, supera os números da indústria automobilística (ARAÚJO, 2013).

Atualmente, o Brasil figura na quinta posição no ranking dos maiores produtores de carne de cavalo (FAO, 2017). De acordo com o Brasil (2017) o movimento financeiro da exportação de carne equina é de US\$ 7 bilhões, sendo exportados cerca de 3 mil toneladas. Cerca de $80 \%$ dos cavalos no Brasil são usados para atividades de campo e/ou produção de carne. Os outros $20 \%$ restantes são os, assim chamados, "animais de elite" (LIMA, 2013). Quando esses "animais de elite" são analisados separadamente são responsáveis pelo faturamento de R $\$ 12$ milhões anualmente.

De acordo com Fábio (2013), a valorização dos animais é substancial, uma vez que animais da raça Quarto de Milha se valorizaram em 56\% de 2009 a 2013. Outras raças como Mangalarga Marchador, tem comportamento semelhante, sendo o faturamento médio destes nos leilões em 2013 em torno de R\$ 94 milhões.

O preço de alguns animais também impressiona. O cavalo mais caro do Brasil é um cavalo Crioulo, que teve seu valor estimado em $\mathrm{R} \$ 16,25$ milhões. De acordo com Guerra Jr. (2008), a raça mais difundida no Brasil é a Mangalarga Marchador, que experimenta valorização dos animais (FÁBIO, 2013). Em 2015 um garanhão desta raça foi avaliado em R\$ 4,02 milhões, quando 5\% de suas cotas reprodutivas foi vendido por R $\$ 201$ mil, fato que o tornou o animal mais caro da história da raça Mangalarga Marchador e, o terceiro no país. 


\subsection{Andamentos do Cavalo}

Com o tempo, o ser humano começou a estudar o padrão de locomoção dos equinos, com o objetivo de corrigir defeitos e aperfeiçoar os padrões de cada andamento. De acordo com Ensminger (1990), os andamentos do cavalo são divididos em naturais (andamentos que a maioria dos cavalos pode executar, sem treinamento), ou artificiais, que são, em geral, usados em competições e requerem elevado grau de treinamento, tanto de cavalo quanto de cavaleiro. Os andamentos naturais são reclassificáveis em outras duas categorias distintas: saltados e não saltados (ANDRADE, 1986).

\subsubsection{Passo}

O andamento de menor velocidade dos cavalos é o passo, que é feito por todas as raças (TOLEDO, 2006). Trata-se de um andamento simétrico e, por isso, os pares de membros contralaterais são igualmente espaçados no tempo e no espaço, o que permite uma movimentação dissociada dos membros direitos e esquerdos (CLAYTON; HOBBS, 2017). A despeito da reduzida velocidade do passo (em média $7 \mathrm{~km} / \mathrm{h}$ - HARRIS 1993) provavelmente este seja o andamento mais complexo dos cavalos (BARREY, 2013). Uma vez que neste andamento não há suspensão (momento em que o animal perde contato com o solo nos quatro membros), a cobertura de terreno fica dependente do alcance dos membros (MOORE, 2010).

A propulsão do movimento inicia-se sempre com os membros posteriores (CLAYTON, 2016; CLAYTON; HOBBS, 2017). Assim, se o animal inicia o movimento com o membro posterior direito, a sequência de todos os movimentos é: membro pélvico direito, membro torácico direito, membro pélvico esquerdo e membro torácico esquerdo. Todos os movimentos de apoio, elevação e avanço dos cascos seguem uma cadência de quatro tempos (BARREY, 2013; MOORE, 2010), em que cada membro está em um tempo diferente (Figura $1)$.

Figura 1 - Esquema visual da sequência de movimentos em uma passada completa do passo em equinos

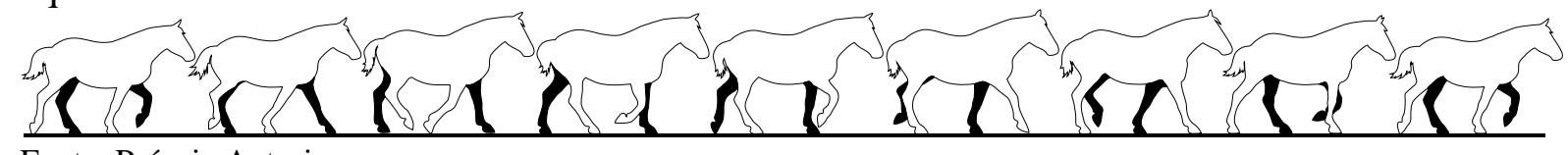

Fonte: Própria Autoria. 
Em geral, os cascos posteriores tocam o solo a frente das pegadas dos cascos anteriores. Isso é muito desejável, uma vez que quanto maior o avanço do trem posterior em relação ao anterior, maior também será o conforto do passo à montada. Para cadenciar o ritmo e alcançar equilíbrio, o pescoço, do animal, move-se para cima e para baixo durante a troca de apoios (HARRIS, 1993). O passo possui duas velocidades, mas usualmente, apenas a velocidade mais lenta é executada; embora existam modalidades equestres baseadas em passo acelerado. Existem até mesmo raças especializadas e selecionadas para altas velocidades ao passo, sem passar para o trote (ANDRADE, 1984; BECK, 1983; HARRIS, 1993).

\subsubsection{Trote}

Em ordem ascendente de velocidade, o próximo andamento (natural) após o passo é o trote. O trote é um andamento a dois tempos, com ampla variação de velocidades, mas que, em média, giram em torno de $13 \mathrm{~km} / \mathrm{h}$ (HARRIS, 1993). Trata-se de outro andamento simétrico no qual o animal possui duas fases de apoio diagonais e duas fases de suspensão (MOORE, 2010). Diferente do passo, no trote o resultado da simetria é que os pares de membros diagonais deslocam-se no mesmo intervalo de tempo, o que resulta em associação destes membros (BARREY, 2013; BROWN et al., 2015; CLAYTON, 2016; CLAYTON; HOBBS, 2017), conferindo a este andamento grande estabilidade (HOBBS et al., 2014; TOLEDO, 2006).

De acordo com Toledo (2006), assim como o passo, o trote também é impulsionado pelo trem posterior, se o movimento se inicia com o membro posterior esquerdo, uma possível sequência de movimentos seria: membro pélvico direito - membro torácico esquerdo, suspensão, membro pélvico esquerdo - membro torácico direito, suspensão (DITTRICH et al., 2001) (Figura 2).

Figura 2 - Esquema visual da sequência de movimentos em uma passada completa do trote em equinos

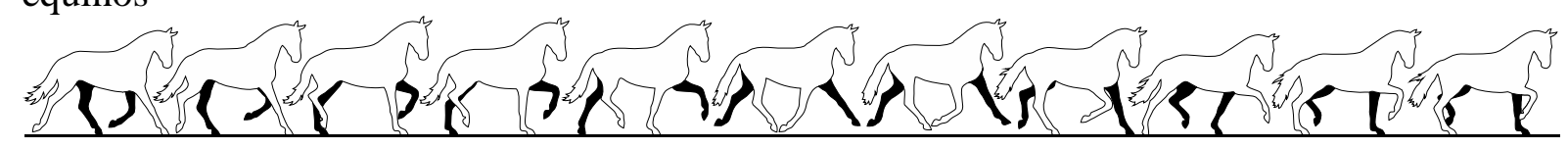

Fonte: Própria Autoria.

\subsubsection{Cânter e Galope}

Outros dois andamentos naturais são executados por todos os cavalos: o cânter e o galope, este último nada mais sendo do que uma variante do primeiro em velocidade, levando 
a corrida (BARREY, 2013; ROBERTS, 1995). Sendo um andamento a três tempos, o cânter (Figura 3), em geral, é mais rápido que o trote médio, podendo atingir velocidades em torno de $30 \mathrm{~km} / \mathrm{h}$ (TOLEDO, 2006). Este é um andamento assimétrico no qual o membro predominante (último a deixar o solo - BARREY, 2013) está do mesmo lado nos pares dianteiros e posteriores (CLAYTON; HOBBS, 2017). A velocidade e a cobertura de terreno no Cânter dependem da amplitude da passada do cavalo, sendo esta dependente, neste andamento, do comprimento do animal e a relação comprimento/altura.

O galope, ou corrida, é o andamento mais veloz do cavalo. Trata-se de uma evolução em velocidade do cânter, ao qual é muito parecido, exceto pelo ritmo. O galope é um andamento a 4 tempos, dissociado portanto, cuja velocidade média gira em torno de $50 \mathrm{~km} / \mathrm{h}$. No cânter a fase de apoio dos pares de membros diagonais é sincronizada, já no galope o deslocamento dos membros diagonais é dissociado (BARREY, 2013). A cobertura de terreno com esse andamento é muito maior, mas, ainda sim, depende, agora não só da amplitude da passada, mas também, do comprimento corporal do cavalo (HARRIS, 1993). Geser-Von Peinen et al. (2013), trabalhando com dados de oscilação vertical entre cavalo e cavaleiro, reportaram que no galope o centro de massa dos equídeos é menos sujeito a ação de forças verticais que no cânter.

Figura 3 - Esquema visual da sequência de movimentos em uma passada completa do cânter em equinos

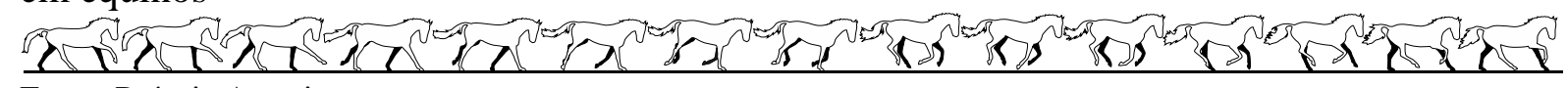

Fonte: Própria Autoria.

\subsubsection{Andadura}

Analogamente ao trote, outro andamento que alguns animais apresentam naturalmente é a andadura. No Brasil, ela é desclassificatória quando da concessão de registro genealógico em todas as associações de criadores de cavalos de marcha e trote, com exceção dos animais destinados a competições de surke. Trata-se de um andamento com deslocamento totalmente lateral, em que os membros se deslocam aos pares direitos e esquerdos, alternando entre apoios bipedais e suspensão dos quatro membros (DE ANDRADE, 2009; TOLEDO, 2006) (Figura 4). 
Figura 4 - Esquema visual da sequência de movimentos em uma passada completa da andadura em equinos

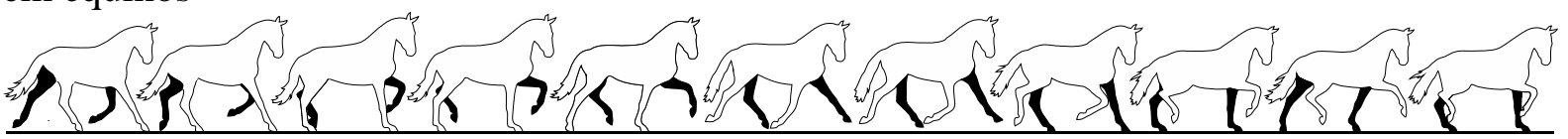

Fonte: Própria Autoria.

\subsubsection{A marcha}

Entre o trote e a andadura existe um outro andamento intermediário (Figura 5), executado por cavalos de algumas raças de maneira natural. A marcha reúne um rendimento elevado (característica do trote) com alta comodidade e conforto à montada (atributo próprio da andadura) sem, contudo, apresentar momentos de suspensão (ANDERSSON et al., 2012; ANDRADE, 1986; DE ANDRADE, 2009; TOLEDO, 2006).

A marcha é um andamento dissociado, de modo que cada membro se encontra em um tempo diferente das fases de apoio, elevação e avanço no trajeto realizado pelo membro. Desta forma, a duração das fases de apoio e elevação de cada membro não é a mesma, bem como, para os pares de membros em deslocamentos laterais e diagonais (LAGE, 2001; NASCIMENTO, 1999; TOLEDO, 2006). Com efeito, o resultado desta dissociação é um maior, senão constante, contato do animal com o solo por meio dos membros, o que não ocorre no trote que alterna momentos de apoio e completa suspensão. Este constante contato com o solo é responsável pela maciez e comodidade do cavalo de marcha (PROCÓPIO, 2004; TOLEDO, 2006).

Figura 5 - Diagrama dos tipos de andamento dos cavalos

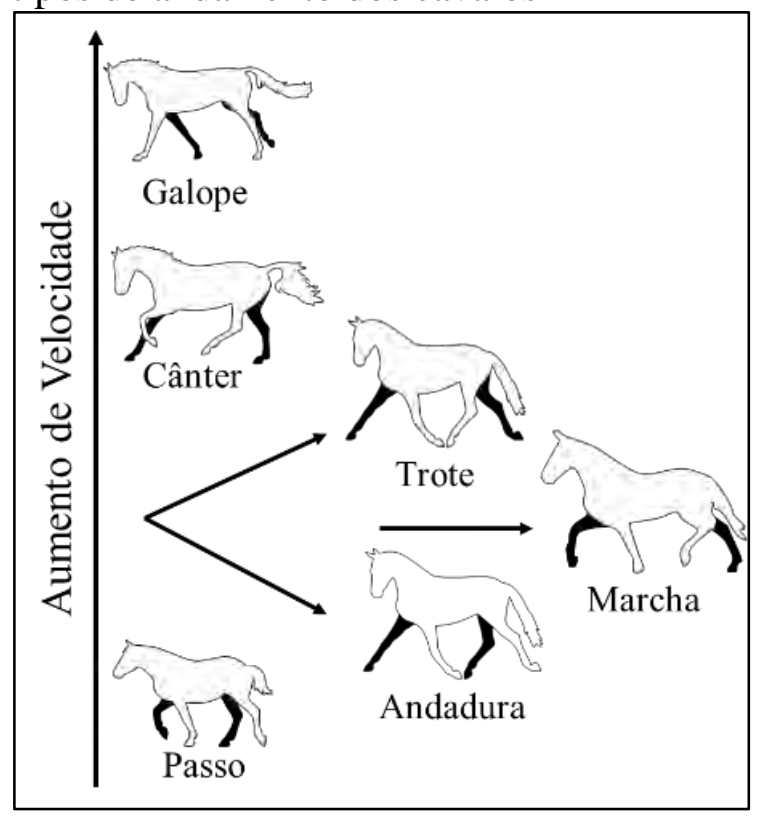

Fonte: Própria Autoria. 
Por definição a marcha é um andamento dissociado e cômodo, alternando apoios diagonais e laterais, intercalados por momentos de tríplice apoio. Segundo Araújo (2013), no Brasil há, oficialmente, cinco raças de equinos marchadores. Nestas raças, é considerado desclassificatório para a concessão de registro genealógico o trote e a andadura. São elas: Piquira, Campolina, Mangalarga, Mangalarga Marchador e Campeiro, cada uma executa uma ou mais marchas que são agrupadas em três tipos fundamentais (Figura 6).

Figura 6 - Diagrama posicionando as várias modalidades de marcha entre a andadura e trote

Andadura

Fonte: BUSSIMAN, F. O. Parâmetros genéticos relacionados à marcha e à conformação de equinos da raça Mangalarga. 2015. 49 f. Trabalho de Conclusão de Curso (Graduação) - Faculdade de Zootecnia e Engenharia de Alimentos, Universidade de São Paulo, Pirassununga, 2015.

\subsubsection{Marcha Batida}

Hussni, Wißdorf e Nicoletti (1996), discutiram que a marcha batida seria um andamento simétrico com 4 batidas e oito momentos de apoios. Por sua vez, Seidel (1989), sugeriu que tais características são próprias do passo, o que reforça a ideia de que a marcha seria equivalente, em diagrama e sequência de apoios, ao passo acelerado. Jung (1998), reportou que a variação natural da marcha batida seria entre 6 e 8 momentos de apoio. Desta forma a marcha batida seria um andamento com predominância dos deslocamentos em diagonal (HUSSNI; WIßDORF; NICOLETT, 1996; NICODEMUS; CLAYTON, 2003).

Embora trate-se de um andamento a 4 tempos, as batidas dos cascos se aproximam a dois tempos, uma vez que o grau de dissociação não seria tão elevado. Fruto da dissociação, os cascos dos pares de membros em diagonal, alçam e apoiam em momentos diferentes, fazendo com que se ouça um som de "pra-pra" ao longo da movimentação do cavalo (ANDRADE, 1984). Se completa, em sequência de apoios, a proporção de tríplices apoios gira em torno de $20 \%$ do tempo total da passada e, tornam-se ausentes os apoios monopedais, duplos (frontais e traseiros) e quádruplos. 


\subsubsection{Marcha Picada}

A marcha picada foi definida como um andamento simétrico a 4 tempos, com 8 momentos de apoios (HUSSNI; WIBDORF; NICOLETTI, 1996), chamada de marcha propriamente dita, por Chieffi (1943), por apresentar momentos de tríplice apoio intercalados a apoios bipedais laterais definidos (JUNG, 1998; WIBDORF, 1990; WIßDORF; SEVERIN, 1992). Neste tipo de andamento ocorre predominância dos deslocamentos em lateral (NICODEMUS; CLAYTON, 2003), ou seja, membros de um mesmo lado do corpo, com maior tempo de elevação dos membros anteriores, o que reduz o rendimento das passadas, uma vez que o avanço horizontal do membro é prejudicado em detrimento do deslocamento vertical (ANDRADE, 1984; DE ANDRADE, 2009).

Tratando-se de um andamento a 4 tempos, devido ao elevado grau de dissociação presente nesta modalidade de marcha, as batidas dos cascos no solo ocorrem também em quatro momentos. Fruto deste deslocamento completamente dissociado, o diagrama da marcha picada segue o mesmo diagrama do passo, portanto cada batida dos cascos no solo é ouvida separadamente, o que em geral leva a um som de "taca-taca-taca" (ARAÚJO, 2013). Segundo Toledo (2006), os apoios triplos são maiores do que $20 \%$ do tempo de duração da passada, não ocorrendo apoios monopedais.

\subsubsection{Marcha de Centro}

Trata-se de um andamento intermediário às marchas batida e picada, com dissociação entre os membros diagonais e laterais, de tal forma que não seja identificado um membro predominante durante a movimentação. A proporção entre apoios diagonais e laterais é a mesma, de tal forma que haja uma frequência regular e bem definida de apoios tríplices. Possui 4 tempos em 8 momentos e uma sequência de apoios idêntica à do passo - quatro tríplices, dois bipedais diagonais e dois bipedais laterais (TOLEDO, 2006).

\subsubsection{Marcha Trotada}

Segundo Chieffi (1943), a marcha trotada é um andamento com 2 batidas e 6 momentos de apoio. Seria um andamento simétrico a dois tempos (HUSSNI; WI $\beta$ DORF; NICOLETTI, 1996) próximo à marcha batida, porém não apresentando apoios bipedais laterais, que são substituídos por apoios monopedais, posteriores e anteriores (WIßDOR, 1990). A 
dissociação nesta marcha é bem menor que nas outras, o que a aproxima do trote, sendo por alguns autores chamada de Trote marchado (SIMÕES, 1983). Todavia, não possui suspensão total dos quatro membros, o que não a classifica como trote. As proporções de apoios triplos são inferiores a $20 \%$ do tempo total de duração da passada e, os apoios laterais, inferiores a 5\% (TOLEDO, 2006). Trata-se de um andamento que possui comodidade, sem perda de equilíbrio, conservando a agilidade, uma vez que as amplitudes de movimentos das passadas posteriores e anteriores são equivalentes (SIMÕES, 1983).

\subsubsection{Bioquímica, Fisiologia e Morfologia da marcha}

A marcha seria um exercício de submáxima exigência metabólica e estressante em nível fisiológico (DI FILIPPO et al., 2016; LAGE et al., 2017). Após sessões de treinamento ou competição os cavalos apresentam sinais de hiperventilação semelhantes aos apresentados por cavalos em exercício de alta velocidade como: cross-country, adestramento, enduro e corrida de obstáculos (MARTINS et al., 2017). Em virtude da hiperventilação, os animais aumentam a pressão sanguínea de $\mathrm{CO}_{2}$ e há excesso de bases no sangue, caracterizando desequilíbrio ácido-base, todavia, garanhões são mais susceptíveis a essas mudanças do que as éguas. Estas sofrem mais com sinais bioquímicos de desidratação, tais como aumento de eritrócitos e hemácias, elevação do hematócrito e aumento da catálise proteica (que fora acumulada durante o exercício) com consequente aumento de permeabilidade das membranas musculares (DI FILIPPO et al., 2016; MARTINS et al., 2017).

Coelho et al. (2017) discutiram que a contração esplênica esforço-dependente da marcha seria uma resposta do sistema nervoso simpático, a fim de melhorar o transporte de oxigênio durante o exercício, através da ativação de receptores adrenérgicos. Tal ativação se dá por meio da hemoconcentração, causada, principalmente, pela redução do volume do plasma por meio da sudorese, respiração e redistribuição do volume vascular, aumento de eritrócitos e hemoglobina, o que levaria a um quadro de semidesidratação (DI FILIPPO et al., 2016; MARTINS et al., 2017).

O volume globular de animais marchadores é bastante semelhante ao de animais Quarto de Milha e inferior a animais das raças Árabe, Crioulo e Puro Sangue Inglês. Sendo estes últimos os de maior reserva esplênica, uma vez que animais de provas de resistência, categoria na qual se insere a marcha, possuiriam maior volume plasmático, o que justificaria diferenças raciais relacionadas a modalidade equestre para qual a raça se especializou (COELHO et al., 2017). De Rezende et al. (2014) avaliaram ainda que após marchar por 50 
min em velocidade constante de $12 \mathrm{~km} / \mathrm{h}$, os animais apresentavam não só aumento de lactato e cortisol, comumente observado para outras modalidades equestres, mas também, insulina, que estaria relacionada com a alta mobilização de glicose.

O requerimento de energia dos animais de marcha seria maior que o de animais não marchadores, uma vez que são feitos mais movimentos por unidade de tempo. Tal fato foi pesquisado por Wanderley et al. (2010) e Lage et al. (2017). Estes autores reportaram semelhanças entre a marcha batida e marcha picada, tanto no estresse fisiológico, quanto nas alterações bioquímicas, naturais, do pós-exercício. Por outro lado, ambos encontraram evidências de que animais de marcha picada demandariam mais energia. Wanderley et al. (2010), reportaram ainda diferenças nas frequências cardíaca e respiratória, volume de células concentradas e concentração de lactato, que seriam maiores em animais de marcha picada, imediatamente após o início do exercício.

A taxa metabólica e o custo do transporte de oxigênio em animais de marcha picada seriam, também, mais elevados o que aumenta o consumo e requerimento energético do andamento (LAGE et al., 2017). Gama e Souza (2012) argumentaram ainda, que todo esse mecanismo energético ocorreria em presença de oxigênio, isto é, em metabolismo aeróbio, uma vez que não há aumento de aspartato amino transferase e creatinoquinase após o exercício da marcha; o que também seria um indicativo de que, fisiologicamente, a marcha não provoca lesão muscular nos animais marchadores.

Do ponto de vista morfológico, animais de marcha picada tem poucas diferenças de animais de marcha batida em medidas lineares (BUSSIMAN, 2016), todavia Santiago et al. (2014), reportaram diferenças nas medidas angulares e relacionadas à flexão e à extensão dos membros para equinos das marchas batida e picada. Esses mesmos autores reportaram que, em animais de marcha picada, o ângulo escapulo-solo, bem como escapulo-umeral seriam maiores. Por outro lado, o ângulo úmero-radial é maior para os animais de marcha batida, que possuem ainda um menor ângulo pelves-solo do que animais de marcha picada. Bussiman (2016), reportou diferenças no comprimento dorso-lombar entre animais de marcha picada e batida e Santiago et al. (2014), reportam que animais de marcha batida possuem maiores comprimentos de quartela e garupa, bem como larguras de garupa e peito. Desta forma existiriam diferenças intrínsecas tanto na morfologia, quanto na fisiologia de animais de marcha batida e picada. 


\subsection{O cavalo Mangalarga Marchador}

A tropa nacional descende, em sua maioria, dos animais trazidos pelos conquistadores espanhóis e portugueses, bem como, holandeses, franceses e alemães (ARAÚJO, 2013). Segundo Edwards (1994), esses animais são a base da raça Crioula que, por sua vez, vem a ser base para a formação das raças latino-americanas. O Mangalarga Marchador tem sua origem nesses animais, porém, foi selecionado em Minas Gerais para andamento e morfologia específicos (MOTA; PRADO, 2005). Com a vinda de D. João VI e a corte portuguesa para o Brasil, iniciou-se grande importação de animais da raça Alter Real, usados como melhoradores nos animais nacionais, a fim de refinar a morfologia e gerar animais de aparência mais nobre (ARAÚJO, 2013). A base do Mangalarga Marchador, portanto, é de animais ibérico nacionais intercruzados com infusão de genética Alter que, posteriormente, sofreu influência de genética Andaluz, Árabe e Quarto de Milha (CARNEIRO; DUARTE; DIAS, 1991; COSTA et al., 2004; DEASSIS et al., 2009).

De acordo com Simões (1983), a família Junqueira, em Minas Gerais, iniciou a seleção de animais dessa tropa, segundo critérios de beleza, porte, andamento e habilidade de caça. Na época, em homenagem à família que desenvolvia a raça, ficou famosa a tropa do Sul de Minas Gerais, sob o nome de "Cavalo Junqueira", não somente entre usuários, mas também, na corte de D. João VI (ARAÚJO, 2013). O Mangalarga Marchador é um cavalo de porte médio, é ágil e de estrutura forte, sem deixar de ser bem proporcionada. Possui expressão vigorosa, porém, ao mesmo tempo leve na aparência, dotado de pele fina e lisa, pelos lisos e sedosos e, temperamento ativo e dócil. A altura ideal para machos é de 1,52 m e, para as fêmeas é de 1,46 m. Possui cabeça triangular bem delineada, com fronte larga e plana, de perfil retilíneo a subcôncavo no chanfro, olhos expressivos e afastados; as orelhas são médias, paralelas e bem implantadas, as ganachas descarnadas. Tronco harmonioso e musculado, sem deixar de ser leve e, membros bem aprumados (ABCCMM, 1998). A principal característica dos cavalos Mangalarga Marchador é a Marcha, podendo ser Batida ou Picada (TOLEDO, 2006). São aceitos para registro animais das duas modalidades, entretanto animais de trote ou andadura são desclassificados (ABCCMM, 1998).

\subsection{Genética do andamento em equinos}

Ferramentas de pesquisa na Medicina Veterinária e Zootecnia vem sendo criadas por meio da biologia molecular. A técnica de PCR e suas variações possibilitam análises 
altamente sensíveis, com aplicações desde o diagnóstico clínico até o melhoramento genético (OLIVEIRA, 2010). Até há bem pouco tempo atrás, a seleção dos animais era feita com base em características quantitativas de valor econômico, utilizando-se unicamente o fenótipo dos indivíduos. Mas com o avanço da genética molecular, foi alcançado o acesso direto ao genótipo dos animais, levando a resultados mais apurados da estrutura genética populacional e variabilidade genética. Tendo como consequência, o maior ganho para o melhoramento animal: a seleção assistida por marcadores (OLIVEIRA, 2010).

Segundo Manso Filho et al. (2015), a fim de compreender os andamentos do ponto de vista genético, vem sendo estudados nos últimos anos os genes associados à locomoção dos animais. Dentre estes o DRMT3 é dos mais importantes, pois coordena, não só os movimentos entre os membros esquerdos e direitos, mas também, entre membros torácicos e pélvicos (ANDERSSON et al., 2012). Vem sendo demonstrado que este gene se apresenta em uma forma natural ("wild type" ou alelo C) ou sob uma variante mutante (alelo A) (ANDERSSON et al., 2012). O DRMT3 A ocorre pela troca do nucleotídeo Cisteína por Adenosina em dada região do gene (SNP g.22999655C>A); já tendo sido observado que os animais com esta variante apresentam melhor desempenho nas modalidades próprias das raças, quando comparados aos animas de genótipo CC (ANDERSSON et al., 2012; JÄDERKVIST et al., 2015a).

O alelo DRMT3 A também provoca modificações nos andamentos dos animais (MANSO FILHO et al., 2015). Em cavalos Standardbreds o DRMT3-null (A) provoca o maior comprimento da passada devido a maior extensão dos membros, quando comparados aos animais com genótipo CC para o gene DMRT3. Por sua vez, a variante C ocorre em maior frequência nas raças de andamentos associados, já a forma mutante ocorre mais frequentemente nas raças ditas "gaited horses" com andamentos dissociados (marcha e tölk) (ANDERSSON et al., 2012; PATTERSON; STAIGER; BROOKS, 2015; PROMEROVÁ et al., 2014). Tem sido evidenciado que as raças brasileiras possuem o alelo DMRT3 A, seja em raças de andamento dissociado, bem como associado (MANSO FILHO et al., 2015; PATTERSON; STAIGER; BROOKS, 2015; PEREIRA et al., 2016; PROMEROVÁ et al., 2014). Segundo Manso Filho et al. (2015), o genótipo AA do DRMT3 provoca mudanças no padrão de locomoção dos animais, condicionando o surgimento de andamentos dissociados (marcha).

Diferenças entre os mecanismos genéticos de controle das marchas batida e picada, vem sendo apontadas. Manso Filho et al. (2015), relataram que animais Mangalarga Marchador de marcha batida apresentam maior frequência do alelo $\mathrm{C}$, não apresentando a variante $\mathrm{A}$, já os animais de marcha picada possuem maior frequência do alelo A. 


\subsection{Polimorfismos de nucleotídeo único (SNP)}

Do ponto de vista molecular, três tipos de variações ocorrem mais frequentemente na molécula de DNA. Algumas regiões podem ser repetidas ao longo do genoma (minissatélites e microssatélites), enquanto que outras podem ser inseridas ou deletadas (InDels) e há ainda ocorrência de alterações de apenas uma base (polimorfismo de nucleotídeo único - SNP). A medida em que as sequências de nucleotídeos dos genomas tornaram-se conhecidas, observouse grande número de SNPs encontradas ao se comparar segmentos correspondentes do mesmo genoma, com taxa de ocorrência média de 1 a cada 600 bases em cavalos (PEREIRA et al., 2017).

As alterações mais comumente encontradas no DNA envolvem bases nitrogenadas estruturalmente semelhantes. Denominadas transições as trocas que envolvem purinas $(A>G$ ou $\mathrm{G}>\mathrm{A}$ ), ou pirimidinas ( $\mathrm{C}>\mathrm{T}$ ou $\mathrm{T}>\mathrm{C}$ ), já quando ocorrem trocas entre purinas e pirimidinas, são chamadas de transversões. Tais alterações podem ocorrer devido a erros de incorporação de base durante a replicação do DNA ou por fatores ambientais e, quando ocorrem em células reprodutivas e são transmitidas à futura geração são denominadas mutações. Caso sejam encontradas em uma população na frequência mínima de 0,01 (minor allele frequency - MAF $\geq 1 \%$ ) são denominadas de polimorfismos (KWOK; GU, 1999). Neste sentido, as mutações de uma base passam a ser denominadas SNPs.

Os SNPs podem ser intragênicos, quando ocorrem em regiões codificadoras ou com função regulatória, ou intergênicos. Quando a alteração ocorre sem que a sequência aminoacídica mude, os SNPs são denominados sinônimos, podendo a alteração ser conservativa, ou não, em função das características dos aminoácidos envolvidos na troca. Tais modificações podem incorrer em alteração na função ou estrutura da proteína, mesmo se tratando de SNPs sinonímicos sem alteração proteica, mas que alterem a estrutura e estabilidade do RNA mensageiro formado, o que leva, por consequência, à alteração na quantidade de proteína traduzida. Esta também pode ser afetada quando ocorrem alterações nas regiões não traduzidas do RNA mensageiro (5' UTR e 3' UTR). Além disso, polimorfismos gênicos podem promover processamentos alternativos, geração ou supressão de códons de terminação, alteração nos códons de iniciação da tradução e alterações no padrão de expressão de genes quando a troca de bases ocorre em sequências regulatórias (GUIMARÃES; COSTA, 2002).

Polimorfismos em regiões intrônicas ganharam importância pelo fato de não mais poderem ser descartados como possíveis responsáveis diretos por alterações fenotípicas. RNAs não codificantes transcritos a partir de regiões intrônicas (micro-RNAs) podem estar envolvidos 
em diferentes processos biológicos, dentre eles, os controles transcricional e pós-transcricional da expressão gênica (NAKAYA et al., 2007).

Embora a função da maior parte das regiões intergênicas ainda seja desconhecida, sabe-se cada vez mais da sua importância no controle da regulação da expressão gênica. Neste sentido, polimorfismos localizados nestas regiões também podem estar associados às variações fenotípicas. Estudos em humanos e em espécies de interesse zootécnico mostraram a ocorrência de milhões de SNPs distribuídos ao longo do genoma de um indivíduo (Human Genome Project Information, The SNP Consortium LTD, Bovine Genome Sequencing and Analysis Consortium, EquCab2.0 SNP Collection). Além dos marcadores SNPs serem abundantes, a forma como se originam permite a sua distribuição homogênea pelo genoma (CAETANO, 2009).

\subsection{Chips de genotipagem para equinos}

Segundo Chowdhary e Raudsepp (2008), um dos maiores avanços da genômica equina foi o sequenciamento completo do genoma (EquCab2.0) e, por meio dele, a identificação de 1.162.753 SNPs, que ocorrem em diversas raças (WADE et al., 2009). A partir dessa abundância de marcadores puderam ser construídos os primeiros chips de genotipagem de SNPs para equinos. Projetado para a identificação de regiões genômicas modificadas pela seleção (assinaturas de seleção), bem como a identificação de genes e SNPs associados aos fenótipos de interesse nas principais raças de equinos (GWAS), o Equine SNP50 BeadChip da empresa Illumina (Illumina Inc., EUA) constituiu poderosa plataforma para a seleção e o melhoramento genético da espécie, habilitando pesquisadores da área a conduzir vasta gama de experimentos em que a aplicação da genotipagem de polimorfismos de DNA é necessária. Já em sua segunda geração, o SNP chip equino (Equine SNP70 BeadChip; Illumina Inc., EUA) possui 65.157 SNP, dos quais 19 mil são novos marcadores e 45 mil foram validados no Equine SNP50 BeadChip.

Com a necessidade de maior número de marcadores para desenvolver estudos, principalmente de seleção genômica e associação ampla mais refinados, encontra-se disponível atualmente no mercado o Axiom ${ }^{\circledR}$ Equine Genotyping Array (Affymetrix, EUA), com densidade de 670.796 SNPs. Os marcadores deste arranjo foram selecionados a partir de uma amostra de dois milhões de SNP, objetivando otimizar a cobertura genômica considerando a conhecida diversidade genética e a extensão do desequilíbrio de ligação (DL) existente entre as diversas raças de equinos domésticos. Os 74.000 SNP diferentes presentes nos arranjos da 
empresa Illumina (Equine SNP50 e Equine SNP70) foram incluídos neste desenho com a intenção de permitir a compatibilidade, comparação e continuidade de projetos existentes. DNA isolado do sangue ou do bulbo capilar de 347 cavalos de 20 raças equinas foi genotipado para a construção do painel. Devido a sua alta cobertura (1SNP/4.000pb), o chip de genotipagem de SNP da empresa Affymetrix pode ser útil para o mapeamento fino, dispensando, em muitas situações, o resequenciamento de regiões alvo em busca de polimorfismos gênicos responsáveis diretos (causais), ligados ou em forte desequilíbrio de ligação com o fenótipo de interesse.

\subsection{Estudos de associação genômica ampla (GWAS)}

É de fundamental interesse biológico e, muitas vezes, econômico o conhecimento da relação causal entre o polimorfismo genético e as diferenças observáveis no fenótipo (KORTE; FARLOW, 2013). De acordo com Sahana et al. (2010), o principal propósito dos estudos de associação genômica ampla é identificar regiões dos cromossomos que abrigam genes que contribuem para a variação fenotípica de uma característica, servindo posteriormente, como regiões putativas de QTL para estudos mais aprofundados. Os GWAS se baseiam no princípio do desequilíbrio de ligação (DL) em nível populacional.

Estudos de GWAS o fizeram emergir como ferramenta poderosa para revelar as bases genéticas de doenças, bem como de características quantitativas. Em equinos, tais estudos serviram com muito sucesso para identificar SNPs, regiões genômicas e genes relacionados a importantes doenças e síndromes, tais como lordose (COOK; GALLAGHER; BAILEY, 2010), osteocondrose (LYKKJEN et al., 2010; TEYSSÈDRE et al., 2012), neuropatia laringeal recorrente (DUPUIS et al., 2011), nanismo (EBERTH; SWERCZAK; BAILEY, 2009) e síndrome do potro lavanda (BROOKS et al., 2010). Recentemente, características complexas relacionadas ao desempenho em provas têm sido avaliadas (BINNS; BOEHLER; LAMBERT, 2010; FONSECA et al., 2017; HILL et al., 2010; MEIRA et al., 2014; PETERSEN et al., 2013a; SCHRÖDER et al., 2012; STAIGER et al., 2016a).

Com relação às provas esportivas, estudos de associação genômica ampla tem sido conduzidos, principalmente na raça Puro-Sangue Inglês para o desempenho em corridas (BINNS; BOEHLER; LAMBERT, 2010; HILL et al., 2010; TOZAKI et al., 2010) e, em diversas raças, para o salto (BRARD; RICARD, 2015). Características morfológicas (MEIRA et al., 2014; SIGNER-HASLER et al., 2012; STAIGER et al., 2016b; TETENS et al., 2013), de fertilidade (GOTTSCHALK et al., 2016) e temperamento (STAIGER; ALBRIGHT; BROOKS, 2016) também tem sido contempladas. Progressos significativos foram feitos com GWAS para 
identificar loci genéticos associados a doenças complexas e outras características de importância em humanos e animais (STRANGER; STAHL; RAJ, 2011).

Neste contexto, os métodos Bayesianos de GWAS por produzirem probabilidade posterior de associação em vez de P-valores para a hipótese nula de ausência de associação (gerados no modelo "SNP by SNP"), podem ser aplicados com maior confiança quando existe tamanho de amostra relativamente pequeno (ZHAO et al., 2014). Além disso, resultados obtidos por métodos Bayesianos não estão sujeitos a alta taxas de falsos negativos em função do controle rígido de falsos positivos, nem à superestimação dos efeitos de QTL, uma vez que se baseiam em janelas de SNP (PETERS et al., 2012). O método BayesB, em particular, sob modelo de limiar (liability threshold model), mostrou-se robusto para detectar QTLs associados a fenótipos de ocorrência de doenças com expressão binomial (KIZILKAYA et al., 2013).

Os métodos Bayesianos (BayesA, BayesB e BayesC - MEUWISSEN; HAYES; GODDARD, 2001; KIZILKAYA; FERNANDO; GARRICK, 2010; HABIER et al., 2011) tratam-se de uma abordagem não linear na qual os efeitos dos SNPs são obtidos a partir de amostras das distribuições a posteriori, usualmente vindas de uma distribuição de caldas pesadas (ZHANG et al., 2016). Contudo, nestes métodos não é levada em consideração a informação fenotípica dos animais não genotipados. Com o objetivo de considera as informações fenotípicas em totalidade (animais não genotipados e genotipados) em uma única análise (passo único - single step), o modelo BLUP (Best linear unbiased Prediction HENDERSON, 1953, 1975) foi estendido no modelo GBLUP (Genomic best linear unbiased Prediction - AGUILAR et al., 2010).

Wang et al. (2012, 2014) estenderam o método GBLUP para levar em conta diferentes ponderações na diagonal da matriz de relacionamento genômico G (VANRADEN, 2008) o que leva a diferentes proporções de variância explicadas por cada SNP. Este novo método é conhecido como ssGWAS (Single-step genome wide association study) e teve suas vantagens apontadas por Legarra et al. (2014). Dentre as principais vantagens destacam-se: levar em consideração informação extra de animais não genotipados; considerar a existência de pré-seleção e a independência de pseudofenótipos, esses fatores implicariam ainda em maior ganho de acurácia de predição sobre os outros métodos genômicos (LEGARRA et al., 2014).

\subsection{Estrutura populacional nos estudos de associação genômica ampla}

De acordo com Sodero Martins (1987) a estrutura populacional de uma espécie reflete suas características genéticas e demográficas, sendo o resultado da ação de uma série de 
mecanismos evolutivos e ecológicos. Do ponto de vista genético uma população pode ser definida como um conjunto de genes e alelos que são transmitidos através dos acasalamentos (FALCONER; MACKAY, 1996).

O modelo ideal de uma população foi descrito por Wright (1931), no qual as frequências alélicas permanecem inalteradas ao longo das gerações se os princípios do equilíbrio de Hardy-Weinberg (HARDY, 1908; WEINBERG, 1908) se aplicam; são eles: ausência de mutação, seleção, migração e a população deve ser panmítica. Nas populações comerciais a seleção visando um determinado objetivo, ou padrão, leva a mudanças na frequência alélica e/ou cria estruturas genéticas dentro da população (QUINTINHO DE OLIVEIRA, 2010).

Se os acasalamentos não se dão ao acaso, mas em função de um fenótipo de interesse e ou do valor genético do indivíduo, os melhores reprodutores serão usados mais intensamente e por consequência deixarão mais descendentes, o que em ultima análise significa que mais alelos destes reprodutores são deixados na população, de tal forma que seus descendentes passam a possuir uma constituição genética diferente dos descendentes de outros indivíduos.

Fruto destes acasalamentos preferenciais dois fatos importantes podem ocorrer na população: estratificação e endogamia. A endogamia é o acasalamento de indivíduos mais aparentados do que a média da população (ELER, 2017a), seu aumento pode levar a diminuição da variabilidade genética ao longo das gerações (BUSSIMAN et al., 2018), o que torna a população inviável ao longo do tempo. A principal consequência da endogamia é a diminuição da combinação gênica (ELER, 2017b) o que, consequentemente, leva a depressão pela endogamia (FALCONER; MACKAY, 1996). Outra consequência da endogamia é o aumento da homozigose (ELER, 2017b) que leva ao aumento da frequência genotípica em determinados loci.

A estratificação ocorre quando a origem das alterações nas frequências alélicas e na distribuição do fenótipo nas subpopulações não é aleatória (SANTIAGO, 2015). Geralmente a estratificação é intensificada quando as amostras da população vêm de populações ancestrais distintas, ou possuem estruturas familiares muito evidentes (LIU et al., 2013; PURCELL et al., 2007). Nas populações domésticas a estratificação pode ocorrer devido, principalmente, a seleção, endogamia e amostragem em diferentes grupos genéticos (SANTIAGO, 2015).

O problema central da presença de estruturas familiares importantes nos animais genotipados para os estudos de GWAS é a associação espúria dos marcadores com o fenótipo de interesse. Tal associação reflete não o impacto de determinado SNP no fenótipo, mas sim, 
diferenças nas frequências alélicas, de acordo com grupos fenotípicos, para este locus. Este problema ocorre, pois, a diferença na constituição genética da população em análise não é aleatória, uma vez que determinados locus estão respondendo a pressão de seleção, endogamia e, por consequência, estratificam a população.

Para evitar este problema recomenda-se que amostras animais em populações homogêneas ou implementar métodos estatísticos que considerem a estrutura da população em análise como, por exemplo, a inclusão da matriz de parentesco entre os animais nas equações dos modelos mistos ou a adição de componentes principais da matriz de relacionamento genômico no modelo estatístico de associação genômica (DEVLIN; ROEDER, 1999; KANG et al., 2010; LI; YU, 2008; PRICE et al., 2006; THORNTON; MCPEEK, 2010; ZHOU; STEPHENS, 2013).

\subsection{Modelo linear de limiar}

Ao tratar características cuja expressão fenotípica era "tudo ou nada", Dempster e Lerner (1950) propuseram que seria plausível assumir que esses fenótipos dependem de uma ou mais variáveis subjacentes com distribuição contínua. “O valor de cada variável subjacente em um indivíduo em particular, de acordo com esta ótica, dependerá dos fatores genéticos e não genéticos e, o aparecimento do fenótipo requererá que um certo limiar seja excedido" (DEMPSTER; LERNER, 1950, p. 215, tradução nossa). Desta forma são feitas as seguintes pressuposições matemáticas:

1. O valor observado para a variável subjacente é a soma de um componente ambiental com distribuição normal e um componente genético independente com distribuição normal;

2. O fenótipo está presente em todos os indivíduos (e apenas nestes) cuja a variável adjacente excede um determinado limiar;

3. Na variável adjacente a substituição dos genes tem efeitos individualmente pequenos e estritamente aditivos.

Seguindo essas orientações, Gottesman e Shields (1967) ao postularem a teoria poligênica para a herança da esquizofrenia, trataram essa doença como uma característica de limiar que poderia ser predita a partir de um modelo de predisposição. Neste sentido se valeram do conceito de variação quase contínua de Grüneberg (1952), no qual não existem duas categorias de genes atuando em um fenótipo categórico, mas sim duas categorias de efeitos dos genes; bem como do conceito phenodeviant de Lerner (1954), segundo o qual ocorrências 
esporádicas de anormalidades fenotípicas são causadas pela herança mendeliana poligênica, a partir de um certo limiar de homozigose em loci de importância para o fenótipo em questão.

Desta forma, Gottesman e Shields (1967) postularam que a predisposição à esquizofrenia é poligênica e o que é herdado não é o fenótipo: “esquizofrênico ou não", mas a predisposição para o mesmo. Este raciocínio é empregado para as características categóricas nas quais não é a categoria fenotípica em si que é herdada, mas a predisposição genética (valor genético) para expressão do fenótipo; quando em um dado indivíduo, um determinado limiar de valor genético é excedido, o fenótipo ocorre na progênie deste indivíduo (FALCONER, 1965, 1967).

Gianola e Foulley (1983) apresentaram um algoritmo não linear para analisar dados categóricos ordenados. Nestes casos o modelo pressupõe uma variável adjacente que é a combinação linear de variáveis amostradas de distribuições conceituais. Supondo uma variável adjacente contínua $l$ e um conjunto de limiares fixos: $\delta^{\prime}=\left[\delta_{1}<\delta_{2} \ldots<\delta_{m-1}\right]$. No contexto multifatorial, $l$ é assumida normalmente distribuída (BULMER, 1985; CURNOW; SMITH, 1975; DEMPSTER; LERNER, 1950; GIANOLA, 1982), pois, é o resultado da combinação linear de pequenos efeitos de alelos em um número muito grande de loci mais componentes ambientais aleatórios.

O vetor de parâmetros a serem estimados é $\boldsymbol{\theta}=[\boldsymbol{t}, \boldsymbol{\beta}, \boldsymbol{u}]$, em que $\boldsymbol{t}$ é o vetor de solução dos limiares, $\boldsymbol{\beta}$ é o vetor de solução dos efeitos fixos e $\boldsymbol{u}$ é o vetor de solução dos efeitos aleatórios (GIANOLA; FOULLEY, 1983), assumindo-se:

$$
\begin{aligned}
& \boldsymbol{t} \sim N(\tau, \boldsymbol{\Omega}) \\
& \boldsymbol{\beta} \sim N(\alpha, \Gamma) \\
& \boldsymbol{u} \sim N(0, \boldsymbol{G})
\end{aligned}
$$

em que: $\boldsymbol{\Omega}$ e $\Gamma$ são matrizes de covariância diagonais; $\boldsymbol{G}$ é uma matriz de covariâncias não singular. Usualmente $\boldsymbol{G}$ é a matriz de parentesco aditiva se é utilizado um modelo animal sem outros efeitos aleatórios.

Considerando um modelo matricial para analisar uma variável binária, isto é $\boldsymbol{y} \sim B(n ; p)$, com apenas um efeito aleatório, tem-se:

$\boldsymbol{y}=\boldsymbol{X} \boldsymbol{\beta}+\boldsymbol{Z u}+\boldsymbol{e}$

em que $\boldsymbol{y}$ é o vetor de observações fenotípicas, $\boldsymbol{X}$ é a matriz de incidência dos efeitos fixos; $\boldsymbol{Z}$ é a matriz de incidência dos efeitos aleatórios; $\boldsymbol{\beta}$ é o vetor de solução dos efeitos fixos; $\boldsymbol{u}$ é o vetor de solução dos efeitos aleatórios e $\boldsymbol{e}$ é o termo residual. Assumindo-se que: $\boldsymbol{u} \sim N\left(0, \boldsymbol{G}^{\mathbf{- 1}} \sigma_{u}^{2}\right)$, em que $\boldsymbol{G}^{-\mathbf{1}}$ é a inversa da matriz de parentesco aditivo e $\boldsymbol{e} \sim N\left(0, \boldsymbol{I}^{\mathbf{- 1}} \sigma_{e}^{2}\right)$. 
Perez-Enciso, Tempelman e Gianola (1993) mostraram que o parâmetro de alocação do modelo é dado por $\boldsymbol{\theta}^{\prime}=[\boldsymbol{\beta}, \boldsymbol{u}]$ (uma vez que, na prática, não se deseja estimar $\boldsymbol{t}$ - GIANOLA; FOULLEY, 1983), o que leva a equivalência do modelo (1) a:

$\boldsymbol{W} \boldsymbol{\theta}+\boldsymbol{e}$

nestas condições, $\boldsymbol{W}=[\boldsymbol{X}, \boldsymbol{Z}]$, desta forma y é substituída por uma "variável de trabalho" (DEMPSTER; LERNER, 1950; FALCONER, 1965, 1967) resultante da combinação linear de $\boldsymbol{X} \boldsymbol{\beta}+\boldsymbol{Z u}$ (GIANOLA; FOULLEY, 1983).

\subsection{Referências}

ASSOCIAÇÃO BRASILEIRA DOS CRIADORES DO CAVALO MANGALARGA
MARCHADOR - ABCCMM. Padrão da raça. Belo Horizonte, 1998.

AGUILAR, I. et al. Hot topic: A unified approach to utilize phenotypic, full pedigree, and genomic information for genetic evaluation of Holstein final score. Journal of Dairy Science, New York, v. 93, n. 2, p. 743-752, 2010.

ANDERSSON, L. S. et al. Mutations in DMRT3 affect locomotion in horses and spinal circuit function in mice. Nature, London, v. 488, n. 7413, p. 642-646, 2012.

ANDRADE, L. S. Criação e adestramento de cavalos marchadores. Recife-PE: L.S. Andrade, 1984.

ANDRADE, L. S. O condicionamento do cavalo no Brasil: trabalho, competição, reprodução. Recife-PE: Líber Gráfica, 1986.

ARAÚJO, N. Cavalos marchadores brasileiros. Globo Rural, Rio de Janeiro, 2013. Disponível em: <https://globoplay.globo.com/v/2328452/>. Acesso em: 10 mar. 2018.

BARREY, E. Biomechanics of locomotion in the athletic horse. In: HINCHCLIFF, K. W.; KANEPS, A. J.; GEOR, R. J. (Ed.). Equine sports medicine \& surgery. 2nd ed. London: Saunders Ltda, 2013. p. 189-212.

BECK, L. S. O deslocamento e os andamentos do cavalo. Equinos, Uberaba, p. 31-40, 1983.

BINNS, M. M.; BOEHLER, D. A.; LAMBERT, D. H. Identification of the myostatin locus (MSTN) as having a major effect on optimum racing distance in the Thoroughbred horse in the USA. Animal Genetics, Chichester, v. 41, n. suppl. 2, p. 154-158, 2010.

BRARD, S.; RICARD, A. Genome-wide association study for jumping performances in French sport horses. Animal Genetics, Chichester, v. 46, n. 1, p. 78-81, 2015.

BRASIL. Ministério da Indústria, Comércio Exterior e Serviços - MDIC. Exportação Brasileira: produto por fator agregado (Jan-Dez). 2017. Disponível em: $<$ http://www.mdic.gov.br/index.php/comercio-exterior/estatisticas-de-comercioexterior/balanca-comercial-brasileira-acumulado-do-ano?layout=edit\&id=3056>. Acesso em: 
08 mar. 2018.

BRASIL. Ministério da Agricultura, Pecuária e Abastecimento - MAPA. Revisão do estudo do complexo do agronegócio do cavalo. Brasília-DF: MAPA, 2016.

BROOKS, S. A. et al. Whole-genome SNP association in the horse: Identification of a deletion in myosin Va responsible for Lavender Foal Syndrome. PLoS Genetics, San Francisco, v. 6, n. 4, p. 1-7, 2010.

BROWN, S. et al. Swing phase kinematics of horses trotting over poles. Equine Veterinary Journal, Hoboken, v. 47, n. 1, p. 107-112, 2015.

BULMER, M. G. The mathematical theory og quantitative genetics. 2nd ed. Oxford: Clarendon Press, 1985.

BUSSIMAN, F. de O. Diferenças no tipo de marcha e na conformação de equinos das raças marchadoras nacionais. 2015. Pirassununga: Faculdade de Zootecnia e Engenharia de Alimentos, Universidade de São Paulo, 2016.

BUSSIMAN, F. O. et al. Pedigree analysis and inbreeding effects over morphological traits in Campolina horse population. Animal, Cambridge, v. 12, n. 11, p. 2246-2255, 2018.

CAETANO, A. R. Marcadores SNP: Conceitos básicos, aplicaões no manejo e no melhoramento animal e perspectivas para o futuro. Revista Brasileira de Zootecnia, Viçosa, v. 38, n. suppl. 1, p. 64-71, 2009.

CARNEIRO, E.; DUARTE, J. S.; DIAS, M. V. A história do cavalo Mangalarga Marchador. Belo Horizonte: Nova Fronteira, 1991.

CHIEFFI, A. A marcha do cavalo Mangalarga. Revista da Faculdade de Medicina Veterinária e Zootecnia - USP, São Paulo, v. 2, n. 3, p. 177-192, 1943.

CHOWDHARY, B. P.; RAUDSEPP, T. The horse genome derby: racing from map to whole genome sequence. Chromosome Research, Dordrecht, v. 16, n. 1, p. 109-127, 2008.

CLAYTON, H. M. Horse species symposium: Biomechanics of the exercising horse. Journal of Animal Science, Cary, v. 94, n. 10, p. 4076-4086, 2016.

CLAYTON, H. M.; HOBBS, S.-J. The role of biomechanical analysis of horse and rider in equitation science. Applied Animal Behaviour Science, Amsterdam, v. 190, n. 1, p. 123$132,2017$.

CONFEDERAÇÃO DA AGRICULTURA E PECUÁRIA DO BRASIL - CNA. Estudo do complexo do agronegócio cavalo. Coletânea Estudos Gleba, Brasília, v. 1, n. 39, p. 1-68, 2004.

COELHO, C. S. et al. Influência da marcha sobre o heritograma em equinos da raça Mangalarga Marchador. Veterinária e Zootecnia, São Paulo, v. 24, n. 3, p. 563-570, 2017.

COOK, D.; GALLAGHER, P. C.; BAILEY, E. Genetics of swayback in American 
Saddlebred horses. Animal Genetics, Chichester, v. 41, n. suppl. 2, p. 64-71, 2010.

COSTA, M. D. et al. Caracterização demográfica da raça Mangalarga Marchador. Arquivo Brasileiro de Medicina Veterinaria e Zootecnia, Belo Horizonte, v. 56, n. 5, p. 687-690, 2004.

CURNOW, R. N.; SMITH, C. Multifactorial models for familial diseases in man. Journal of the Royal Statistical Society. Series A (General), Chichester, v. 138, n. 2, p. 131-169, 1975.

DE ANDRADE, A. G. P. Análise do padrão cinemático da marcha em equinos por meio de redes neurais artificiais. 2009. 85 f. Tese (Doutorado) - Universidade Federal de Minas Gerais, Belo Horizonte, 2009.

DE REZENDE, H. H. C. et al. Bioquímica sérica e leucometria de equinos mangalarga marchador suplementados com cromo e submetidos à prova de marcha. Bioscience Journal, Darmstadt, v. 30, n. 1, p. 219-225, 2014.

DEASSIS, J. B. et al. Genetic diversity and population structure in Brazilian Mangalarga Marchador horses. Genetics and Molecular Research: GMR, Ribeirão Preto, v. 8, n. 4, p. 1519-1524, 2009.

DEMPSTER, E. R.; LERNER, I. M. Heritability of threshold characters. Genetics, Bethesda, v. 35, n. 2, p. 212-236, 1950.

DEVLIN, B.; ROEDER, K. Genomic control for association studies. Biometrics, Chichester, v. 55, n. December, p. 997-1004, 1999.

DI FILIPPO, P. A. et al. Gender differences-induced changes in serum hematologic and biochemical variables in Mangalarga Marchador horses after a marcha gait competition. Journal of Equine Veterinary Science, Maryland Heights, v. 43, p. 18-22, 2016.

DITTRICH, J. R. et al. Equinos - livro multimídia. Curitiba: Departamento de Zootecnia da Universidade Federal do Paraná, 2001.

DUPUIS, M. C. et al. Results of a haplotype-based GWAS for recurrent laryngeal neuropathy in the horse. Mammalian Genome, New York, v. 22, n. 9-10, p. 613-620, 2011.

EBERTH, J.; SWERCZAK, T.; BAILEY, E. Investigation of dwarfism among miniature Horses using the Illumina Horse SNP50 Bead Chip. Journal of Equine Veterinary Science, Maryland Heights, v. 29, n. 5, p. 315, 2009.

EDWARDS, E. H. Cavalos: um guia ilustrado com mais de 100 raças de cavalos de todo mundo. Rio de Janeiro: Ediouro S.A., 1994.

ELER, J. P. Teorias e métodos em melhoramento genético animal: bases do melhoramento genético animal. Pirassununga: Faculdade de Zootecnia e Engenharia de Alimentos da USP, $2017 \mathrm{a}$.

ELER, J. P. Teorias e métodos em melhoramento genético animal: sistemas de acasalamento. Pirassununga: Faculdade de Zootecnia e Engenharia de Alimentos da USP, 
$2017 b$.

ENSMINGER, M. E. Horses and Horsemanship. 6th ed. Danville: Interstate Publishers, 1990.

FÁBIO, A. C. Mercado bilionário de cavalos se aquece com competições e leilões online. Disponível em:

$<$ https://economia.uol.com.br/agronegocio/noticias/redacao/2013/10/22/esporte-e-leiloes-online-e-via-tv-aquecem-mercado-de-cavalos-milionarios.htm>. Acesso em: 8 mar. 2018.

FALCONER, D. S. The inheritance of liability to certain diseases, estimated from the incidence among relatives. Annals of Human Genetics, Chichester, v. 29, n. 1, p. 51-76, 1965.

FALCONER, D. S. The inheritance of liability to diseases with variable age of onset, with particular reference to diabetes mellitus. Annals of Human Genetics, Chichester, v. 31, n. 1, p. 1-20, 1967.

FALCONER, D. S.; MACKAY, T. F. C. Introduction to quantitative genetics. 4th ed. Essex: Pearson Education Ltda, 1996.

FOOD AND AGRICULTURE ORGANIZATION OF THE UNITED NATIONS - FAO. FAOSTAT. Disponível em: <http://www.fao.org/faostat/en/\#home>. Acesso em: 7 mar. 2018.

FONSECA, M. G. et al. A Genome-wide association study reveals differences in the genetic mechanism of control of the two gait patterns of the Brazilian Mangalarga Marchador Breed. Journal of Equine Veterinary Science, Maryland Heights, v. 53, p. 64-67, 2017.

GAMA, J. da; SOUZA, M. de. Concentrações séricas de aspartato aminotransferase e creatinoquinase e concentrações plasmáticas de lactato em equinos da raça Mangalarga Marchador após. Brazilian Journal of Veterinary Research and Animal Science, São Paulo, v. 49, n. 6, p. 480-486, 2012.

GESER-VON PEINEN, K. et al. Applied load on the horse's back under racing conditions. The Veterinary Journal, London, v. 198, n. 1, p. e88-e92, 2013.

GIANOLA, D. Theory and analysis of threshold characters. Journal of Animal Science, Cary, v. 54, n. 5, p. 1079, 1982.

GIANOLA, D.; FOULLEY, J. L. Sire evaluation for ordered categorical data with a threshold model. Genetics Selection Evolution, London, v. 15, n. 2, p. 201-224, 1983.

GOTTESMAN, I. I.; SHIELDS, J. A polygenic theory of Schizophrenia. Proceedings of the National Academy of Sciences, Washington, v. 58, n. 1, p. 199-205, 1967.

GOTTSCHALK, M. et al. Genome-wide association study for semen quality traits in German Warmblood stallions. Animal Reproduction Science, Amsterdam, v. 171, p. 81-86, 2016.

GRÜNEBERG, H. Genetical studies on the skeleton of the mouse. Journal of Genetics, 
Karnataka, v. 51, n. 1, p. 95, July. 1952.

GUERRA JR., P. Complexo do agronegócio do cavalo no Brasil. In: 67 EXPOSIÇÃO AGROPECUÁRIA DO CEARÁ, 67., 2008, Aracaju, SE. Anais... Aracaju, 2008. 1 CDROM.

GUIMARÃES, P. E. M.; COSTA, M. C. R. SNPs: Sutis diferenças de um código. Biotecnologia, Ciência e Desenvolvimento, Uberlândia, v. 26, p. 24-27, 2002.

HABIER, D. et al. Extension of the bayesian alphabet for genomic selection. BMC Bioinformatics, London, v. 12, art. 186, 2011.

HARDY, G. H. Mendelian proportions in a mixed population. Science, New York, v. 28, n. 706, p. 49-50, 1908.

HARRIS, S. E. Horse gaits, balance and movement. New York: Howell Book House, 1993.

HENDERSON, C. R. Estimation of variance and covariance components. Biometrics, Chichester, v. 9, n. 2, p. 226-252, 1953.

HENDERSON, C. R. Best linear unbiased estimation and prediction under a selection model. Biometrics, Chichester, v. 31, n. 2, p. 423-447, 1975.

HILL, E. W. et al. A genome-wide SNP-association study confirms a sequence variant (g.66493737C $>\mathrm{T}$ ) in the equine myostatin (MSTN) gene as the most powerful predictor of optimum racing distance for Thoroughbred racehorses. BMC Genomics, London, v. 11, n. 1, 2010.

HOBBS, S. J. et al. Posture, flexibility and grip strength in horse riders. Journal of Human Kinetics, katowice, v. 42, n. 1, p. 113-125, 2014.

HUSSNI, C. A.; WISSDORF, H.; NICOLETT, J. L. DE M. Variações da marcha em equinos da raça Mangalarga Marchador. Ciência Rural, Santa Maria, v. 26, n. 1, p. 91-95, 1996.

INSTITUTO BRASILEIRO DE GEOGRAFIA E ESTATÍSTICA - IBGE. Sistema IBGE de Recuperação Automática - SIDRA. 2015.

JÄDERKVIST, K. et al. The importance of the DMRT3 "Gait keeper" mutation on riding traits and gaits in Standardbred and Icelandic horses. Livestock Science, Amsterdam, v. 176, p. 33-39, 2015.

JUNG, H. Reiten auf Gangpferden. Gütersloh: Falken-Vlg., Niedernh., 1998.

KANG, H. M. et al. Variance component model to account for sample structure in genomewide association studies. Nature Genetics, New York, v. 42, n. 4, p. 348-354, 2010.

KELENKA, P. The horse in human history. New York: Cambridge University Press, 2009.

KIZILKAYA, K. et al. Genome-wide association study of infectious bovine keratoconjunctivitis in Angus cattle. BMC Genetics, London, v. 14, art. 23, 2013. 
KIZILKAYA, K.; FERNANDO, R. L.; GARRICK, D. J. Genomic prediction of simulated multibreed and purebred performance using observed fifty thousand single nucleotide polymorphism genotypes. Journal of Animal Science, Cary, v. 88, n. 2, p. 544-551, 2010.

KORTE, A.; FARLOW, A. The advantages and limitations of trait analysis with GWAS: A review. Plant Methods, London, v. 9, art. 29, 2013.

KWOK, P. Y.; GU, Z. Single nucleotide polymorphism libraries: Why and how are we building them? Molecular Medicine Today, kidlington, v. 5, n. 12, p. 538-543, 1999.

LAGE, J. et al. Workload of official contests, net cost of transport, and metabolic power of Mangalarga Marchador horses of marcha batida or picada gaits. Journal of Animal Science, Cary, v. 95, n. 6, p. 2488-2495, 2017.

LAGE, M. C. G. R. Caracterização morfométrica, dos aprumos e do padrão de deslocamento de eqüinos da raça Mangalarga Marchador e suas associações com a qualidade da marcha. 2001. 114 f. Tese (Doutorado) - Universidade de Minas Gerais, Belo Horizonte, 2001.

LEGARRA, A. et al. Single Step, a general approach for genomic selection. Livestock Science, Amsterdam, v. 166, n. 1, p. 54-65, 2014.

LERNER, I. M. Genetic homeostasis. New York: John Wiley \& Sons, 1954.

LI, Q.; YU, K. Improved correction for population stratification in genome-wide association studies by identifying hidden population structures. Genetic Epidemiology, Hoboken, v. 32, n. 1, p. 215-226, 2008.

LIMA, R. Agronegócio do cavalo. Piracicaba: Escola Superior de Agricultura Luiz de Queiroz-USP, 2013.

LIMA, R. A. D. S.; SHIROTA, R.; BARROS, G. S. D. C. Estudo do complexo do agronegócio cavalo. Piracicaba: CEPEA/ESALQ/USP, 2006.

LIU, L. et al. Robust methods for population stratification in genome wide association studies. BMC Bioinformatics, London, v. 14, n. 132, p. 1-12, 2013.

LYKKJEN, S. et al. Genome-wide association analysis of osteochondrosis of the tibiotarsal joint in Norwegian Standardbred trotters. Animal Genetics, Chichester, v. 41, n. suppl. 2, p. 111-120, 2010.

MANSO FILHO, H. C. et al. Alelo DMRT3 mutante em equinos de marcha batida e picada das raças Campolina e Mangalarga Marchador. Ciência Veterinária nos Trópicos, São Paulo, v. 18, n. 1, p. 6-11, 2015.

MARTINS, L. P. et al. Effect of Marcha Exercise on Serum Electrolytes and Acid-Base Balance in Mangalarga Marchador Horses. Journal of Equine Veterinary Science, Maryland Heights, v. 49, p. 108-112, 2017. 
MEIRA, C. T. et al. Speed Index in the Racing Quarter Horse: A Genome-wide Association Study. Journal of Equine Veterinary Science, Maryland Heights, v. 34, n. 11-12, p. 12631268, 2014.

MEUWISSEN, T. H. E.; HAYES, B. J.; GODDARD, M. E. Prediction of total genetic value using genome-wide dense marker maps. Genetics, Bethesda, v. 157, n. 4, p. 1819-1829, 2001 .

MOORE, J. General biomechanics: the horse as a biological machine. Journal of Equine Veterinary Science, Maryland Heights, v. 30, n. 7, p. 379-383, 2010.

MOTA, M. D. S.; PRADO, R. S. A. Estudo genético da pontuação total em equinos Mangalarga. Archivos de Zootecnia, Cordoba, v. 54, p. 25-30, 2005.

NAKAYA, H. I. et al. Genome mapping and expression analyses of human intronic noncoding RNAs reveal tissue-specific patterns and enrichment in genes related to regulation of transcription. Genome Biology, London, v. 8, n. 3, art. R43, 2007.

NASCIMENTO, J. F. Mangalarga marchador: tratado morfofuncional. Belo Horizonte: Criadores do Cavalo Mangalarga Marchador, 1999.

NICODEMUS, M. C.; CLAYTON, H. M. Temporal variables of four-beat, stepping gaits of gaited horses. Applied Animal Behaviour Science, Amsterdam, v. 80, n. 1, p. 133-142, 2003.

OLIVEIRA, A. E. T. Genotipagem da imunoglobulina G, em éguas das raças Campolina e Mangalarga Marchador, na Zona da Mata de Pernambuco. 2010. 43 f. Dissertação (Mestrado) - Universidade Federal Rural de Pernambuco, Recife, 2010.

OUTRAM, A. K. et al. The earliest horse harmessing and milking. Science, Washington, v. 323, p. 1332-1335, March. 2009.

PATTERSON, L.; STAIGER, E. A.; BROOKS, S. A. DMRT3 is associated with gait type in Mangalarga Marchador horses, but does not control gait ability. Animal Genetics,

Chichester, v. 46, n. 2, p. 213-215, 2015.

PEREIRA, G. L. et al. MSTN, CKM, and DMRT3 Gene Variants in Different Lines of Quarter Horses. Journal of Equine Veterinary Science, Maryland Heights, v. 39, p. 33-37, 2016.

PEREIRA, G. L. et al. Genotype imputation and accuracy evaluation in racing quarter horses genotyped using different commercial SNP Panels. Journal of Equine Veterinary Science, Maryland Heights, v. 58, p. 89-96, 2017.

PEREZ-ENCISO, M.; TEMPELMAN, R. J.; GIANOLA, D. A comparison between linear and poisson mixed models for litter size in iberian pigs. Livestock Production Science, v. 35, n. 3, p. 303-316, 1993.

PERNOUD, R. Luz sobre a idade média. Mem Martins: Publicações Europa-América, 1997. 
PETERS, S. O. et al. Bayesian genome-wide association analysis of growth and yearling ultrasound measures of carcass traits in brangus heifers. Journal of Animal Science, Cary, v. 90, n. 10, p. 3398-3409, 2012.

PETERSEN, J. L. et al. Genome-wide analysis reveals selection for important traits in domestic horse breeds. PLoS Genetics, San Francisco, v. 9, n. 1, art. E1003211, 2013.

PRICE, A. L. et al. Principal components analysis corrects for stratification in genome-wide association studies. Nature Genetics, v. 38, n. 8, p. 904-909, 2006.

PROCÓPIO, A. M. Análise cinemática da locomoção de eqüiinos marchadores. 2004. 193 f. Tese (Doutorado) - Universidade Federal de Minas Gerais, Belo Horizonte, 2004.

PROMEROVÁ, M. et al. Worldwide frequency distribution of the "Gait keeper" mutation in the DMRT3 gene. Animal Genetics, Chichester, v. 45, n. 2, p. 274-282, 2014.

PURCELL, S. et al. PLINK: A Tool Set for Whole-genome association and population-based linkage analyses. American Journal of Human Genetics, Cambridge, v. 81, n. 3, p. 559$575,2007$.

QUINTINHO DE OLIVEIRA, H. P. Estudo da estrutura genética populacional e dos efeitos do programa de melhoramento genético em um rebanho Nelore. 2010. $74 \mathrm{f}$. Tese (Doutorado) - Faculdade de Zootecnia e Engenharia de Alimentos, Pirassununga, 2010.

RIBEIRO, D. B. O Cavalo: raças, qualidades e defeitos. Rio de Janeiro: Globo, 1988.

ROBERTS, T. D. M. Understanding balance: the mechanics of posture and locomotion. London: Chapman \& Hall, 1995.

SAHANA, G. et al. Genome-wide association mapping for female fertility traits in Danish and Swedish Holstein cattle. Animal Genetics, Chichester, v. 41, n. 6, p. 579-588, 2010.

SANTIAGO, G. G. Estudo de associação genômica ampla para características de produção em bovinos da raça Canchim. 2015. 63 f. Dissertação (Mestrado) - Universidade Federal de Mato Grosso do Sul, Campo Grande, 2015.

SANTIAGO, J. M. et al. Comparação entre as medidas morfométricas de equinos mangalarga marchador de marcha batida e marcha picada. Arquivo Brasileiro de Medicina Veterinaria e Zootecnia, v. 66, n. 2, p. 635-639, 2014.

SCHRÖDER, W. et al. A genome-wide association study for quantitative trait loci of showjumping in Hanoverian warmblood horses. Animal Genetics, Chichester, v. 43, n. 4, p. 392400, 2012.

SCHUBERT, M. et al. Prehistoric genomes reveal the genetic foundation and cost of horse domestication. Proceedings of the National Academy of Sciences, Washington, v. 111, n. 52, p. E5661-E5669, 2014.

SEIDEL, H. Spezielle Bewegunsgslehre. In: Lehrbuch der Physiologie der 
Haustiere. 18th ed. Jena: Gustav Fischer Verlag, 1989. p. 841-870.

SIGNER-HASLER, H. et al. A genome-wide association study reveals loci influencing height and other conformation traits in horses. PLoS ONE, San Francisco, v. 7, n. 5, p. 3-8, 2012.

SIMÕES, F. Mangalarga e o cavalo de sela brasileiro. 3. ed. São Paulo: Editora dos Criadores Ltda, 1983.

SODERO MARTINS, P. Estrutura populacional, fluxo gênico e conservação "in situ". Ipef, Monte Alegre, v. 35, p. 71-78, 1987.

STAIGER, E. A. et al. Loci impacting polymorphic gait in the Tennessee Walking Horse. Journal of Animal Science, Cary, v. 94, n. 4, p. 1377-1386, 2016 a.

STAIGER, E. A. et al. Skeletal variation in Tennessee Walking Horses maps to the LCORL/NCAPG gene region. Physiological Genomics, v. 48, n. 5, p. 325-335, 2016b.

STAIGER, E. A.; ALBRIGHT, J. D.; BROOKS, S. A. Genome-wide association mapping of heritable temperament variation in the Tennessee Walking Horse. Genes, Brain and Behavior, Hoboken, v. 15, n. 5, p. 514-526, 2016.

STRANGER, B. E.; STAHL, E. A.; RAJ, T. Progress and promise of genome-wide association studies for human complex trait genetics. Genetics, Bethesda, v. 187, n. 2, p. 367383, 2011.

TETENS, J. et al. A genome-wide association study indicates LCORL/NCAPG as a candidate locus for withers height in German Warmblood horses. Animal Genetics, Chichester, v. 44, n. 4, p. 467-471, 2013.

TEYSSÈDRE, S. et al. Genome-wide association studies for osteochondrosis in French trotter horses. Journal of Animal Science, Cary, v. 90, n. 1, p. 45-53, 2012.

THORNTON, T.; MCPEEK, M. S. Article roadtrips: case-control association testing with partially or completely unknown population and pedigree structure. The American Journal of Human Genetics, Cambridge, v. 86, n. 2, p. 172-184, 2010.

TOLEDO, A. P. A locomoção dos equídeos o livro da marcha. São José dos Campos: Toledo Horse Editores, 2006.

TOZAKI, T. et al. A genome-wide association study for racing performances in Thoroughbreds clarifies a candidate region near the MSTN gene. Animal Genetics, Chichester, v. 41, n. suppl. 2, p. 28-35, 2010.

VANRADEN, P. M. Efficient methods to compute genomic predictions. Journal of Dairy Science, New York, v. 91, n. 11, p. 4414-4423, 2008.

WADE, C. M. et al. Genome sequence, comparative analysis, and population genetics of the domestic horse. Science, Washington, v. 326, n. 5954, p. 865-867, 2009.

WANDERLEY, E. K. et al. Metabolic changes in four beat gaited horses after field marcha 
simulation. Equine Veterinary Journal, Hoboken, v. 42, n. suppl. 38, p. 105-109, 2010.

WANG, H. et al. Genome-wide association mapping including phenotypes from relatives without genotypes. Genetics Research, Cambridge, v. 94, n. 2, p. 73-83, 2012.

WANG, H. et al. Genome-wide association mapping including phenotypes from relatives without genotypes in a single-step (ssGWAS) for 6-week body weight in broiler chickens. Frontiers in Genetics, Lausanne, v. 5, p. 1-10, May. 2014.

WARMUTH, V. et al. Reconstructing the origin and spread of horse domestication in the Eurasian steppe. Proceedings of the National Academy of Sciences, Washington, v. 109, n. 21, p. 8202-8206, 2012.

WEINBERG, W. Über Vererbungsgesetze beim Menschen. Zeitschrift für induktive Abstammungs- und Vererbungslehre, Heidelberg, v. 1, n. 1, p. 440-460, 1908.

WIßDOR, H. Darstellung der Gangarten Marcha Batida, Marcha Picada und Tölt der brasilianischen Mangalarga-Marchadores als Hilfe zur Lahmheitsdiagnostik bei Gangartenpferden. Pferdeheilkunde, Baden-Baden, v. 32, n. 6, p. 273-276, 1990.

WIBDOR, H.; SEVERIN, D. Wie marschieren sie denn? Freizeit im Sattel, Bonn, v. 34, p. 78-79, 1992.

WRIGHT, S. Evolution in mendelian populations. Genetics, Bethesda, v. 16, n. 2, p. 97-159, 1931.

ZHANG, X. et al. Weighting strategies for single-step genomic BLUP: An iterative approach for accurate calculation of GEBV and GWAS. Frontiers in Genetics, Lausanne, v. 7, p. 114, Aug. 2016.

ZHAO, X. et al. A genome-wide association study for canine cryptorchidism in Siberian Huskies. Journal of Animal Breeding and Genetics, Berlin, v. 131, n. 3, p. 202-209, 2014.

ZHOU, X.; STEPHENS, M. Genome-wide efficient mixed model analysis for association.

Nature Genetics, New York, v. 44, n. 7, p. 821-824, 2013. 


\section{AVALIAÇÃO GENÉTICA DO TIPO DE MARCHA EM CAVALOS} MANGALARGA MARCHADOR: COMPARAÇÃO DE MODELOS NA PRESENÇA DE EFEITOS FIXOS COM VARIÂNCIA NULA

F.O. Bussiman ${ }^{1}$, B.A. dos Santos $^{2}$, B.C. Abreu Silva ${ }^{3}$, G.C. Mamani Mamani ${ }^{3}$, B.F. Santana ${ }^{3}$, L. Grigoletto ${ }^{3}$, G. Luis Pereira ${ }^{2}$, B.C. Perez ${ }^{1}$, H.N. Oliveira ${ }^{4}$, J.P. Eler $^{3}$, J.B.S. Ferraz ${ }^{3}$, E.C. Mattos $^{3}$, R.A. Curi ${ }^{2}$, J.C.C. Balieiro ${ }^{5}$

${ }^{1}$ Departamento de Zootecnia, Faculdade de Zootecnia e Engenharia de Alimentos, Universidade de São Paulo (FZEA/USP), Av. Duque de Caxias Norte, 225, 13.635-900, Pirassununga, São Paulo, Brasil;

${ }^{2}$ Departamento de Melhoramento Animal, Faculdade de Zootecnia e Engenharia de Alimentos, Universidade Estadual Paulista Júlio de Mesquita Filho (FMVZ/UNESP), Rua José Barbosa de Barros, 1780, Fazenda Experimental Lageado, 18.618-307, Botucatu, São Paulo, Brasil;

${ }^{3}$ Grupo de Melhoramento Animal, Biotecnologia e Transgenia, Departamento de Medicina Veterinária, Faculdade de Zootecnia e Engenharia de Alimentos, Universidade de São Paulo (GMAB-FZEA/USP), Av. Duque de Caxias Norte, 225, 13.635-900, Pirassununga, São Paulo, Brazil;

${ }^{4}$ Departamento de Zootecnia, Faculdade de Ciências Agrárias e Veterinárias, Universidade Estadual Paulista Júlio de Mesquita Filho (FCAV/UNESP), Via de Acesso Prof. Paulo Donato Castellane s/n, 14884-900 - Jaboticabal, São Paulo, Brasil;

${ }^{5}$ Departamento de Nutrição e Produção Animal, Faculdade de Medicina Veterinária e Zootecnia, Universidade de São Paulo (FMVZ/USP), Av. Duque de Caxias Norte, 225, 13.635-900, Pirassununga, São Paulo, Brasil.

RESUMO: Características binárias são, na maioria dos casos, definidas por dois níveis que representam presença ou ausência de um aspecto fenotípico de interesse. Entretanto, o tipo de andamento em cavalo pode ser mais complexo, nele não há designação de ausência, mas um outro nível fenotípico desejável. O objetivo do presente trabalho foi investigar estratégias de modelagem para analisar uma característica binária com níveis de um dado efeito fixo mostrando baixa ou nenhuma variação. Foram considerados 1.230 dados sobre o tipo de andamento (informação fenotípica) e 3.172 dados de pedigree, utilizando um total de 15 modelos de limiar diferentes. Os efeitos de grupo de contemporâneos, rebanho e proprietário foram testados como efeitos fixos e aleatórios. A classe de idade, assim como o coeficiente de endogamia, para cada animal, foi considerada como covariáveis. As herdabilidades para o tipo de andamento variaram de 0,59 a 0,97. A média de acurácia de predição ficou entre $14,27 \%$ e $48,78 \%$. O maior tempo de processamento foi de 87,27 minutos para o modelo 11 e o menor foi observado no modelo 1 (58,95 minutos). Concordância entre os rankings para os critérios de informação foi encontrada entre o AIC e o BIC para o modelo 15. A complexidade tem uma influência importante tanto na estimação quando na predição genética, o modelo mais ajustado considerou os efeitos de rebanho/fazenda como fixos e a classe de idade como uma covariável.

Palavras-chave: Comparação de modelos. Modelos de limiar. Modelagem. Andamento. Acurácia de predição. 


\begin{abstract}
Binary traits are in most cases defined by two levels that represent presence and absence of one phenotypic aspect of interest. However, the gait type in horses can be more complex, in which there is no absence designation, but another desired phenotype level. The aim of this wok was to investigate modelling strategies for analyzing a binary trait with levels of a given fixed effect which show low or no variation. 1,230 records of the type of gait (phenotypic information) and 3,171 pedigree records were considered, performing a total of 15 different threshold models. The effects of contemporary group, stud and proprietary were tested as fixed and random effects. The class of age, as well as the inbreeding coefficient for each animal, were considerate as covariables. Heritabilities for gait ranged from 0.59 to 0.97 . The mean for the prediction accuracy was between $14.27 \%$ and $48.78 \%$. The higher processing time was 86.27 minutes for model 11 and the lowest was observed for model 1 (58.95 minutes). Concordance between rankings for information criterion was found between AIC and BIC for model 15. Complexity has a very important influence on both parameters' estimation and genetic predictions; the best fitting model considered the effects of stud/farm as fixed and the class of age as a covariate.
\end{abstract}

Keywords: Model comparison. Threshold models. Modelling. Gait. Accuracy of prediction.

\title{
3.1 Introdução
}

Com mais de 600.000 animais registrados na Associação Brasileira dos Criadores do Cavalo Mangalarga Marchador (ABCCMM), o Mangalarga Marchador representa o maior rebanho de cavalos do Brasil (BRASIL, 2016). Atualmente esta raça vem sendo exportada para a Bélgica, Holanda, Portugal, Israel, Canadá, Uruguai, Peru, USA, Alemanha, Congo, Argentina , França, Áustria e Itália (FONSECA et al., 2017), alcançando importância, não só nacional, mas internacional. Suas origens estão associadas aos cavalos da península Ibérica, tais como: Árabe, Berbere, Alter Real e Andaluz.

De acordo com (DI FILIPPO et al., 2016) cada tipo de andamento do Cavalo Mangalarga Marchador é distinto nos movimentos laterais ou diagonais, mas ambos precisam ser confortáveis. Estes dois tipos de andamentos podem ser descritos como um andamento de 4 batidas (CARNEIRO DE REZENDE et al., 2016) com momentos de tríplice apoio. Eles são chamados Marcha Batida (MB) e Marcha Picada (MP) e, a diferença entre estes andamentos está na proporção de apoios laterais, que é maior na marcha picada que na batida. $\mathrm{O}$ andamento nesta raça nunca foi analisado sob um modelo animal, por isso a evidência de existência de variância genética aditiva deveria ser investigada.

Características binárias foram largamente discutidas nas análises genéticas (GIANOLA, 1982; STOCK; DISTL; HOESCHELE, 2008; STOCK; HAMANN; DISTL, 2005; VAN VLECK, 1972) porque elas necessitam uma modelagem particular, uma vez que a característica não é uma variável contínua e não assume uma distribuição Gaussiana. Modelos 
de limiar foram usados para esta tarefa com ganho em confiabilidade e eficiência de predição (MATOS et al., 1997; MEIJERING; GIANOLA, 1985), mas todos eles não levam em conta os efeitos fixos com variância nula. A influência dos grupos de contemporâneos na avaliação genética foi bem discutida por Van Vleck (1987), que apresentou o impacto da variância e do número efetivo de progênies por reprodutor dentro de cada grupo de contemporâneo.

Devido à natureza desta característica, uma modelagem intuitiva não é simples se conseguir. O fenótipo é definido pela presença de dois níveis que não indicam presença e ausência, como nas características binárias clássicas, consideradas nos estudos de melhoramento animal. Assim, o objetivo do presente trabalho foi aplicar diferentes estratégias em modelos de limiar que poderiam ser usadas para analisar o tipo de andamento em cavalos Mangalarga Marchador sob um modelo animal, considerando os efeitos fixos com variância nula, para avaliações genéticas e futuras predições genômicas.

\subsection{Material e Métodos}

\subsubsection{Dados disponíveis}

Os dados para este estudo foram coletados da base de dados da ABCCMM, disponível gratuitamente online. Para cada animal, a associação mantém registros de genealogia, proprietário, criador, sexo, data de nascimento e dados de competição; esta última informação foi utilizada para acessar o tipo de andamento dos animais (MB ou MP). Para animais específicos, importantes em sua fazenda de nascimento ou nacionalmente, foram encontrados vídeos online ou documentos antigos contendo o seu tipo de andamento. Quando disponível essa informação foi também considerada neste estudo. O conjunto de dados completo para este estudo consistiu de 1.230 dados fenotípicos sobre o tipo de andamento e 3.172 animais no pedigree (Tabela 1$)$.

\subsubsection{Edição de dados}

Para as análises, os grupos de contemporâneos (CG) foram criados pela concatenação de rebanho (568 níveis), ano de nascimento (78 níveis - 1900 a 2017) e estação de nascimento ( 1 = nascimento entre janeiro e junho; 2 = nascimento entre julho e dezembro). Foram excluídos do conjunto de dados todos os grupos com menos de duas observações, assim, o conjunto de dados final continha 1.030 CG. Para este estudo o fenótipo foi tratado como uma variável binomialmente distribuída $(0=\mathrm{MP}$ e $1=\mathrm{MB})$. 
Como a natureza de criação destes cavalos é baseada no uso de rebanhos com apenas um fenótipo (somente MP, ou somente MB), CG sem variância fenotípica (todos 0, ou todos 1) precisam ser considerados nas análises, uma vez que a exclusão levaria a uma perda considerável de informação válida, impactando a habilidade de predição/estimação. A Tabela 1 apresenta uma descrição dos dados utilizados (a estrutura do pedigree foi acessada utilizandose o software CFC - SARGOLZAEI; IWASAKI; COLLEAU, 2006).

Tabela 1 - Descrição dos dados fenotípicos e de pedigree usados neste estudo

\begin{tabular}{|c|c|}
\hline Parâmetros & Valor \\
\hline \multicolumn{2}{|l|}{ Pedigree } \\
\hline Número de animais & 3.172 \\
\hline Número de reprodutores & 931 \\
\hline Progênie & 2.383 \\
\hline Número de matrizes & 1.880 \\
\hline Progênie & 2.387 \\
\hline Número de endogâmicos & 676 \\
\hline Porcentagem de endogâmicos & 21,32 \\
\hline Coeficiente médio de endogamia (todos os animais) & 0,02 \\
\hline Coeficiente médio de endogamia (endogâmicos) & 0,07 \\
\hline Média de progênie por reprodutor & 2,56 \\
\hline Média de progênie por matriz & 1,27 \\
\hline Coeficiente médio de parentesco & 0,01 \\
\hline Média de gerações completas & 2,02 \\
\hline Número de fundadores & 780 \\
\hline \multicolumn{2}{|l|}{$\begin{array}{l}\text { Dados Fenotípicos } \\
\end{array}$} \\
\hline Número de grupos de contemporâneos (CG) & 1.080 \\
\hline Variância média por CG & 0,02 \\
\hline Número médio de animais por CG & 2,24 \\
\hline Número de animais de Marcha Picada & 226 \\
\hline Número de animais de Marcha Batida & 1.004 \\
\hline Parentesco médio entre os dois grupos fenotípicos & 0,03 \\
\hline Variância fenotípica & 184,47 \\
\hline Número de proprietários (Prop) & 554 \\
\hline Variância media por Prop & 0,07 \\
\hline Número médio de animais por Prop & 2,22 \\
\hline Número de rebanhos (Farm) & 568 \\
\hline Número médio de animais por Farm & 2,17 \\
\hline
\end{tabular}




\subsubsection{Modelos de análise}

Como não havia informações sobre quando o cavalo foi vendido ou movido de seu rebanho de nascimento, os efeitos de proprietário foram considerados para controlar possíveis mudanças no fenótipo durante a vida do animal. A classe de idade foi testada como uma covariável para considerar possíveis efeitos de treinamento. Uma vez que os animais de MP foram mais endogâmicos que os animais de $\mathrm{MB}$, o coeficiente de endogamia foi incluído como uma covariável. Objetivando investigar o melhor modelo para conduzir a avaliação genética do tipo de andamento em condições tão restritivas, foram testados 15 modelos diferentes:

$$
\begin{aligned}
& y_{i j k l}=C G_{i}+\operatorname{Prop}(\text { Farmer })_{j}+\beta_{1} F+\beta_{2} \text { Age }+u_{k}+e_{i j k l} \\
& y_{i j k l}=C G_{i}+\beta_{1} F+\beta_{2} \text { Age }+u_{j}+\operatorname{Prop}(\text { Farmer })_{k}+e_{i j k l} \\
& y_{i j k l}=C G_{i}+\operatorname{Prop}_{j}+\beta_{1} F+\beta_{2} \text { Age }+u_{k}+e_{i j k l} \\
& y_{i j k l}=C G_{i}+\beta_{1} F+\beta_{2} A g e+u_{j}+\operatorname{Prop}_{k}+e_{i j k l} \\
& y_{i j k l}=C G_{i}+\operatorname{Prop}_{j}+u_{k}+e_{i j k l} \\
& y_{i j k l}=C G_{i}+u_{j}+\operatorname{Prop}_{k}+e_{i j k l} \\
& y_{i j k l}=\operatorname{Prop}(\text { Farmer })_{i}+\beta_{1} F+\beta_{2} A g e+u_{j}+C G_{k}+e_{i j k l} \\
& y_{i j k l}=\beta_{1} F+\beta_{2} \text { Age }+u_{i}+C G_{j}+\text { Prop }(\text { Farmer })_{k}+e_{i j k l} \\
& y_{i j k l}=\text { Prop }_{i}+\beta_{1} F+\beta_{2} \text { Age }+u_{j}+C G_{k}+e_{i j k l} \\
& y_{i j k l}=\beta_{1} F+\beta_{2} A g e+u_{i}+C G_{j}+\operatorname{Prop}_{k}+e_{i j k l} \\
& y_{i j k l}=\operatorname{Prop}_{i}+u_{j}+C G_{k}+e_{i j k l} \\
& y_{i j k l m n}=\text { Farm }_{i}+\text { Farmer }_{j}+{\text { Prop }(\text { Farmer })_{k}}_{1}+\beta_{1} F+\beta_{2} \text { Age }+u_{l}+C G_{m}+e_{i j k l m n} \\
& y_{i j l}=C G_{i}+u_{j}+e_{i j l} \\
& y_{i j k}=u_{i}+e_{i j k} \\
& y_{i j k}=\text { Farm }_{i}+\beta_{1} \text { Age }+u_{j}+e_{i j k}
\end{aligned}
$$

em que, $y$ representa o vetor de observações fenotípicas; $C G$ representa o efeito sistemático de grupo de contemporâneo; Prop(Farmer) representa o efeito sistemático de proprietário aninhado em criador; $F$ e Age são os efeitos das covariáveis endogamia e classe de idade; $\beta$ representa o coeficiente de regressão das covariáveis; Prop, Farm, Farmer são os efeitos sistemáticos de proprietário, criatório e criador, respectivamente; $u$ representa o efeito genético aditivo de animal, com $u \sim N\left(0, A^{-1} \sigma_{u}^{2}\right)$ e $e$ representa o termo residual aleatório, com $e \sim N\left(0, I \sigma_{e}^{2}\right)$. Em todos os modelos, quando um efeito aparece depois de $u$, este efeito foi tratado como um efeito aleatório não correlacionado a uma matriz de (co)variâncias definida pelo pedigree, nesses casos: $\operatorname{Prop}($ Farmer $) \sim N\left(0, I \sigma_{\text {Prop (Farmer })}^{2}\right)$; Prop $\sim N\left(0, I \sigma_{\text {Prop }}^{2}\right)$ and $C G \sim N\left(0, I \sigma_{C G}^{2}\right)$. 


\subsubsection{Estimação dos parâmetros genéticos}

As análises foram implementadas em uma abordagem Bayesiana e as inferências foram feitas a partir das distribuições a posteriori dos parâmetros. A distribuição a posteriori de todos os parâmetros desconhecidos é $p(\theta \mid y) \propto p(y \mid \theta) p(\theta)$, onde $\theta$ é a coleção de parâmetros desconhecidos nos modelos; $p(\theta)$ representa a densidade a priori de $\theta, p(y \mid \theta)$ é a distribuição condicional dos parâmetros. A distribuição a priori de todos os parâmetros foi definida como: $p(\theta) \propto p\left(u \mid \sigma_{u}^{2}\right) p\left(\sigma_{u}^{2}\right) p\left(\sigma_{e}^{2}\right)$, isto é: $p(\theta) \propto N\left(u \mid 0, A \sigma_{u}^{2}\right) \chi^{-2}\left(\sigma_{u}^{2} \mid d f_{u}, S_{u}\right)$ $\chi^{-2}\left(\sigma_{e}^{2} \mid d f_{e}, S_{e}\right)$ onde $\chi^{-2}(. \mid d f, S)$ é uma distribuição de Qui-quadrado inversa escalonada com $d f$ graus de liberdade e um parâmetro de escala $S$.

As análises foram conduzidas usando o software THRGIBBS1F90 (MISZTAL et al., 2002a). Uma única cadeia de 2.000.000 de amostras foi gerada, com um período de burnin de 1.000.000 de amostras e, um intervalo de salvamento a cada 100 amostras. Desta maneira, as inferências foram feitas sobre 10.000 amostras da distribuição a posteriori e, a evidência de convergência foi checada por inspeção visual (traceplots) e pelo teste de Geweke (GEWEKE, 1992), implementado no pacote "coda" (PLUMMER et al., 2006) do software e linguagem $R$ (R CORE TEAM, 2016).

\subsubsection{Comparando modelos}

Objetivando-se comparar os 15 modelos propostos, foi calculada a correlação de Pearson, assim como de Spearman, entre os valores genéticos preditos (EBV) dos diferentes modelos. Para verificar se EBVs correlacionados foram distantes uns dos outros, a distância euclidiana entre eles foi usada. Para todos os modelos, as comparações com os EBVs foram feitas apenas com os animais fenotipados. Para investigar a diferença global entre os modelos foi utilizada a distância euclidiana entre todos os parâmetros estimado para cada modelo e, os resultados são apresentados como heatmaps.

Para comparar a parametrização nos modelos foram considerados os critérios de informação de deviância (DIC - SPIEGELHALTER et al., 2002); critério de informação bayesiano de Schwarz (BIC - SCHWARZ, 1978) e o critério de informação de Akaike (AIC AKAIKE, 1973). Para avaliar a aplicabilidade dos modelos, o tempo de processamento foi calculado para cada modelo. Adicionalmente, foi calculada a média de erro quadrática (MSE MEVIK; CEDERKVIST, 2004). Para o cálculo da porcentagem de viés (PSB - YAPO; GUPTA; SOROOSHIAN, 1996), o vetor de observações fenotípicas $Y$ foi transformado em 
uma variável probit, isto é: Probit $(Y) \sim N(0,1)$. Para verificar a superestimação/subestimação nos modelos foi calculado a diferença entre a variância fenotípica a partir dos dados e a estimada por cada modelo (DVF).

\subsubsection{Concordância fenotípica}

Como esta característica não é uma característica binária convencional, isto é o fenótipo codificado como zero não implica em animais que não exibiram o fenótipo, mas na verdade possuem outro nível fenotípico, a variância genética será influenciada pela covariância genética entre os animais dentro de cada grupo fenotípico (MP ou MB); se animais mais aparentados também possuem o mesmo fenótipo isso pode magnificar a variância genética.

Assim, para verificar as herdabilidades esperadas, a concordância entre os fenótipos da progênie e seus progenitores foi calculada. Ela foi feita para cada tipo de andamento (0 ou 1) dentro de cada nível fenotípico dos pais. Adicionalmente, a matriz de parentesco via pedigree entre os animais dos dois tipos de andamento e a conectabilidade média entre os animais fenotipados foi investigada.

\subsection{Resultados}

\subsubsection{Diagnósticos de convergência}

A visualização gráfica os traceplots para todos os modelos não apresentou sinais de tendências. Sinais de não convergência foram observados apenas no modelo 14 (Apêndice A). Todos os escores $\mathrm{Z}$ para o teste de Geweke para a distribuição a posteriori de $\sigma_{u}^{2}, \sigma_{e}^{2}$, $h^{2}, d_{\text {Prop }}^{2}$ e $d_{C G}^{2}$ variaram de $-3,00$ a $+3,00$ e, a maioria deles ficou entre $-2,50$ a $+2,50$ para todos os modelos. Altos valores para o escore $\mathrm{Z}$ do teste de Geweke talvez sugiram que um longo período de burn-in ajudaria a atender melhor convergência em alguns componentes específicos para alguns modelos.

Todos os modelos passaram no teste de estacionariedade de Heidelberger-Welch ( $r$-Lag50 - HEIDELBERGER; WELCH, 1983), o maior valor de escore Z de Geweke foi -2,98 para a estimativa de herdabilidade do modelo 1 com uma autocorrelação de 0,12 e, o maior valor de $r$-Lag50 foi 0,32 para a variância genética aditiva estimada a partir do modelo 4 , com um valor de escore de $\mathrm{Z}$ de 1,63 (Tabela 2). 
Tabela 2 - Médias a posteriori, Medianas, HPD, Escore de Z Geweke e r-Lag50 para os parâmetros genéticos estimados de acordo com cada modelo

\begin{tabular}{|c|c|c|c|c|c|c|c|}
\hline \multirow{2}{*}{ Modelo } & \multirow{2}{*}{ Parâmetro } & \multirow{2}{*}{ Média } & \multirow{2}{*}{ Mediana } & \multicolumn{2}{|c|}{ Intervalo HPD } & \multirow{2}{*}{$\begin{array}{l}\text { Geweke } \\
\text { (Z-escore) }\end{array}$} & \multirow{2}{*}{$r-\operatorname{Lag} 50$} \\
\hline & & & & $(5 \%$ & $95 \%)$ & & \\
\hline \multirow{4}{*}{1} & $\sigma_{u}^{2}$ & 15,75 & 5,48 & $(0,26$ & $54,55)$ & $-1,78$ & 0,30 \\
\hline & $\sigma_{e}^{2}$ & 0,79 & 0,83 & $(0,06$ & $1,21)$ & 2,79 & 0,17 \\
\hline & $\sigma_{P}^{2}$ & 16,54 & 6,43 & $(0,95$ & $54,74)$ & $-1,77$ & 0,30 \\
\hline & $h^{2}$ & 0,85 & 0,86 & $(0,64$ & $1,00)$ & $-2,98$ & 0,12 \\
\hline \multirow{4}{*}{2} & $\overline{\sigma_{u}^{2}}$ & 12,94 & 5,36 & $(0,43$ & $54,71)$ & 1,39 & 0,12 \\
\hline & $\sigma_{e}^{2}$ & 0,79 & 0,83 & $(0,08$ & $1,20)$ & $-1,52$ & 0,06 \\
\hline & $\sigma_{P}^{2}$ & 13,73 & 6,28 & $(1,28$ & $55,11)$ & 1,39 & 0,12 \\
\hline & $h^{2}$ & 0,84 & 0,85 & $(0,64$ & $1,00)$ & 2,22 & 0,04 \\
\hline \multirow{4}{*}{3} & $\overline{\sigma_{u}^{2}}$ & 8,76 & 3,28 & $(0,08$ & $30,73)$ & $-1,51$ & 0,27 \\
\hline & $\sigma_{e}^{2}$ & 0,81 & 0,80 & $(0,12$ & $1,34)$ & 1,07 & 0,01 \\
\hline & $\sigma_{P}^{2}$ & 9,56 & 4,23 & $(0,54$ & $31,07)$ & $-1,53$ & 0,27 \\
\hline & $h^{2}$ & 0,76 & 0,78 & $(0,42$ & $1,00)$ & $-0,44$ & 0,21 \\
\hline \multirow{5}{*}{4} & $\overline{\sigma_{u}^{2}}$ & 23,99 & 7,56 & $(0,36$ & $79,41)$ & 1,63 & 0,32 \\
\hline & $\sigma_{e}^{2}$ & 0,73 & 0,78 & $(0,00$ & $1,18)$ & $-2,34$ & 0,13 \\
\hline & $\sigma_{P}^{2}$ & 29,62 & 13,64 & $(2,10$ & $86,46)$ & 1,62 & 0,31 \\
\hline & $h^{2}$ & 0,61 & 0,64 & $(0,17$ & $1,00)$ & 2,73 & 0,11 \\
\hline & $d_{\text {Prop }}^{2}$ & 0,32 & 0,27 & $(0,00$ & $0,76)$ & $-2,60$ & 0,10 \\
\hline \multirow{4}{*}{5} & $\sigma_{u}^{2}$ & 13,54 & 3,80 & $(0,06$ & $58,58)$ & $-0,88$ & 0,19 \\
\hline & $\sigma_{e}^{2}$ & 0,76 & 0,78 & $(0,00$ & $1,26)$ & $-0,50$ & 0,09 \\
\hline & $\sigma_{P}^{2}$ & 14,30 & 4,74 & $(0,48$ & $58,65)$ & $-0,90$ & 0,19 \\
\hline & $h^{2}$ & 0,77 & 0,80 & $(0,42$ & $1,00)$ & $-0,31$ & 0,17 \\
\hline \multirow{5}{*}{6} & $\sigma_{u}^{2}$ & 23,74 & 6,63 & $(0,43$ & $53,67)$ & $-0,54$ & 0,17 \\
\hline & $\sigma_{e}^{2}$ & 0,76 & 0,81 & $(0,05$ & $1,23)$ & 0,00 & 0,06 \\
\hline & $\sigma_{P}^{2}$ & 29,44 & 12,71 & $(2,05$ & $62,47)$ & $-0,52$ & 0,17 \\
\hline & $h^{2}$ & 0,59 & 0,61 & $(0,20$ & $0,99)$ & $-0,60$ & 0,05 \\
\hline & $d_{\text {Prop }}^{2}$ & 0,33 & 0,30 & $(0,01$ & $0,73)$ & 0,63 & 0,05 \\
\hline \multirow{5}{*}{7} & $\sigma_{u}^{2}$ & 289,32 & 42,11 & $(2,69$ & $546,30)$ & $-0,34$ & $-0,01$ \\
\hline & $\sigma_{e}^{2}$ & 0,58 & 0,60 & $(0,00$ & $1,05)$ & $-0,79$ & 0,05 \\
\hline & $\sigma_{P}^{2}$ & 299,42 & 50,97 & $(3,93$ & $570,25)$ & $-0,33$ & $-0,01$ \\
\hline & $h^{2}$ & 0,85 & 0,86 & $(0,74$ & $1,00)$ & $-0,17$ & 0,03 \\
\hline & $d_{C G}^{2}$ & 0,12 & 0,12 & $(0,00$ & $0,23)$ & 0,49 & 0,01 \\
\hline \multirow{5}{*}{8} & $\sigma_{u}^{2}$ & 269,89 & 43,44 & $(2,80$ & $657,70)$ & $-2,70$ & 0,02 \\
\hline & $\sigma_{e}^{2}$ & 0,57 & 0,58 & $(0,00$ & $1,05)$ & 2,23 & 0,07 \\
\hline & $\sigma_{P}^{2}$ & 280,11 & 52,03 & $(4,16$ & $677,12)$ & $-2,71$ & 0,02 \\
\hline & $h^{2}$ & 0,86 & 0,86 & $(0,74$ & $1,00)$ & $-2,31$ & 0,03 \\
\hline & $d_{C G}^{2}$ & 0,12 & 0,12 & $(0,00$ & $0,22)$ & 1,11 & 0,00 \\
\hline
\end{tabular}

$d_{P r o p}^{2}$ é o efeito de Proprietário dado como uma fração da variância fenotípica. $d_{C G}^{2}$ é o efeito de grupo de contemporâneo dado como fração da variância fenotípica.

Fonte: Própria autoria.

(Continua na próxima página). 
Tabela 2 (Continuação) - Médias a posteriori, Medianas, HPD, Escore Z de Geweke e $r$-Lag50 para os parâmetros genéticos estimados de acordo com cada modelo.

\begin{tabular}{|c|c|c|c|c|c|c|c|}
\hline \multirow{2}{*}{ Modelo } & \multirow{2}{*}{ Parâmetro } & \multirow{2}{*}{ Média } & \multirow{2}{*}{ Mediana } & \multicolumn{2}{|c|}{ Intervalo HPD } & \multirow{2}{*}{$\begin{array}{c}\text { Geweke } \\
\text { (Z-escore) }\end{array}$} & \multirow{2}{*}{$r-\operatorname{Lag} 50$} \\
\hline & & & & $(5 \%$ & $95 \%)$ & & \\
\hline \multirow{6}{*}{9} & $\sigma_{u}^{2}$ & 4,97 & 4,51 & $(1,83$ & $8,82)$ & 0,10 & $-0,01$ \\
\hline & $\sigma_{e}^{2}$ & 0,84 & 0,84 & $(0,65$ & $1,03)$ & 0,48 & $-0,02$ \\
\hline & $\sigma_{P}^{2}$ & 6,29 & 5,75 & $(2,83$ & $10,33)$ & $-0,20$ & $-0,01$ \\
\hline & $h^{2}$ & 0,78 & 0,78 & $(0,64$ & $0,91)$ & 1,36 & $-0,02$ \\
\hline & $d_{C G}^{2}$ & 0,07 & 0,06 & $(0,00$ & $0,18)$ & $-1,08$ & $-0,03$ \\
\hline & $\sigma_{u}^{2}$ & 195,34 & 42,72 & $(3,35$ & $817,10)$ & $-0,65$ & $-0,04$ \\
\hline \multirow{5}{*}{10} & $\sigma_{e}^{2}$ & 0,47 & 0,46 & $(0,01$ & $0,95)$ & 0,22 & $-0,02$ \\
\hline & $\sigma_{P}^{2}$ & 218,31 & 63,80 & $(7,51$ & $852,70)$ & $-0,66$ & $-0,04$ \\
\hline & $h^{2}$ & 0,71 & 0,69 & $(0,52$ & 0,99) & $-0,74$ & $-0,03$ \\
\hline & $d_{C G}^{2}$ & 0,06 & 0,06 & $(0,00$ & $0,12)$ & $-0,17$ & $-0,03$ \\
\hline & $d_{\text {Prop }}^{2}$ & 0,21 & 0,23 & $(0,01$ & $0,36)$ & 0,99 & $-0,02$ \\
\hline \multirow{5}{*}{11} & $\sigma_{u}^{2}$ & 5,37 & 4,49 & $(1,71$ & $9,01)$ & 0,90 & $-0,01$ \\
\hline & $\sigma_{e}^{2}$ & 0,83 & 0,83 & $(0,65$ & $1,04)$ & $-0,93$ & $-0,01$ \\
\hline & $\sigma_{P}^{2}$ & 6,76 & 5,73 & $(2,62$ & $10,53)$ & 0,90 & $-0,01$ \\
\hline & $h^{2}$ & 0,78 & 0,78 & $(0,63$ & $0,90)$ & 0,00 & $-0,03$ \\
\hline & $d_{C G}^{2}$ & 0,07 & 0,06 & $(0,00$ & $0,19)$ & 0,28 & $-0,03$ \\
\hline \multirow{5}{*}{12} & $\sigma_{u}^{2}$ & 5,56 & 4,12 & $(0,93$ & 12,11) & $-1,99$ & 0,01 \\
\hline & $\sigma_{e}^{2}$ & 0,90 & 0,91 & $(0,69$ & $1,15)$ & 2,23 & 0,01 \\
\hline & $\sigma_{P}^{2}$ & 8,10 & 6,38 & $(2,10$ & $16,39)$ & $-1,85$ & 0,01 \\
\hline & $h^{2}$ & 0,65 & 0,67 & $(0,43$ & $0,86)$ & $-2,09$ & 0,00 \\
\hline & $d_{C G}^{2}$ & 0,19 & 0,19 & $(0,00$ & $0,38)$ & 1,62 & $-0,01$ \\
\hline \multirow{4}{*}{13} & $\sigma_{u}^{2}$ & 12,93 & 5,51 & $(0,46$ & $46,36)$ & $-0,82$ & 0,08 \\
\hline & $\sigma_{e}^{2}$ & 0,80 & 0,82 & $(0,14$ & $1,23)$ & 0,10 & 0,04 \\
\hline & $\sigma_{P}^{2}$ & 13,73 & 6,43 & $(1,16$ & $46,68)$ & $-0,83$ & 0,08 \\
\hline & $h^{2}$ & 0,85 & 0,86 & $(0,65$ & $1,00)$ & $-0,97$ & 0,04 \\
\hline \multirow{4}{*}{14} & $\overline{\sigma_{u}^{2}}$ & 477,76 & 117,35 & $(4,95$ & $1768,00)$ & $-1,21$ & 0,09 \\
\hline & $\sigma_{e}^{2}$ & 0,44 & 0,39 & $(0,00$ & $0,97)$ & 0,38 & 0,04 \\
\hline & $\sigma_{P}^{2}$ & 480,70 & 120,05 & $(6,20$ & 1771,99) & $-1,20$ & 0,09 \\
\hline & $h^{2}$ & 0,97 & 0,98 & $(0,91$ & $1,00)$ & $-1,28$ & 0,03 \\
\hline \multirow{4}{*}{15} & $\sigma_{u}^{2}$ & 6,31 & 5,92 & $(2,11$ & $11,15)$ & 1,95 & 0,01 \\
\hline & $\sigma_{e}^{2}$ & 0,93 & 0,93 & $(0,76$ & $1,09)$ & 0,18 & 0,00 \\
\hline & $\sigma_{P}^{2}$ & 7,239 & 6,86 & $(3,08$ & $12,09)$ & 1,97 & 0,01 \\
\hline & $h^{2}$ & 0,85 & 0,86 & $(0,76$ & $0,95)$ & 1,50 & 0,01 \\
\hline
\end{tabular}

$d_{P r o p}^{2}$ é o efeito de Proprietário dado como uma fração da variância fenotípica. $d_{C G}^{2}$ é o efeito de grupo de contemporâneo dado como fração da variância fenotípica.

Fonte: Própria autoria.

\subsubsection{Concordância fenotípica}

Em torno de 70\% de toda a progênie de garanhões MP também exibiu o andamento MP e a porcentagem de MB foi 30\%, quando olhada a mesma concordância para os garanhões de $\mathrm{MB}$, foi encontrada $82 \%$ da progênie com o fenótipo MB (mesmo do pai) e $18 \%$ divergindo 
(MP). Para as éguas, a concordância entre éguas MB e progênies MB foi de $92 \%$ (8\% da progênie nasceu com MP); para as éguas MP, 79\% da progênie nasceu com o mesmo fenótipo da mãe, $21 \%$ divergiu. A conectabilidade média entre os animais fenotipados foi de 0,04 $\pm 0,08$ (média \pm desvio-padrão) (Figura 1), mas para os animais MP e MB o parentesco médio, dentro dos grupos, foi de $0,06 \pm 0,13$ e $0,04 \pm 0,09$, respectivamente.

Figura 1 - Conectabilidade entre os animais fenotipados como um heatmap ( $\mathrm{f}=$ coeficiente de parentesco)

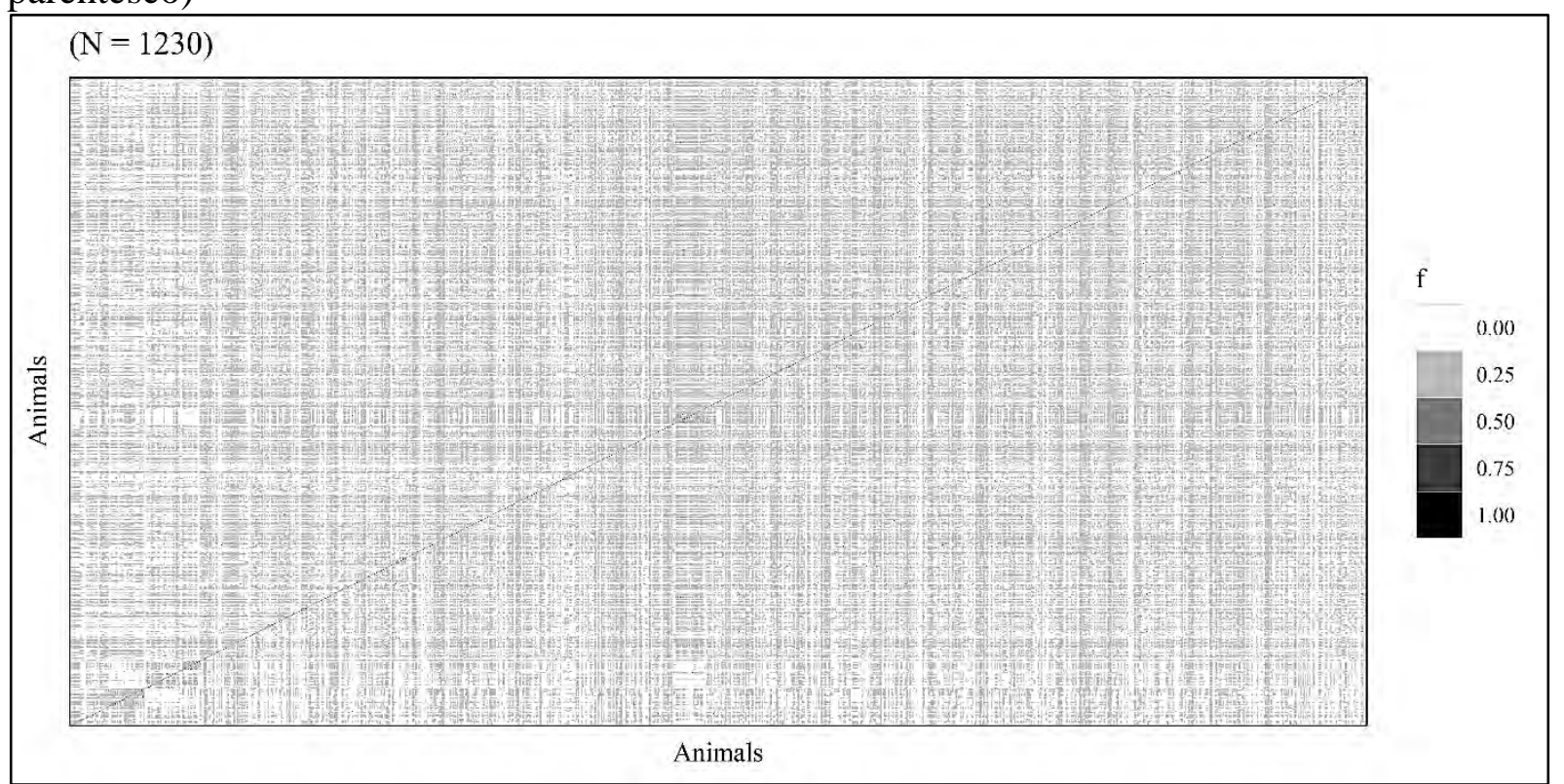

Fonte: Própria autoria.

\subsubsection{Efeito das covariáveis}

A média global a posteriori para o efeito do coeficiente de endogamia como uma covariável variou de $-26,16$ a 5,98, para os modelos 10 e 2, respectivamente. Todos os intervalos de alta densidade a posteriori (HPD) para essa covariável incluíram o zero, exceto para o modelo 11. Para os modelos 1, 2, 3, 4, 9 e 11 os efeitos do aumento do coeficiente de endogamia foram positivos, variando de 2,46 (modelo 9) a 5,98 (modelo 2) e, para os modelos 7, 8 e 10 eles foram negativos, com alta magnitude (variando de -26,16 a -23,70 - modelos 10 e 2, respectivamente) (Tabela 3).

Os efeitos da classe de idade variaram de $-0,19$ a 0,15 , modelos 10 e 2, respectivamente. O mesmo padrão de HPDs foi observado para esta covariável (todos os HPDs incluíram o zero), mas foram intervalos menores do que os intervalos para o coeficiente de endogamia. Nos modelos 3, 7, 8, 10, 11 e 15 o efeito da classe de idade foi negativo, enquanto 
que nos modelos 1, 2, 4 e 9 essas estimativas foram positivas (Tabela 4). O padrão dos efeitos da classe de idade no modelo 15 é mostrado na Figura 2.

Tabela 3 - Média a posteriori, Mediana, HPD, Escore Z de Geweke e $r$-Lag50 das estimativas dos efeitos do coeficiente de endogamia como uma covariável

\begin{tabular}{cccc|ccc}
\hline \multirow{2}{*}{ Modelo } & \multirow{2}{*}{ Média } & \multirow{2}{*}{ Mediana } & \multicolumn{2}{c}{$\begin{array}{c}\text { HPD } \\
\text { (intervalo) }\end{array}$} & $\begin{array}{c}\text { Geweke } \\
\text { (Z-Escore) }\end{array}$ & r-Lag50 \\
\cline { 4 - 5 } & & & $(5 \%$ & $95 \%)$ & \\
\hline 1 & 5,39 & 5,27 & $(-3,97$ & $15,95)$ & $-0,29$ & 0,09 \\
2 & 5,98 & 5,54 & $(-3,72$ & $16,56)$ & 0,76 & 0,04 \\
3 & 2,18 & 1,76 & $(-10,12$ & $16,01)$ & 2,20 & 0,03 \\
4 & 5,35 & 4,91 & $(-6,31$ & $17,62)$ & 2,00 & 0,05 \\
7 & $-23,70$ & $-2,99$ & $(-122,94$ & $47,61)$ & 0,04 & 0,00 \\
8 & $-25,27$ & $-4,13$ & $(-139,77$ & $49,06)$ & 3,07 & 0,08 \\
9 & 2,46 & 2,43 & $(-1,70$ & $6,75)$ & 0,15 & 0,00 \\
10 & $-26,16$ & $-5,40$ & $(-168,13$ & $53,40)$ & 0,73 & $-0,04$ \\
11 & 5,36 & 5,30 & $(0,02$ & $10,46)$ & $-0,77$ & 0,01 \\
\hline
\end{tabular}

Fonte: Própria autoria.

Tabela 4 - Média a posteriori, Mediana, HPD, Escore Z de Geweke e $r$-Lag50 das estimativas dos efeitos da classe de idade como uma covariável

\begin{tabular}{cccc|ccc}
\hline \multirow{2}{*}{ Modelo } & \multirow{2}{*}{ Média } & \multirow{2}{*}{ Mediana } & \multicolumn{2}{c}{$\begin{array}{c}\text { HPD } \\
\text { (intervalo) }\end{array}$} & $\begin{array}{c}\text { Geweke } \\
\text { (Z-Escore) }\end{array}$ & r-Lag50 \\
\cline { 4 - 5 } & & & $(5 \%$ & $95 \%)$ & \\
\hline 1 & 0,09 & 0,08 & $(-0,060$ & $0,300)$ & $-0,38$ & 0,96 \\
2 & 0,15 & 0,17 & $(-0,080$ & $0,380)$ & $-2,58$ & 0,98 \\
3 & $-0,08$ & $-0,08$ & $(-0,330$ & $0,180)$ & 4,25 & 0,96 \\
4 & 0,12 & 0,15 & $(-0,090$ & $0,330)$ & 3,19 & 0,98 \\
7 & $-0,16$ & $-0,11$ & $(-0,410$ & $0,010)$ & $-0,18$ & 0,03 \\
8 & $-0,17$ & $-0,12$ & $(-0,440$ & $0,010)$ & 3,06 & 0,09 \\
9 & 0,00 & 0,00 & $(-0,010$ & $0,010)$ & $-0,72$ & 0,00 \\
10 & $-0,19$ & $-0,13$ & $(-0,520$ & $0,010)$ & 0,61 & $-0,05$ \\
11 & $-0,00$ & $-0,00$ & $(-0,010$ & $0,010)$ & 0,26 & $-0,02$ \\
15 & $-0,002$ & $-0,002$ & $(-0,001$ & $0,007)$ & 0,50 & $-0,02$ \\
\hline
\end{tabular}

Fonte: Própria autoria. 
Figura 2 - Média a posteriori do efeito estimado de cada classe de idade no modelo 15

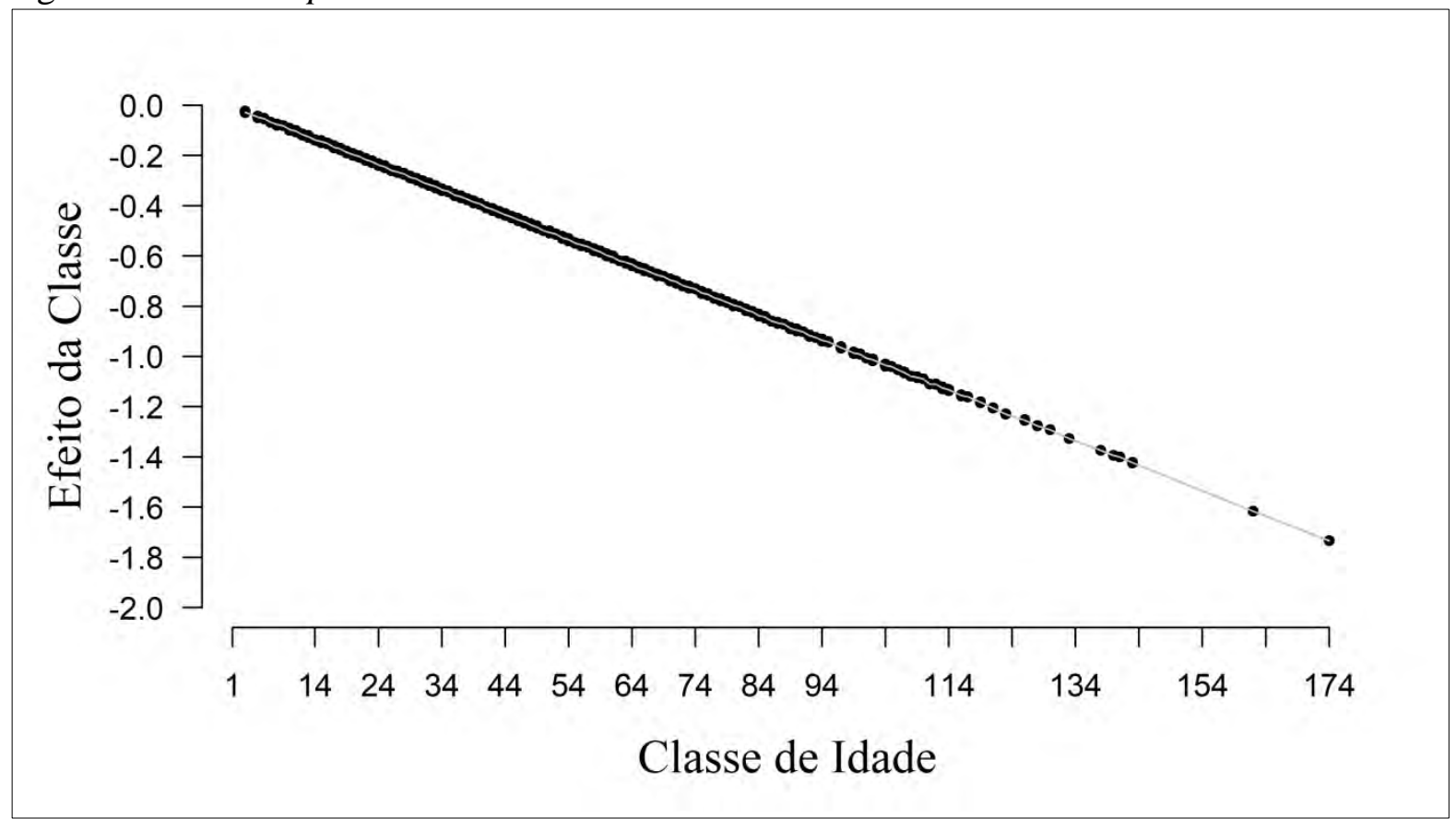

Fonte: Própria autoria.

\subsubsection{Distâncias e correlações}

A correlação de Pearson entre os valores genéticos por distintos modelos oscilou entre 0,18 e 1,00 para as correlações entre os modelos 14 e 3 e, entre os modelos 7 e 8 , respectivamente. Para as correlações de Spearman, o intervalo observado foi de 0,00 a 1,00 para a correlação entre o ranking dos modelos 14 e 3 e, entre os modelos 7 e 8 , respectivamente. Em geral, as correlações foram elevadas dentro dos grupos de modelos com CG como efeito fixo ou aleatório, mas baixa entre eles. A distância euclidiana entre os EBVs de todos os modelos foi estimada entre 0,00 e 847,70. O maior valor de distância foi observado entre o modelo 14 e todos os outros, valores médios foram observados para as distâncias entre os modelos 7, 8 e 10 e todos os outros (Figura 3). O mesmo padrão de distância entre os EBV também foi observado quando considerada a distância geral entre as estimativas dos modelos, a qual foi de 0 a 820,31 . 
Figura 3 - Heatmaps para as correlações de Pearson entre os valores genéticos estimados em cada modelo (A); correlações de Spearman do ranking dos valores genéticos estimados em cada modelo (B); distância euclidiana entre os valores genéticos estimados em cada modelo (C) e para os parâmetros estimados (D)

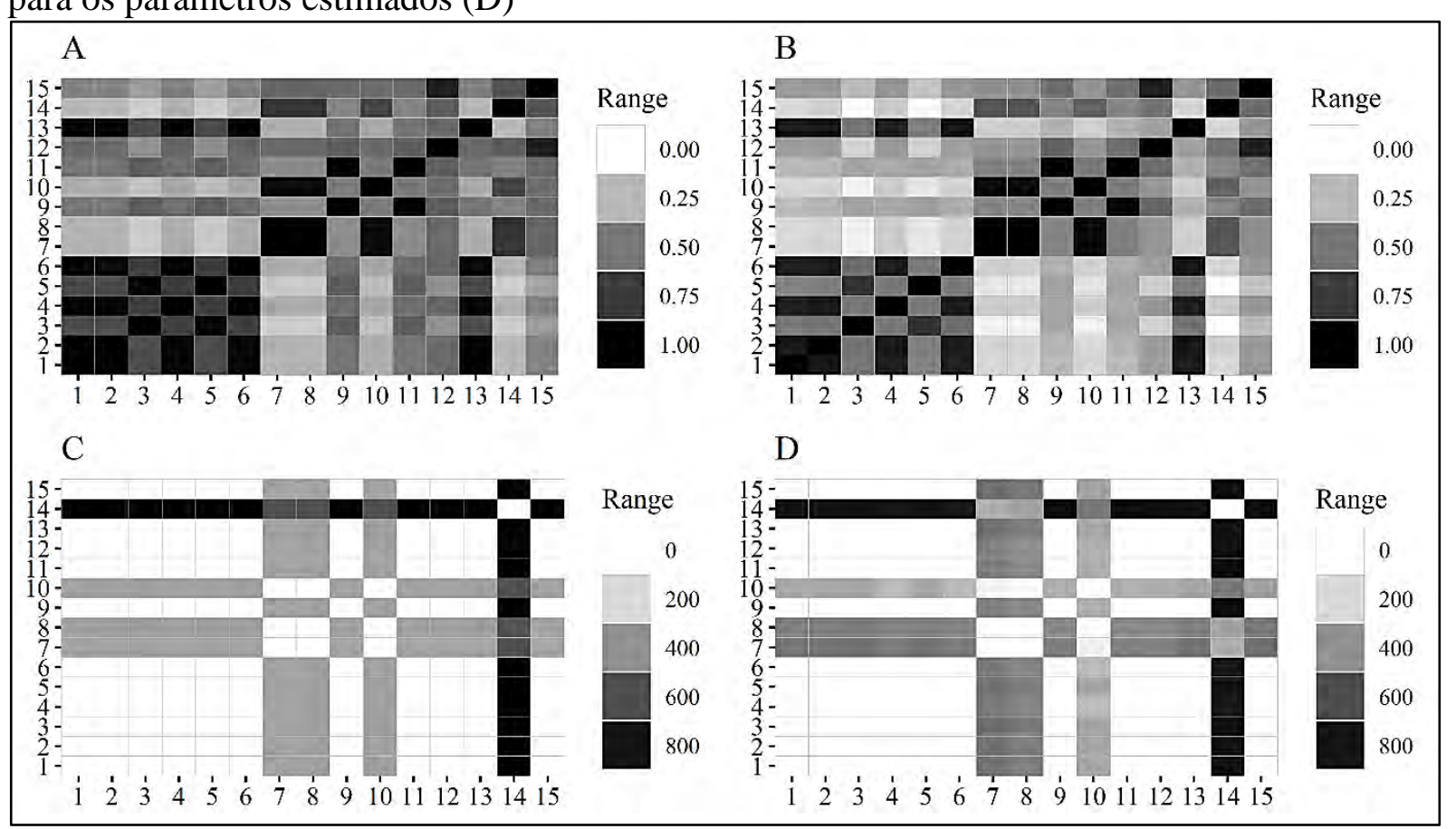

Fonte: Própria autoria.

\subsubsection{Critérios de informação}

Considerando todos os modelos, o DIC variou de -347.924,56 a 2.572,85 (modelos 7 e 11, respectivamente). Os valore de AIC oscilaram entre 10.840,96 e14.922,95, modelos 15 e 5, respectivamente. O critério BIC variou de 28.819,37 a 41.416,21, modelos 15 e 12, respectivamente. Apesar da grande variação observada para os critérios de informação, o tempo de processamento para as análises variou de 58,95 a 86,27 minutos (modelos 1 e 11, respectivamente) (Tabela 5). A média de acurácia de predição (ACC) oscilou entre 0,14 e 1,00, modelos 3 e 14 respectivamente. O modelo para o qual foi observada a menor DVF (modelo 10) foi o modelo com maior média de ACC (Figura 4). 
Tabela 5 - Critérios de informação e empo de processamento de acordo com cada modelo

\begin{tabular}{clrllr}
\hline Modelo & 2LL & \multicolumn{1}{c}{ DIC } & AIC & BIC & Tempo (min) \\
\hline 1 & $4.288,18$ & $-21.178,40$ & $13.476,18$ & $36.973,43$ & 58,95 \\
2 & $4.558,59$ & $-128.217,21$ & $13.746,59$ & $37.243,84$ & 62,73 \\
3 & $5.270,18$ & $1.929,24$ & $14.784,18$ & $39.115,14$ & 63,08 \\
4 & $4.462,49$ & $2.406,80$ & $13.976,49$ & $38.307,44$ & 65,47 \\
5 & $5.412,95$ & $-35.439,13$ & $14.922,95$ & $39.243,68$ & 82,92 \\
6 & $4.338,70$ & $-64.831,19$ & $13.848,70$ & $38.169,43$ & 85,18 \\
7 & $3.960,85$ & $-347.924,56$ & $13.148,85$ & $36.646,10$ & 64,08 \\
8 & $4.181,39$ & 737,68 & $13.369,39$ & $36.866,64$ & 67,62 \\
9 & $3.765,48$ & $2.447,54$ & $13.279,48$ & $37.610,44$ & 64,42 \\
10 & $3.832,84$ & $-166.429,50$ & $13.346,84$ & $37.677,80$ & 67,08 \\
11 & $3.792,35$ & $2.572,85$ & $13.302,35$ & $37.623,08$ & 86,27 \\
12 & $3.850,23$ & $-6.262,04$ & $14.410,23$ & $41.416,21$ & 65,25 \\
13 & $4.728,16$ & $-23.022,66$ & $13.130,16$ & $34.617,31$ & 75,35 \\
14 & $3.804,34$ & $-242.719,70$ & $12.206,34$ & $33.693,49$ & 79,47 \\
15 & $3.810,96$ & $-9.649,90$ & $10.840,96$ & $28.819,37$ & 66,40 \\
\hline
\end{tabular}

${ }^{1}$ Log da função máxima verossimilhança.

Fonte: Própria autoria.

\subsubsection{Erros de predição e viés}

Os resultados observados para a porcentagem de viés (PSB) variaram entre 7,62\% a 67,10\%, modelos 15 e 14 respectivamente, enquanto que a MSE oscilou de 75,36 a 638,00, modelos 15 e 14 respectivamente. As médias de PSB obtidas nos modelos considerando CG como efeito fixo ou aleatório foram, respectivamente, 19,05\% e 30,89\%. As MSE médias para os dois grupos (CG como efeito fixo ou aleatório) foram 181,42 e 294,45, respectivamente. A MSE observada para o modelo sem o efeito de CG, mas com o efeito de criatório, foi similar as dos modelos que incluíram CG e o modelo mais viesado foi o modelo sem efeitos fixos (14) (Figura 4). 
Figura 4 - Diferença entre a estimativa de variância fenotípica a partir dos dados e dos modelos (A); média quadrática de erros (B - cinza); porcentagem de viés $(\mathrm{B}$ - preto) e acurácias de predição: média $(\mathrm{C}$ - preto) e máxima $(\mathrm{C}-$ cinza $)$

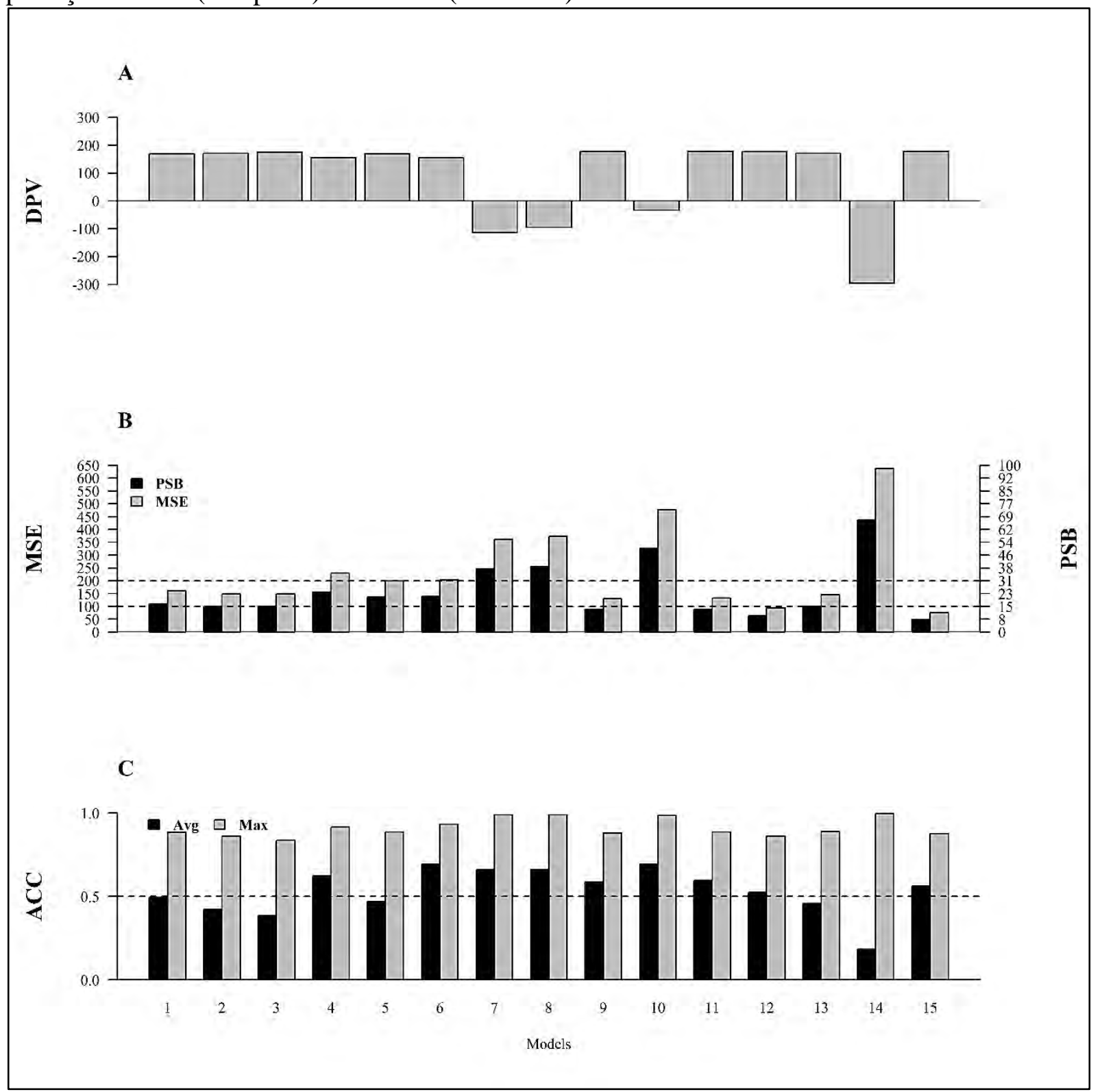

Fonte: Própria autoria.

\subsection{Discussão}

\subsubsection{Diagnósticos de convergência}

A visualização gráfica das cadeias de Markov mostrou sinais de não-convergência para alguns parâmetros nos modelos de 1 a 14 (Apêndice A). Para alguns componentes específicos o escore $\mathrm{Z}$ de Geweke apontou para um longo período de burnin visando uma melhor convergência: a variância genética aditiva no modelo 8; as estimativas de variância residual para os modelos 1, 4, 8 e 12; a herdabilidade para os modelos 1, 2, 4 e 8, mostrando 
que nestes modelos, devido a parametrização, parâmetros específicos para o amostrador de gibbs (como um longo período de burnin) poderiam beneficiar a convergência. Como discutido por Cowles e Carlin (1996), o teste Z de Geweke leva em consideração viés e variância, mas tem a desvantagem de ser sensível a janela espectral especificada, assim, é possível que modelos com valores altos de Z-escore poderiam também ser beneficiados por um maior intervalo de salvamento.

Os intervalos de alta densidade a posteriori não foram tão estreitos as médias $a$ posteriori, o que poderia estar mais relacionado com a quantidade de informação fenotípica do que com a modelagem, porque a quantidade de animais MP foi sensivelmente menor do que a de animais $\mathrm{MB}$ e, neste caso, os efeitos sem variação (CG e criatório) foram mantidos na estimação. Devido a manutenção dos efeitos sem variância fenotípica no processo de estimação, o teste de estacionariedade de Heidelberger-Welch (HEIDELBERGER; WELCH, 1983) deveria ser um bom parâmetro para verificar a qualidade da amostragem e convergência. Neste caso, os modelos 1, 2, 3 e 4 mostraram problemas com as estimativas da covariável idade no teste de estacionariedade. Para esses modelos uma cadeia maior poderia beneficiar a amostragem, uma vez que o amostrador de gibbs permanece na mesma região da distribuição a posteriori dos parâmetros.

É possível que a convergência tenha sido afetada pela mantença dos grupos de contemporâneos e os criatórios sem variação, o que fez com que as soluções do sistema de equações ficassem perto da média do grupo; neste sentido grupos com média zero representam um grande obstáculo para as análises, isso poderia levar a estimação constante e um amostrador não transicional. Neste caso, uma menor complexidade do modelo deve ser requerida para a amostragem e para atentar para uma melhor convergência, uma vez que a parametrização fica menor e a quantidade de informação torna o modelo capaz de estimar todos os efeitos.

\subsubsection{Concordância fenotípica}

Como o fenótipo nesta raça representa não ausência ou presença, mas a ocorrência de dois andamentos diferentes, a herdabilidade desta característica deveria ser alta, devido a concordância entre o tipo de andamento dos pais e da progênie. Em geral, pais apresentando andamento MB também possuem MB como fenótipo de sua progênie e o mesmo foi observado nos animais de andamento MP.

Os altos valores de concordância entre pais e progênie MB podem estar relacionados com o número de animais $\mathrm{MB}$ no banco de dados usado neste estudo. $\mathrm{O}$ fato de 
que éguas tenham mais concordância entre seu fenótipo e o de sua progênie foi uma observação completamente nova, isso pode estar relacionado a alguma herança materna, mas é possível que o elevado número de fêmeas fenotipadas, quando comparado com machos, fez com que esse percentual aumentasse a despeito dos garanhões.

A conectividade média entre todos os animais fenotipados foi baixa o que talvez impactou as estimativas de herdabilidade a posteriori, mas também o parentesco entre cada grupo fenotípico (tipo de andamento). Isso magnificou a variância genética, uma vez que a diferença na covariância genética dentro de cada tipo de andamento implicou em diferenças entre cada grupo, assim, a solução para a variância genética aditiva aumentou.

\subsubsection{Efeitos das covariáveis}

O alto efeito da endogamia no fenótipo talvez esteja relacionado com a proporção de animais endogâmicos dentro de cada tipo de andamento ( $\mathrm{MP}=58,40 \%$; $\mathrm{MB}=29,10 \%)$, mas também com a média de endogamia de acordo com o fenótipo ( $\mathrm{MP}=2,99 \%$; $\mathrm{MB}=1,92 \%$ ). De fato, em todos as estimativas do coeficiente de regressão do fenótipo pela endogamia, o HPD incluiu o zero, o que sugere a ausência de relação entre o coeficiente de endogamia e o fenótipo.

Para a covariável idade o mesmo padrão foi encontrado, mas a magnitude dos efeitos foi muito menor do que para as estimativas de endogamia. Os baixos efeitos da idade talvez estejam relacionados com o impacto do treinamento no fenótipo observado. No passado era muito comum para os criadores a mudança do andamento de alguns animais de acordo com seu interesse em particular. Este fato no presente talvez ainda aconteça, mas em menor escala, assim o impacto da idade, representando o treinamento do animal foi baixo.

Do ponto de vista da convergência, nas covariáveis em todos os modelos (exceto para o modelo 15) um período de burnin mais longo levaria a benefício na estimativa das distribuições a posteriori. Para a idade nos modelos 1, 2, 3 e 4 mais amostras seriam também necessárias, o que implicaria em mais tempo de processamento, diminuindo as chances destes modelos serem usados no futuro em análises genômicas ou implementações de programas genéticos. 


\subsubsection{Distâncias e correlações}

Nas estimações clássicas do melhoramento animal uma pressuposição dos modelos é que a variância entre CG/rebanhos é homocedástica (VAN VLECK, 1987). Quando grupos de contemporâneos ou efeitos fixos talvez tenham variância heterogênea, metodologias apropriadas são necessárias para lidar com isso (GIANOLA, 1986; HENDERSON, 1984; HILL, 1984). Um dos métodos propostos é usar o efeito fixo de rebanho ao invés de um grupo de contemporâneos completamente definido. As estimativas de rebanho neste estudo foram alcançadas pelo uso de criatório, que representa o maior "grupo de contemporâneos" possível para incluir os efeitos não genéticos sobre o tipo de andamento.

Os resultados observados para os EBVs dos animais quando considerando diferentes modelos foram amplamente diferentes. As correlações para os EBVs obtidos por modelos que consideraram os CG como efeito fixo foram maiores do que as correlações entre os EBVs preditos por modelos com CG como efeito aleatório, é plausível que dependendo da parametrização dos modelos as soluções para os CGs afete a quantidade de variância genética positiva ou negativamente, implicando em severas diferenças entre o mesmo CG quando este é considerado como efeito fixo ou aleatório. Pascoa et al. (2013) reportaram poucas diferenças entre efeitos fixos ou aleatórios dos CGs, neste estudo as elevadas diferenças são relacionadas com efeitos fixos e aleatórios com média e variância zero, o que superestima a variância fenotípica, consequentemente reduz a herdabilidade devido a grande diferença entre os grupos/efeitos.

Uma vez que as correlações de Pearson foram diferentes por modelo, as correlações de Spearman foram também impactadas pela estrutura de variância neste estudo. Ødegård et al. (2007) discutiram que EBVs altamente correlacionados (correlação de Pearson) também possuem uma correlação alta entre seu ranking (correlação de Spearman), o que foi encontrado no presente estudo de maneira similar. O ranking dos EBVs foi altamente correlacionado para aqueles modelos com efeito fixo de CG/criatório e mais não correlacionado entre os modelos com efeitos aleatórios de CG/criatório. Isso pode ser atribuído a parametrização nestes modelos, como sugerido por Perez et al. (2017), modelos diferentes mas com a mesma parametrização talvez resultem em EBVs e rankings muito correlacionados.

A distância euclidiana tem sido reportada como uma boa medida para avaliar dados ecológicos (LEGENDRE; ANDERSSON, 1999; MCARDLE; ANDERSON, 2001) e também para valores genéticos estimados (CUYABANO et al., 2015). A distância euclidiana pode ser uma informação de quão perto é duas estimativas de diferentes modelos, enquanto que a 
correlação apenas considera a variância comum entre duas estimativas ou variáveis. No presente estudo foi observado que EBVs altamente correlacionados também são menos distantes um do outro, mostrando que a correlação pode ser um bom parâmetro quando a distância não é aplicável. A distância global entre as estimativas dos modelos pode ser interpretada como uma estratégia para identificar como a parametrização em cada modelo lida com as estimativas e o quão próximos são diferentes modelos, baseado em cada parâmetro estimado. Como mostrado na Figura 3, a distância entre os modelos e os EBVs tiveram o mesmo padrão, mostrando que o EBV pode ser um bom ponto de checagem para verificar a proximidade entre modelos diferentes em parametrização.

\subsubsection{Critérios de informação}

O AIC foi proposto para selecionar o modelo com as melhores predições, mas não é um critério apropriado para comparar estimativas de parâmetros, nestes casos uma penalização precisa ser aplicada. O critério Bayesiano de Schwartz, em essência, tenta identificar o modelo verdadeiro em um grupo de modelos testados (SPIEGELHALTER et al., 2014). Como discutido por Kuha (2004), a maioria dos critérios de informação são generalizações do DIC ou BIC, os quais são mais comumente utilizados para comparação de modelos. Neste estudo nós apresentamos os três critérios de informação (DIC, BIC e AIC), mas em alguns casos a concordância entre o BIC e o AIC talvez aponte para o melhor modelo, uma vez que o AIC pode mostrar qual foi o melhor preditor e o BIC qual foi o melhor estimador. Robert e Titterington (2002) discutiram a capacidade do DIC de lidar com modelos com "overfit" e, Ando (2007) mostrou que isso pode estar relacionado com a complexidade de escolha de uma distribuição preditiva pelo DIC. Assim, neste estudo a concordância do $15^{\circ}$ modelo aparecendo como melhor tanto no AIC como no BIC deve ser considerada como uma vantagem para seu uso em futuras análises desta característica.

Considerando o DIC, alguns modelos tiveram problemas com as estimativas do número efetivo de parâmetros, isto é, valores muito negativos para esta estimativa, diminuindo os resultados de DIC como proposto por Spiegelhalter et al. (2002). Nestes casos talvez o problema seja a complexidade do modelo e a quantidade de informação para calcular todos os parâmetros. O $15^{\circ}$ modelo, o qual obteve os melhores valores de AIC e BIC, não foi o melhor para o DIC, mas ainda teve um bom valor para este critério de informação e talvez seja um bom modelo do ponto de vista de comparação de "qualidade de ajuste" e complexidade. O tempo de processamento para todos os modelos foi muito similar; alguns modelos levaram muito pouco 
tempo para amostrar todas as amostras e outros mais tempo. As diferenças mais severas foram observadas nos modelos mais parametrizados, mas uma relação não tão clara entre o tempo de processamento e a parametrização foi encontrada neste estudo. Talvez a quantidade de dados aliada a complexidade do modelo impacte o tempo de processamento, aumentando-o ou diminuindo-o. Em análises futuras isso deve ser considerado como um critério importante, por causa da exequibilidade do modelo na prática.

\subsubsection{Erros de predição e viés}

Como mostrado na Figura 4, todas as estimativas de variância fenotípica dos modelos diferiram da estimativa a partir dos dados e isso provavelmente foi relacionado com a mantença dos efeitos fixos sem variância fenotípica (todos "uns" ou todos “zeros") nas análises. Quando nós observamos estas diferenças, os modelos que levaram em conta os efeitos dos grupos de contemporâneos como fixo foram iguais aos modelos com efeito de criatório ao invés de CG, nós sugerimos que neste caso do zero informativo, o efeito de criatório pode atuar como um CG, absorvendo os efeitos ambientais e tornando a estimação possível. Isso pode ter ocorrido pelo fato de que quando a complexidade de um CG formal foi reduzida e, os dados não tiveram nenhuma restrição imposta, o número de reprodutores dentro de cada CG /criatório aumentou, assim como o número de observações dentro deles, permitindo as estimações, em concordância com o que foi dito por Van Vleck (1987).

Todos os modelos tiveram uma porcentagem de viés; assim, foi interessante que o modelo mais ajustado de acordo com o BIC e o AIC também obteve a menor proporção de viés, neste caso isso foi uma confirmação dos critérios de informação na preditividade dos modelos. Todos os modelos tiveram valores elevados de MSE, mas não é propósito do melhoramento predizer fenótipos, ao invés disso é desejada uma boa habilidade de predição (EBV), assim, todos os modelos com menores erros e viés não devem ser considerados separadamente dos critérios de informação.

\subsection{Conclusão}

Parece que, considerando bancos de dados pequenos e características que não seguem uma distribuição Binomial clássica (presença e ausência), modelos com menor complexidade e mesmo considerando efeitos fixos de menor magnitude do que grupos de contemporâneos são beneficiados por menores viés e erros médios de predição. Quando efeitos 
fixos com variância nula são mantidos no modelo, podem ocorrer dois problemas: amostrador estacionário e soluções próximas à média dos efeitos, estes problemas tendem a ser resolvidos com um grande número de amostras geradas da distribuição a posteriori e uma menor complexidade nos modelos. A complexidade tem uma influência considerável tanto na estimação dos parâmetros, quanto nas predições genéticas. Para tornar análises do tipo de andamento em cavalos exequível, um modelo de menor complexidade deve ser utilizado, considerando efeitos fixos de rebanho/criatório e idade como uma covariável, mas são necessários mais estudos para identificar a melhor estratégia de modelagem para esta característica.

\subsection{Referências}

AKAIKE, H. Information theory and an extensión of the maximum likelihood principle. In: PARZEN, E.; TANABE, K.; KITAGAWA, G. (Ed.). Selected papers of Hirotugu Akaike. New York: Springer, 1973. p. 267-281.

ANDO, T. Bayesian predictive information criterion for the evaluation of hierarchical Bayesian and empirical Bayes models. Biometrika, Oxford, v. 94, n. 2, p. 443-458, 2007.

BRASIL. Ministério da Agricultura, Pecuária e Abastecimento - MAPA. Revisão do estudo do complexo do agronegócio do cavalo. Brasília-DF: MAPA, 2016.

CARNEIRO DE REZENDE, A. S. et al. Skeletal muscle fiber composition of untrained mangalarga marchador fillies. Journal of Equine Veterinary Science, Maryland Heights, v. 36, p. 101-104, 2016.

COWLES, M. K.; CARLIN, B. P. Markov chain Monte Carlo convergence diagnostics: a comparative review. Journal of the American Statistical Association, Alexandria, v. 91, n. 434, p. 883-904, 1996.

CUYABANO, B. C. D. et al. Bootstrap study of genome-enabled prediction reliabilities using haplotype blocks across Nordic Red cattle breeds. Journal of Dairy Science, New York, v. 98, n. 10, p. 7351-7363, 2015.

DI FILIPPO, P. A. et al. Gender differences-induced changes in serum hematologic and biochemical variables in Mangalarga Marchador horses after a marcha gait competition. Journal of Equine Veterinary Science, Maryland Heights, v. 43, p. 18-22, 2016.

FONSECA, M. G. et al. A Genome-wide association study reveals differences in the genetic mechanism of control of the two gait patterns of the Brazilian Mangalarga Marchador Breed. Journal of Equine Veterinary Science, Maryland Heights, v. 53, p. 64-67, 2017.

GEWEKE, J. Evaluating the accuracy of sampling-based approaches to the calculation of posterior moments. Bayesian Statistics, Oxford, v. 4, p. 169-193, 1992. 
GIANOLA, D. Theory and analysis of threshold characters. Journal of Animal Science, Cary, v. 54, n. 5, p. 1079-1096, 1982.

GIANOLA, D. On selection criteria and estimation of parameters when the variance is heterogeneous. Theoretical and Applied Genetics, Heidelberg, v. 72, n. 5, p. 671-677, 1986.

HEIDELBERGER, P.; WELCH, P. D. Simulation run length control in the presence of an initial transient. Operations Research, Catonsville, v. 31, n. 6, p. 1109-1144, 1983.

HENDERSON, C. R. Applications of linear models in animal breeding models. Guelph: University of Guelph, 1984. 384 p.

HILL, W. G. On selection among groups with heterogeneous variance. Animal Production, Cambridge, v. 39, n. 3, p. 473-477, 1984.

KUHA, J. AIC and BIC: Comparisons of assumptions and performance. Sociological Methods and Research, Thousand Oaks, v. 33, n. 2, p. 188-229, 2004.

LEGENDRE, P.; ANDERSSON, M. J. Distance-based redundancy analysis: Testing multispecies responses in multifactorial ecological experiments. Ecological Monographs, Hoboken, v. 69, n. 1, p. 1-24, 1999.

MATOS, C. et al. Genetic analysis of discrete reproductive traits in sheep using linear and nonlinear models: I. Estimation of genetic parameters. Journal of Animal Science, Cary, v. 75, p. 76-87, 1997.

MCARDLE, B. H.; ANDERSON, M. J. Fitting multivariate models to community data: A comment on distance-based redundancy analysis. Ecology, Hoboken, v. 82, n. 1, p. 290-297, 2001.

MEIJERING, A.; GIANOLA, D. Linear versus nonlinear methods of sire evaluation for categorical traits: a simulation study. Genetics Selection Evolution, London, v. 17, p. 115$132,1985$.

MEVIK, B. H.; CEDERKVIST, H. R. Mean squared error of prediction (MSEP) estimates for principal component regression (PCR) and partial least squares regression (PLSR). Journal of Chemometrics, Garsington, v. 18, n. 9, p. 422-429, 2004.

MISZTAL, I. et al. BLUPF90 and related programs (BGF90). In: WORLD CONGRESS ON GENETICS APPLIED TO LIVESTOCK PRODUCTION, 7., 2002, Montpellier.

Proceedings... Montepellier, 2002. 2 p.

ØDEGÅRD, J. et al. Evaluation of statistical models for genetic analysis of challenge-test data on ISA resistance in Atlantic salmon (Salmo salar): Prediction of progeny survival. Aquaculture,Amsterdam, v. 266, n. 1-4, p. 70-76, 2007.

PASCOA, L. et al. Effect of several structures of contemporary groups on estimates of (co)variance and genetic parameters for weaning weight in nellore cat. Ciencia Animal Brasileira, Goiania, v. 14, n. 2, p. 151-158, 2013. 
PEREZ, B. C. et al. Count Bayesian models for genetic analysis of in vitro embryo production traits in Guzerá cattle. Animal, Cambridge, v. 11, n. 9, 2017.

PLUMMER, M. et al. CODA: convergence diagnosis and output analysis for MCMC. $\mathbf{R}$ News, Vienna, v. 6, p. 7-11, March. 2006.

R CORE TEAM. R Development Core TeamR: a language and environment for statistical computing. 2016.

ROBERT, C. P.; TITTERINGTON, D. M. Discussion on "Bayesian measures of model complexity and fit" (by D.J. Spiegelhalter, N.G. Best, B.P. Carlin and A. van der Linde). Journal of the Royal Statistical Society. Series B: Statistical Methodology, Chichester, v. 64, n. 4, p. 621-622, 2002.

SCHWARZ, G. Estimating the dimension of a model. Annals of Statistics, Shaker Heights, v. 6, n. 2, p. 461-464, 1978.

SPIEGELHALTER, D. J. et al. Bayesian measures of model complexity and fit. Journal of the Royal Statistical Society. Series B: Statistical Methodology, Chichester, v. 64, n. 4, p. 583-616, 2002.

SPIEGELHALTER, D. J. et al. The deviance information criterion: 12 years on. Journal of the Royal Statistical Society. Series B: Statistical Methodology, Chichester, v. 76, n. 3, p. 485-493, 2014.

STOCK, K. F.; DISTL, O.; HOESCHELE, I. Bayesian prediction of breeding values for multivariate binary and continuous traits in simulated horse populations using threshold-linear models with Gibbs sampling. Animal, Cambridge, v. 2, n. 1, p. 9-18, 2008.

STOCK, K. F.; HAMANN, H.; DISTL, O. Estimation of genetic parameters for the prevalence of osseous fragments in limb joints of Hanoverian Warmblood horses. Journal of Animal Breeding and Genetics, Hamburg, v. 122, n. 4, p. 271-280, 2005.

VAN VLECK, L. D. Estimation of heritability of threshold characters. Journal of Dairy Science, New York, v. 55, n. 2, p. 218-225, 1972.

VAN VLECK, L. D. Contemporary groups for genetic evaluations. Journal of Dairy Science, New York, v. 70, n. 11, p. 2456-2464, 1987.

YAPO, P.; GUPTA, H. V.; SOROOSHIAN, S. Automatic calibration of conceptual rainfallrunoff models: sensitivity to calibration data. Journal of Hydrology, Amsterdam, v. 181, p. 23-48, 1996. 


\title{
4 FREQUÊNCIAS ALÉLICAS E GENOTÍPICAS DO GENE DMRT3 NA RAÇA DE CAVALOS BRASILEIRA MANGALARGA MARCHADOR E SUA ASSOCIAÇÃO COM OS TIPOS DE MARCHA
}

\author{
F.O. Bussiman 1 , B.A. dos Santos ${ }^{2}$, B.C. Abreu Silva ${ }^{3}$, B.C. Perez ${ }^{1}$, G.L. Pereira ${ }^{2}$, L.A.L. \\ Chardulo $^{2}$, J.P. Eler ${ }^{3}$, J.B.S. Ferraz ${ }^{3}$, E.C. Mattos ${ }^{3}$, R.A. Curi ${ }^{2}$, J.C.C. Balieiro ${ }^{4}$
}

${ }^{1}$ Departamento de Zootecnia, Faculdade de Zootecnia e Engenharia de Alimentos, Universidade de São Paulo (FZEA/USP), Av. Duque de Caxias Norte, 225, 13.635-900, Pirassununga, São Paulo, Brasil;

2Departamento de Melhoramento Animal, Faculdade de Zootecnia e Engenharia de Alimentos, Universidade Estadual Paulista Júlio de Mesquita Filho (FMVZ/UNESP), Rua José Barbosa de Barros, 1780, Fazenda Experimental Lageado, 18.618-307, Botucatu, São Paulo, Brasil;

3 Grupo de Melhoramento Animal, Biotecnologia e Transgenia, Departamento de Medicina Veterinária, Faculdade de Zootecnia e Engenharia de Alimentos, Universidade de São Paulo (GMAB-FZEA/USP), Av. Duque de Caxias Norte, 225, 13.635-900, Pirassununga, São Paulo, Brasil;

4Departamento de Nutrição e Produção Animal, Faculdade de Medicina Veterinária e Zootecnia, Universidade de São Paulo (FMVZ/USP), Av. Duque de Caxias Norte, 225, 13.635-900, Pirassununga, São Paulo, Brasil.

RESUMO: O gene DMRT3 foi descrito como o principal gene que influencia a marcha em equinos; mas a maioria dos estudos examinou seus efeitos comparando as informações de indivíduos trotados e marchados. Dentro da raça brasileira Mangalarga Marchador, os animais podem apresentar dois tipos de andamentos (marcha batida e marcha picada), os quais diferem na forma de movimento - diagonal (marcha batida) ou lateral (marcha picada). Examinamos uma possível associação do SNP g.22999655C > A DMRT3 com o tipo de marcha, nesta raça de dois andamentos. O parentesco entre os indivíduos foi calculado para os dois grupos fenotípicos, assim como o coeficiente de endogamia e sua tendência ao longo das gerações. As frequências alélicas e genotípicas foram estimadas com base nos dados genotípicos de 310 equinos (205 marcha batida; 105 marcha picada). Dois modelos de limiar foram utilizados para determinar a proporção da variância fenotípica explicada pelos genótipos do DMRT3. A média de parentesco para animais com marcha batida foi de $0,04 \pm 0,00$, enquanto na marcha picada foi de $0,05 \pm 0,01$ (maior que a média populacional de $0,04 \pm 0,00$ ). O coeficiente de endogamia foi de 1,71 e 3,48\% para os animais com marcha batida e marcha picada, respectivamente. Os efeitos do gene DMRT3 variaram de 9,94 a 10,77\% (como proporção da variância fenotípica) quando incluídos como efeito aleatório não correlacionado e como covariável, respectivamente. As frequências genotípicas do DMRT3 e os padrões de parentesco e endogamia poderiam ser resultado da seleção nesta raça, resultando em confusão estatística entre os efeitos do DMRT3 e a estrutura populacional.

Palavras-chave: Parentesco. Endogamia. Variância explicada. Efeito de SNP. Marcha. 


\begin{abstract}
The DMRT3 gene has been described as the main gene influencing gait in horses; but most studies have examined its effects by comparing information from trotted and gaited individuals. Within the Brazilian Mangalarga Marchador breed, animals can present two types of gaits (marcha batida and marcha picada), which differ in the movement form - diagonal (marcha batida) or lateral (marcha picada). We examined a possible association of the g.22999655C>A DMRT3 SNP with the type of gait, in this two-gait breed. The relationship between individuals was calculated for the two phenotypic groups, as well as the inbreeding coefficient and its trend over generations. The allelic and genotypic frequencies were estimated based on genotype data from 310 horses (205 marcha batida; 105 marcha picada). Two threshold models were used to determine the proportion of phenotypic variance explained by DMRT3 genotypes. The average coancestry for animals with marcha batida was $0.04 \pm 0.00$, whereas in marcha picada it was $0.05 \pm 0.01$ (higher than the population mean of $0.04 \pm 0.00$ ). The inbreeding coefficient was 1.71 and $3.48 \%$ for marcha batida and marcha picada animals, respectively. Effects of the DMRT3 gene ranged from 9.94 to $10.77 \%$ (as a proportion of phenotypic variance) when included as an uncorrelated random effect and as a covariable, respectively. The genotypic frequencies of the DMRT3 and the patterns of kinship and inbreeding could be a result of selection in this breed, resulting in statistical confusion between the DMRT3 effects and population structure.
\end{abstract}

Keywords: Kinship. Inbreeding. Variance explained. SNP effect. Gait.

\title{
4.1 Introdução
}

O cavalo Mangalarga Marchador é uma raça de equinos brasileira que se originou dos animais trazidos pelos conquistadores europeus e foi selecionado ao longo dos anos para marcha e morfologia específicas (MOTA; PRADO, 2005). Em 1949, foi fundada a Associação Brasileira de Criadores do Cavalo Mangalarga Marchador (ABCCMM) e, hoje, esta raça figura na primeira posição em número de animais registrados no Brasil. Recentemente, esta raça foi declarada como "a raça nacional". Estes cavalos são, atualmente, exportados globalmente, alcançando importância internacional (FONSECA et al., 2017). Nesta raça, os animais apresentam dois tipos de andamentos chamados marcha batida (MB) e marcha picada (MP), que diferem na forma de movimento - diagonal ou lateral, respectivamente.

Por definição, os andamentos chamados de "marcha" no Brasil são andamentos dissociados, que são reconhecidos pelos momentos de apoios tripedais. Dissociação significa que cada membro está em uma fase diferente durante o movimento do cavalo. De acordo com Nicodemus e Clayton (2003), ambos os andamentos no cavalo Mangalarga Marchador são andamentos de quatro batidas, os quais podem ser entendidos como uma forma de passo acelerado. Devido a dissociação, cavalos marchadores podem executar vários tipos de suporte durante a movimentação e, alguns destes tipos são predominantes. O tempo de apoios diagonais 
no andamento MB é maior do que na MP, enquanto que na MP o tempo de apoios laterais é maior. Estes dois andamentos possuem apoios tripedais intercalados com apoios bipedais.

Segundo Manso Filho et al. (2015), nos últimos anos genes distintos têm sido estudados com o objetivo de avaliar as origens genéticas dos tipos marcha. Entre os genes candidatos mais promissores está o DMRT3, descrito como responsável por influenciar os padrões de movimento dos membros esquerdo e direito, bem como coordenação torácica e pélvica (ANDERSSON et al., 2012). Andersson et al. (2012), Patterson, Staiger e Brooks (2015) e Promerová et al. (2014), relataram que o alelo mutante A do SNP g.22999655C > A do DMRT3 é o de maior frequência em cavalos marchadores, enquanto que em animais de trote a variante selvagem (C) está em maior frequência. Além disso, o alelo A tem sido associado com a boa qualidade do passo e da marcha, quando comparados aos animais com genótipo CC (ANDERSSON et al., 2012; JÄDERKVIST et al., 2015a).

Estudos recentes relataram frequências alélicas e genotípicas para o SNP g.22999655C>A e reportaram que animais de marcha picada teriam uma alta frequência do alelo A em comparação com animais que exibem marcha batida (FONSECA et al., 2017; MANSO FILHO et al., 2015; PATTERSON; STAIGER; BROOKS, 2015; PEREIRA et al., 2016; PROMEROVÁ et al., 2014). No entanto, esta relação permanece incerta e as frequências genotípicas observadas sugerem que, embora o DMRT3 tem uma associação com a marcha, não seria a variante causal exclusiva para os diferentes tipos de marcha no cavalo Mangalarga Marchador. Para melhor entender seu papel, nós examinamos a relação entre o gene DMRT3 e os tipos de andamento cavalos Mangalarga Marchador; nós também investigamos os padrões de parentesco e endogamia de acordo com os genótipos e fenótipos observados.

\subsection{Material e métodos}

\subsubsection{Animais e pedigree}

Foram coletadas amostras de sangue de 310 cavalos (105 MP e 205 MB) em várias propriedades $(\mathrm{N}=14)$ nos estados de São Paulo e Minas Gerais, bem como durante a $36^{\mathrm{a}}$ Exposição Nacional do Cavalo Mangalarga Marchador, tentando representar a diversidade desta raça no Brasil. Este estudo foi conduzido de acordo com os princípios éticos na experimentação animal (UNESP, Botucatu, Brasil; Número de aprovação 29/2017). Informações de pedigree para todos os indivíduos fenotipados foi coletada no website público da ABCCMM. O arquivo de pedigree completo considerado para este estudo continha 3.172 
cavalos com um parentesco médio de 0,007 (excluindo auto relacionamentos) e uma média de gerações equivalentes completas de 2,02 (máximo de 6,23). No total, o pedigree continha 931 garanhões e 1.880 éguas, com um número médio de progênie de 2,56 e 1,27 para garanhões e éguas, respectivamente. O tamanho médio de família foi de 2,25 e variou de 2 a 7 e o número de grupos de irmãos completos foi de 130. O número de animais por geração é mostrado na Figura 1.

Figura 1 - Número de cavalos Mangalarga Marchador por geração do pedigree

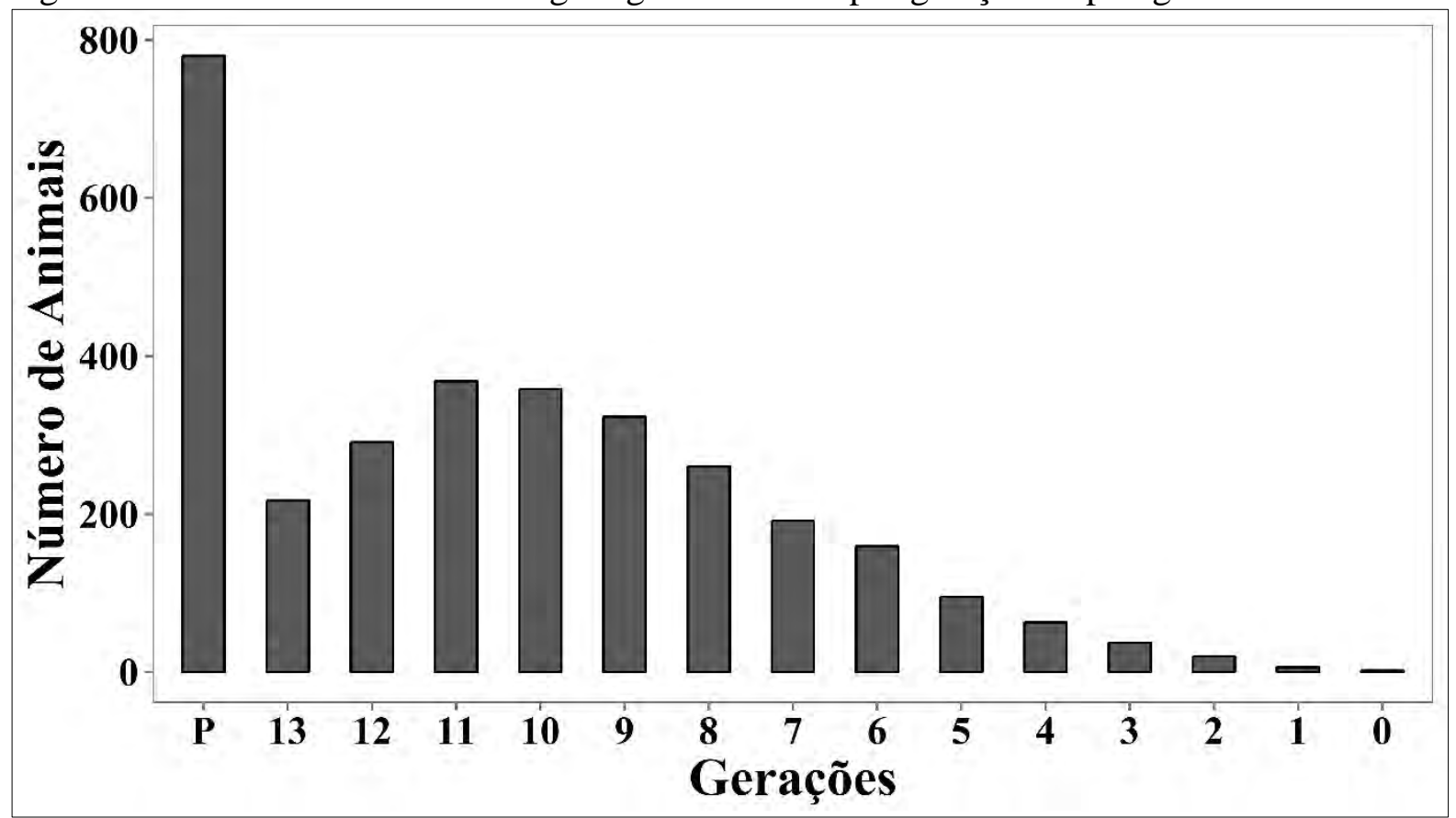

$\mathrm{P}=$ Geração parental - Fundadores;

0 = Geração atual.

Fonte: Própria autoria.

O DNA foi obtido para cada animal com o kit Illustra Blood GenomicPrep Mini Spin (GE Healthcare), seguindo as especificações do fabricante. A concentração e a pureza foram fixadas em $10 \mathrm{ng} / \mu \mathrm{l}$ e 1,7 (razão 260/280), respectivamente. Após a extração de DNA, todos os animais coletados foram genotipados para o SNP g.22999655C> A por PCR-RFLP de acordo com Pereira et al. (2016).

\subsubsection{Determinação do tipo de marcha}


Para cada anima, a informação sobre o tipo de marcha foi obtida assistindo-se um vídeo do animal em movimento (montado e em liberdade) e por documentos antigos de registros dos criadores mostrando o tipo de marcha. A informação de competições no site da ABCCMM foi checada para confirmar a categoria na qual o animal compete (MP ou MB). A pessoa que assistiu as filmagens foi sempre a mesma e, o andamento foi confirmado visualmente verificando que o deslocamento do animal envolveu predominantemente movimentos laterais (MP) ou diagonais (MB).

\subsubsection{Parentesco, endogamia e frequências alélicas}

A relação genética entre animais fenotipados e o coeficiente de endogamia $(\mathrm{F})$ para cada indivíduo foram calculados. O numerador da matriz de relacionamento (NRM - EMIK; TERRILL, 1949; HENDERSON, 1976, 1975) foi construído usando o software CFC (SARGOLZAEI; IWASAKI; COLLEAU, 2006), contendo a expectativa de ligação genética entre todos indivíduos no pedigree. Os animais foram agrupados de acordo com o fenótipo (MB ou MP) e os genótipos (AA, CA e CC) e, os coeficientes de parentesco foram calculados dentro e entre os grupos. O coeficiente $\mathrm{F}$ foi usado para identificar as possíveis tendências de endogamia ao longo das gerações. As frequências alélicas e genotípicas foram estimadas por contagem alelos e genótipos dentro de cada grupo de fenótipo e dividido pelo total de informação, isto é, o número total de alelos (ou genótipos). Adicionalmente, o teste para o equilíbrio de Hardy-Weinberg (HARDY, 1908; WEINBERG, 1908) foi realizado para os genótipos.

\subsubsection{Efeito do DMRT3}

Dois modelos categóricos de limiar lineares mistos foram propostos para estimar o efeito do DMRT3 no tipo de marcha:

$$
\begin{aligned}
& Y_{i j k}=\beta_{1} \text { Ageclass }+\beta_{2} \text { DMRT3 }+ \text { Farm }_{i}+u_{j}+e_{k} \\
& Y_{i j k l}=\beta_{1} \text { Ageclass }+ \text { Farm }_{i}+u_{j}+\text { DMRT }_{k}+e_{l}
\end{aligned}
$$

em que $\beta_{1}$ é o coeficiente de regressão para a covariável Ageclass (classe de idade) em ambos os modelos; $\beta_{2}$ é o coeficiente regressão dos genótipos do DMRT3 (codificado como $\mathrm{AA}=1$, $\mathrm{CA}=2$ e $\mathrm{CC}=3$ ) no modelo 1 ; os genótipos do DMRT3 (identicamente codificado) foram 
tratados como um efeito aleatório (modelo 2), com: DMRT3 N $\left(0, I_{D M R T 3}^{2}\right) ; F^{2} a r m_{i}$ representa o efeito sistemático de criatório; $u_{j}$ representa o efeito aleatório de animal, com variância como: $u \sim N\left(0, A \sigma_{u}^{2}\right)$, em que $A$ é a matriz inversa do NRM e $e$ representa os termos residuais aleatórios, no qual $e \sim N\left(0, I \sigma_{e}^{2}\right)$.

As análises foram implementadas utilizando-se uma abordagem Bayesiana, assim, as inferências foram feitas a partir da distribuição a posteriori dos parâmetros. Baseado na regra de Bayes, a densidade a posteriori dos parâmetros desconhecidos é $p(\theta \mid Y) \propto p(Y \mid \theta) p(\theta)$, em que $\theta$ representa a coleção de todos os parâmetros desconhecidos nos modelos, $p(\theta)$ é a distribuição a priori de $\theta, p(\theta \mid Y)$ é a distribuição a posteriori dos parâmetros desconhecidos. A distribuição conjunta a priori de todos os parâmetros foi definida como: $p(\theta) \propto$ $p\left(u \mid \sigma_{u}^{2}\right) p\left(\sigma_{u}^{2}\right) p\left(\sigma_{e}^{2}\right)$, isto é, $p(\theta) \propto N\left(u \mid 0, A \sigma_{u}^{2}\right) X^{-2}\left(\sigma_{u}^{2} \mid d f_{u}, S_{u}\right) X^{-2}$

$\left(\sigma_{e}^{2} \mid d f_{e}, S_{e}\right)$, em que $X^{-2}\left(. \mid d f ., S\right.$ ) é uma distribuição de $X^{2}$ inversa escalonada com $d f$ graus de liberdade e o parâmetro de escala $S$.

As análises foram realizadas usando o software THRGIBBS1F90 (MISZTAL et al., 2002). Foram gerados 2.000 .000 de amostras em uma única cadeia, assumindo um período de burnin de 1.000 .000 e um intervalo de salvamento a cada 100 amostras. Assim, as inferências foram feitas a partir de 10.000 amostras da distribuição a posteriori. A convergência das cadeias de MCMC foi verificada aplicando-se o teste de Geweke (GEWEKE, 1992) e HeidelbergerWelch (HEIDELBERGER; WELCH, 1983), usando o pacote 'coda' (PLUMMER et al., 2006) do Software R (R CORE TEAM, 2016).

No caso em que genótipos do DMRT3 foram tratados como uma covariável (1), a proporção da variação fenotípica explicada foi calculada de acordo com Shim et al. (2015):

$$
P V E=\frac{2 \widehat{\beta}^{2} p(1-p)}{2 \widehat{\beta}^{2} p(1-p)+(\operatorname{se}(\widehat{\beta}))^{2} 2 N p(1-p)}
$$

em que, $P V E$ é a proporção de variância fenotípica explicada; $\hat{\beta}$ é o coeficiente estimado para o efeito do DMRT3; $p$ é a frequência do alelo menor do DMRT3; se $(\hat{\beta})$ é o erro padrão para o coeficiente estimado e $N$ é o tamanho amostral.

No caso em que genótipos do DMRT3 foram tratados como um efeito aleatório não correlacionado (2) a proporção da variância fenotípica explicada foi calculada como:

$$
P V E=\frac{\sigma_{D M R T 3}^{2}}{\sigma_{u}^{2}+\sigma_{D M R T 3}^{2}+\sigma_{e}^{2}}
$$


em que, $\sigma_{D M R T 3}^{2}$ é o componente de variância estimado para os genótipos do DMRT3; $\sigma_{u}^{2}$ é a variância genética aditiva e $\sigma_{e}^{2}$ é a variância residual.

\subsection{Resultados}

\subsubsection{Parentesco, endogamia e frequência alélica}

A visualização gráfica do NRM (dados não mostrados) revelou diferenças entre o padrão de parentesco dentro dos grupos de marcha. O coeficiente médio de parentesco, considerando toda a população no pedigree e para os animais sem fenótipos foi de $0,04 \pm 0,06$ e $0,06 \pm 0,09$, respectivamente. O único grupo fenotípico que apresentou coeficiente de parentesco médio maior que a média da população no pedigree $(0,05 \pm 0,09)$ foi o grupo MP (Tabela 1).

$\underline{\text { Tabela } 1 \text { - Estatística descritiva do coeficiente de parentesco de cavalos Mangalarga Marchador }}$

\begin{tabular}{lrrrrr}
\hline \multicolumn{1}{c}{ Grupo de animais } & Média & \multicolumn{1}{c}{ Mínimo } & Máximo & SD & \multicolumn{1}{c}{ N } \\
\hline Pedigree total & 0,04 & $9,54 \times 10^{-07}$ & 1,06 & 0,06 & 3.172 \\
Marcha Batida & 0,04 & $3,81 \times 10^{-06}$ & 0,97 & 0,07 & 205 \\
Marcha Picada & 0,05 & $9,54 \times 10^{-07}$ & 0,81 & 0,09 & 105 \\
Não fenotipados & 0,06 & $3,81 \times 10^{-06}$ & 0,84 & 0,09 & 2.862 \\
\hline
\end{tabular}

$\mathrm{SD}=$ desvio-padrão; $\mathrm{N}=$ Número de animais.

Fonte: Própria autoria.

A média de F para os indivíduos MP e MB foi 3,48 e 1,71\%, respectivamente. As diferenças na média de $\mathrm{F}$ entre os dois grupos foi significativa baseada no teste $\mathrm{T}(\mathrm{P}<0,001)$ (Tabela 2). Todos os animais endogâmicos apresentaram uma tendência decrescente para o F, mas as tendências não diferem dentro de cada grupo fenotípico (Figura 2). Adicionalmente, a proporção de animais em classes de 5 a 20\% de F foi maior em animais MP do que MB (Tabela $3)$. 
Tabela 2 - Estatística descritiva do coeficiente de cavalos Mangalarga Marchador

\begin{tabular}{lrrrrr}
\hline \multicolumn{1}{c}{ Grupo de animais } & \multicolumn{1}{c}{ Média } & \multicolumn{1}{c}{ Mínimo } & \multicolumn{1}{c}{ Máximo } & \multicolumn{1}{c}{ SD } & $\%$ do total \\
\hline Pedigree total & 0,015 & 0,000 & 0,410 & 0,040 & 21,310 \\
Marcha Batida & 0,017 & 0,000 & 0,410 & 0,050 & 40,490 \\
Marcha Picada & 0,035 & 0,000 & 0,310 & 0,050 & 75,240 \\
Não fenotipados & 0,009 & 0,000 & 0,310 & 0,040 & 0,310 \\
\hline
\end{tabular}

$\mathrm{SD}=$ desvio-padrão;

$\mathrm{N}=$ Número de animais.

Fonte: Própria autoria.

Figura 2 - Tendências de endogamia ao longo das gerações de acordo com o tipo de andamento e, todos os cavalos Mangalarga Marchador ou endogâmicos. A: todos os animais de marcha batida $(\mathrm{P}=0,012)$; $\mathrm{B}$ : todos os animais de marcha picada $(\mathrm{P}=0,300)$; $\mathrm{C}$ : endogâmicos de marcha batida $(\mathrm{P}=0,046)$ e $\mathrm{D}$ : endogâmicos de marcha picada $(\mathrm{P}=0,045)$
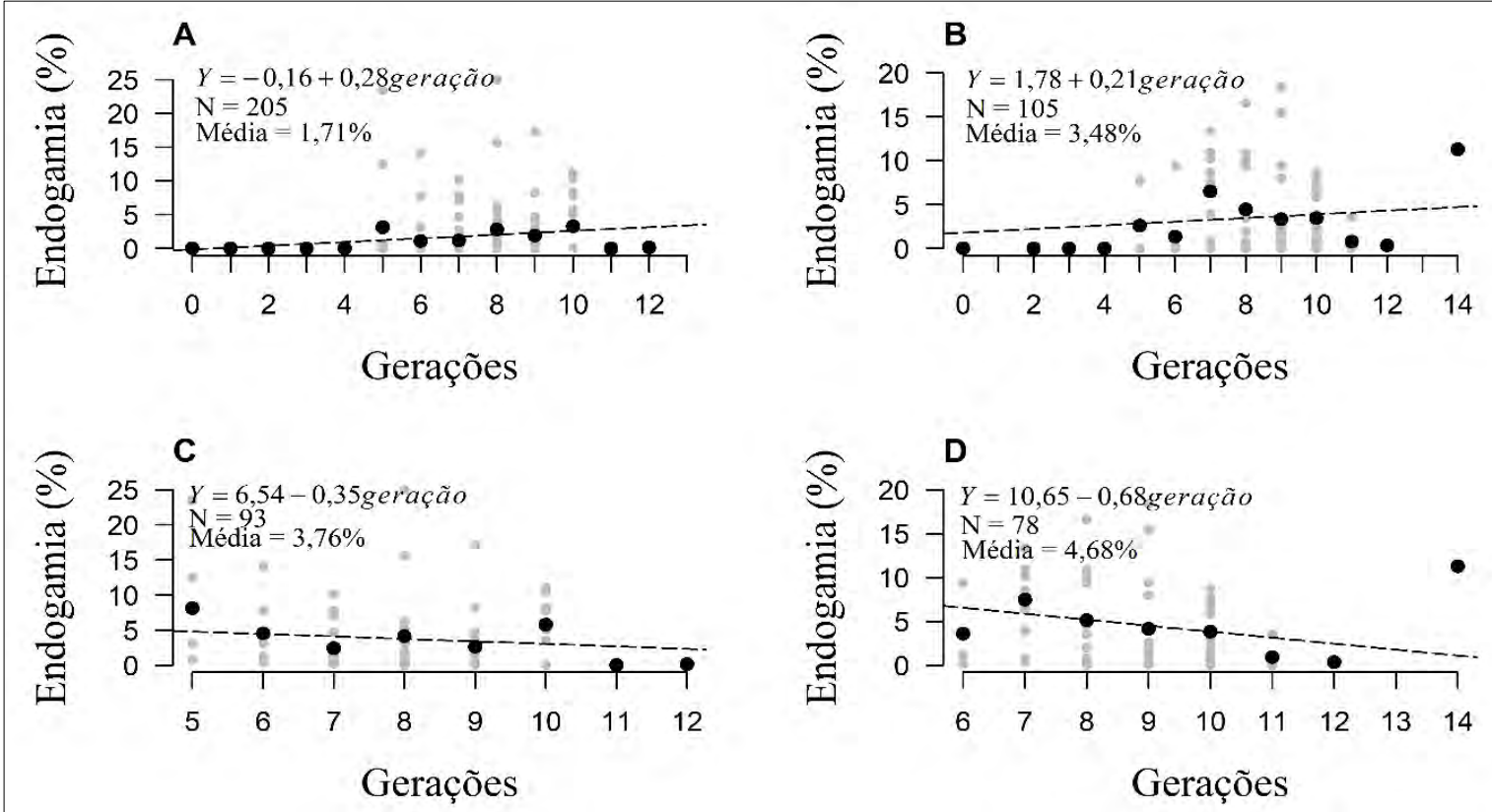

Fonte: Própria autoria.

Tabela 3 - Número de cavalos Mangalarga Marchador por classe de endogamia e porcentagem de cada classe

\begin{tabular}{|c|c|c|c|c|c|c|}
\hline \multirow{2}{*}{ Categorias de $\mathrm{F}(\%)$} & \multicolumn{2}{|c|}{ Pedigree total } & \multicolumn{2}{|c|}{ Marcha Batida } & \multicolumn{2}{|c|}{ Marcha Picada } \\
\hline & $\mathrm{N}$ & $\%$ do total & $\mathrm{N}$ & $\%$ do total & $\mathrm{N}$ & $\%$ do total \\
\hline 0,00 a 2,50 & 2.757 & 86,92 & 168 & 81,95 & 65 & 61,90 \\
\hline 2,50 a 5,00 & 85 & 2,68 & 14 & 6,83 & 11 & 10,48 \\
\hline 5,00 a 10,00 & 141 & 4,45 & 13 & 6,34 & 18 & 17,14 \\
\hline 10,00 a 15,00 & 99 & 3,12 & 5 & 2,44 & 7 & 6,67 \\
\hline 15,00 a 20,00 & 37 & 1,17 & 2 & 0,98 & 4 & 3,81 \\
\hline 20,00 a 25,00 & 4 & 0,13 & 1 & 0,49 & 0 & 0,00 \\
\hline$\geq 25,00$ & 49 & 1,54 & 2 & 0,98 & 0 & 0,00 \\
\hline Total & 3.172 & 100 & 205 & 100 & 105 & 100 \\
\hline
\end{tabular}

$\mathrm{N}=$ Número de animais.

Fonte: Própria autoria. 
A frequência observada do alelo A do DMRT3 para todos os indivíduos fenotipados foi de 0,47 (Figura 3A), e estava em maior abundância dentro do grupo de indivíduos $\operatorname{MP}(0,93)$. $\mathrm{O}$ alelo $\mathrm{C}$ estava em maior frequência entre animais MB $(0,77)$, que também foi maior do que em todos os indivíduos fenotipados (0,53 - Figura 3A). As frequências genotípicas foram 0,33, 0,27 e 0,40 (Figura 3B) para os genótipos AA, CA e CC, respectivamente (considerando-se os dados em todos os animais fenotipados). Para o grupo de indivíduos MB, foi encontrada uma maior frequência de equinos heterozigotos $(0,34)$ e uma frequência muito baixa de homozigotos AA $(0,06)$. Dentro do grupo de animais MP, a frequência de homozigotos CC foi zero e de AA foi de 0,87. Assim, a frequência de heterozigotos foi de 0,13 (Figura 3B). O valor de $\mathrm{P}$ para $\mathrm{O}$ teste de equilíbrio de Hardy-Weinberg (HWE) para o total de animais foi $\mathrm{P}=4.32 \times 10^{-16}$; para os animais MP foi de 1,00 e, para os animais MB foi de 0,69.

Figura 3 - Frequências alélicas do SNP g.22999655C > A de acordo com o tipo de andamento e na população total (A); frequências genotípicas do SNP g.22999655C > A de acordo com o tipo de andamento e na população total (B)

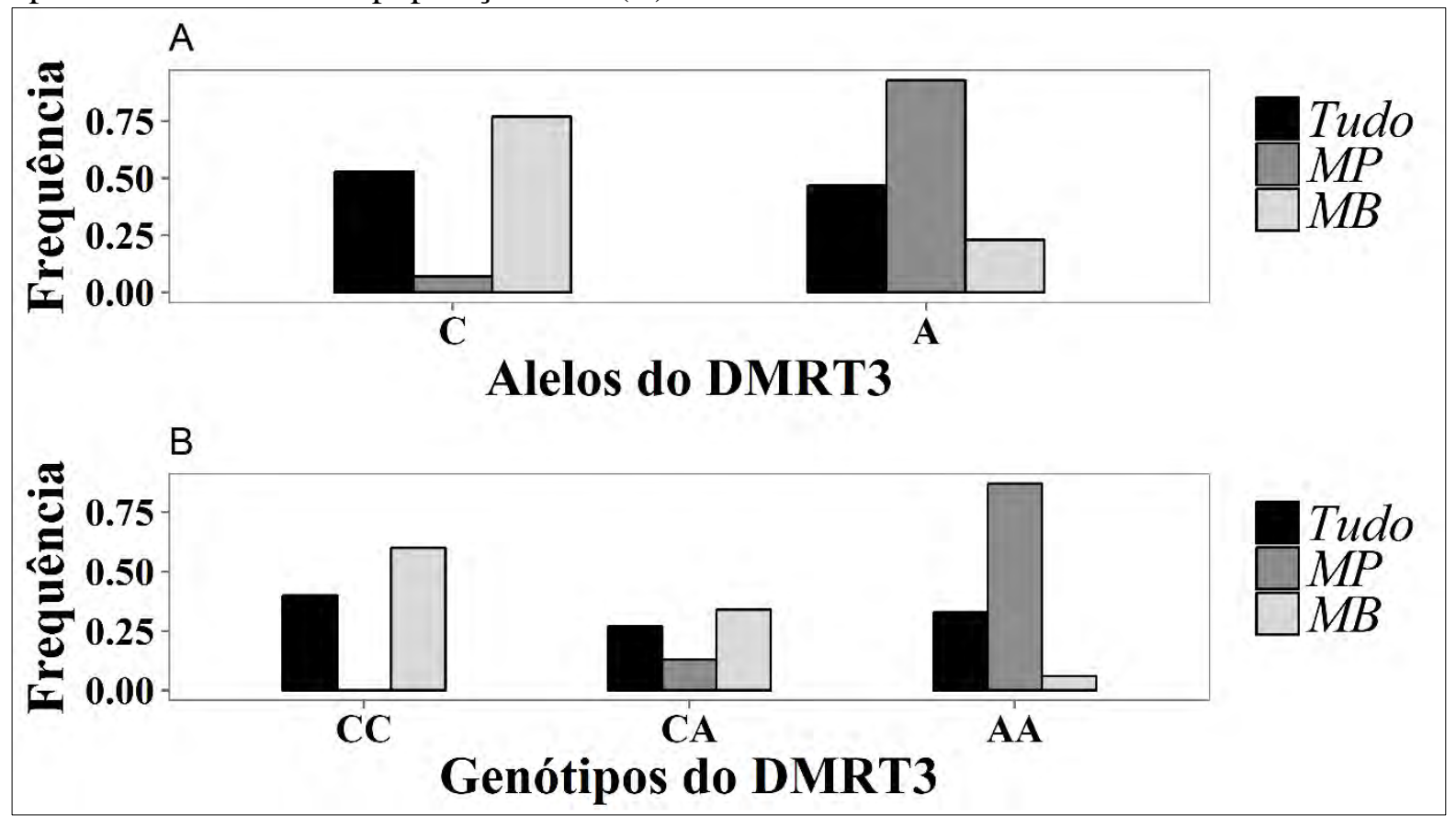

Fonte: Própria autoria.

A média de $\mathrm{F}$ foi diferente entre os grupos genotípicos dentro de cada tipo de marcha (Tabela 4). Enquanto nos animais MP com genótipo AA, o F foi de 3,42\%, nos animais MB com genótipo AA foi de $0,74 \%$. O número de gerações equivalentes médias também foi diferente; nos animais MP com genótipo AA foi de 1,83 e nos animais MB com genótipo CC foi de 4,55 (Tabela 4). O parentesco médio nos animais MP com o genótipo CA foi de 0,11 , 
enquanto que nos animais AA, com a mesma marcha, foi de 0,06 . Por outro lado, os animais AA exibindo marcha MB foram o grupo mais relacionado, o que pode ser devido a subfamílias dentro do grupo de marcha MB.

Tabela 4 - Número de cavalos Mangalarga Marchador, porcentagem de endogamia, número médio de gerações equivalentes e parentesco médio por genótipo do DMRT3 de acordo com o tipo de andamento

\begin{tabular}{cccccccc}
\hline Andamento & Genótipo & N & Endogâmicos & F & FI & DGE & f \\
\hline \multirow{4}{*}{ MP } & AA & 91 & 66 & $3,42 \%$ & $4,71 \%$ & 1,83 & 0,06 \\
& CA & 14 & 12 & $3,85 \%$ & $4,50 \%$ & 4,27 & 0,11 \\
& CC & - & - & - & - & - & - \\
\cline { 2 - 8 } MB & AA & 12 & 5 & $0,74 \%$ & $1,79 \%$ & 3,47 & 0,12 \\
& CA & 70 & 33 & $2,62 \%$ & $5,55 \%$ & 3,55 & 0,04 \\
& CC & 123 & 85 & $1,28 \%$ & $2,86 \%$ & 4,45 & 0,03 \\
\hline
\end{tabular}

$\mathrm{N}$ = número de animais; $\mathrm{F}$ e $\mathrm{FI}$ = coeficiente de endogamia em todos os animais e nos animais endogâmicos, respectivamente; $\mathrm{DGE}=$ número médio de gerações equivalentes e $\mathrm{f}=$ parentesco médio dentro dos grupos.

Fonte: Própria autoria.

\subsubsection{Efeito do DMRT3}

A visualização gráfica dos traceplots para os dois modelos não apresentou qualquer tendência ou sinais de não-convergência (dados não mostrados). Os escores de $\mathrm{Z}$ para o teste de Geweke para a distribuição a posteriori de $\sigma_{u}^{2}, \sigma_{e}^{2}, h^{2}$ e DMRT3 variaram de - 1,50 a 1,83. Todas as estimativas passaram no teste estacionariedade de Heidelberger-Welch ( $r$-Lag50 HEIDELBERGER; WELCH, 1983). O maior valor de Z-escore $(1,83)$ foi observado para o efeito dos genótipos do DMRT3 quando tratado como uma covariável, também apresentando uma autocorrelação de 0,08, que foi o maior valor observado para o r-Lag50. Médias a posteriori estimadas (intervalo de alta densidade a posteriori) para a herdabilidade foram 0,45(0,03-0,83) e 0,26(0,00-0,28) para os modelos 1 e 2, respectivamente. As proporções de variância fenotípica explicada pelo DMTR3 foram muito similares, 10,77 e 9,94\%, quando testados como uma covariável e como um efeito aleatório, respectivamente (Tabela 5).

Tabela 5 - Médias e medianas a posteriori, intervalo de alta densidade a posteriori (HPD), escores Z de Geweke e autocorrelação ( $r$-Lag50) para o efeito dos genótipos do DMRT3 de acordo com o tratamento (covariável ou efeito aleatório)

\begin{tabular}{|c|c|c|c|c|c|c|}
\hline \multirow{2}{*}{ DMRT3 } & \multirow{2}{*}{ Média $^{1}$} & \multirow{2}{*}{ Mediana $^{1}$} & \multicolumn{2}{|c|}{ Intervalo HPD ${ }^{1}$} & \multirow{2}{*}{$\begin{array}{c}\text { Escore } \\
\mathrm{Z} \text { de Geweke }\end{array}$} & \multirow{2}{*}{$r-\operatorname{Lag} 50$} \\
\hline & & & $5 \%$ & $95 \%$ & & \\
\hline Covariável & 10,77 & 10,90 & 5,22 & 17,03 & 1,83 & 0,08 \\
\hline Efeito Aleatório & 9,94 & 10,00 & 9,90 & 10,00 & $-1,08$ & $-0,01$ \\
\hline
\end{tabular}




\subsection{Discussão}

Como a seleção na raça Mangalarga Marchador é baseada principalmente em pedigree, o acasalamento de animais importantes/campeões e seus familiares é uma prática comum entre os criadores. Este fato pode explicar as diferenças observadas de parentesco e F dentro de cada tipo de marcha. Como consequência do acasalamento endogâmico baseado no tipo de marcha, ambos os grupos são separados na população.

O padrão de parentesco apresentado por animais MB poderia ser associado com o grande número de fundadores que também exibiam este mesmo fenótipo. A média mais elevada para o parentesco em animais MP está relacionada com a frequência de altos valores de parentesco dentro deste grupo. Os altos valores de parentesco encontrados nos indivíduos MP estão relacionados com parentesco atual (acasalamentos mais recentes causando esse relacionamento). Alguns criadores preferem acasalar animais MB com MP (D. ZABOTTO NETO, comunicação pessoal, maio de 2017), isso explica o valor de relacionamento genético $(0,03)$ entre estes grupos.

A média de F observada para o pedigree considerado neste estudo (1,50\%) foi muito próxima das estimativas baseadas na população completa desta raça (COSTA et al., 2005; DEASSIS et al., 2009). Isso mostra que os animais que nós estudamos são uma amostra representativa da população Mangalarga Marchador. A média de F em animais endogâmicos $(7,10 \%)$ foi maior do que a encontrada para os mesmos autores, o que resultou de alguns animais altamente endogâmicos no pedigree considerado, influenciando a estimativa do coeficiente.

Valores maires de F em animais MP podem ser resultado da alta frequência de parentescos, uma vez que esta frequência é maior em animais MP do que MB. Patterson, Staiger e Brooks (2015), relataram valores mais altos de endogamia em animais MB (1,20\%) e menores em indivíduos MP (0,16\%), o que também foi relatado por Manso Filho et al. (2015), que encontraram 31,63\% de endogamia em animais MB e 2,42\% em MP. Os maiores valores de F encontrados neste estudo talvez estejam associados à presença de alguns animais de "elite" no grupo de MP, o que aumenta a F, uma vez que nesta raça, em geral, animais top são altamente endogâmicos.

Uma vez que as tendências foram calculadas dentro de cada grupo de marcha, o aumento da endogamia pode ser um alerta para o acasalamento preferido para animais com a mesma marcha. Em outras palavras, o aumento da endogamia implica em um aumento da 
probabilidade de acasalamento de animais relacionados. Se essa relação é observada dentro de cada grupo de marcha, a preferência pela mesma marcha faz sentido. Este fato não foi confirmado nos animais MP, que apresentaram a menor tendência (ganho de 0,21 em F por geração - não significativo $\mathrm{P}>0,05)$. A tendência de $\mathrm{F}$ em indivíduos endogâmicos mostrou que $\mathrm{F}$ em animais $\mathrm{MB}$ (-0,35 F/geração) levará mais tempo para diminuir a partir de um certo nível, enquanto em animais com MP (-0,68 F/geração) esta diminuição é mais acentuada, geração após geração, o que pode estar relacionado com a redução do número de animais altamente endogâmicos.

Como consequência deste cenário (de parentesco e endogamia), os alelos que estão relacionados ao tipo de marcha foram diferentemente fixados dentro de cada marcha. As frequências alélicas do DMRT3 encontradas neste estudo foram próximas às relatadas por Fonseca et al. (2017), Manso Filho et al. (2015), Patterson, Staiger e Brooks (2015) e Promerová et al. (2014), mas as frequências de genótipos CC em indivíduos MB foram diferentes (0,94, 0,85 e 0,93 - FONSECA et al., 2017; MANSO FILHO et al., 2015; PATTERSON; STAIGER; BROOKS, 2015, respectivamente), o que é um resultado da alta frequência de heterozigotos CA no grupo de marcha MB, encontrado neste estudo. A maior frequência do genótipo CA observada neste estudo pode ser uma indicação da origem diversa dos animais amostrados, os quais foram amostrados não só na exposição nacional, mas em muitas propriedades (em SP e MG).

Nós especulamos que os animais heterozigotos que apresentam MB existem na população, mas por uma coincidência de amostragem, eles não foram amostrados em abundância até agora. Também é plausível que animais com um genótipo específico de DMTR3 tenham qualidade diferente na marcha e por isso, não estavam representados na competição nacional e não foram amostrados por Fonseca et al. (2017), Patterson, Staiger e Brooks (2015). Outra possibilidade é o fato de que animais com genótipos específicos do DMRT3 preferem diferentes tipos de marcha em liberdade (STAIGER et al., 2016) o que poderia ter influenciado as avaliações da marcha de alguns animais amostrados, que foram avaliados em liberdade. Animais MB com genótipo AA foram encontrados neste estudo, como observado anteriormente por Manso Filho et al. (2015).

Como uma das consequências do HWE é a independência dos alelos dentro dos genótipos enquanto as frequências alélicas permanecem constantes, o valor $\mathrm{P}$ encontrado para a população sugere uma dependência dos alelos dentro dos genótipos. Isso também pode ser uma consequência de um sistema de acasalamentos não aleatórios, que dissemina haplótipos (ou alelos) específicos, aumento a frequência dos genótipos correspondentes. As subpopulações 
de animais MP e MB estavam em HWE; embora, quando analisadas em conjunto, não estavam. O número de homozigotos foi maior do que o esperado; consequentemente, existiam poucos heterozigotos na amostra total; isso pode indicar que a seleção dentro de animais MP é fortemente relacionada com a mutação do DMRT3. A seleção na subpopulação MP provavelmente é relacionada com acasalamento de animais selecionados dentro do mesmo fenótipo e parentes próximos, aumentando o parentesco entre os animais MP e, consequentemente, a endogamia.

Considerando que todos os animais tiveram o fenótipo definido e confirmado por assistir a um filme de seu movimento (sempre filmado pela mesma pessoa), poderíamos especular que esta é uma evidência que confirma a hipótese de Patterson, Staiger e Brooks (2015), de que o DMRT3 está associado, mas não determina completamente o tipo de marcha em cavalos Mangalarga Marchador.

O número médio de gerações equivalentes completas nos animais CA de MP talvez indique que alto parentesco neste grupo foi criado nas gerações passadas. Da mesma forma, o parentesco entre os animais MP com genótipo AA foi mais recente, uma vez o número de gerações equivalentes foi o menor encontrado neste estudo. Isso poderia estar relacionado com a seleção de animais MP; inicialmente em direção do genótipo CA e agora a seleção se tornouse intimamente relacionada com o genótipo AA.

O número de gerações equivalentes completas sendo nos genótipos dos animais MB mostrou que o critério de seleção desses animais não está relacionado a um genótipo. Todos os coeficientes de parentesco foram relacionados às gerações passadas, e o baixo grau de parentesco dentro de cada grupo genotípico pode indicar o acasalamento de animais de todos os genótipos. $\mathrm{O}$ alto parentesco entre os animais MB com o genótipo AA pode indicar que esses animais formam uma subfamília.

Considerando que todos os cavalos tiveram seu fenótipo definido e confirmado ao assistir-se um vídeo de seu movimento (sempre pela mesma pessoa), nós especulamos que esta evidencia confirma a hipótese de Patterson, Staiger e Brooks (2015), que indicou que o DMRT3 é associado ao tipo de andamento mas não o determina em cavalos Mangalarga Marchador.

As estimativas dos parâmetros mostraram que o tipo de marcha em cavalos Mangalarga Marchador apresenta uma moderada/alta herdabilidade, sugerindo a sua determinação genética. Os efeitos dos genótipos de DMRT3 foram muito altos para esta característica, embora possam ser uma função das frequências genotípicas, devido à endogamia e parentesco, uma vez que as diferenças nas proporções de homozigotos (AA/CC) e 
heterozigotos (CA) em cada grupo fenotípico estava mais relacionado aos padrões de parentesco e endogamia do que ao tipo de marcha.

Uma alta influência do gene DMRT3 sobre as características da marcha tem sido relatada por vários autores (FEGRAEUS et al., 2015; JÄDERKVIST et al., 2015b; NEGRO RAMA et al., 2016; RICARD, 2015), que descobriam que alguns genótipos também poderiam estar relacionados a melhor desempenho (AA, FEGRAEUS et al., 2015), trote em liberdade (CC e CA, JÄDERKVIST et al., 2015b) e efeito negativo sobre características de corrida (CC, RICARD, 2015), explicando em torno de 0,30 a 1,67\% da variância genética aditiva (NEGRO RAMA et al., 2016).

\subsection{Conclusão}

Constatamos que, apesar do importante papel desempenhado pelo gene DMRT3 na coordenação dos membros dos equinos, seus efeitos sobre o tipo de marcha na raça Mangalarga Marchador ainda não são claros. Existe um padrão de parentesco e endogamia que pode estar afetando as frequências genotípicas deste gene. Animais de marcha batida apresentam maiores frequências dos genótipos CC e CA do gene DMRT3; nosso estudo é o primeiro que encontrou uma alta frequência de genótipo CA neste grupo fenotípico. As frequências genotípicas do DMRT3 e os padrões de parentesco e endogamia podem ser um resultado da seleção nesta raça, causando confusão estatística entre os efeitos do DMRT3 e a estrutura populacional. Estudos futuros de associação genômica ampla entre marcadores genéticos e o tipo de marcha podem ajudar a explicar como essa característica é geneticamente determinada.

\subsection{Referências}

ANDERSSON, L. S. et al. Mutations in DMRT3 affect locomotion in horses and spinal circuit function in mice. Nature, London, v. 488, n. 7413, p. 642-646, 2012.

COSTA, M. D. et al. Análise temporal da endogamia e do tamanho efetivo da população de eqüinos da raça Mangalarga Marchador. Arquivo Brasileiro de Medicina Veterinaria e Zootecnia, Belo Horizonte, v. 57, n. 1, p. 112-119, 2005.

DEASSIS, J. B. et al. Genetic diversity and population structure in Brazilian Mangalarga Marchador horses. Genetics and Molecular Research: GMR, Ribeirão Preto, v. 8, n. 4, p. 1519-1524, 2009.

EMIK, L. O.; TERRILL, C. E. Systematic procedures for calculating inbreeding coefficients. Journal of Heredity, Oxford, v. 40, n. 2, p. 51-55, 1949. 
FEGRAEUS, K. J. et al. Different DMRT3 genotypes are best adapted for harness racing and riding in finnhorses. Journal of Heredity, Oxford, v. 106, n. 6, p. 734-740, 2015.

FONSECA, M. G. et al. A Genome-wide association study reveals differences in the genetic mechanism of control of the two gait patterns of the Brazilian Mangalarga Marchador Breed. Journal of Equine Veterinary Science, Maryland Heights, v. 53, p. 64-67, 2017.

GEWEKE, J. Evaluating the accuracy of sampling-based approaches to the calculation of posterior moments. Bayesian Statistics, Oxford, v. 4, p. 169-193, 1992.

HARDY, G. H. Mendelian proportions in a mixed population. Science, New York, v. 28, n. 706, p. 49-50, 1908.

HEIDELBERGER, P.; WELCH, P. D. Simulation run length control in the presence of an initial transient. Operations Research, Catonsville, v. 31, n. 6, p. 1109-1144, 1983.

HENDERSON, A. C. R. A Simple method for computing the inverse of a numerator relationship matrix used in prediction of breeding values. Biometrics, Chichester, v. 32, n. 1, p. 69-83, 1976.

HENDERSON, C. R. Rapid method for computing the inverse of a relationship matrix. Journal of Dairy Science, New York, v. 58, n. 11, p. 1727-1730, 1975.

JÄDERKVIST, K. et al. The importance of the DMRT3 “Gait keeper" mutation on riding traits and gaits in Standardbred and Icelandic horses. Livestock Science, Amsterdam, v. 176, p. 33-39, 2015a.

JÄDERKVIST, K. et al. The DMRT3 “Gait keeper” mutation affects harness racing performance and riding traits in Finnhorses. Journal of Equine Veterinary Science, Maryland Heights, v. 35, n. 5, p. 399, 2015 b.

MANSO FILHO, H. C. et al. Alelo DMRT3 mutante em equinos de marcha batida e picada das raças Campolina e Mangalarga Marchador. Ciência Veterinária nos Trópicos, São Paulo, v. 18, n. 1, p. 6-11, 2015.

MISZTAL, I. et al. BLUPF90 and related programs (BGF90). In: WORLD CONGRESS ON GENETICS APPLIED TO LIVESTOCK PRODUCTION, 7., 2002, Montpellier.

Proceedings... Montepellier, 2002. 2 p.

MOTA, M. D. S.; PRADO, R. S. A. Estudo genético da pontuação total em equinos Mangalarga. Archivos de Zootecnia, Cordoba, v. 54, p. 25-30, 2005.

NEGRO RAMA, S. et al. Quantitative analysis of short- and long-distance racing performance in young and adult horses and association analysis with functional candidate genes in Spanish Trotter horses. Journal of Animal Breeding and Genetics, Hamburg, v. 133, p. 347-356, 2016.

NICODEMUS, M. C.; CLAYTON, H. M. Temporal variables of four-beat, stepping gaits of gaited horses. Applied Animal Behaviour Science, Amsterdam, v. 80, n. 1, p. 133-142, 2003. 
PATTERSON, L.; STAIGER, E. A.; BROOKS, S. A. DMRT3 is associated with gait type in Mangalarga Marchador horses, but does not control gait ability. Animal Genetics,

Chichester, v. 46, n. 2, p. 213-215, 2015.

PEREIRA, G. L. et al. MSTN, CKM, and DMRT3 Gene variants in different lines of quarter horses. Journal of Equine Veterinary Science, Maryland Heights, v. 39, p. 33-37, 2016.

PLUMMER, M. et al. CODA: convergence diagnosis and output analysis for MCMC. R News, Vienna, v. 6, p. 7-11, March. 2006.

PROMEROVÁ, M. et al. Worldwide frequency distribution of the "Gait keeper" mutation in the DMRT3 gene. Animal Genetics, Chichester, v. 45, n. 2, p. 274-282, 2014.

R CORE TEAM. R Development Core TeamR: A Language and Environment for Statistical Computing, 2016. Disponível em: <https://www.r-project.org/>

RICARD, A. Does heterozygosity at the DMRT3 gene make French trotters better racers? Genetics Selection Evolution, v. 47, n. 1, p. 1-16, 2015.

SARGOLZAEI, M.; IWASAKI, H.; COLLEAU, J. J. CFC: A tool for Monitoring genetic diversity. Proceedings of the 8th World Congress on Genetics Applied to Livestock Production. Anais...Belo Horizonte: 2006

SHIM, H. et al. A Multivariate Genome-Wide Association Analysis of 10 LDL Subfractions, and Their Response to Statin Treatment, in 1868 Caucasians. PLoS ONE, San Francisco, v. 4, n. 10, p. 1-20, 2015.

STAIGER, E. A. et al. Loci impacting polymorphic gait in the Tennessee Walking Horse. Journal of Animal Science, Cary, v. 94, n. 4, p. 1377-1386, 2016.

WEINBERG, W. Über Vererbungsgesetze beim Menschen. Zeitschrift für induktive Abstammungs- und Vererbungslehre, v. 1, n. 1, p. 440-460, 1908. 
5 ESTUDO DE ASSOCIAÇÃO GENÔMICA AMPLA: ENTENDENDO A BASE GENÉTICA DO TIPO DE MARCHA EM CAVALOS BRASILEIROS MANGALARGA MARCHADOR

F.O. Bussiman ${ }^{1}$, B.A. dos Santos ${ }^{2}$, B.C. Abreu Silva ${ }^{3}$, G.C. Mamani Mamani ${ }^{3}$, L. Grigoletto ${ }^{3}$, G. L. Pereira ${ }^{2}$, B.C. Perez ${ }^{1}$, G.C. Ferraz ${ }^{4}$, J.B.S. Ferraz ${ }^{3}$, E.C. Mattos ${ }^{3}$, J.P. Eler ${ }^{3}$, R.V. Ventura $^{5}$, R.A. Curi ${ }^{2}$, J.C.C. Balieiro ${ }^{5}$

${ }^{1}$ Departamento de Zootecnia, Faculdade de Zootecnia e Engenharia de Alimentos, Universidade de São Paulo (FZEA/USP), Av. Duque de Caxias Norte, 225, 13.635-900, Pirassununga, São Paulo, Brasil;

${ }^{2}$ Departamento de Melhoramento Animal, Faculdade de Zootecnia e Engenharia de Alimentos, Universidade Estadual Paulista Júlio de Mesquita Filho (FMVZ/UNESP), Rua José Barbosa de Barros, 1780, Fazenda Experimental Lageado, 18.618-307, Botucatu, São Paulo, Brasil;

${ }^{3}$ Grupo de Melhoramento Animal, Biotecnologia e Transgenia, Departamento de Medicina Veterinária, Faculdade de Zootecnia e Engenharia de Alimentos, Universidade de São Paulo (GMAB-FZEA/USP), Av. Duque de Caxias Norte, 225, 13.635-900, Pirassununga, São Paulo, Brasil;

${ }^{4}$ Departamento de Morfologia e Fisiologia Animal, Faculdade de Ciências Agrárias e Veterinárias, Universidade Estadual Paulista Júlio de Mesquita Filho (FCAV/UNESP), Rota de acesso Paulo Donato Castellane, 14.884-900, Jaboticabal, São Paulo, Brasil;

${ }^{5}$ Departamento de Nutrição e Produção Animal, Faculdade de Medicina Veterinária e Zootecnia, Universidade de São Paulo (FMVZ/USP), Av. Duque de Caxias Norte, 225, 13.635-900, Pirassununga, São Paulo, Brasil.

RESUMO: A variante ECA23: g.22999655C > A do gene DMRT3 tem sido descrita como quase um pré-requisito para andamentos de quatro tempos em cavalos, mas isso permanece incerto para os dois tipos distintos de marcha observados na raça Mangalarga Marchador (MM) brasileira. O objetivo deste estudo foi realizar um GWAS de passo único, prospectando a arquitetura genética da marcha batida (MB) e marcha picada (MP) em equinos MM. Registros fenotípicos de 1.230 animais e um arquivo de pedigree contendo 3,172 indivíduos foram considerados na análise. Um total de 192 cavalos (86 MB e 106 MP) foi genotipado com 670k (Thermo Fisher Scientific) e 48 cavalos foram imputados a partir de 65k (Illumina) para 670k. O GWAS foi conduzido em uma abordagem Bayesiana. Para a estimativa dos efeitos dos SNPs, foram realizadas três iterações. A posição dos SNPs que explicaram mais de $1 \%$ da variância genética aditiva foi usada para prospectar regiões genômicas em janelas de 250kb. Dos 69 genes identificados, 39 não estavam anotados em cavalos e foram comparados com o banco de dados do NCBI. A análise de enriquecimento funcional revelou que oito vias metabólicas podem estar envolvidas com o tipo de marcha; a maioria está relacionada ao metabolismo de aminoácidos, energia e sistema imunológico. Os genes encontrados foram associados a diferenças no metabolismo energético entre animais dos grupos marcha batida ou marcha picada, bem como com alterações metabólicas após o exercício da marcha.

Palavras-chave: GWAS de passo único, estímulos externos, metabolismo da marcha, $R O R \beta$, cavalo. 


\begin{abstract}
The ECA23:g.22999655C>A DMRT3 variant has been described as an almost prerequisite for the four-beat gait in horses, but this remains uncertain for the two distinct gait types observed in the Brazilian Mangalarga Marchador (MM) breed. The aim of this study was to perform a single-step GWAS prospecting the genetic architecture of the marcha batida (MB) and marcha picada (MP) in MM horses. Phenotypic records from 1,230 animals and a pedigree file containing 3,172 individuals were considered in the analysis. A total of 192 (86 MB and $106 \mathrm{MP}$ ) horses were genotyped with 670k equine genotyping array (Thermo Fisher Scientific) and 48 horses were imputed from 65k (Illumina) to 670k. The GWAS was conducted in a Bayesian approach. For the estimation of SNP effects, three iterations were performed. The position from SNPs that explained more than $1 \%$ of additive genetic variance were used to prospect genomic regions in windows of $250 \mathrm{~kb}$. From the 69 identified genes, 39 were not annotated in horses and were blasted against the NCBI database. The enrichment analysis revealed eight metabolic pathways may be involved with the gait type; most were related to the metabolism of amino acid, energy, and immune system. The found genes were associated with differences in the energetic metabolism between animals from the marcha batida or marcha picada groups, as well as with metabolic changes after gait exercise.
\end{abstract}

Keywords: Single-step GWAS, External stimuli, Gait metabolism, $R O R \beta$, Horse.

\title{
5.1 Introdução
}

O cavalo Mangalarga Marchador (MM) é uma raça brasileira de cavalos marchadores que tem alcançado grande importância internacional, uma vez que é agora exportada para a Bélgica, Holanda, Portugal, Israel, Canadá, Uruguai, Peru, EUA, Alemanha, Congo, Argentina, França, Áustria e Itália (FONSECA et al., 2017). Atualmente, existem cerca de 600.000 animais registrados na Associação Brasileira de Criadores do Cavalo Mangalarga Marchador (ABCCMM), representando o maior rebanho de cavalos do Brasil (MAPA, 2016). Suas origens estão nos animais da Península Ibérica trazidos para o Brasil desde o descobrimento, mas aqui selecionados para marcha confortável, que pode ser realizada de duas maneiras diferentes, com predomínio dos movimentos laterais (Marcha Picada - MP) ou diagonais (Marcha Batida - MB) (DI FILIPPO et al., 2016).

Ambos os tipos de marcha são andamentos de quatro batidas, em que o cavalo não tem um tempo de suspensão dos quatro membros (CARNEIRO DE REZENDE et al., 2016) e as diferenças na frequência de passadas, amplitude de movimento, velocidade, a exigência de energia e os custos metabólicos de cada marcha fazem com que os andamentos sejam diferentes (WANDERLEY et al., 2010). Estudos foram realizados para determinar a base genética da marcha de cavalos (FONSECA et al., 2017; MANSO FILHO et al., 2015; PATTERSON; STAIGER; BROOKS, 2015), no entanto, quando analisados em conjunto, esses dois tipos de marcha permanecem incertos do ponto de vista da arquitetura genética. A bioquímica e a 
fisiologia desses dois tipos de marcha foi discutida por Di Filippo et al. (2016); Lage et al. (2017) e Martins et al. (2017), estes autores mostraram que as diferenças bioquímicas entre os andamentos de quatro batidas na raça MM poderiam estar associadas à melhor adaptação a um exercício com similaridade à corrida.

Andersson et al. (2012) relataram a influência da variante ECA23:g.22999655C>A do gene DMRT3 na determinação da marcha em equinos, mas Fonseca et al. (2017); Manso Filho et al. (2015) e Patterson, Staiger e Brooks (2015) estudaram a ação desse polimorfismo sobre o tipo de marcha no cavalo MM revelando um possível controle poligênico nesta característica. Portanto, o objetivo do presente trabalho foi realizar um estudo de associação genômica ampla em passo único (ssGWAS - WANG et al., 2012a) para prospectar regiões genômicas, polimorfismos de nucleotídeo único (SNPs) e genes relacionados com o tipo de marcha, caracterizando a arquitetura genética desta característica, bem como, investigar a capacidade de predição pelos SNPs significativos, na raça de cavalos Mangalarga Marchador.

\subsection{Material e métodos}

\subsubsection{Coleta de sangue, extração de DNA e genotipagem de SNPs}

Amostras de sangue de 310 cavalos (105 MP e 205 MB) foram colhidas em 14 fazendas nos estados de São Paulo e Minas Gerais, bem como durante a 36 ${ }^{a}$ Exposição Nacional do cavalo MM. A ocorrência de irmãos completos foi evitada. O DNA foi extraído para cada animal a partir de alíquotas de sangue com o kit Illustra Blood GenomicPrep Mini Spin (GE Healthcare, EUA) pelas recomendações do fabricante. Após a extração, o DNA foi quantificado em um espectrofotômetro NanoDrop Lite (Thermo Fisher Scientific, EUA) e sua integridade foi verificada em gel de agarose a $0,8 \%$. A concentração e a pureza foram ajustadas para 10 ng/ $\mu \mathrm{L}$ e 1,7 (proporção 260/280), respectivamente. Depois disso, foram selecionados 192 cavalos (86 MP e $106 \mathrm{MB}$ ) e genotipados a 670k com o Axiom ${ }^{\circledR}$ Equine Genotyping Array (Thermo Fisher Scientific, EUA).

\subsubsection{Dados disponíveis}

Para este estudo foram utilizados 1.230 registros de marcha (227 animais MP e 1.006 animais MB - PI). O pedigree continha 3.172 animais; em média 2,02 gerações completas e com um número médio de progênies de 2,56 e 1,27 para garanhões e éguas, respectivamente. 
O coeficiente médio de endogamia foi de 2,00\% para o pedigree completo e 7,00\% para os animais endogâmicos. Informações sobre proprietário, criador e sexo, disponíveis no site da ABCCMM, foram coletadas para cada animal. Do total de PI, 48 animais já estavam genotipados em 65k em 2015 com o Equine SNP70 BeadChip (Illumina Inc, EUA). Informações detalhadas sobre a genotipagem destes animais podem ser encontradas em Fonseca et al. (2017).

\subsubsection{Imputação de genótipo e controle de qualidade}

Um total de 570.401 marcadores, obtidos do painel de alta densidade (HD - Axiom ${ }^{\circledR}$ Equine Genotyping Array - Thermo Fisher Scientific, USA), foram usados neste estudo. Todos os marcadores localizados nos cromossomos sexuais ou desconhecidos foram excluídos neste painel. Um filtro de call rate de 0,90 foi aplicado em marcadores e animais no referido painel genômico. No painel de baixa densidade (LowD) (Equine SNP70 BeadChip - Illumina Inc, EUA) foram excluídos aqueles marcadores que não eram compartilhados com o painel HD, bem como os marcadores repetidos e os localizados nos cromossomos sexuais. Estes dois painéis (HD e LowD) compartilharam cerca de 56.506 marcadores (em 240 cavalos) que foram incluídas em uma análise de componentes principais (PCA) para verificar a ocorrência de populações distintas nas amostras de referência e imputação. A matriz de relacionamento (A HENDERSON, 1975) foi também submetida a uma análise de PCA para certificar que os animais genotipados representavam a variabilidade encontrada no pedigree utilizado neste estudo. Após todas as exclusões, os animais no painel LowD $(\mathrm{N}=48)$ foram imputados para 570.401 marcadores usando o software BEAGLE versão 4,0 (BROWNING; BROWNING, 2013, 2016, 2007). Para calcular a acurácia de imputação dos genótipos, 48 animais foram amostrados aleatoriamente a partir do conjunto de animais genotipados no painel HD. Após isso, eles tiveram seus genótipos mascarados para 56.506 marcadores (número de SNPs compartilhados entre os dois painéis) e foram imputados para 570,401 marcadores. Depois disso, a taxa de concordância entre o genótipo e imputado e o genótipo original foi utilizado para acessar a acurácia.

O controle de qualidade $(\mathrm{QC})$ dos genótipos foi realizado após a imputação no software PREGSF90 (AGUILAR; MISZTAL; TSURUTA, 2014), assim SNPs com conflitos mendelianos (71), menos de 0,95 de call rate (0), monomórficos (63.096), frequência do alelo menor $(\mathrm{MAF}) \leq 1 \%$ (44.537) e SNPs com uma diferença entre a frequência observada e esperada para o teste de equilíbrio de Hardy-Weinberg maior do que 0,15 (1.174) foram 
excluídos. Além disso, animais com um call rate $<0,95(0)$ e devido a conflitos mendelianos (1) foram excluídos. Após o QC restaram 461.523 SNPs e 239 animais (133 MB e 106 MP).

\subsubsection{Estudo de associação genômica ampla e capacidade de previsão}

A fim de analisar a associação genética entre o l-ésimo SNP e o tipo de marcha (0 = MP; $1=\mathrm{MB}$ ), foi utilizado o seguinte modelo:

$y_{i j k}=\beta_{1} P C 1+\beta_{2} P C 2+\beta_{3} A g e+F_{a r m}+u_{j}+e_{i j k}$

em que: $y_{i j k}$ é o vetor de observações fenotípicas (tipo de marcha); $\beta_{1} \ldots \beta_{3}$ são os coeficientes de regressão para as covariáveis $P C 1$ (primeiro componente principal da matriz de relacionamento genômico - G), PC2 (segundo componente principal da matriz G) e Age (classe de idade); Farm $_{i}$ é o efeito sistemático de criatóro; $u_{j}$ é o efeito aleatório genético aditivo de animal, com $\hat{u} \sim N\left(0, \boldsymbol{H} \sigma_{u}^{2}\right)$, em que $\boldsymbol{H}$ é a matriz de relacionamentos combinando informações de pedigree e genômicas de acordo com Aguilar et al. (2010) e, $e_{i j k}$ representa os termos residuais aleatórios com $e \sim N\left(0, I \sigma_{e}^{2}\right)$.

Todas as análises foram implementadas usando uma abordagem Bayesiana, desta forma as inferências foram feitas sobre a distribuição a posteriori dos parâmetros. De acordo com regra de Bayes, a distribuição a posteriori dos parâmetros é $p(\theta \mid Y) \propto p(Y \mid \theta) p(\theta)$, em que $\theta$ é a coleção de todos os parâmetros desconhecidos no modelo (1); $p(\theta)$ é a distribuição a priori para $\theta ; p(\theta \mid Y)$ é a distribuição a posteriori dos parâmetros e $p(Y \mid \theta)$ é a distribuição condicional do fenótipo dados os parâmetros. A distribuição conjunta a priori de $\theta$ foi dada como: $(\theta) \propto p\left(u \mid \sigma_{u}^{2}\right) p\left(\sigma_{u}^{2}\right) p\left(\sigma_{e}^{2}\right)$, isto é: $p(\theta) \propto N\left(u \mid 0, A \sigma_{u}^{2}\right) X^{-2}\left(\sigma_{u}^{2} \mid d f_{u}, S_{u}\right) X^{-2}\left(\sigma_{e}^{2} \mid d f_{e}, S_{e}\right)$, em que $X^{-2}(. \mid d f, S$.) é uma distribuição de Qui-quadrado inversa e escalonada com $d f$ graus de liberdade e o parâmetro de escala $S$.

As análises foram realizadas utilizando o software THRGIBBS1F90 (MISZTAL et al., 2002). Foi gerada uma única cadeia com 2.000.000 de amostras, assumindo um período de burnin de 1.000.000 e um intervalo de salvamento a cada 100 amostras; portanto, todas as inferências foram feitas sobre 10.000 amostras da distribuição a posteriori; foram feitas três iterações para o GWAS. A convergência da amostragem MCMC foi verificada graficamente e aplicando o teste de Geweke (GEWEKE, 1992) e o teste Heidelberger-Welch 
(HEIDELBERGER; WELCH, 1983), utilizando-se o pacote “coda” (PLUMMER et al., 2006) do software R (R CORE TEAM, 2016).

Se assumirmos uma forma matricial $(\boldsymbol{y}=\boldsymbol{X} \boldsymbol{\beta}+\boldsymbol{Z} \boldsymbol{u}+\boldsymbol{e})$ para o modelo (1), a matriz de covariâncias para os termos aleatórios é dada por:

$\operatorname{Var}\left[\begin{array}{l}u \\ e\end{array}\right]=\left[\begin{array}{cc}H \sigma_{u}^{2} & 0 \\ 0 & I \sigma_{e}^{2}\end{array}\right]$

em que: $\boldsymbol{H}$ é a matriz de relacionamento combinando informações genômicas e de pedigree; sua inversa é dada por:

$H^{-1}=\left[\begin{array}{cc}A_{11}^{-1} & A_{12}^{-1} \\ A_{21}^{-1} & A^{-1}+\left(G^{-1}-A_{22}^{-1}\right)\end{array}\right]$

em que: $\boldsymbol{A}_{\mathbf{1 1}}^{-\mathbf{1}}, \boldsymbol{A}_{\mathbf{1 2}}^{-\mathbf{1}}$ e $\boldsymbol{A}_{\mathbf{2 1}}^{-\mathbf{1}}$ são as inversas dos primeiro, segundo e terceiro quadrante da matriz de relacionamento via pedigree (animais não genotipados) e $\boldsymbol{G}^{\mathbf{- 1}}-\boldsymbol{A}_{\mathbf{2 2}}^{\mathbf{- 1}}$ é a diferença entre a matriz de parentesco realizado $\left(\boldsymbol{G}^{-\mathbf{1}}\right)$ e o esperado $\left(\boldsymbol{A}_{\mathbf{2 2}}^{-\mathbf{1}}\right)$ para os animais genotipados. Neste caso, $\boldsymbol{G}$ foi construída de acordo com VanRaden (2008) e foram assumidas as frequências alélicas da população em análise para ajustes de compatibilidade com $\boldsymbol{A}_{\mathbf{2 2}}$, como proposto por Chen et al. (2011).

Para calcular os efeitos de cada SNP $(\hat{l})$ foi utilizada a matriz de relação genômica ponderada $\boldsymbol{G}^{*}$ através da equação: $\hat{l}=D Z^{\prime}\left[Z D Z^{\prime}\right]^{-1} \hat{u}$ (PEREIRA et al., 2018; WANG et al., 2012, 2014) seguindo os passos descritos por Wang et al. (2012, 2014). Para calcular a variância genética aditiva direta explicada por cada SNP, utilizou-se a seguinte equação:

$\frac{\operatorname{Var}\left(l_{j}\right)}{\sigma_{u}^{2}} x 100=\frac{\operatorname{Var}\left(\sum_{1}^{N} \mathbf{z}_{j} \hat{l}_{j}\right)}{\sigma_{u}^{2}} x 100$

em que $l_{j}$ é o valor genético do j-ésimo SNP; $l_{j}$ é variância direta genética aditiva; $N$ é o número de animais; $\boldsymbol{z}_{j}$ representa o conteúdo genético para o j-ésimo SNP em todos os animais e $\hat{l}_{j}$ é o efeito do j-ésimo SNP.

Para obter-se a taxa de falso descobrimento (FDR) para cada SNP, o teste $T^{2}$ (UTSUNOMIYA et al., 2013) foi utilizado para calcular os P-valores que foram ajustados pelo procedimento de Benjamini-Hochberg (BENJAMINI; HOCHBERG, 1995). Apenas 
marcadores com FDR $<0.05$ foram usados nas análises subsequentes. Para verificar a capacidade de todos os marcadores que explicaram mais de $1 \%$ da variância genética aditiva em distinguir o tipo de marcha, uma simples análise de cluster foi realizada com base no genótipo para esses SNPs, usando o tipo de marcha como a variável de agrupamento. Uma análise de validação cruzada foi realizada para calcular a porcentagem de correta classificação da marcha predita e, para ver a estratificação a nível fenotípico este subconjunto de marcadores foi utilizado para criar uma nova matriz $\mathbf{G}$ e depois disso foi realizada uma PCA desta "nova G”, todas as análises foram realizadas no software estatístico R (R CORE TEAM, 2016).

\subsubsection{Anotação de genes e enriquecimento funcional}

Como a extensão do desequilíbrio de ligação na raça MM é curta (análise de desequilíbrio de ligação - LD, realizada com o 239 animais genotipados, revelou valores de $\mathrm{r}^{2}$ abaixo de 0,3 e 0,2 para marcadores distante entre 15 e $20 \mathrm{~kb}$ ), para a prospecção de genes ligados com os SNPs que explicaram mais de $1 \%$ da variância genética aditiva, uma janela genômica de $250 \mathrm{~kb}$ foi considerada. Para cada janela, o cromossomo e as coordenadas genômicas (início/fim) foram usados como entrada na ferramenta online BioMart do banco de dados Ensembl (ZERBINO et al., 2018) para encontrar os genes em seu interior, bem como suas sequências. Como muitos dos genes não estavam anotados em cavalos, suas sequências foram "blastadas" com a base de dados completa do NCBI no software Blast2GO (B2G) (CONESA et al., 2005) para se obter informação sobre a sua possível função. Foram utilizadas as opções standard do B2G e foi adotado 5\% como nível de significância para o teste exato de Fisher para análise de enriquecimento.

\subsection{Resultados}

\subsubsection{Imputação, estratificação populacional e representação de pedigree}

A PCA da matriz A revelou a presença de duas famílias distintas bem definidas no pedigree (Figura 1A), e o posicionamento dos animais genotipados sobre o espaço gráfico mostrou uma boa representação da variação do pedigree. Os dois grupos de animais genotipados (65k e 670k) não foram segregados (Apêndice B), o que implicou em resultados de imputação confiáveis. A PCA depois da imputação reposicionado alguns animais no gráfico, mas manteve a estrutura de população. Ao nível fenotípico, os animais genotipados foram 
estratificados, o que implica os menores valores de parentesco genômico entre os animais MP e MB (Figura 1B).

Figura 1 - Análise de componentes principais (PCA) da matriz de relacionamento via pedigree (A); PCA da matriz genômica após a imputação (461.523 SNPs) de acordo com o tipo de andamento (B).

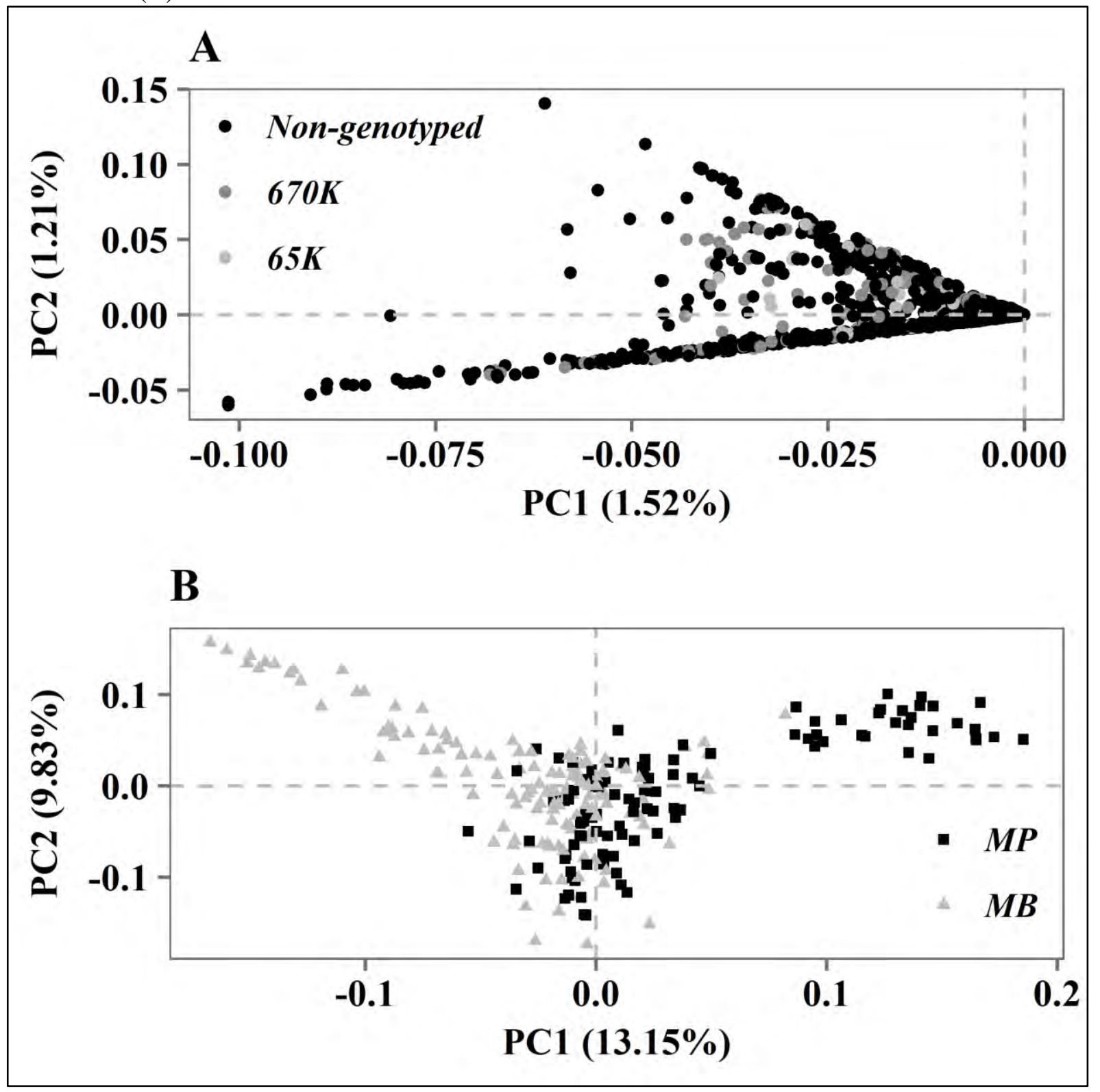

Fonte: Própria autoria.

A acurácia média da imputação dos genótipos foi de $92,63 \% \pm 0,25 \%$, a qual foi homogênea entre todos os cromossomas (Figura 2). A variação dentro dos animais não foi grande e todos os animais apresentaram boas taxas de concordância (Apêndice B). Além disso, a relação entre a MAF e a taxa de concordância média também foi investigada, mostrando que 
a imputação de genótipos funcionou bem para todas as classes de MAF dos SNPs exceto para os SNPs mais variacionais $(0,4 \leq \mathrm{MAF} \geq 0,5)$.

Figura 2 - Acurácia de imputação dos genótipos como taxa de concordância entre os genótipos imputados e os verdadeiros de acordo com o cromossomo.

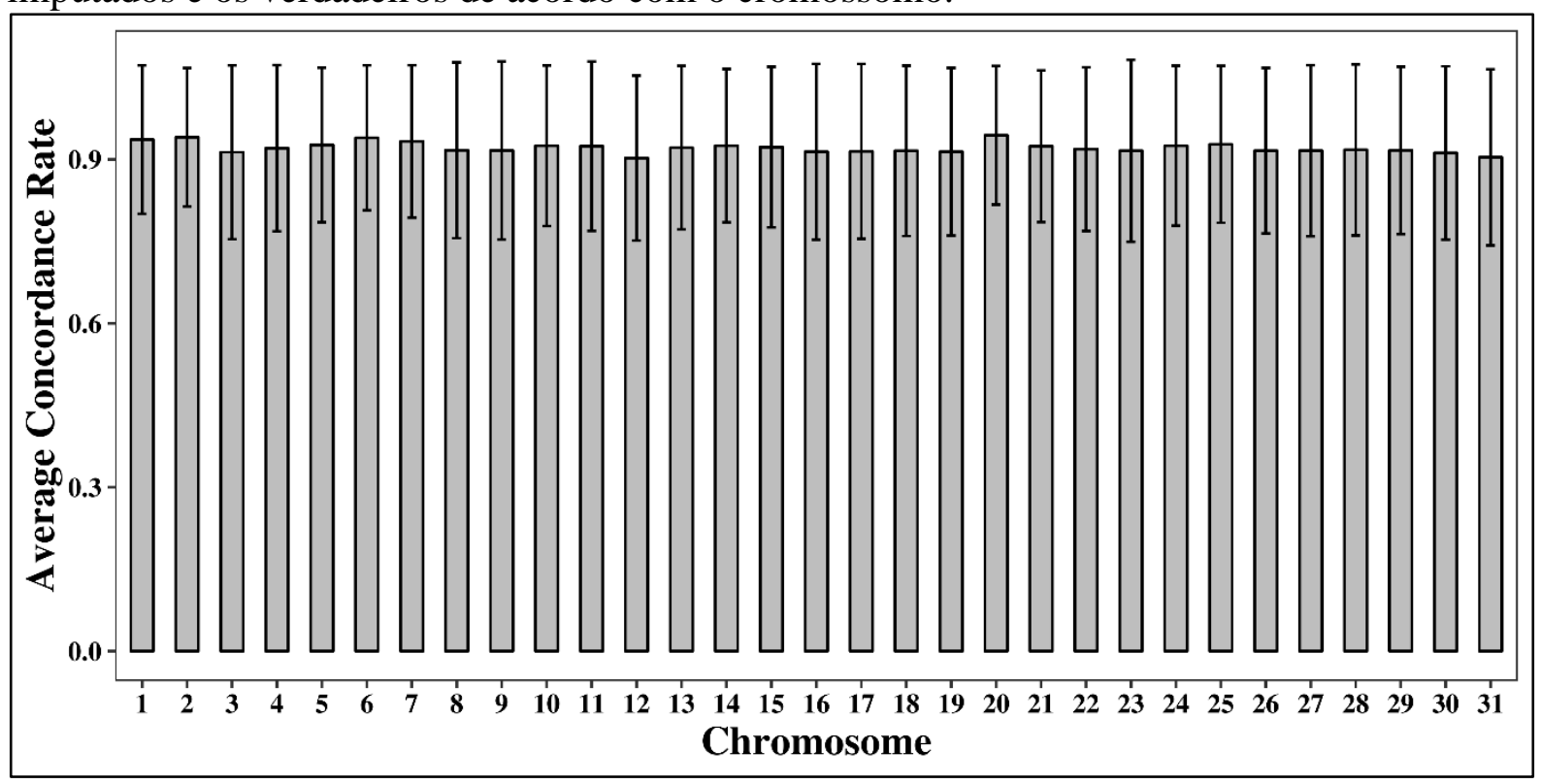

Fonte: Própria autoria.

\subsubsection{Componentes de variância}

Não foram encontrados sinais de não convergência ou tendências na visualização gráfica dos traceplots para cada componente de variância (dados não mostrados). Todos os escores de $\mathrm{Z}$ para o teste de Geweke da distribuição a posteriori dos parâmetros variaram de $-0,29$ a 1,32. Os valores mais elevados de escores de $\mathrm{Z}$ de Geweke foram encontrados nas estimativas de herdabilidade para o tipo de marcha, sugerindo que um período de burnin mais longo melhoraria a convergência. Todos os parâmetros passaram no teste de estacionariedade de Heidelberger-Welch (Tabela 1). A estimativa de herdabilidade a posteriori foi de 0,83 (0,71$0,94)$ e a variância fenotípica foi de 6,34 (2,64 - 10,85). Nenhum dos maiores intervalos de densidade a posteriori incluiu o zero, implicando na existência de todos os parâmetros. 
Tabela 1 - Médias e medianas a posteriori, intervalos de alta densidade, escores $\mathrm{Z}$ de Geweke e $r$-Lag50 para as estimativas dos componentes de variância do tipo de andamento.

\begin{tabular}{|c|c|c|c|c|c|c|}
\hline \multirow{2}{*}{ Componente de Variância } & \multirow{2}{*}{ Média } & \multirow{2}{*}{ Mediana } & \multicolumn{2}{|c|}{ Intervalo HPD } & \multirow{2}{*}{$\begin{array}{c}\text { Escore Z } \\
\text { de Geweke }\end{array}$} & \multirow{2}{*}{$r-\operatorname{Lag} 50$} \\
\hline & & & $(5 \%$ & $95 \%)$ & & \\
\hline Variância genética aditiva & 5,40 & 5,06 & $(1,73$ & $9,95)$ & 0,96 & 0,00 \\
\hline Variância residual & 0,94 & 0,94 & $(0,79$ & $1,10)$ & $-0,29$ & 0,00 \\
\hline Variância fenotípica & 6,34 & 6,01 & $(2,64$ & $10,85)$ & 0,95 & 0,00 \\
\hline Herdabilidade & 0,83 & 0,84 & $(0,71$ & $0,94)$ & 1,32 & 0,00 \\
\hline
\end{tabular}

Fonte: Própria autoria.

\subsubsection{Associação genômica ampla e análise funcional}

Vinte e dois SNPs, localizados nos cromossomos 4 (5 SNPs), 6 (2), 16 (1), 23 (11), 26 (1) e 29 (2), foram responsáveis por 42,43\% da variância genética aditiva (Tabela 2). Devido à natureza desta característica (binária), as variantes de efeito menor foram regredidas para zero durante o processo de ponderação e re-estimação do ssGWAS, de modo que no Manhattan plot a maior parte dos SNPs se manteve em zero proporção de variância genética aditiva (Figura 3).

No total, foram encontrados 69 genes nas janelas de $250 \mathrm{~kb}$ consideradas, mas 39 não estavam anotados em equinos (Apêndice C). Do total de genes não anotados, 39 foram "blastados" com um escore de similaridade entre 53,60 e 100,00\% e um valor de e variando de 0 a $2,26 \times 10^{-5}$. 
Tabela 2 - Posição dos SNPs cromossomo, regiões genômicas e proporção da variância genética aditiva por eles explicada.

\begin{tabular}{|c|c|c|c|c|c|}
\hline \multirow{2}{*}{$\begin{array}{l}\text { SNP posição } \\
\text { (bp) }\end{array}$} & \multirow{2}{*}{$\mathrm{Chr}^{1}$} & \multicolumn{3}{|c|}{ Região } & \multirow{2}{*}{$\begin{array}{c}\text { Variância genética } \\
\text { aditiva }(\%)\end{array}$} \\
\hline & & Nome & Início & Fim & \\
\hline 95.530 .303 & 4 & 95530303_4 & 95.405 .303 & 95.655 .303 & 1,47 \\
\hline 95.541 .786 & 4 & 95541786_4 & 95.416 .786 & 95.666 .786 & 1,26 \\
\hline 95.644 .265 & 4 & 95644265_4 & 95.519 .265 & 95.769 .265 & 1,50 \\
\hline 95.704 .189 & 4 & 95704189_4 & 95.579 .189 & 95.829 .189 & 1,77 \\
\hline 95.843 .696 & 4 & 95843696_4 & 95.718 .696 & 95.968 .696 & 1,89 \\
\hline 26.511 .708 & 6 & 26511708_6 & 26.386 .708 & 26.636 .708 & 3,26 \\
\hline 73.076 .296 & 6 & 73076296_6 & 72.951 .296 & 73.201.296 & 1,16 \\
\hline 29.380 .920 & 16 & 29380920_16 & 29.255 .920 & 29.505 .920 & 2,22 \\
\hline 13.420 .227 & 23 & 13420227_23 & 13.295 .227 & 13.545 .227 & 3,34 \\
\hline 14.986 .689 & 23 & 14986689_23 & 14.861 .689 & 15.111 .689 & 4,30 \\
\hline 16.892 .410 & 23 & 16892410_23 & 16.767 .410 & 17.017 .410 & 1,68 \\
\hline 16.892 .719 & 23 & 16892719_23 & 16.767 .719 & 17.017 .719 & 1,68 \\
\hline 17.961.772 & 23 & 17961772_23 & 17.836 .772 & 18.086 .772 & 1,42 \\
\hline 17.982 .265 & 23 & 17982265_23 & 17.857 .265 & 18.107.265 & 1,04 \\
\hline 17.985 .802 & 23 & 17985802_23 & 17.860 .802 & 18.110 .802 & 1,73 \\
\hline 23.143 .405 & 23 & 23143405_23 & 23.018 .405 & 23.268 .405 & 1,50 \\
\hline 23.443 .921 & 23 & 23443921_23 & 23.318 .921 & 23.568 .921 & 1,24 \\
\hline 23.494 .785 & 23 & 23494785_23 & 23.369 .785 & 23.619 .785 & 1,39 \\
\hline 23.597 .542 & 23 & 23597542_23 & 23.472 .542 & 23.722 .542 & 1,96 \\
\hline 18.598 .541 & 26 & 18598541_26 & 18.473 .541 & 18.723 .541 & 2,28 \\
\hline 17.178.229 & 29 & 17178229_29 & 17.053 .229 & 17.303 .229 & 3,17 \\
\hline 20.239 .175 & 29 & 20239175_29 & 20.114 .175 & 20.364 .175 & 1,17 \\
\hline
\end{tabular}

${ }^{1}$ Cromossomo.

Fonte: Própria autoria. 
Figura 3 - Manhattan plot da porcentagem de variância genética aditiva explicada por cada SNP para o tipo de andamento utilizando o método ssGWAS2 ( $3^{\mathrm{a}}$ iteração).

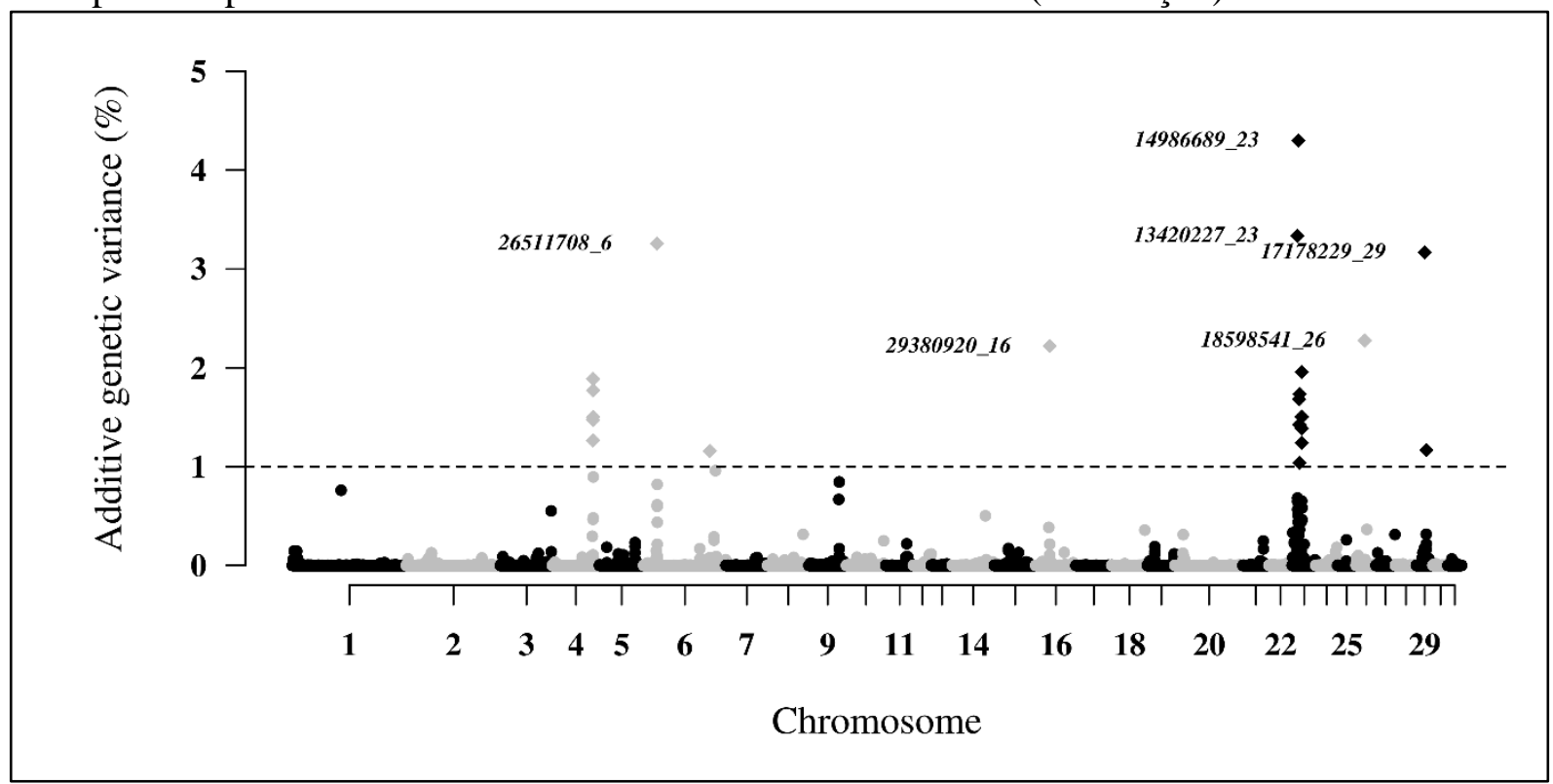

Fonte: Própria autoria.

Setenta termos de ontologia gênica foram associados a estes genes, mas nenhum deles foi significativamente enriquecido $(\mathrm{P}>0,05)$ (Apêndice $\mathrm{C}$ ). Oito vias metabólicas significativas $(\mathrm{P}<0,05)$ foram encontradas (Apêndice $\mathrm{D})$, nas quais oito genes estavam envolvidos. O gene PSAT1 foi associado a biossíntese de antibióticos; metabolismo da vitamina B6; metabolismo de glicina, serina e treonina e, metabolismo de metano. O gene $S U V 39 H 2$ foi envolvido na degradação lisina e, os genes TRPM6 e TRPV6 foram associados com a absorção de minerais. Os outros quatro genes são genes ainda não anotados em cavalos; eles foram associados ao metabolismo da riboflavina (ENSECAG00000020675) e transdução olfativa (ENSECAG00000005756, ENSECAG00000005541 e ENSECAG00000005404), estes genes foram "blastados" com um elevado valor de semelhança (> 90\%) e um baixo valor de e $\left(7.95 \times 10^{-112}\right)$ com 5 espécies (Pan paniscus/Homo sapiens, Rhinolophus sinicus, Loxodonta africana e Otolemur garnettii, respectivamente) (Tabela 3). 
Tabela 3 - Gene ID, valor de e, porcentagem de similaridade, espécies e nome dos genes para os resultados do "blast" dos genes não-anotados relacionados com vias metabólicas.

\begin{tabular}{ccclc}
\hline Gene ID & Valor de e & Sim. $^{1}$ & \multicolumn{1}{c}{ Espécies } & Nome do gene \\
\hline ENSECAG00000020675 & $7,95 \times 10^{-112}$ & $98,80 \begin{array}{l}\text { Pan paniscus } \\
\text { Homo sapiens }\end{array}$ & RFK \\
& & $1,03 \times 10^{-168}$ & 93,90 Rhinolophus sinicus & OR6C1 \\
ENSECAG00000005541 & $0,00 \times 10^{+00}$ & 95,80 Loxodonta africana & OR6C1 \\
ENSECAG00000005756 & ENSECAG00000005404 & $0,00 \times 10^{+00}$ & 94,60 Otolemur garnettii & OR6C70 \\
\hline
\end{tabular}

${ }^{1}$ Similaridade (\%).

Fonte: Própria autoria.

\subsubsection{Habilidade de predição fenotípica}

Do total de animais MB, 92,54\% foram corretamente classificados, enquanto que este mesmo percentual foi de $84,91 \%$ dos animais MP, consequentemente, foram omitidos 7,46 e 15,09\% dos animais MB e MP, respectivamente. Quando comparados, os erros de inclusão foram 11,43 e 10,00\% para os animais MB e MP, respectivamente; o que implicou em uma acurácia geral de 89,17\% (Apêndice E).

A proporção de homozigose dentro dos tipos de marcha foi diferente (Apêndice E), enquanto que o homozigoto "AA" foi o menos abundante no grupo MB para todos os SNPs que explicaram > 1\% da variância genética aditiva, o homozigoto "BB" foi o menos abundante nos animais MP. A proporção de heterozigose foi semelhante dentro de cada grupo de marcha, o que pode explicar a proporção de variância genética aditiva retida por esses SNPs e relacionado a este fato a estratificação baseada apenas nestes SNPs não foi marcadamente forte.

Quando considerados os dois primeiros componentes principais, os dois grupos fenotípicos foram bem separados e alguns animais que possuem composição genética similar permaneceram próximos no biplot. Adicionalmente, as frequências alélicas de cada SNP que explicou mais de $1 \%$ da variância genética aditiva nos dois grupos do tipo de marcha são mostradas na Tabela 4. 
Tabela 4 - Frequências alélicas dos SNPs que explicaram mais de 1\% da variância genética aditiva de acordo com o tipo de andamento.

\begin{tabular}{|c|c|c|c|c|c|c|c|c|}
\hline \multirow{3}{*}{$\begin{array}{l}\text { SNP posição } \\
\text { (bp) }\end{array}$} & \multirow{3}{*}{$\mathrm{Chr}^{1}$} & \multirow{3}{*}{$\begin{array}{c}\text { Alelos } \\
\left(\mathrm{A}_{1} / \mathrm{A}_{2}\right)\end{array}$} & \multicolumn{4}{|c|}{ Marcha } & \multirow{3}{*}{ Localização } & \multirow{3}{*}{ Gene Id ou Nome } \\
\hline & & & \multicolumn{2}{|c|}{ MP } & \multicolumn{2}{|c|}{$\mathrm{MB}$} & & \\
\hline & & & $\mathrm{A}_{1}$ & $\mathrm{~A}_{2}$ & $\mathrm{~A}_{1}$ & $\mathrm{~A}_{2}$ & & \\
\hline 95.530 .303 & 4 & $\mathrm{~A} / \mathrm{G}$ & 0,55 & 0,45 & 0,43 & 0,57 & Intron & ENSECAG00000010338 \\
\hline 95.541 .786 & 4 & $\mathrm{~A} / \mathrm{G}$ & 0,54 & 0,46 & 0,41 & 0,59 & Intron & ENSECAG00000010338 \\
\hline 95.644 .265 & 4 & $\mathrm{~A} / \mathrm{G}$ & 0,50 & 0,50 & 0,37 & 0,63 & Intron & $\begin{array}{l}\text { ENSECAG00000013402 } \\
\text { ENSECAG00000010950 }\end{array}$ \\
\hline 95.704 .189 & 4 & $\mathrm{~A} / \mathrm{G}$ & 0,52 & 0,48 & 0,37 & 0,63 & Intron & ENSECAG00000010950 \\
\hline 95.843 .696 & 4 & $\mathrm{~A} / \mathrm{G}$ & 0,43 & 0,57 & 0,24 & 0,76 & Intron & ENSECAG00000014336 \\
\hline 26.511 .708 & 6 & $\mathrm{~T} / \mathrm{C}$ & 0,49 & 0,51 & 0,34 & 0,66 & Intron & $P P P 1 R 7$ \\
\hline 73.076 .296 & 6 & $\mathrm{~A} / \mathrm{G}$ & 0,46 & 0,54 & 0,35 & 0,65 & Upstream & ENSECAG00000005541 \\
\hline 29.380 .920 & 16 & $\mathrm{~T} / \mathrm{C}$ & 0,54 & 0,46 & 0,31 & 0,69 & Intergenic & - \\
\hline 13.420 .227 & 23 & $\mathrm{~T} / \mathrm{C}$ & 0,61 & 0,39 & 0,36 & 0,64 & Intron & PSATI \\
\hline 14.986 .689 & 23 & $\mathrm{~T} / \mathrm{C}$ & 0,60 & 0,40 & 0,32 & 0,68 & Upstream & GCNTI \\
\hline 16.892 .410 & 23 & $\mathrm{~A} / \mathrm{G}$ & 0,73 & 0,27 & 0,28 & 0,72 & Intergenic & - \\
\hline 16.892 .719 & 23 & $\mathrm{~T} / \mathrm{C}$ & 0,73 & 0,27 & 0,28 & 0,72 & Intergenic & - \\
\hline 17.961.772 & 23 & $\mathrm{~A} / \mathrm{C}$ & 0,64 & 0,36 & 0,21 & 0,79 & Upstream & ENSECAG00000017708 \\
\hline 17.982 .265 & 23 & $\mathrm{~T} / \mathrm{G}$ & 0,64 & 0,36 & 0,30 & 0,70 & Intergenic & - \\
\hline 17.985 .802 & 23 & $\mathrm{~T} / \mathrm{C}$ & 0,65 & 0,35 & 0,30 & 0,70 & Intergenic & - \\
\hline 23.143 .405 & 23 & $\mathrm{~A} / \mathrm{G}$ & 0,78 & 0,22 & 0,24 & 0,76 & Intron & ENSECAG00000023609 \\
\hline 23.443 .921 & 23 & $\mathrm{~A} / \mathrm{G}$ & 0,75 & 0,25 & 0,25 & 0,75 & Intergenic & - \\
\hline 23.494 .785 & 23 & $\mathrm{~T} / \mathrm{C}$ & 0,76 & 0,24 & 0,27 & 0,73 & Intergenic & - \\
\hline 23.597.542 & 23 & $\mathrm{~T} / \mathrm{C}$ & 0,76 & 0,24 & 0,27 & 0,73 & Intergenic & - \\
\hline 18.598 .541 & 26 & $\mathrm{~A} / \mathrm{G}$ & 0,56 & 0,44 & 0,44 & 0,56 & Exon & RFo0026 \\
\hline 17.178 .229 & 29 & $\mathrm{~A} / \mathrm{G}$ & 0,32 & 0,68 & 0,49 & 0,51 & Intron & $C A C N B 2$ \\
\hline 20.239 .175 & 29 & $\mathrm{~T} / \mathrm{G}$ & 0,49 & 0,51 & 0,37 & 0,63 & Intergenic & - \\
\hline
\end{tabular}

${ }^{1}$ Cromossomo.

Fonte: Própria autoria.

\subsection{Discussão}

\subsubsection{Representação do pedigree, estratificação da população e imputação}

As estruturas familiares são muito comuns em populações domésticas com pedigree e este fato é também observado em cavalos. Isso é provavelmente associado a um sistema de acasalamento com base no uso intenso de animais específicos que têm mais prêmios em competições, ou são considerados mais importantes. Essa intensa utilização assimétrica cria um padrão de parentesco dentro das famílias, mas como alguns animais de uma família são frequentemente utilizados em acasalamento com indivíduos de outras famílias, a diversidade genética global é mantida na população. A PCA revelou duas estruturas familiares no 
considerado com alguns animais posicionados entre cada família, o que provavelmente está relacionado aos padrões de parentesco entre e dentro dessas famílias observadas. Além disso, os animais genotipados não formaram um cluster ou estrutura familiar na PCA do pedigree.

Como os dois grupos genotipados permaneceram juntos na PCA, esperava-se que eles compartilhassem haplótipos, o que levaria a uma imputação mais precisa. No entanto, os haplótipos não compartilhados impactaram a imputação. Assim, a acurácia não foi próxima de 0,98, como relatado em estudos anteriores em cavalos (CORBIN et al., 2014; FRISCHKNECHT et al., 2014; PEREIRA et al., 2017). Estes haplótipos não compartilhados também foram relacionados com o tipo de marcha, uma vez que os animais parecem ser segregados de acordo com o fenótipo. Isso também pode ser resultado da fundação da raça Mangalarga Marchador, o que implicaria em diferentes fundadores usados para criar os fenótipos, e o cruzamento de indivíduos de fenótipos diferentes (MB ou MP) ocorreu após o estabelecimento do padrão MB e MP desejado. Ao analisar a relação entre as classes de MAF e a acurácia de imputação, a alta taxa de concordância nas primeiras classes pode ser um resultado de SNPs fixados dentro do painel. Uma vez que os animais estavam divididos a nível fenotípico, a adição dos dois primeiros componentes principais como covariáveis no modelo de análise foi justificada para correção de uma possível estratificação populacional. Como as equações dos modelos mistos incluem a matriz de relacionamento ( $\boldsymbol{A}$ e no caso do modelo single-step, $\boldsymbol{H})$, as estruturas familiares foram corrigidas naturalmente pela resolução das equações no processo de iteração.

\subsubsection{Componentes de variância}

A visualização gráfica das cadeias mostrou sinais de convergência para todos os parâmetros em todas as iterações. Apesar da quantidade de dados, o intervalo de HPD para a estimativa a posteriori de herdabilidade foi estreito, bem como para a variância residual. Os escores $\mathrm{Z}$ de Geweke apontaram para um período de burnin adequado, exceto para a herdabilidade que poderia se beneficiar de um longo burnin, mas como discutido por Cowles e Carlin (1996) o teste de Geweke é sensível à janela espectral e ainda depende da experiência do estatístico. O teste de estacionariedade Heidelberger-Welch é aplicado entre as cadeias, o que o transforma em um bom parâmetro de convergência, no qual todos os parâmetros passaram, uma vez que a autocorrelação foi igual a zero, o que sugere que as amostras guardadas da distribuição a posteriori foram informativas para os cálculos. 
Alguns autores (DIETL; HOFFMANN; ALBRECHT, 2004; TEEGEN, 2008; VALERA et al., 2008) encontraram valores elevados de herdabilidade para características de marcha (contínuas) em equinos, o que foi encontrado neste estudo. A concordância entre os fenótipos dos genitores e o de seus descendentes (um fato muito comum nesta raça) pode explicar o alto valor da herdabilidade. O parentesco medido dentro e entre cada grupo fenotípico também pode ter impacto nas estimativas, uma vez que grupos mais relacionados podem aumentar a covariância entre grupos, sobrestimando a variância genética aditiva. Esse fato também pode ocorrer quando os animais fenotipados são endogâmicos, resultando em uma similaridade genética mais forte entre os indivíduos.

\subsubsection{Associação genômica ampla e análise funcional}

O número de regiões genômicas associadas com a definição das categorias fenotípicas encontrado neste estudo sugere o controle poligênico sobre os tipos de marcha, em concordância com Fonseca et al. (2017) e Patterson, Staiger e Brooks (2015), que foram os primeiros estudos que revelaram o possível controle poligênico do tipo de marcha nesta raça. A análise individual da função realizada pelo produto proteico de cada um dos 69 genes mapeados nas janelas de $250 \mathrm{~kb}$ em torno dos SNPs que explicaram mais de $1 \%$ da variância genética aditiva para distinguir o tipo de marcha permitiu destacar alguns genes que seguem: $R O R \beta, C E P 78$, OR6C2, HSPA14, MTERF4 e RFK. Uma discussão adicional sobre os outros genes candidatos encontrados como supostamente importantes para os tipos de marcha é apresentada no Apêndice F.

O gene ROR $\beta$ está envolvido no desenvolvimento da retina (FUJIEDA et al., 2009), portanto este gene pode estar associado à percepção de estímulos. Koch et al. (2017) revelaram o papel deste gene no andamento do animal. Segundo esses autores, para um controle dinâmico do movimento, os animais necessitam do feedback de aferências mecanossensoriais. A modalidade sensorial mais fortemente relacionada ao controle motor é a mecanossensibilização e o controle motor adaptativo depende das respostas às forças mecânicas que são geradas dentro e fora do corpo (TUTHILL; WILSON, 2016). Esse mecanismo de feedback deve ser seletivamente modulado na dependência da tarefa e do contexto. Neste campo os interneurônios inibitivos expressando o receptor nuclear órfão $R O R \beta$, durante a marcha têm um papel importante em um ritmo locomotor fluido (KOCH et al., 2017).

Pode-se dizer que o gene CEP78 está relacionado a estímulos externos, como visual e auditivo (FU et al., 2017; NAMBURI et al., 2016) que podem estar relacionados à capacidade 
de treinamento dos equinos, uma vez que é possível que eles possam diferenciar os estímulos externos de acordo com o tipo de marcha. Este gene também possui uma função celular que assegura a homeostase do centrossomo (HOSSAIN et al., 2017). Na percepção de estímulos externos, o gene OR6C2 é um receptor olfativo, mas Fernández et al. (2014) relataram que esse gene está relacionado ao processo neurológico, à percepção sensorial e à cognição. Este gene pode estar envolvido na via de transdução olfativa observada, desempenhando um papel na habilidade do cavalo para treinamento ou adaptação.

O gene HSPA14 está relacionado ao estresse oxidativo (CHILUKOTI et al., 2013) e tem sido relacionado à adaptação às condições tropicais (CHAN; NAGARAJ; REVERTER, 2010). Este gene pode estar relacionado com a adaptação destes cavalos às alterações metabólicas que a marcha requer. Também é possível que o estresse oxidativo, que é diferente de acordo com o tipo de marcha, seja uma resposta desse gene. Um outro gene que pode estar envolvido neste processo de metabolismo oxidativo é o gene MTERF4. Este gene está relacionado com a disfunção mitocondrial (YE et al., 2015) e controla a biogênese e a translação mitocondrial (CÁMARA et al., 2011).

Outro gene que desempenha um papel no estresse oxidativo é o gene RFK. Este gene é responsável por acoplar o receptor 1 à NADPH-oxidase, que produz espécies reativas de oxigênio (ROS) (YAZDANPANAH et al., 2009). As ROS são moléculas de defesa e sinalização envolvidas em várias respostas celulares no sistema imune (BEDARD; KRAUSE, 2007; LAMBETH, 2004). O envolvimento desse gene na determinação da marcha pode estar associado ao tipo de estresse oxidativo em cada marcha, uma vez que a conformação dos músculos pode ser afetada pelas ROS (BACURAU et al., 2009; LAWLER; SONG; DEMAREE, 2003), mas também as ROS podem modular a contração do músculo esquelético (REID, 2001).

Após os treinos ou competições, os equinos marchadores apresentam hiperventilação semelhante a animais de alta velocidade, como cross-country, adestramento, enduro e corrida de obstáculos (MARTINS et al., 2017). Como consequência desta hiperventilação, os animais aumentam a pressão de $\mathrm{CO}_{2}$ no sangue, o que leva a desequilíbrio ácido-base. No entanto, os garanhões são mais suscetíveis a essas alterações pós-exercício do que as éguas (DI FILIPPO et al., 2016; MARTINS et al., 2017). Este dimorfismo sexual metabólico também pode estar relacionado com os genes DMRT1 e DMRT2 (encontrado neste estudo), mas também com o gene DMRT3 encontrado por Andersson et al. (2012). Esses genes foram descritos como responsáveis pela diferenciação sexual em mamíferos e, o DMRT1 é considerado o principal gene na diferenciação masculina (HECKERT; AGBOR, 2015). É 
plausível que, apesar do dimorfismo morfológico entre garanhões e éguas, os dimorfismos metabólicos sejam os responsáveis pela relação entre esses genes e a marcha, juntamente com o possível efeito pleiotrópico (DMRT1, DMRT2 e DMRT3 atuando em ambos, dimorfismo sexual e marcha em equinos) que têm sido relatado na literatura (ANDERSSON et al., 2012; PATTERSON; STAIGER; BROOKS, 2015; PROMEROVÁ et al., 2014).

É notável que o gene DMRT3 não apareceu na prospecção de genes após o GWAS. De fato, este gene foi descrito como quase um pré-requisito para a marcha de quatro batidas e também foi investigado na raça Mangalarga Marchador. No painel imputado, após o QC, restaram 32 SNPs que estão em algum nível de LD com o gene DMRT3 (Apêndice G), mas nenhum deles explicou mais que $1 \%$ da variação genética aditiva. Assim, as frequências genotípicas do SNP ECA23:g.22999655C > A do gene DMRT3 dentro de cada tipo de marcha relatadas na literatura (FONSECA et al., 2017; PATTERSON; STAIGER; BROOKS, 2015) podem ser resultado de parentesco e endogamia nessa raça, o que pode explicar esse não aparecimento, uma vez que este estudo foi o primeiro a analisar os efeitos dos SNPs sob um modelo animal. Por outro lado, isso pode estar relacionado com a frequência do alelo menor desses SNPs ou com a extensão do LD nesta raça.

Como o número de genes observados foi próximo ao número de termos de ontologia gênica (GO) a eles relacionados, esses GO não foram significativamente enriquecidos, mas foram encontradas oito vias metabólicas significativamente associadas a oito genes. A relação entre essas vias está associada às diferenças bioquímicas e metabólicas observadas nos animais MP e MB; uma vez que há diferenças marcantes nos metabolismos de lactato, aminoacídico e energético desses animais.

A marcha é um exercício de exigência metabólica submáxima, mas estressante a nível fisiológico (DI FILIPPO et al., 2016; LAGE et al., 2017). Portanto, as vias metabólicas detectadas neste estudo podem estar relacionadas com a capacidade para cada tipo de marcha. Os genes encontrados estão associados a metabolismos importantes que foram anteriormente investigados num sentido fisiológico (COELHO et al., 2017; DI FILIPPO et al., 2016; LAGE et al., 2017; MARTINS et al., 2017).

A degradação aminoacídica e o metabolismo do metano podem estar relacionados às diferenças metabólicas entre os animais MP e MB. Como a frequência de passadas por unidade de tempo na marcha MP é maior que na marcha MB, os animais MP devem gastar mais energia e por isso têm mais alterações metabólicas após as sessões de exercício. Este fato foi estudado por Lage et al. (2017) e Wanderley et al. (2010); esses autores constataram que os animais MB e MP são semelhantes no estresse fisiológico e nas alterações bioquímicas pós- 
exercício. Por outro lado, ambos os autores encontraram evidências de que os animais MP exigem mais energia. Wanderley et al. (2010) relataram diferenças nas frequências cardíaca e respiratória, concentração de lactato e volume celular que seriam maiores em animais MP do que em animais MB, imediatamente após o início do exercício. O custo metabólico de energia e de transporte de oxigênio $\left(\mathrm{O}_{2}\right)$ em animais MP também é maior do que em animais $\mathrm{MB}$, o que aumenta as exigências energéticas dessa marcha (MP) (LAGE et al., 2017).

Estas diferenças metabólicas e energéticas podem também influenciar o sistema imunológico, o que justificaria a via do metabolismo da vitamina B6 encontrada. A vitamina B6 está relacionada com 150 outras enzimas, o que representam 4\% de toda a atividade enzimática (PERCUDANI; PERACCHI, 2009). Devido a essa ampla ação da vitamina B6 e um grande número de enzimas a ela relacionado, é possível que esta via tenha sido significativa pela interação com as demais vias.

Em seres humanos, a vitamina B6 foi relacionada a diversas funções, mas frequentemente está relacionada à inflamação (PERCUDANI; PERACCHI, 2009; UELAND et al., 2017). Haas et al. (2015) explicaram como o lactato interage com as células T, atuando na resposta inflamatória, como um sinal para as células T para entrar em locais inflamatórios. É plausível que, devido à diferença na frequência de movimentos entre cada marcha, os animais que fazem uma marcha de alta frequência também apresentem alterações semelhantes à inflamação em suas articulações. O lactato é então aumentado, o que sinaliza para as células T a necessidade de controle inflamatório; lá age o B6 como um precursor de enzimas.

A absorção do mineral está associada ao metabolismo aminoacídico, pois os minerais estão presentes na composição de todos os aminoácidos, assim, encontrou-se a via de absorção do mineral, uma vez que está relacionado às demais vias encontradas. Como muitos minerais agem como um catalisador para as reações químicas nos organismos, eles também podem estar relacionados com o metabolismo energético pela ativação de enzimas e vias metabólicas. Outro metabólito que está associado ao metabolismo de minerais e energia é a insulina, que é aumentada após o exercício como a consequência da intensa mobilização de glicose no sangue (DE REZENDE et al., 2014).

A semelhança foi suficiente para prospectar a função dos genes "blastados", uma vez que nenhum foi "blastado" com similaridade menor que 90\%. O ENSECAG00000020675 foi "blastado" com o gene $R F K$ com uma similaridade de $98 \%$, significando que as funções desses genes são as mesmas ou muito semelhantes. O gene $R F K$ é uma riboflavina quinase que está envolvida na proteção celular contra o estresse oxidativo e relacionada ao estresse oxidativo (HIRANO et al., 2011). Esta evidência do envolvimento do RFK e do estresse 
oxidativo precisa ser confirmada, mas se isso estiver correto, o $R F K$ pode desempenhar um papel na capacidade para a marcha em equinos, pois eles possuem alterações metabólicas relacionadas à presença ou ausência de oxigênio durante o exercício.

Os outros três genes (ENSECAG00000005756, ENSECAG00000005541, ENSECAG00000005404) encontrados foram "blastados" com receptores olfativos em Myotis davidii, Loxodonta africana e Equus caballus com similaridades variando de 93 a $95 \%$. A olfação interfere na organização social e reconhecimento de agressão (LIEBENAUER; SLOTNICK, 1996), bem como na percepção de dominância (KARAVANICH; ATEMA, 1991), que também está relacionada ao reconhecimento de estímulos externos. A resposta aos estímulos externos está fortemente relacionada às características anatômico-fisiológicas que são o resultado da seleção natural (BONSMA, 1949), que pode estar associada à resposta de luta ou fuga. A decisão de fugir ou lutar frente a um predador depende do reconhecimento de feromônios de alarme (HUNT, 2007) e está relacionada às experiências prévias dos animais com agressão (STARK; HAZLETT, 1972), que pode estar associada ao processo evolutivo dos cavalos. Uma visualização da interação de todas as vias é mostrada no Apêndice H. Além disso, os haplótipos preditos dos SNPs associados são apresentados no Apêndice I.

O fenótipo usado neste estudo é de difícil obtenção uma vez que requer treinamento para avaliação ou dados de competição confiáveis, o que nem sempre é possível porque os criadores podem mudar o andamento dos animais durante as competições. Assim, foram usados pouco animais no GWAS, mas este estudo foi pioneiro em metodologia ao considerar um modelo animal para avaliar o tipo de andamento em cavalos MM e aplicar analises "blast". Tentou-se controlar a taxa de falso descobrimento pelo uso da metodologia single-step, entretanto nós reconhecemos as limitações deste estudo. Adicionalmente o FDR para cada SNP é apresentado no Apêndice J.

\subsubsection{Habilidade de predição fenotípica}

Uma vez que a homozigose observada para os animais foi diferente entre os grupos fenotípicos, as proporções de correta classificação dos animais MP e MB podem sugerir que a heterozigose nesses SNPs é semelhante. A proporção de homozigose nos dois grupos de marcha pode refletir as estruturas familiares, bem como os fundadores que as originaram. Animais que deixam mais descendentes, consequentemente, deixam mais alelos na população. Se estes animais deixarem alelos através de linhagens paternas e maternas, as frequências genotípicas podem ser afetadas. De outro modo, essa homozigose "AA" e "BB" diferente poderia ser uma 
indicação de seleção para os diferentes genótipos através da seleção para os fenótipos MB ou MP.

Como consequência das proporções similares de heterozigose, os animais de altamente heterozigotos permanecem juntos no biplot, mas a estratificação ocorreu nos animais que são altamente homozigotos. Essa estratificação na PCA com base nos SNPs que explicaram mais de $1 \%$ da variância genética aditiva pode ser explicada contrastando os homozigotos "AA" e "BB", nos animais MP e MB, respectivamente (mas também as frequências alélicas dentro de cada marcha). A similaridade na heterozigosidade entre os dois grupos de marcha também aumenta a variância genética explicada por cada um desses SNPs, uma vez que nos cálculos a proporção de variância genética aditiva é ponderada pelas frequências alélicas.

\subsection{Conclusão}

Embora não tenha sido possível identificar a variante causativa da marcha em cavalos Mangalarga Marchador, este estudo apresenta bases à hipótese de que as diferenças genéticas entre os andamentos MB e MP estão intimamente relacionadas com as diferenças metabólicas entre os animais que exibem tipos diferentes de marcha. Os genes observados neste estudo podem indicar a consequência de um processo de adaptação evolutiva para a habilidade de marchar, o que alterou o metabolismo energético dos diferentes andamentos, como consequência várias vias metabólicas foram alteradas. Os SNPs associados detectados podem ser usados para melhorar a seleção da marcha nesta raça, se desejado. Contudo, a segregação com base neles depende da proporção de heterozigosidade, que irá sempre ser influenciada pela estrutura da população. Estudos futuros são necessários para descrever a herança genética da marcha nessa raça e também para estabelecer estratégias de genotipagem e fenotipagem de rotina.

\subsection{Referências}

AGUILAR, I. et al. Hot topic: A unified approach to utilize phenotypic, full pedigree, and genomic information for genetic evaluation of Holstein final score1. Journal of Dairy Science, New York, v. 93, n. 2, p. 743-752, 2010.

AGUILAR, I.; MISZTAL, I.; TSURUTA, S. PREGSF90-POSTGSF90: Computational tools for the implementation of single-step genomic selection and genome-wide association with ungenotyped. 10 $^{\text {th }}$ World Congress on Genetics Applied to Livestock Production, n. August, p. 90-92, 2014. 
ANDERSSON, L. S. et al. Mutations in DMRT3 affect locomotion in horses and spinal circuit function in mice. Nature, London, v. 488, n. 7413, p. 642-646, 2012.

BACURAU, A. V. N. et al. Sympathetic hyperactivity differentially affects skeletal muscle mass in developing heart failure: role of exercise training. Journal of Applied Physiology, v. 106, n. 5, p. 1631-1640, 2009.

BEDARD, K.; KRAUSE, K.-H. The NOX Family of ROS-Generating NADPH Oxidases: Physiology and Pathophysiology. Physiological Reviews, v. 87, n. 1, p. 245-313, 2007.

BENJAMINI, Y.; HOCHBERG, Y. Controlling the False Discovery Rate: A pratical and powerful approach to multiple testing. J R Statist. Soc. B, v. 57, n. 1, p. 289-300, 1995.

BONSMA, J. C. Breeding cattle for increased adaptability to tropical and subtropical environments. The Journal of Agricultural Science, v. 39, n. 2, p. 204-221, 1949.

BROWNING, B. L.; BROWNING, S. R. Improving the accuracy and efficiency of identityby-descent detection in population data. Genetics, v. 194, n. 2, p. 459-471, 2013.

BROWNING, B. L.; BROWNING, S. R. Genotype Imputation with Millions of Reference Samples. American Journal of Human Genetics, v. 98, n. 1, p. 116-126, 2016.

BROWNING, S. R.; BROWNING, B. L. Rapid and Accurate Haplotype Phasing and Missing-Data Inference for Whole-Genome Association Studies By Use of Localized Haplotype Clustering. The American Journal of Human Genetics, v. 81, n. 5, p. 10841097, 2007.

CÁMARA, Y. et al. MTERF4 regulates translation by targeting the methyltransferase NSUN4 to the mammalian mitochondrial ribosome. Cell Metabolism, v. 13, n. 5, p. 527$539,2011$.

CARNEIRO DE REZENDE, A. S. et al. Skeletal Muscle Fiber Composition of Untrained Mangalarga Marchador Fillies. Journal of Equine Veterinary Science, Maryland Heights, v. 36, p. 101-104, 2016.

CHAN, E. K. F.; NAGARAJ, S. H.; REVERTER, A. The evolution of tropical adaptation: Comparing taurine and zebu cattle. Animal Genetics, Chichester, v. 41, n. 5, p. 467-477, 2010.

CHEN, C. Y. et al. Genome-wide marker-assisted selection combining all pedigree phenotypic information with genotypic data in one step: An example using broiler chickens. Journal of Animal Science, Cary, v. 89, n. 1, p. 23-28, 2011.

CHILUKOTI, R. K. et al. Effects of irbesartan on gene expression revealed by transcriptome analysis of left atrial tissue in a porcine model of acute rapid pacing in vivo. International Journal of Cardiology, v. 168, n. 3, p. 2100-2108, 2013.

COELHO, C. S. et al. Influência da marcha sobre o heritograma em equinos da raça Mangalarga Marchador. Veterinária e Zootecnia, v. 24, n. 3, p. 563-570, 2017. 
CONESA, A. et al. Blast2GO: A universal tool for annotation, visualization and analysis in functional genomics research. Bioinformatics, v. 21, n. 18, p. 3674-3676, 2005.

CORBIN, L. J. et al. The utility of low-density genotyping for imputation in the Thoroughbred horse. Genetics Selection Evolution, v. 46, n. 1, p. 1-14, 2014.

COWLES, M. K.; CARLIN, B. P. Markov Chain Monte Carlo Convergence Diagnostics: A Comparative Review. Journal of the American Statistical Association, v. 91, n. 434, p. 883-904, 1996.

DE REZENDE, H. H. C. et al. Bioquímica sérica e leucometria de equinos mangalarga marchador suplementados com cromo e submetidos à prova de marcha. Bioscience Journal, v. 30, n. 1, p. 219-225, 2014.

DI FILIPPO, P. A. et al. Gender Differences-Induced Changes in Serum Hematologic and Biochemical Variables in Mangalarga Marchador Horses After a Marcha Gait Competition. Journal of Equine Veterinary Science, Maryland Heights, v. 43, p. 18-22, 2016.

DIETL, G.; HOFFMANN, S.; ALBRECHT, S. Parameters and trends of mare inspections of Mecklenburger Warmblut Horse. Archiv für Tierzucht, v. 47, p. 107-117, 2004.

FERNÁNDEZ, A. I. et al. Copy number variants in a highly inbred Iberian porcine strain. Animal Genetics, Chichester, v. 45, n. 3, p. 357-366, 2014.

FONSECA, M. G. et al. A Genome-Wide Association Study Reveals Differences in the Genetic Mechanism of Control of the Two Gait Patterns of the Brazilian Mangalarga Marchador Breed. Journal of Equine Veterinary Science, Maryland Heights, v. 53, p. 6467, 2017.

FRISCHKNECHT, M. et al. Imputation of sequence level genotypes in the FranchesMontagnes horse breed. Genetics Selection Evolution, v. 46, n. 1, p. 1-8, 2014.

FU, Q. et al. CEP78 is mutated in a distinct type of usher syndrome. Journal of Medical Genetics, v. 54, n. 3, p. 190-195, 2017.

FUJIEDA, H. et al. Retinoic acid receptor-related orphan receptor $\alpha$ regulates a subset of cone genes during mouse retinal development. Journal of Neurochemistry, v. 108, n. 1, p. 91$101,2009$.

GEWEKE, J. Evaluating the accuracy of sampling-based approaches to the calculation of posterior moments. Bayesian Statistics, Oxford, v. 4, p. 169-193, 1992.

HAAS, R. et al. Lactate regulates metabolic and proinflammatory circuits in control of T cell migration and effector functions. PLoS Biology, San Francisco, v. 13, n. 7, p. 1-24, 2015.

HECKERT, L. L.; AGBOR, V. A. DMRT1 and the road to masculinity. Sertoli Cell Biology, p. 123-174, 1 jan. 2015.

HEIDELBERGER, P.; WELCH, P. D. Simulation Run Length Control in the Presence of an Initial Transient. Operations Research, v. 31, n. 6, p. 1109-1144, 1983. 
HENDERSON, C. R. Rapid method for computing the inverse of a relationship matrix. Journal of Dairy Science, New York, v. 58, n. 11, p. 1727-1730, 1975.

HIRANO, G. et al. Involvement of riboflavin kinase expression in cellular sensitivity against cisplatin. International Journal of Oncology, v. 38, n. 4, p. 893-902, 2011.

HOSSAIN, D. et al. Cep78 controls centrosome homeostasis by inhibiting EDD-DYRK2DDB1. EMBO reports, v. 18, n. 4, p. 632-644, 2017.

HUNT, G. J. Flight and fight: A comparative view of the neurophysiology and genetics of honey bee defensive behavior. Journal of Insect Physiology, v. 53, n. 5, p. 399-410, 2007.

KARAVANICH, C.; ATEMA, J. Role of Olfaction in Recognition of Dominance in the American Lobster ( Humarus americanus ). The Biological Bulletin, v. 181, n. 2, p. 359-360, 1991.

KOCH, S. C. et al. ROR $\beta$ Spinal Interneurons Gate Sensory Transmission during Locomotion to Secure a Fluid Walking Gait. Neuron, v. 96, n. 6, p. 1419-1431.e5, 2017.

LAGE, J. et al. Workload of official contests, net cost of transport, and metabolic power of Mangalarga Marchador horses of marcha batida or picada gaits. Journal of Animal Science, Cary, v. 95, n. 6, p. 2488-2495, 2017.

LAMBETH, J. D. NOX enzymes and the biology of reactive oxygen. Nature Reviews Immunology, v. 4, n. 3, p. 181-189, 2004.

LAWLER, J. M.; SONG, W.; DEMAREE, S. R. Hindlimb unloading increases oxidative stress and disrupts antioxidant capacity in skeletal muscle. Free Radical Biology and Medicine, v. 35, n. 1, p. 9-16, 2003.

LIEBENAUER, L. L.; SLOTNICK, B. M. Social organization and aggression in a group of olfactory bulbectomized male mice. Physiology and Behavior, v. 60, n. 2, p. 403-409, 1996.

MANSO FILHO, H. C. et al. Alelo DMRT3 mutante em equinos de marcha batida e picada das raças Campolina e Mangalarga Marchador. Ciência Veterinária nos Trópicos, v. 18, n. 1 , p. 6-11, 2015.

MAPA. Revisão do Estudo do Complexo do Agronegócio do Cavalo. 1. ed. BrasíliaDF: MAPA, 2016.

MARTINS, L. P. et al. Effect of Marcha Exercise on Serum Electrolytes and Acid-Base Balance in Mangalarga Marchador Horses. Journal of Equine Veterinary Science, Maryland Heights, v. 49, p. 108-112, 2017.

MISZTAL, I. et al. BLUPF90 and related programs (BGF90). In: WORLD CONGRESS ON GENETICS APPLIED TO LIVESTOCK PRODUCTION, 7., 2002, Montpellier.

Proceedings... Montepellier, 2002. 2 p.

NAMBURI, P. et al. Bi-allelic Truncating Mutations in CEP78, Encoding Centrosomal 
Protein 78, Cause Cone-Rod Degeneration with Sensorineural Hearing Loss. American Journal of Human Genetics, v. 99, n. 5, p. 1222-1223, 2016.

PATTERSON, L.; STAIGER, E. A.; BROOKS, S. A. DMRT3 is associated with gait type in Mangalarga Marchador horses, but does not control gait ability. Animal Genetics, Chichester, v. 46, n. 2, p. 213-215, 2015.

PERCUDANI, R.; PERACCHI, A. The B6 database: A tool for the description and classification of vitamin B6-dependent enzymatic activities and of the corresponding protein families. BMC Bioinformatics, v. 10, p. 273, 2009.

PEREIRA, G. L. et al. Genotype Imputation and Accuracy Evaluation in Racing Quarter Horses Genotyped Using Different Commercial SNP Panels. Journal of Equine Veterinary Science, Maryland Heights, v. 58, p. 89-96, 2017.

PEREIRA, G. L. et al. Genomic regions associated with performance in racing line of Quarter Horses. Livestock Science, v. 211, n. October 2017, p. 42-51, 2018.

PLUMMER, M. et al. CODA: convergence diagnosis and output analysis for MCMC. $\mathbf{R}$ News, v. 6, p. 7-11, March. 2006.

PROMEROVÁ, M. et al. Worldwide frequency distribution of the "Gait keeper" mutation in the DMRT3 gene. Animal Genetics, Chichester, v. 45, n. 2, p. 274-282, 2014.

R CORE TEAM. R Development Core TeamR: a language and environment for statistical computing. 2016.

REID, M. B. Invited Review: Redox modulation of skeletal muscle contraction: what we know and what we don't. Journal of Applied Physiology, Bethesda, v. 90, n. 2, p. 724-731, 2001.

STARK, B.; HAZLETT, B. A. Effects of olfactory experience on aggression in Mus musculus and Peromyscus maniculatus. Behavioral Biology, Maryland Heights, v. 7, n. 2, p. 265-269, 1972.

TEEGEN, R. Analysen eines Zuchtprogrammes am Beispiel des Trakehner Zuchtverbandes. 2008. 109 f. Dissertação (Mestrado) - Universität zu Kiel, Kiel, Deutschland, 2008.

TUTHILL, J. C.; WILSON, R. I. Mechanosensation and adaptive motor control in insects John. Current Biology, Cambridge, v. 20, n. 26, p. 1022-1038, 2016.

UELAND, P. M. et al. Inflammation, vitamin B6 and related pathways. Molecular Aspects of Medicine, Kidlington, v. 53, p. 10-27, 2017.

UTSUNOMIYA, Y. T. et al. Genome-wide association study for birth weight in Nellore cattle points to previously described orthologous genes affecting human and bovine height. BMC Genetics, London, v. 14, art. 52, 2013.

VALERA, M. et al. Genetic parameters of biokinematic variables of the trot in Spanish 
Purebred horses under experimental treadmill conditions. Veterinary Journal, London, v. 178, n. 2, p. 219-226, 2008.

VANRADEN, P. M. Efficient methods to compute genomic predictions. Journal of Dairy Science, New York, v. 91, n. 11, p. 4414-4423, 2008.

WANDERLEY, E. K. et al. Metabolic changes in four beat gaited horses after field marcha simulation. Equine Veterinary Journal, Hoboken, v. 42, n. suppl. 38, p. 105-109, 2010.

WANG, C. L. et al. Comparison of five methods for genomic breeding value estimation for the common dataset of the $15^{\text {th }}$ QTL-MAS Workshop. BMC Proceedings, London, v. 6, n. suppl 2, p. S13, 2012.

WANG, H. et al. Genome-wide association mapping including phenotypes from relatives without genotypes. Genetics Research,Cambridge, v. 94, n. 2, p. 73-83, 2012.

WANG, H. et al. Genome-wide association mapping including phenotypes from relatives without genotypes in a single-step (ssGWAS) for 6-week body weight in broiler chickens. Frontiers in Genetics, Lausanne, v. 5, , p. 1-10, May. 2014.

YAZDANPANAH, B. et al. Riboflavin kinase couples TNF receptor 1 to NADPH oxidase. Nature, London, v. 460, n. 7259, p. 1159-1163, 2009.

YE, X. et al. MTERF4 regulates the mitochondrial dysfunction induced by MPP+in SHSY5Y cells. Biochemical and Biophysical Research Communications, v. 464, n. 1, p. $214-$ $220,2015$.

ZERBINO, D. R. et al. Ensembl 2018. Nucleic Acids Research, Oxford, v. 46, n. D1, p. D754-D761, 2018. 


\section{CONSIDERAÇÕES FINAIS}

Este trabalho foi o primeiro a abordar os aspectos da modelagem para o tipo de marcha em equinos Mangalarga Marchador, objetivando viabilizar futuras avaliações genéticas. Um obstáculo importante foi a quantidade de dados que, por ser reduzida, implicou em estratégias bastante ousadas para que a estimação dos componentes de variância fosse possível. Em uma primeira aproximação aos dados, num resumo, publicado na $16^{\text {a }}$ reunião ALPA/2018, foi constatado que a restrição nos dados, principalmente para variância dos efeitos fixos/sistemáticos, prejudicava muito a convergência das análises e inviabilizava as predições dos valores genéticos. Desta forma, optou-se pela manutenção dos efeitos fixos/sistemáticos com variância nula no modelo e, reduziu-se a complexidade do mesmo, a fim de permitir as estimações e predições.

Além de avaliar qual seria o melhor modelo para as análises, este estudo avaliou também o impacto da estrutura de parentesco e endogamia entre os grupos fenotípicos (marcha batida e marcha picada) nas frequências alélicas e genotípicas do gene DMRT3. Apesar da pouca profundidade de pedigree, o mesmo foi constituído da totalidade de relacionamento encontrado no banco de dados da ABCCMM. Foi possível verificar que os animais de marcha picada são mais endogâmicos que os animais de marcha batida e o padrão de parentesco entre os dois grupos é bastante distinto. Enquanto que animais de marcha batida possuem coeficientes de parentesco variando de 0 a 1 , dentro do grupo, os animais de marcha picada possuem uma frequência bastante elevada dos extratos superiores deste coeficiente. Tal fato seguramente afeta os alelos do DMRT3 fazendo com que, a despeito de seu efeito na coordenação dos membros, seu efeito sobre o tipo de andamento seja confundido com uma estrutura populacional bastante pronunciada.

Até o presente estudo, nenhum trabalho de GWAS para o tipo de andamento que foi conduzido com cavalos Mangalarga Marchador utilizou os marcadores como efeito aleatório ou, estimou os efeitos dos SNPs sob um modelo animal. Neste trabalho, por ter sido utilizado um modelo de GWAS de passo único, as estruturas populacionais foram, naturalmente, corrigidas durante a solução dos sistemas de equações, uma vez que a matriz de relacionamento considerada para interligar os diversos níveis do efeito aleatório genético aditivo (animal) foi a matriz $\boldsymbol{H}$ que pondera, não somente, as informações de pedigree, mas também, as informações genômicas. Os resultados encontrados neste trabalho apontam à adaptação evolutiva dos animais ao andamento, não sendo possível, contudo, dizer o que ocorreu primeiro: andamento ou mudanças metabólicas. 
Não foi possível identificar a(s) variante(s) causal(ais) do tipo de marcha em equinos Mangalarga Marchador, mas este estudo serve de base para levantar diversas hipóteses para futuros trabalhos. Certamente trabalhos com outras abordagens ômicas contribuiriam muito para o entendimento acerca das marchas batida e picada. Devido à natureza "binária" desta característica estudos de expressão gênica/proteica diferencial tem grande potencial em futuras pesquisas, uma vez que seria possível verificar que, talvez as diferentes marchas sejam resultado de diferentes níveis de expressão dos mesmos genes/proteínas. 


\section{APÊNDICE A - Gráficos de convergência}

Figura S1 - Traceplots das variâncias genética aditiva e residual em todos os modelos testados.
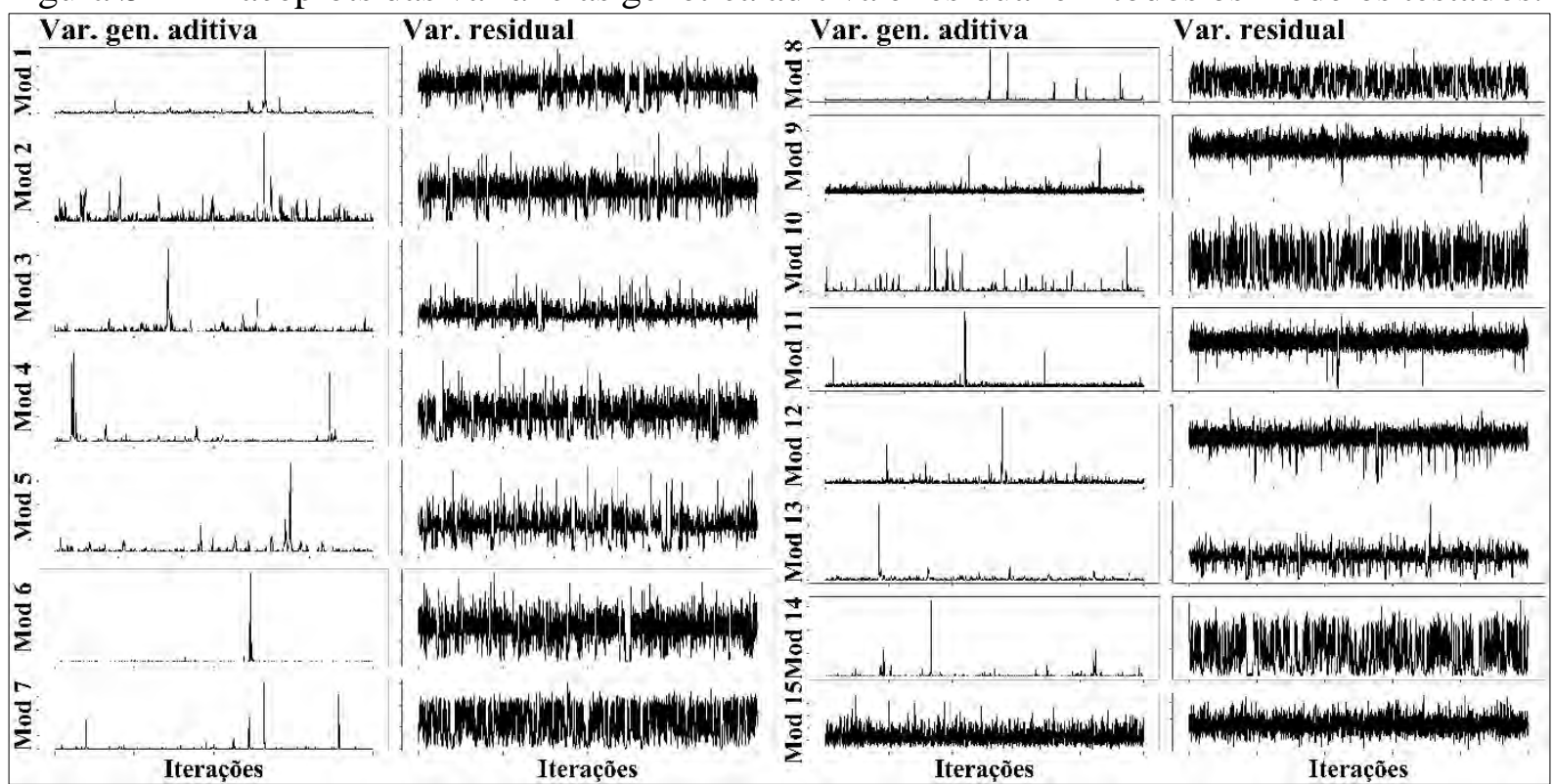

Var. gen. aditiva = Variância genética aditiva;

Var. residual = Variância residual;

Mod = Modelo.

Fonte: Própria autoria.

Figura S2 - Traceplots dos efeitos aleatórios de grupo de contemporâneos e proprietário em todos os modelos testados que continham estes efeitos.

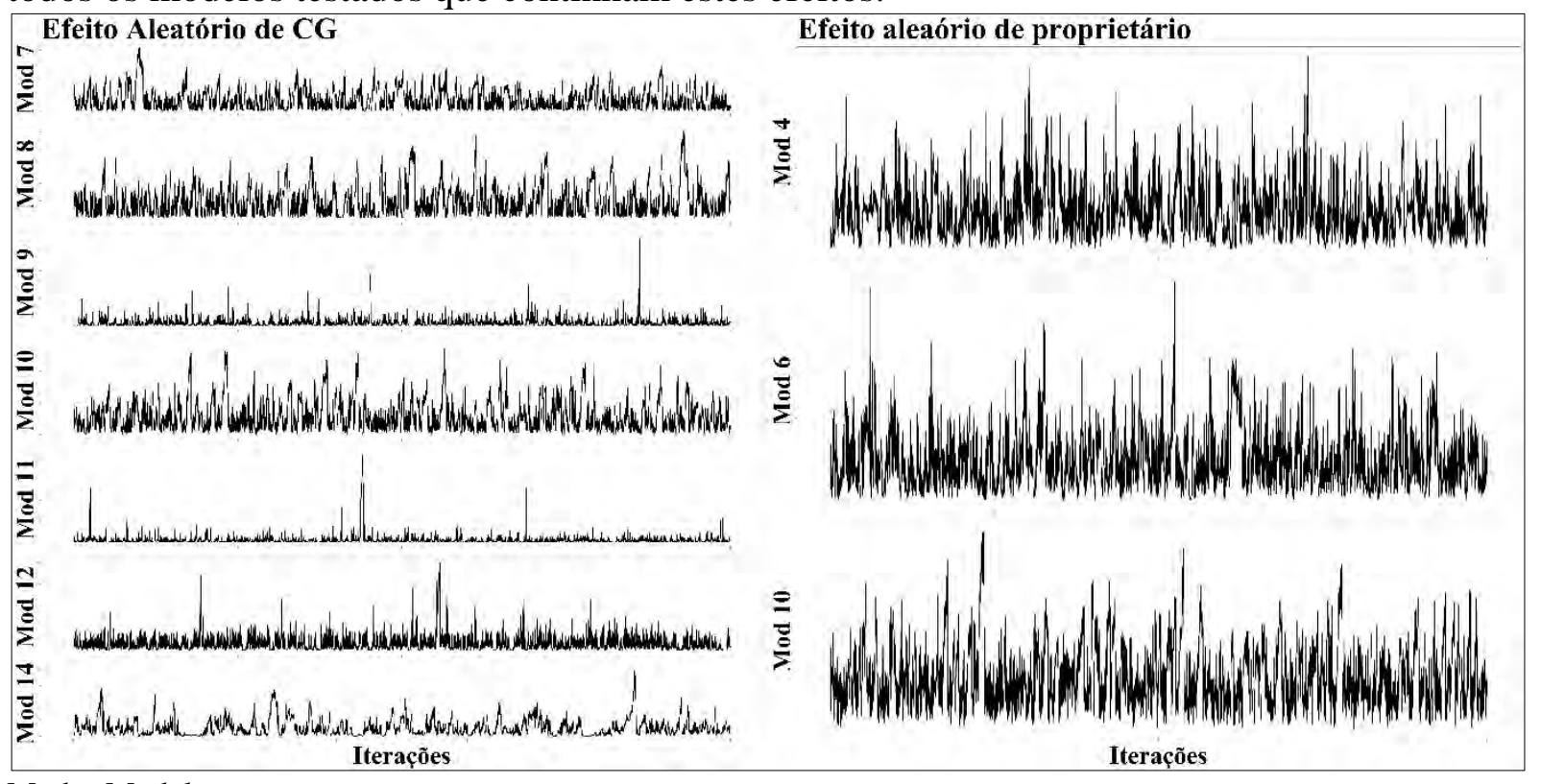

Mod = Modelo.

Fonte: Própria autoria. 


\section{APÊNDICE B - Resultados de Imputação}

Figura S1 - PCA da matriz de relacionamento genômica construída apenas com SNPs compartilhados entre os dois painéis (56.506 marcadores - A); PCA da matriz de relacionamento genômica após a imputação (461.523 SNPs) de acordo com a densidade inicial (B).

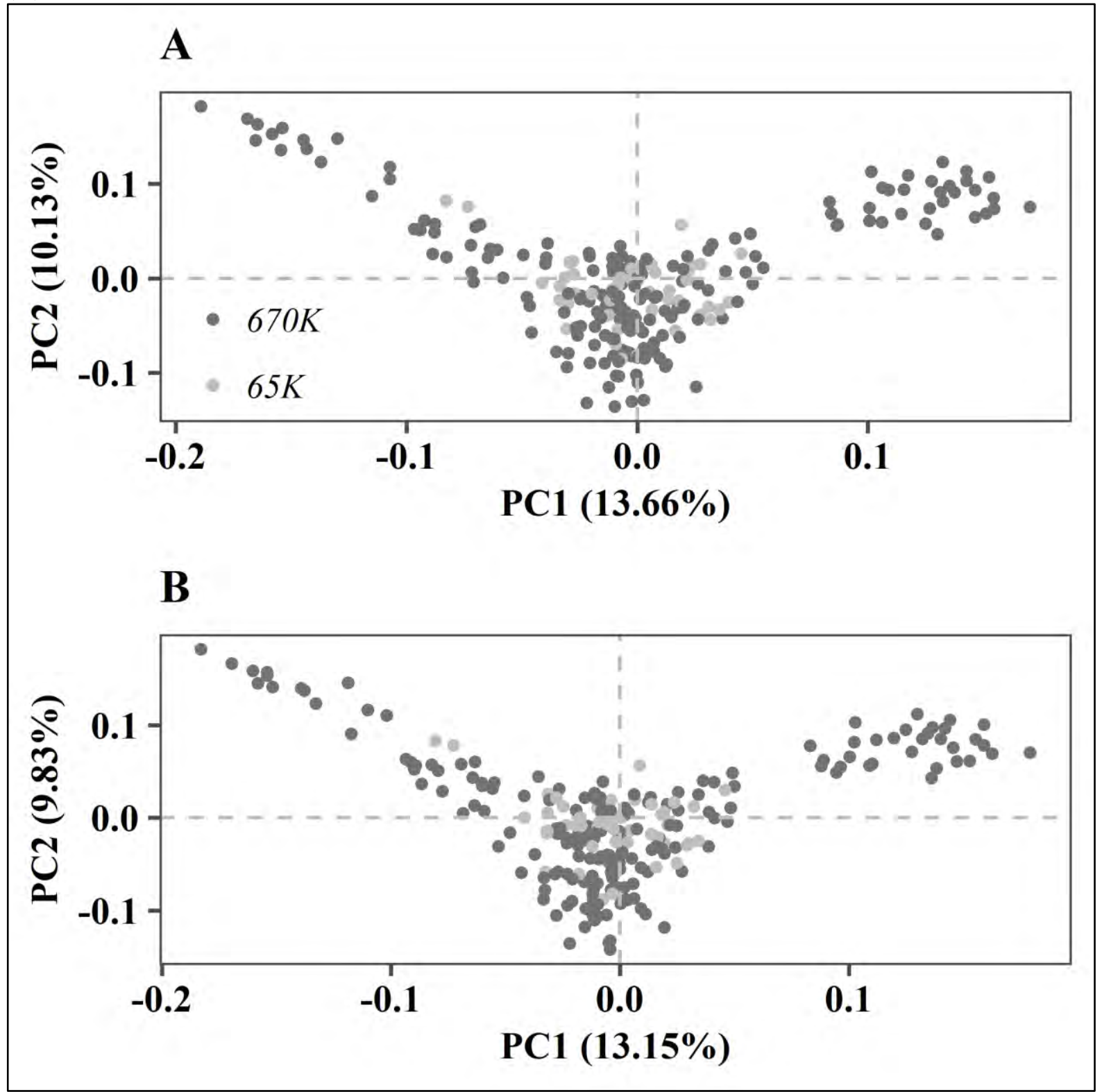

Fonte: Própria autoria. 
Figura S2 - Acurácia de imputação de genótipos dada como taxa de concordância entre os genótipos imputados e os verdadeiros por animal (A) e por classe de frequência do alelo menor (B).

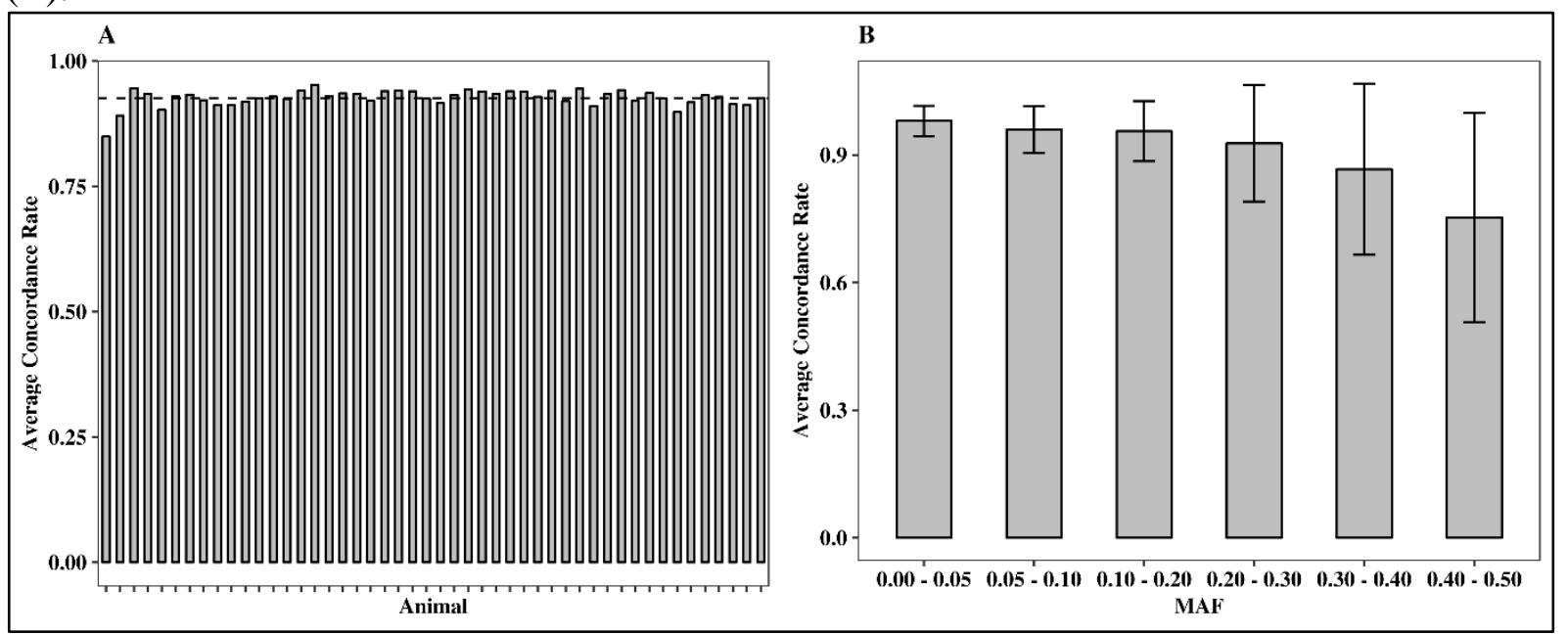

Average Concordance Rate $=$ Taxa de Concordância Média;

MAF = Frequência do alelo menor.

Fonte: Própria autoria. 


\section{APÊNDICE C - Genes encontrados e enriquecimento funcional}

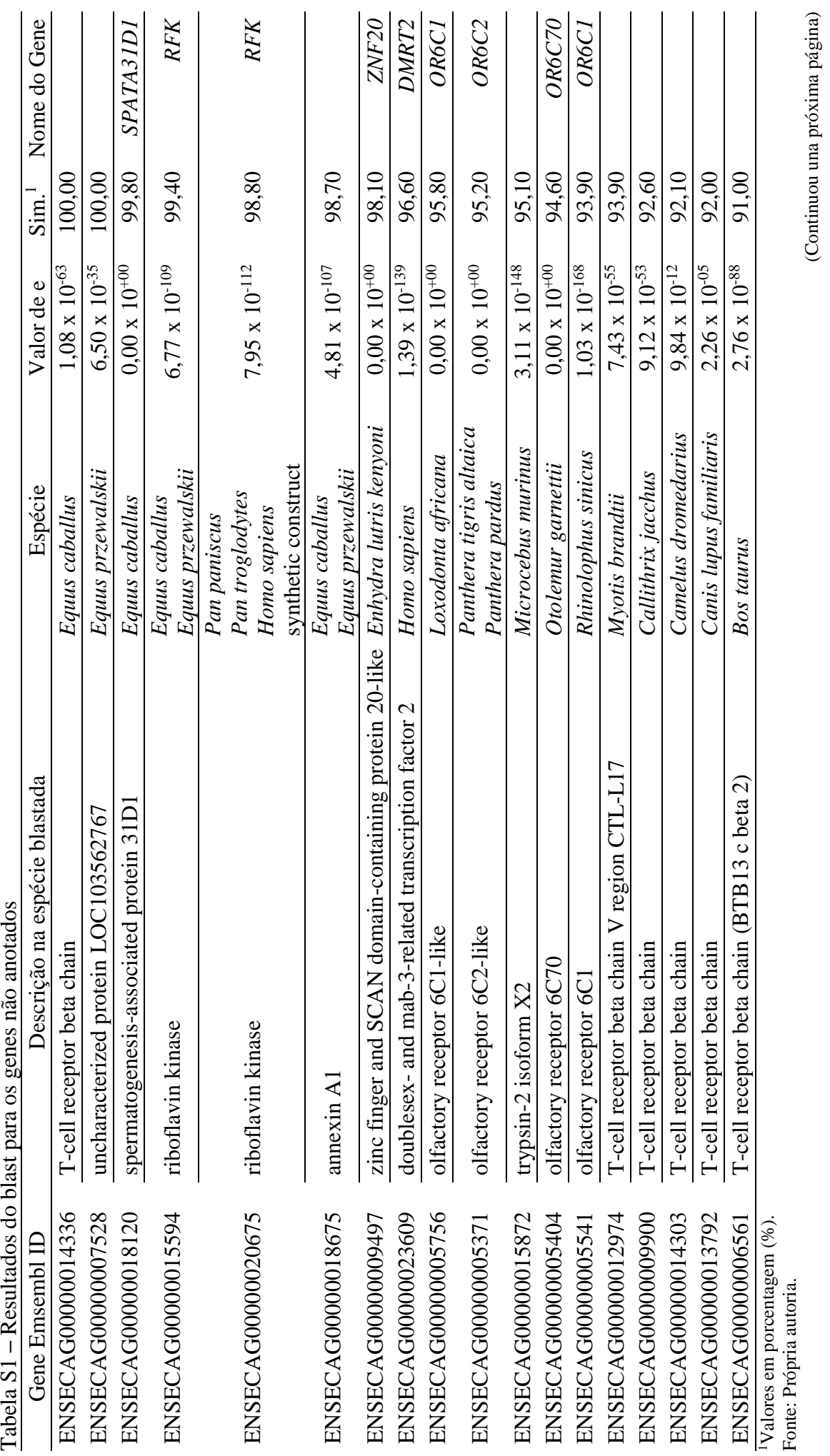




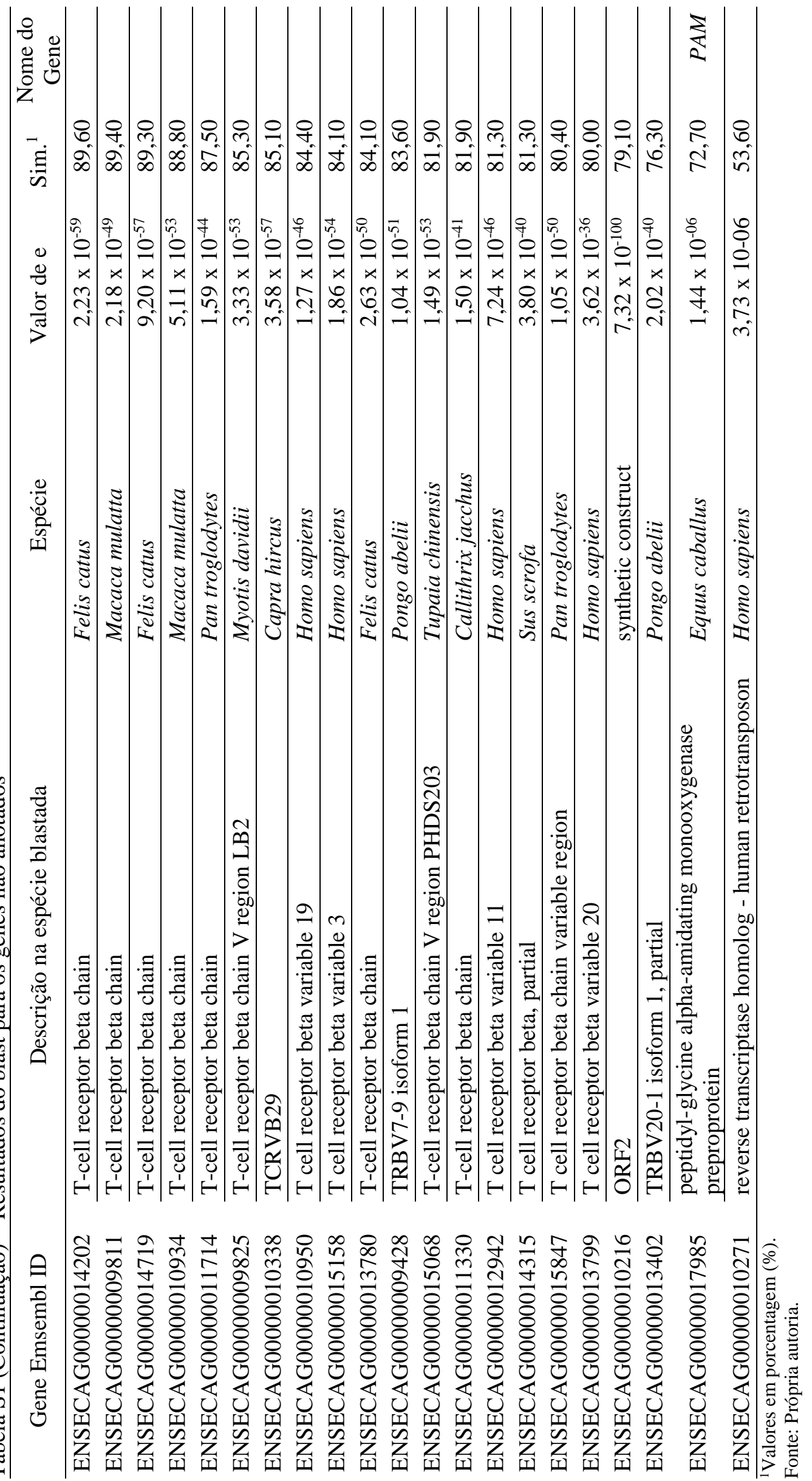




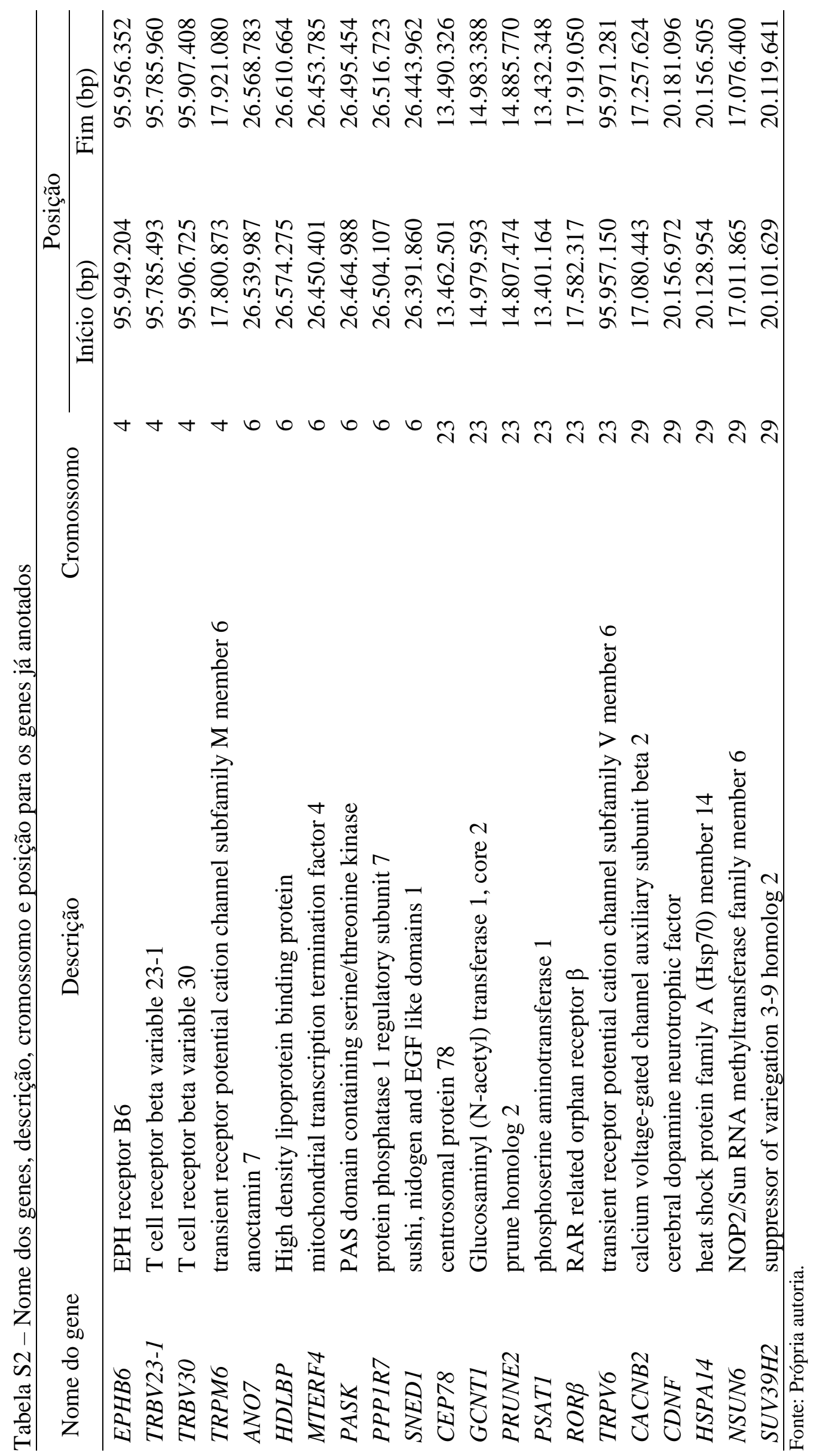




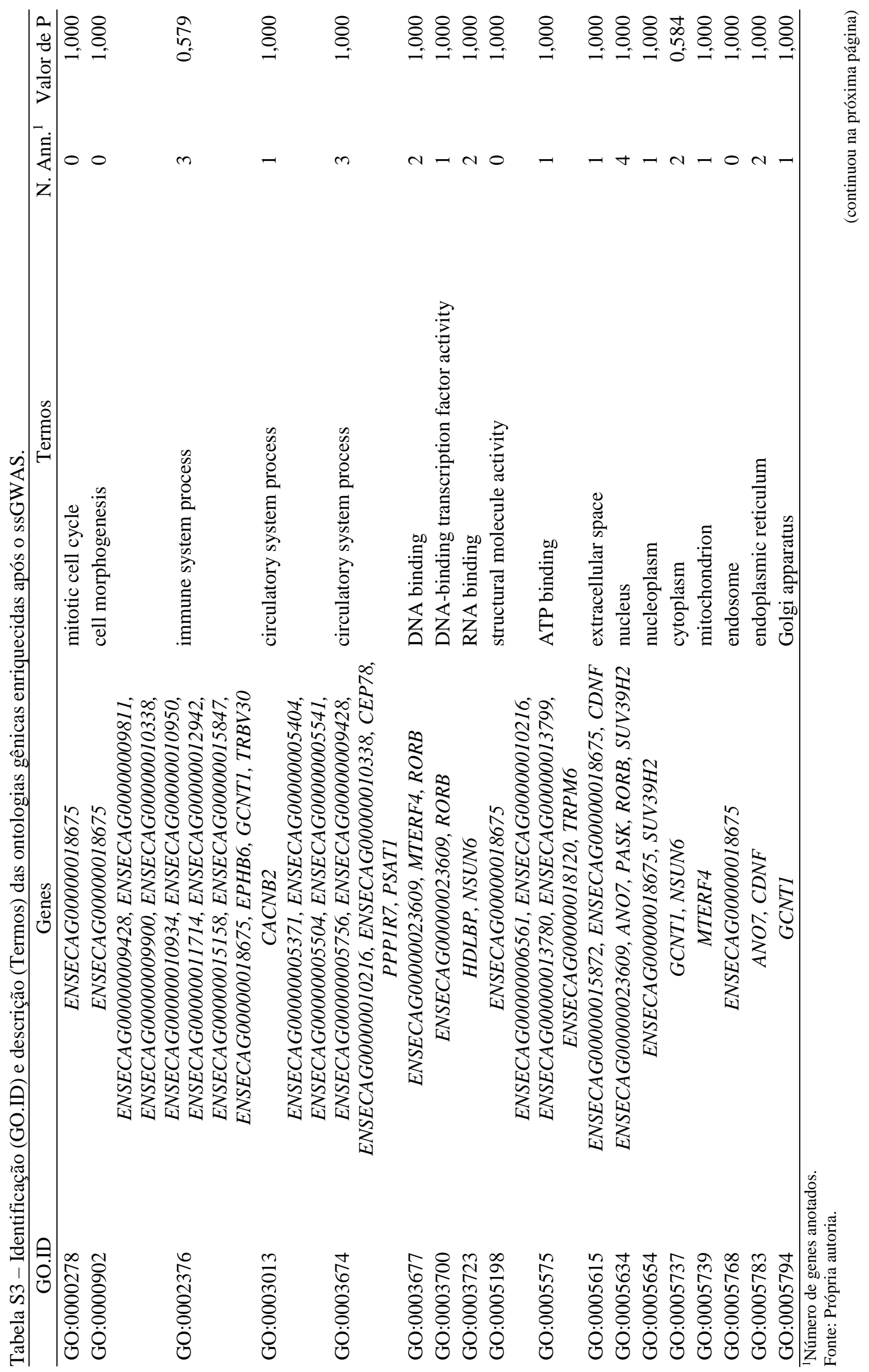




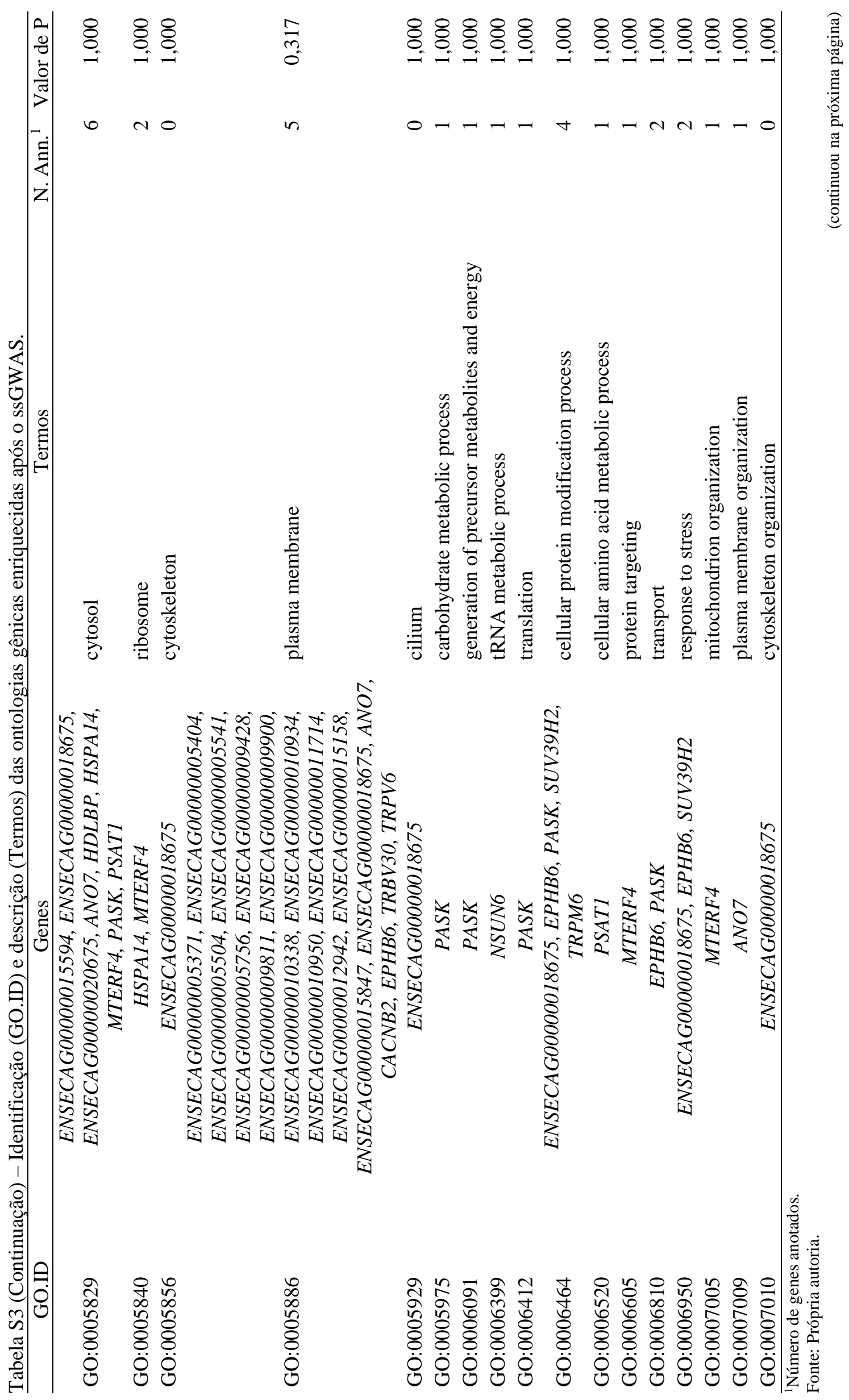




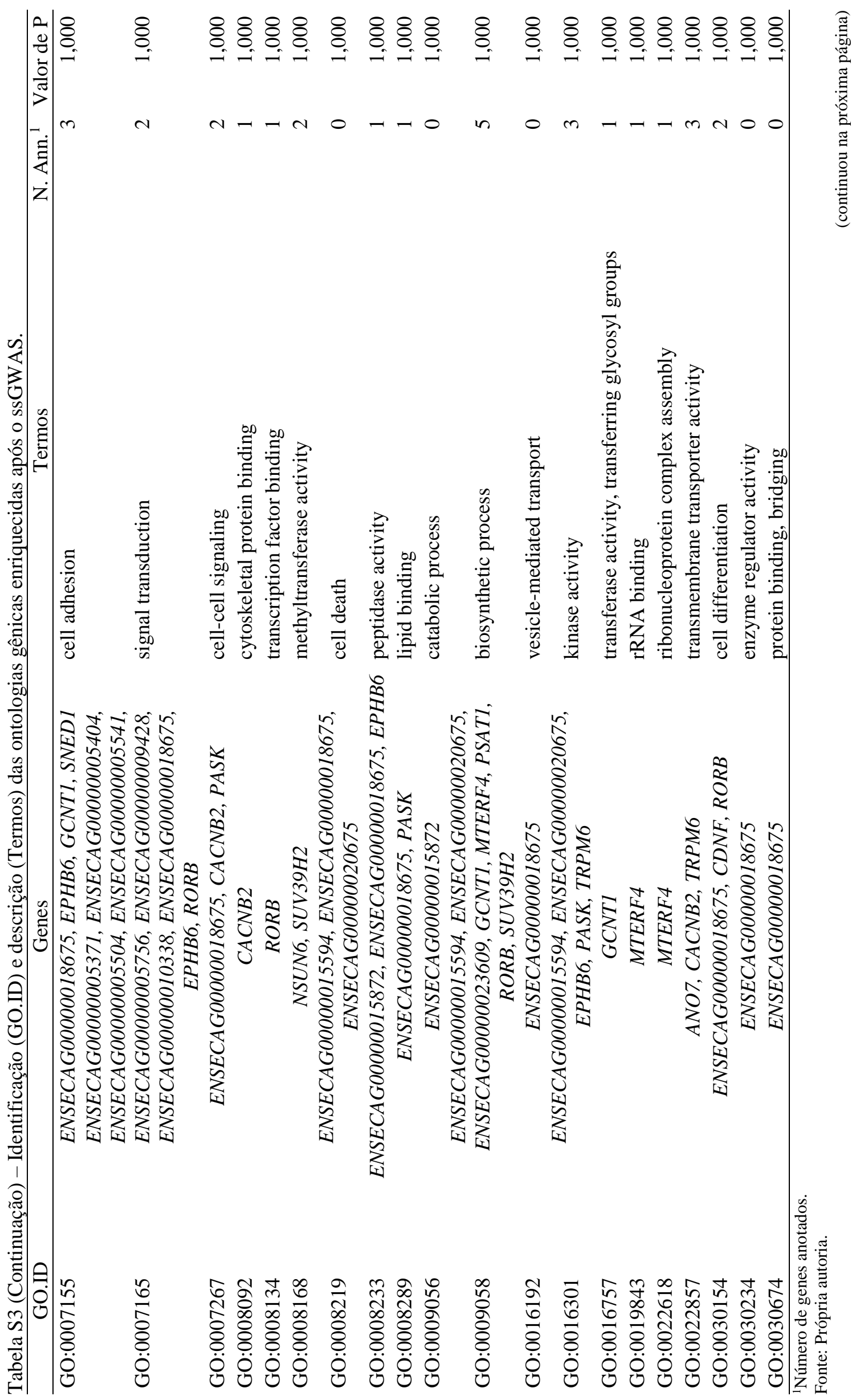




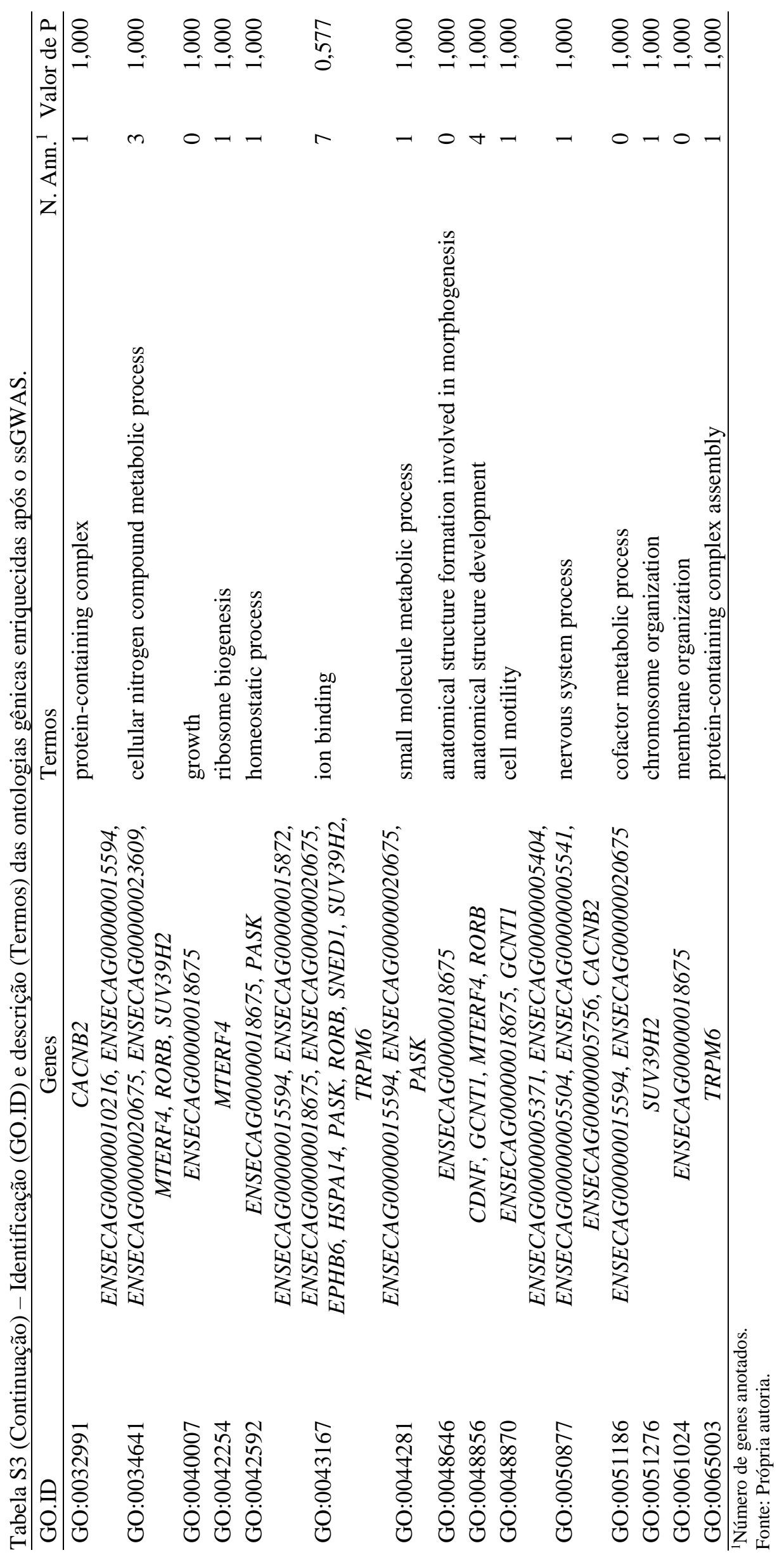




\section{APÊNDICE D - Vias metabólicas associadas ao tipo de marcha}

Figura S1 - Biossíntese de antibióticos

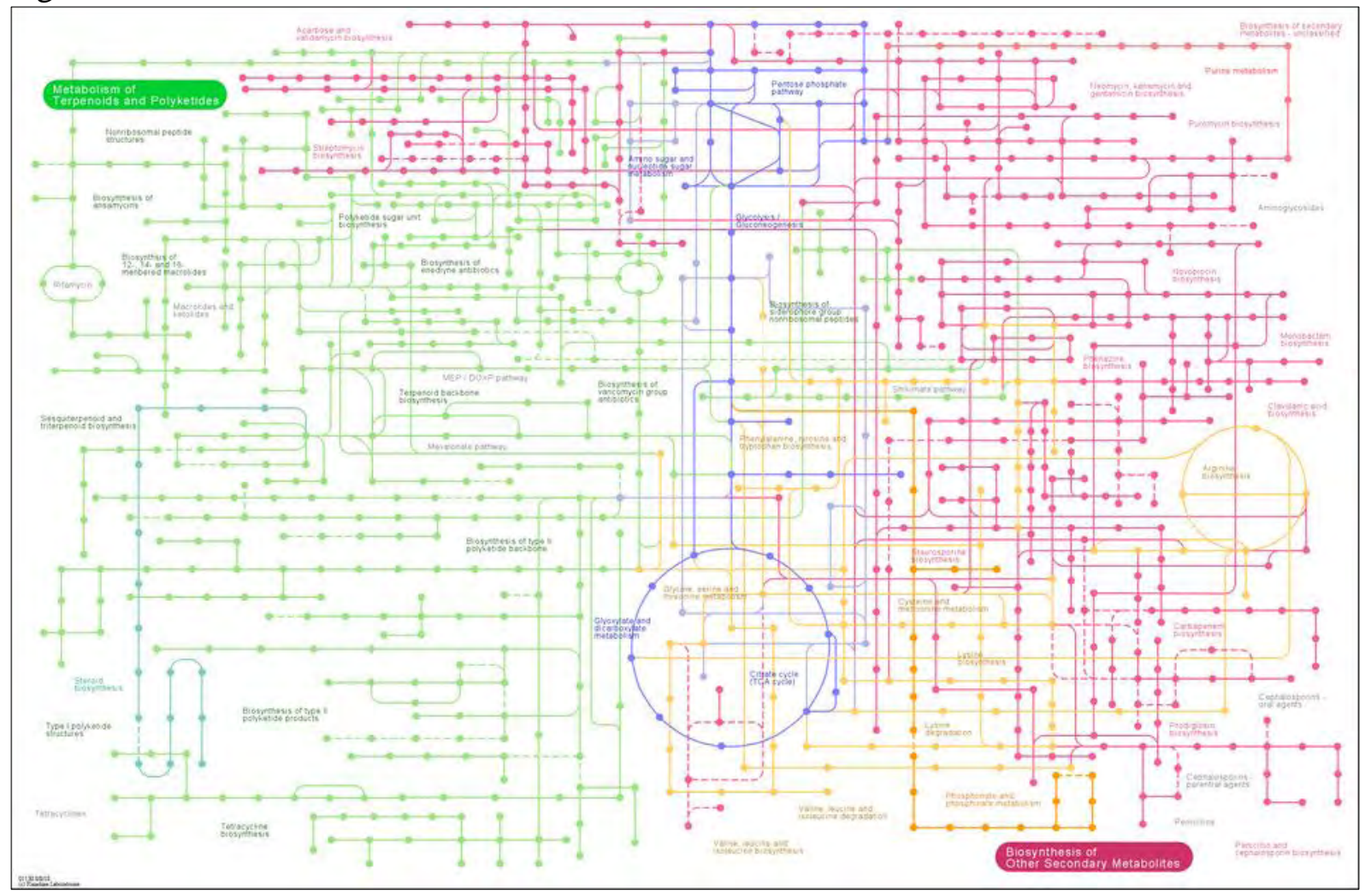

Fonte: Kegg pathway Database.

Figura S2 - Metabolismo de vitamina B6.

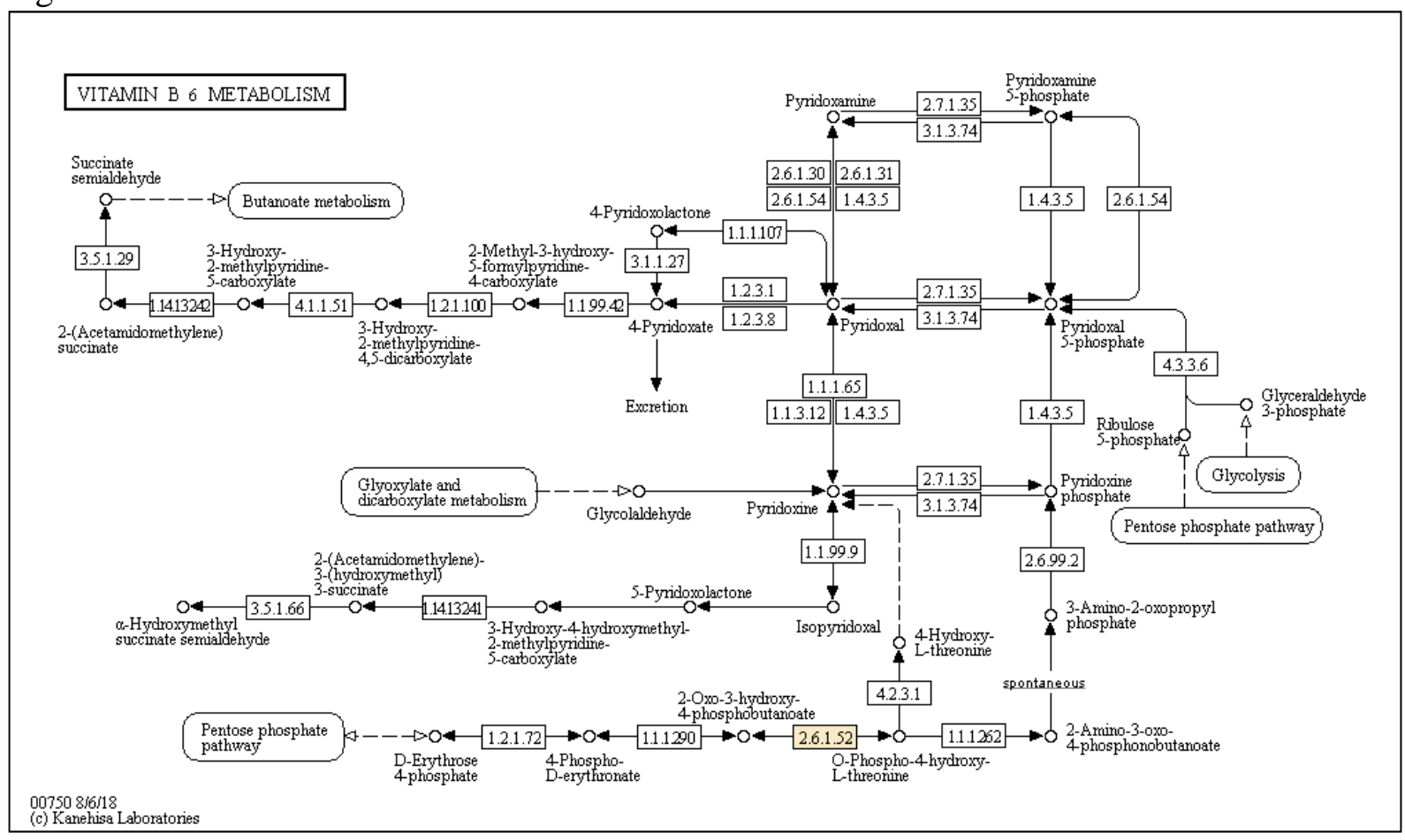

Fonte: Kegg pathway Database. 
Figura S3 - Metabolismo de glicina, serina e treonina.

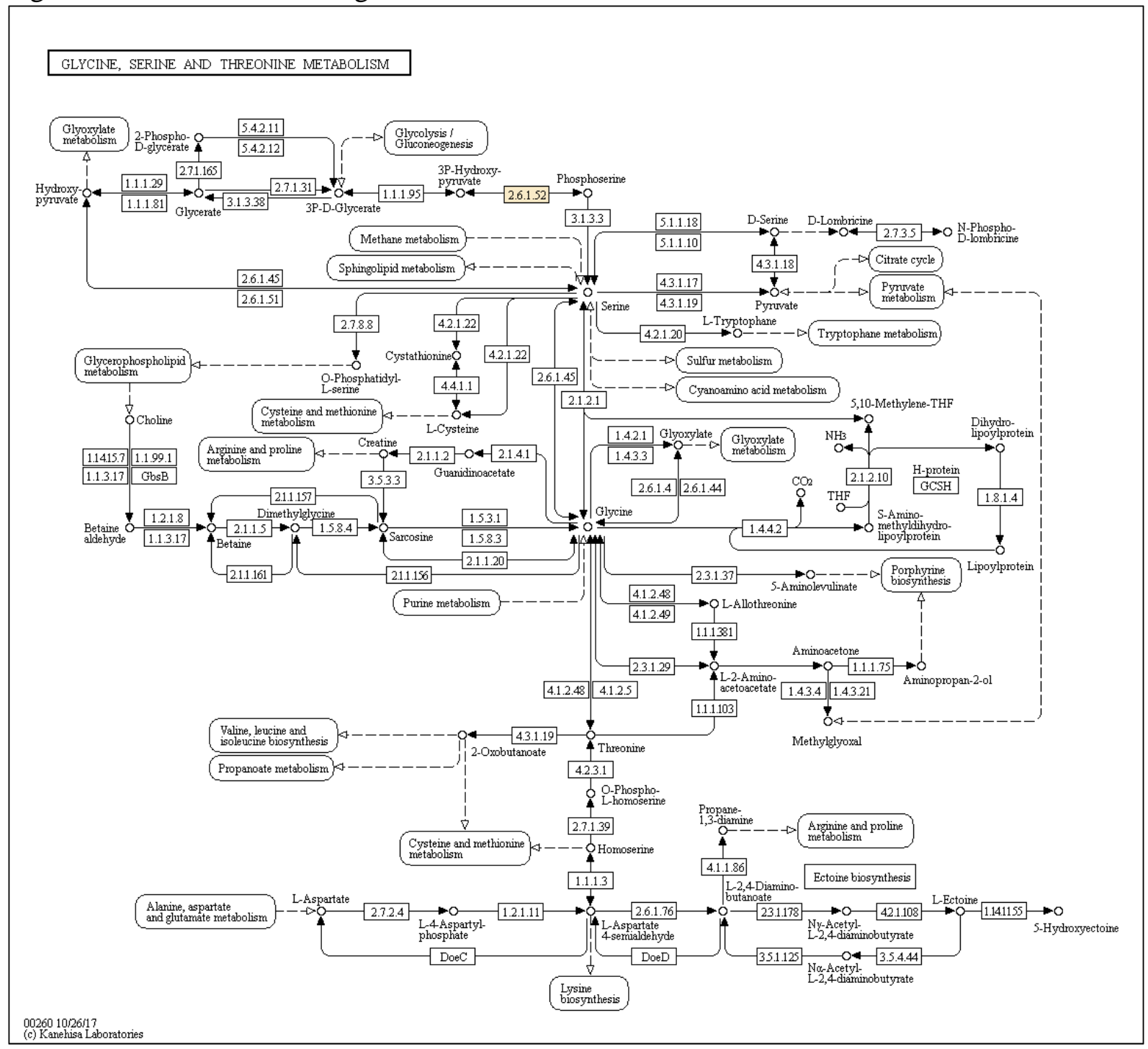

Fonte: Kegg pathway Database. 
Figura S4 - Metabolismo de metano.

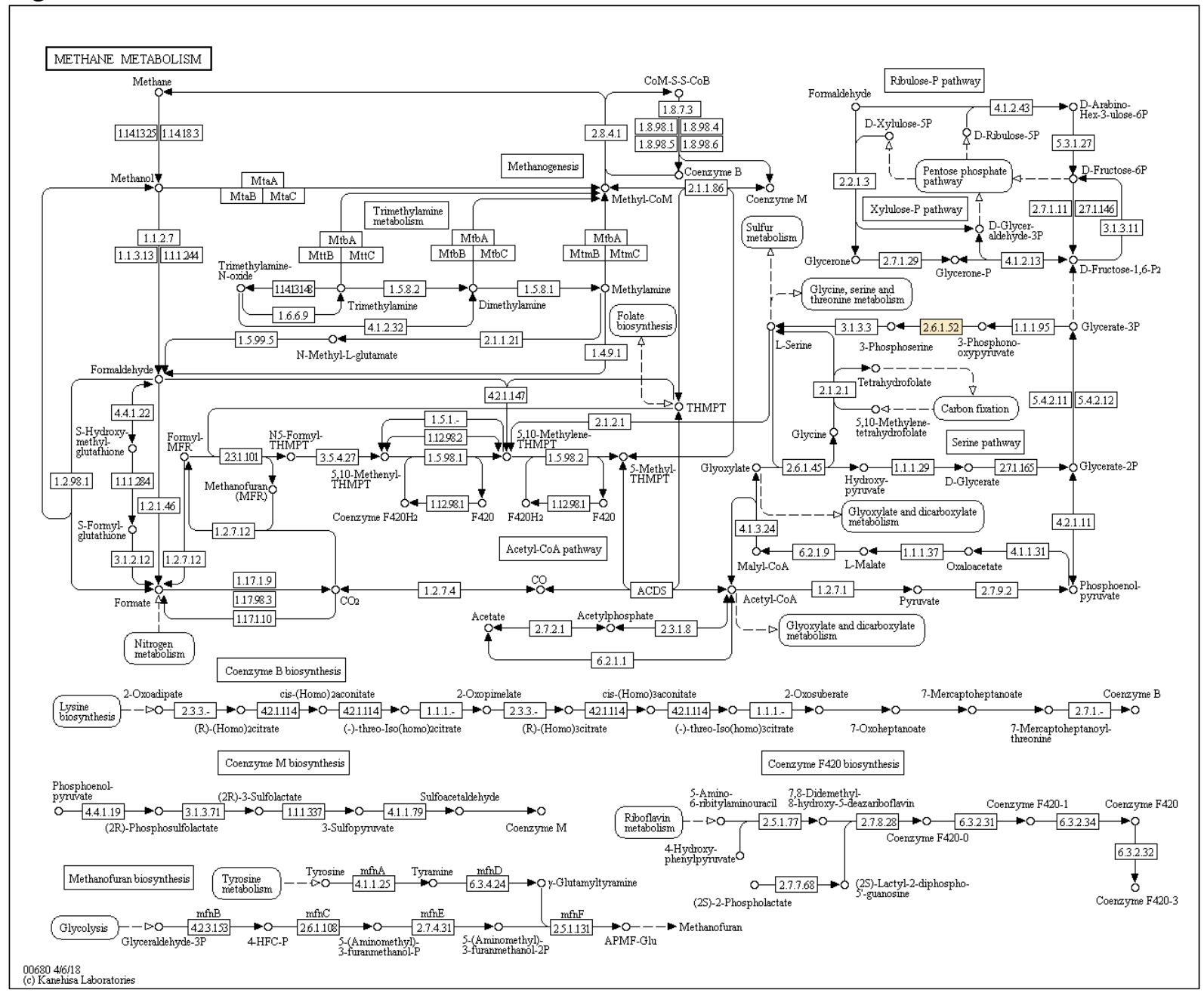

Fonte: Kegg pathway Database. 
Figura S5 - Degradação de Lisina.

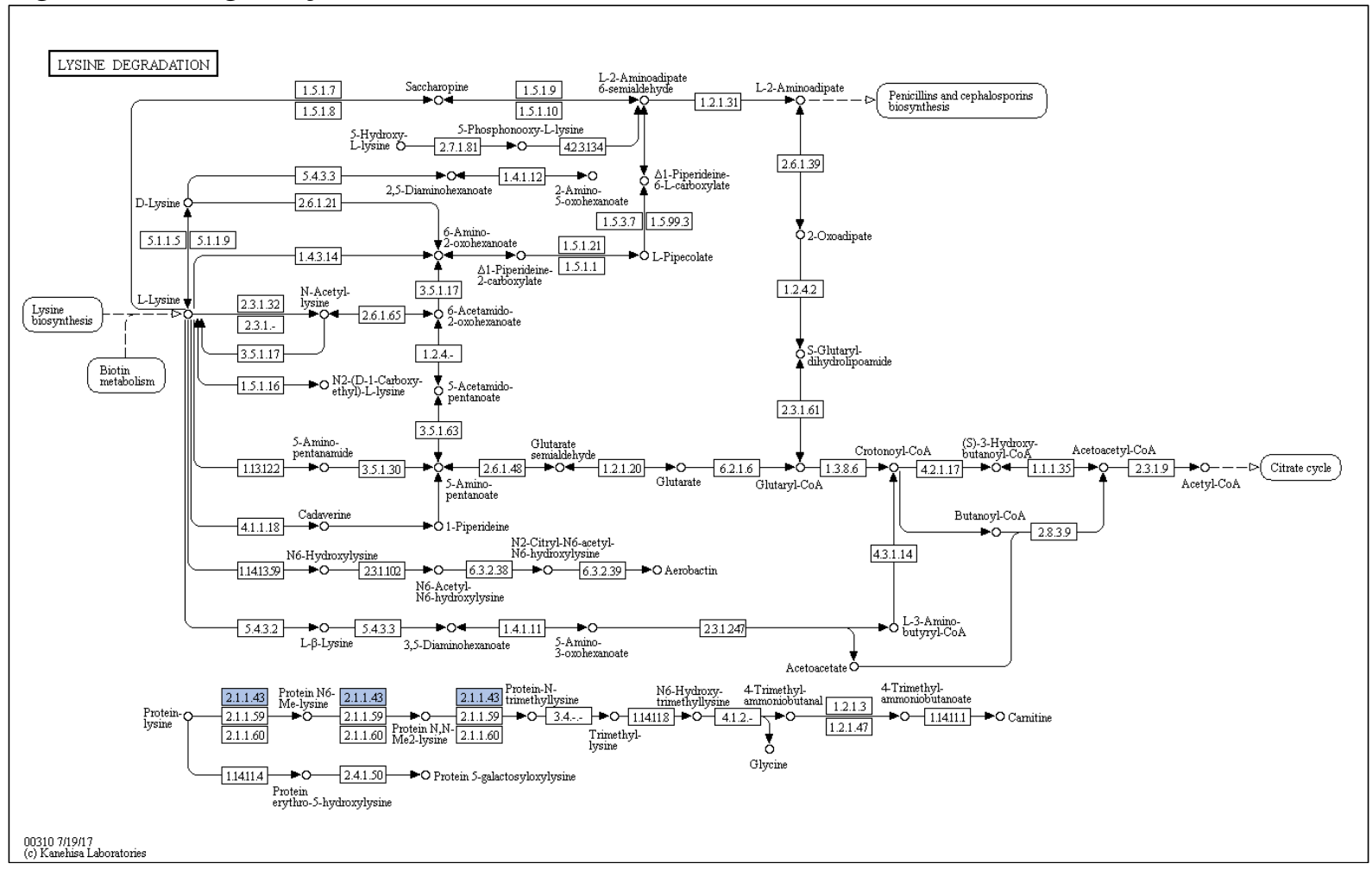

Fonte: Kegg pathway Database. 
Figura S6 - Absorção Mineral.

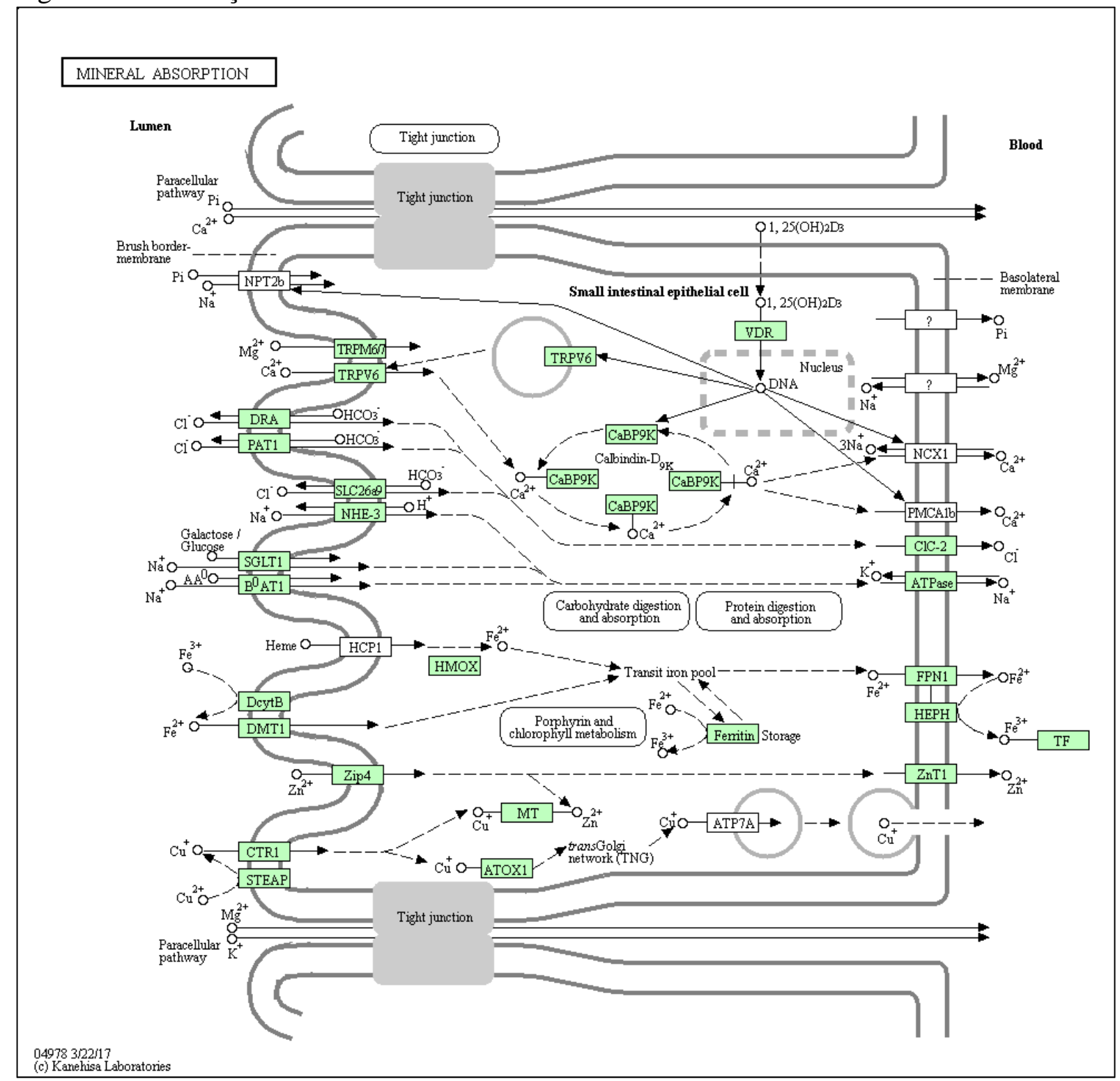

Fonte: Kegg pathway Database. 
Figura S7 - Metabolismo de riboflavina.

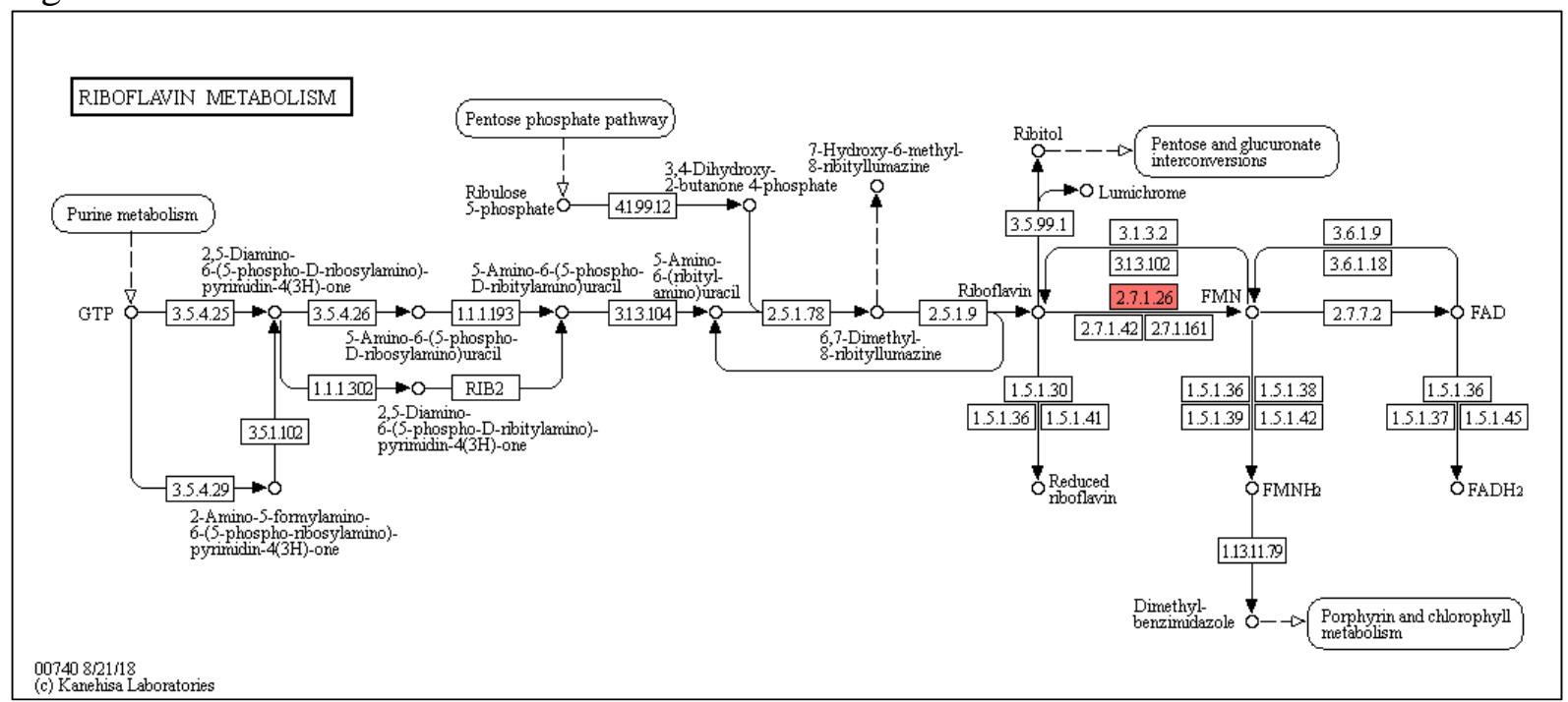

Fonte: Kegg pathway Database.

Figura S8 - Transdução olfatória.

OLFACTORY TRANSDUCTION
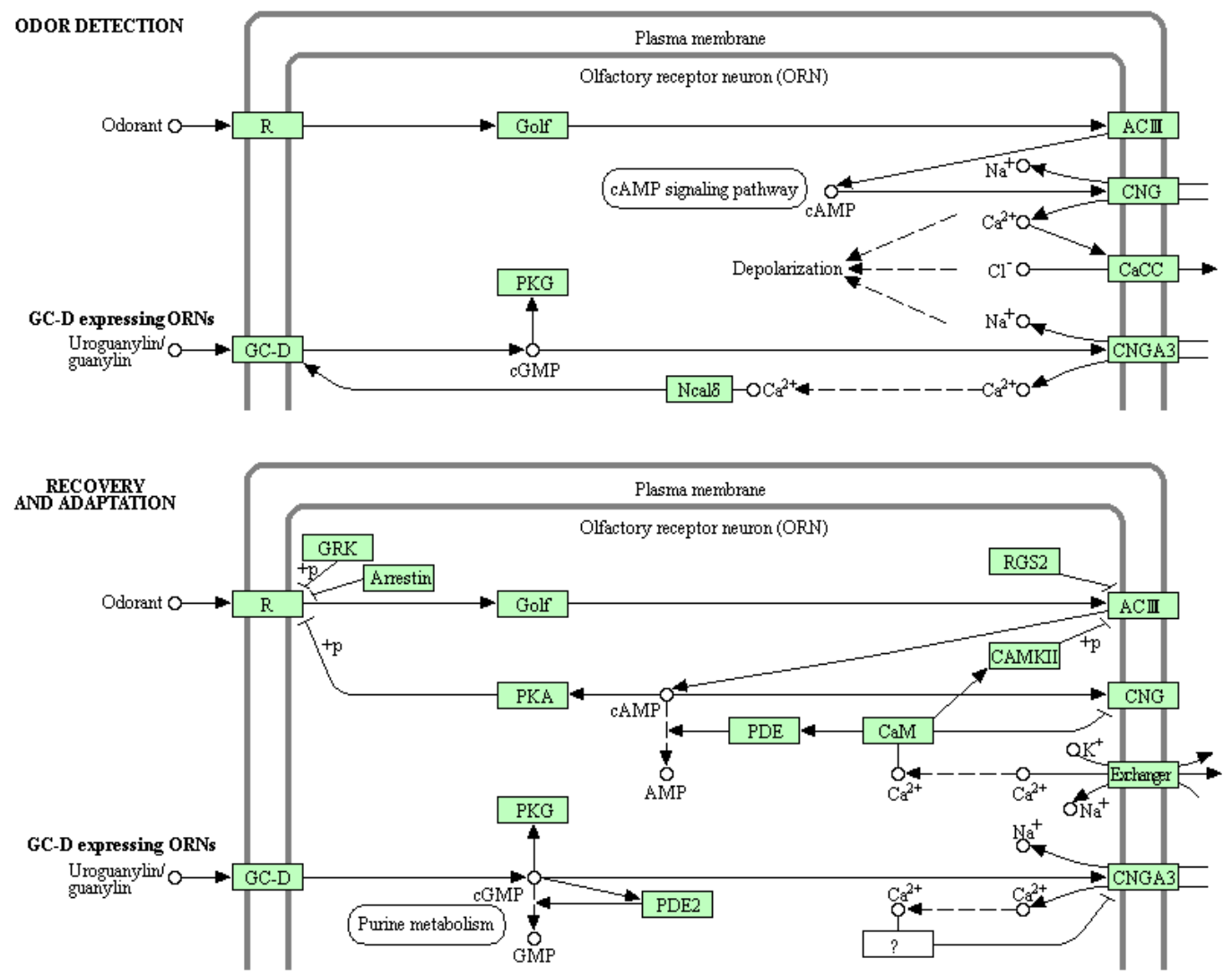

04740 12/9/15

(c) Kanehisa Laboratories

Fonte: Kegg pathway Database. 


\section{APÊNDICE E - Resultados da habilidade de predição fenotípica}

Tabela S1 - Matriz de confusão para a classificação do andamento baseada nos SNPs que explicaram mais de $1 \%$ da variância genética aditiva.

\begin{tabular}{lrrrrr}
\hline \multirow{2}{*}{ Grupo classificado } & \multicolumn{2}{c}{ Grupo verdadeiro } & \multirow{2}{*}{ Total } & \multirow{2}{*}{ Erros de inclusão } \\
\cline { 2 - 3 } & Marcha Batida & Marcha Picada & & & 0,11 \\
Marcha Batida & 124 & 16 & 140 & 0,10 \\
Marcha Picada & 10 & 90 & 100 & \\
Total & 134 & 106 & 240 & \\
Erros de omissão & 0,07 & 0,15 & & \\
\hline
\end{tabular}

Fonte: Própria autoria.

Figura S1 - Frequências genotípicas dos SNPs que explicaram mais de 1\% da variância genética aditiva nos animais apresentando marcha batida (A) e marcha picada (B).

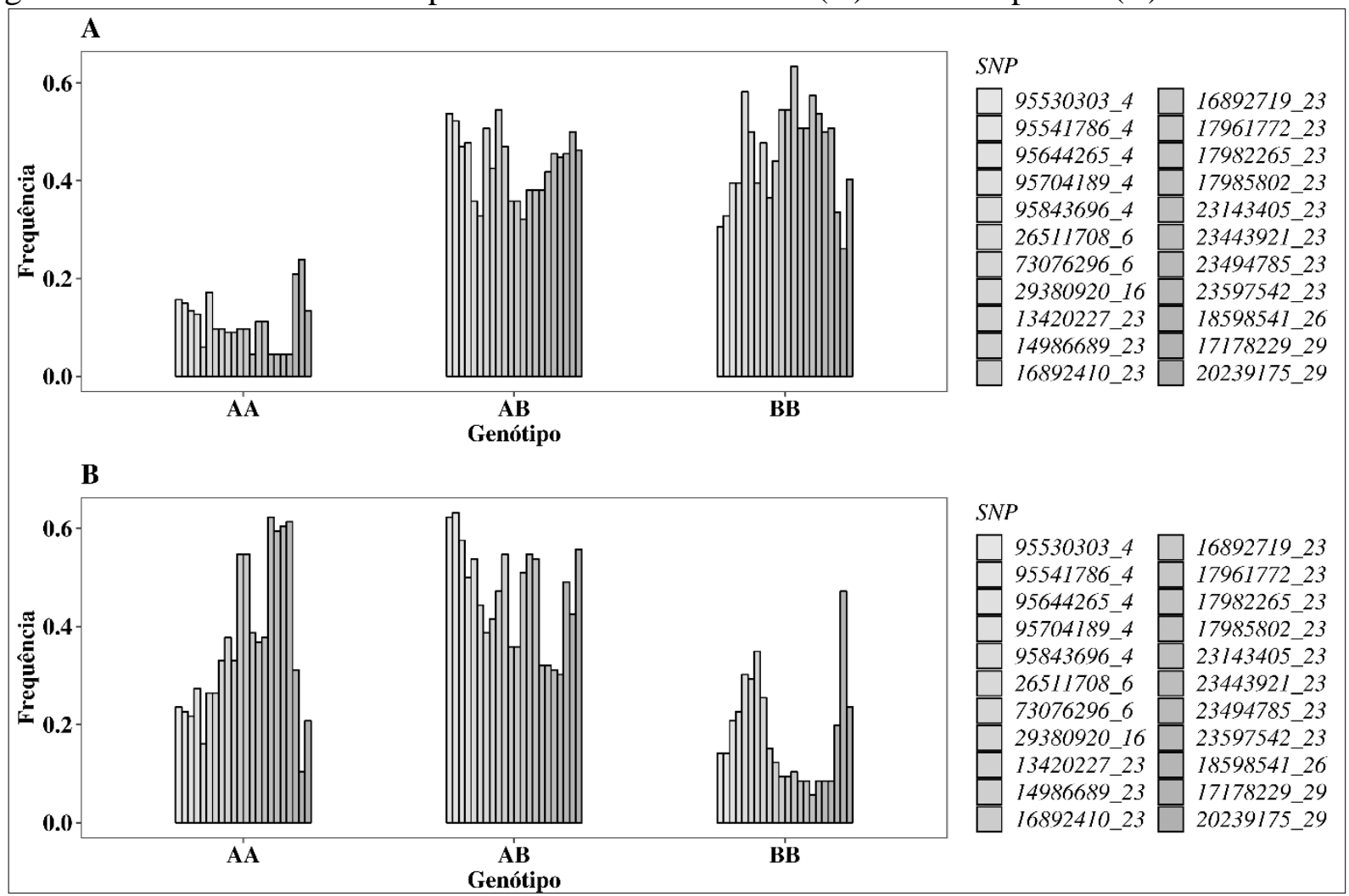

Fonte: Própria autoria. 
Figura S2 - Análise de componentes principais da matriz de relacionamentos genômica construída com base nos SNPs que explicaram mais de $1 \%$ da variância genética aditiva, de acordo com tipo de andamento: primeiro e segundo componentes $(\mathrm{C})$; primeiro e terceiro componentes (D) e segundo e terceiro componentes (E).

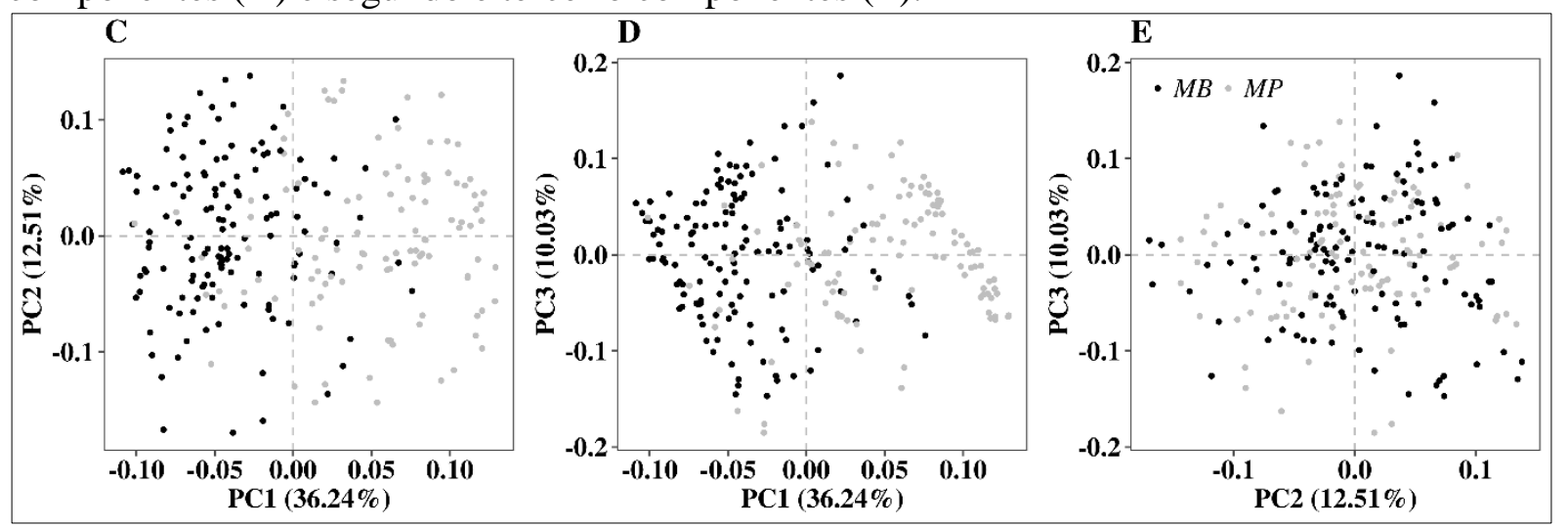

Fonte: Própria autoria. 


\section{APÊNDICE F - Outros genes possivelmente envolvidos na determinação do tipo de marcha}

O gene anexina Al tem sido descrito como uma proteína anti-inflamatória, com funções relacionadas à apoptose e fagocitose (DAKIN; DUDHIA; SMITH, 2013). McNeil et al. (2006) descreveram esse gene como uma maquinaria de reparo, envolvida no processo de fusão celular e apontaram que sua expressão é aumentada quando ocorre distrofia muscular. É possível que este gene atue sobre os tendões diferencialmente para animais MP ou MB. De outra forma, o gene ANO7 está relacionado à abertura de canais celulares de cloreto na dependência do aumento de $\mathrm{Ca}^{2+}$ intracelular (TIAN; SCHREIBER; KUNZELMANN, 2012) e Wanitchakool et al. (2014) descreveram esse gene como um fosfolipídio scramblase. Tais canais são responsáveis pela transdução olfativa e pela excitação neuronal (DURAN et al., 2012).

Em humanos, o gene $C A C N B 2$ está relacionado à pressão arterial e ao risco de hipertensão (LIN et al., 2011), além de insuficiência cardíaca e transtornos mentais (SOLDATOV, 2015a). Este gene age sobre os canais de cálcio, codificando as subunidades $\beta$, que são moduladores dos canais de $\mathrm{Ca}^{2+}$ (CHERNYAVSKAYA et al., 2012; SOLDATOV, 2015b). É possível que este gene atue sobre a via do metabolismo de cálcio que foi encontrado neste estudo.

O gene $C D N F$ atua sobre o processo neuroinflamatório (NADELLA et al., 2014) e pode ser responsável pela conversão de células NG2 em astrócitos, além de aliviar o estresse e prevenir a morte de neurônios na neurodegeneração. Este gene também atua como um neuroprotetor contra a perda de dopamina mesencefálica (BACK et al., 2013) que afeta o desempenho motor (DAUER; PRZEDBORSKI, 2003). Esse gene pode atuar tanto no desempenho motor (pela proteção contra as perdas de dopamina no mesencéfalo, devido ao alto nível de estresse da MP) como na recuperação inflamatória (causada pelos níveis de lactato após o exercício). Outro gene que age sobre a inflamação é o GCNT1 que está relacionado ao recrutamento de linfócitos (MARDAHL et al., 2016). O papel da inflamação na determinação do tipo de marcha permanece incerto, mas estes genes são relacionados com a recuperação dos tecidos e a adaptação fisiológica para a marcha.

O gene EPHB6 é um dos receptores da EPH que são a maior família conhecida de receptores de tirosina quinases. Estas proteínas estão relacionadas à orientação axonal, organização tecidual e plasticidade sináptica (FOX; KANDPAL, 2011). Este gene está também

relacionado com a sinalização das células T (HAFNER et al., 2003). É possível que esse gene 
atue sobre a organização do tecido neurológico por sua ação sobre a orientação axonal, o que pode estar relacionado ao tipo de marcha. Além disso, esse gene pode atuar sobre a inflamação nos tendões por meio do recrutamento de células-T.

Um gene que pode afetar os outros é o $H D L B P$, que está relacionado ao metabolismo do colesterol (FIDGE, 1999), e também desempenha um papel importante na manutenção da estrutura da heterocromatina, segregação cromossômica e regulação da expressão gênica (WANG et al., 2005).

O gene NSUN6 está relacionado com a metilação da citosina (AGUILO et al., 2016) e medeia as ligações entre o citoesqueleto e o nucleosqueleto (TELFORD et al., 2015). Este gene também é um farmacogênico envolvido na resposta à varfarina, um anticoagulante para o tratamento de trombose (HANSEN; BRUNAK; ALTMAN, 2009) e McGivney et al. (2009) apontaram que esse gene está envolvido na adaptação às respostas ao exercício.

$\mathrm{O}$ gene PASK está envolvido no processo de resposta à pancreatite e medeia diretamente os efeitos da glicose na transcrição gênica (DA SILVA XAVIER; RUTTER; RUTTER, 2004). Hao; Rutter (2008), discutiram a relevância deste gene no metabolismo energético. Esse gene também pode estar envolvido na via do metabolismo de metano que está conectado ao metabolismo energético. Segundo Hofer et al. (2001) o gene PPP1R7 compartilha a região promotora com o gene $P A S K$, assim esses genes podem agir juntos. O principalmente papel do gene PPPIR7 está ligado com a mitose (RENOUF et al., 1995) e funções da matriz extracelular (MORAN et al., 2002).

O gene PRUNE2 está associado com câncer e glioblastomas em células indiferenciadas (CHERAY et al., 2011), mas Li et al. (2011) apresentaram evidências de que esse gene é expresso em núcleos motores cranianos, neurônios motores na medula espinhal e neurônios sensoriais que podem ser relacionados a novas funções desse gene, que permanecem incertas.

Presente no cérebro e no fígado (BAEK et al., 2003) o gene PSAT1 é responsável pela segunda etapa da biossíntese de serina, desempenhando um papel nas funções metabólicas (LIAO et al., 2016). O que pode explicar o envolvimento deste gene nas vias metabólicas as quais foi significativamente associado. As funções desse gene no metabolismo aminoacídico podem estar ligadas à nutrição que desempenha um papel na formação e manutenção das fibras musculares.

O número de receptores de células T encontrado pode estar relacionado às respostas inflamatórias que são produzidas pelo organismo do animal após o exercício. Essa resposta deve-se ao lactato como sinalização para o recrutamento de células $\mathrm{T}$ e é possível que o 
recrutamento dessas células seja diferente de acordo com o tipo de marcha, uma vez que elas apresentam diferentes alterações nas concentrações de lactato. Essa associação entre o tipo de marcha e o sistema imune pode confirmar o grande número de genes que possuem funções imunológicas, bem como funções celulares (RTC, SNED1, SUV39H-2, TRBV23-1, TRBV30, TRPM6 e TRPV6).

\section{Referências}

AGUILO, F. et al. Deposition of 5-Methylcytosine on Enhancer RNAs Enables the Coactivator Function of PGC-1 $\alpha$. Cell Reports, v. 14, n. 3, p. 479-492, 2016.

BACK, S. et al. Gene therapy with AAV2-CDNF provides functional benefits in a rat model of Parkinson's disease. Brain and Behavior, v. 3, n. 2, p. 75-88, 2013.

BAEK, J. Y. et al. Characterization of human phosphoserine aminotransferase involved in the phosphorylated pathway of 1-serine biosynthesis. Biochemical Journal, v. 373, n. 1, p. 191200, 2003.

CHERAY, M. et al. Glycosylation-related gene expression is linked to differentiation status in glioblastomas undifferentiated cells. Cancer Letters, v. 312, n. 1, p. 24-32, 2011.

CHERNYAVSKAYA, Y. et al. Voltage-gated calcium channel CACNB2 $(\beta 2.1)$ protein is required in the heart for control of cell proliferation and heart tube integrity. Developmental Dynamics, v. 241, n. 4, p. 648-662, 2012.

DA SILVA XAVIER, G.; RUTTER, J.; RUTTER, G. A. Involvement of Per-Arnt-Sim (PAS) kinase in the stimulation of preproinsulin and pancreatic duodenum homeobox 1 gene expression by glucose. Proceedings of the National Academy of Sciences, v. 101, n. 22, p. 8319-8324, 2004.

DAKIN, S. G.; DUDHIA, J.; SMITH, R. K. W. Science in brief: Resolving tendon inflammation. A new perspective. Equine Veterinary Journal, Hoboken, v. 45, n. 4, p. 398400, 2013.

DAUER, W.; PRZEDBORSKI, S. Parkinson's disease: Mechanisms and models. Neuron, v. 39, n. 6, p. 889-909, 2003.

DURAN, C. et al. ANOs 3-7 in the anoctamin/Tmem16 Cl- channel family are intracellular proteins. AJP: Cell Physiology, v. 302, n. 3, p. C482-C493, 2012.

FIDGE, N. H. High density lipoprotein receptors, binding proteins, and ligands. Journal of Lipid Research, v. 40, n. 187, p. 201, 1999.

FOX, B. P.; KANDPAL, R. P. A paradigm shift in EPH receptor interaction: Biological relevance of EPHB6 interaction with EPHA2 and EPHB2 in breast carcinoma cell lines.

Cancer Genomics and Proteomics, v. 8, n. 4, p. 185-193, 2011. 
HAFNER, C. et al. Loss of EphB6 expression in metastatic melanoma. International journal of oncology, v. 23, n. 6, p. 1553-1559, 2003.

HANSEN, N. T.; BRUNAK, S.; ALTMAN, R. B. Generating genome-scale candidate gene lists for pharmacogenomics. Clinical Pharmacology and Therapeutics, v. 86, n. 2, p. 183$189,2009$.

HAO, H. X.; RUTTER, J. The role of PAS kinase in regulating energy metabolism. IUBMB Life, v. 60, n. 4, p. 204-209, 2008.

HOFER, T. et al. Mammalian PASKIN, a PAS-serine/threonine kinase related to bacterial oxygen sensors. Biochemical and Biophysical Research Communications, v. 288, n. 4, p. 757-764, 2001.

LI, S. et al. The expression and localization of Prune 2 mRNA in the central nervous system. Neuroscience Letters, v. 503, n. 3, p. 208-214, 2011.

LIAO, K. M. et al. Overexpression of the PSAT1 gene in nasopharyngeal carcinoma is an indicator of poor prognosis. Journal of Cancer, v. 7, n. 9, p. 1088-1094, 2016.

LIN, Y. et al. Genetic variations in CYP17A1, CACNB2 and PLEKHA7 are associated with blood pressure and/or hypertension in she ethnic minority of China. Atherosclerosis, v. 219, n. 2, p. 709-714, 2011.

MARDAHL, M. et al. Core 2 B1,6-N-acetylglucosaminyltransferase-I, crucial for P-selectin ligand expression is controlled by a distal enhancer regulated by STAT4 and T-bet in CD4+ T helper cells 1. Molecular Immunology, v. 77, p. 132-140, 2016.

MCGIVNEY, B. A. et al. Transcriptional adaptations following exercise in Thoroughbred horse skeletal muscle highlights molecular mechanisms that lead to muscle hypertrophy.

BMC Genomics, v. 10, p. 1-18, 2009.

MCNEIL, A. K. et al. Requirement for annexin A1 in plasma membrane repair. Journal of Biological Chemistry, v. 281, n. 46, p. 35202-35207, 2006.

MORAN, J. L. et al. Gene expression changes during mouse skeletal myoblast differentiation revealed by transcriptional profiling. Physiological Genomics, v. 10, n. 2, p. 103-111, 2002.

NADELLA, R. et al. Transient transfection of human CDNF gene reduces the 6hydroxydopamine-induced neuroinflammation in the rat substantia nigra. Journal of Neuroinflammation, v. 11, n. 1, p. 1-18, 2014.

RENOUF, S. et al. Molecular cloning of a human polypeptide related to yeast sds22, a regulator of protein phosphatase-1. FEBS Letters, v. 375, n. 1-2, p. 75-78, 1995.

SOLDATOV, N. CACNB2: An Emerging Pharmacological Target for Hypertension, Heart Failure, Arrhythmia and Mental Disorders. Current Molecular Pharmacology, v. 8, n. 1, p. 32-42, 2015a. 
SOLDATOV, N. CACNB2: An Emerging Pharmacological Target for Hypertension, Heart Failure, Arrhythmia and Mental Disorders. Current Molecular Pharmacology, v. 8, n. 1, p. 32-42, $2015 b$.

TELFORD, B. J. et al. Synthetic Lethal Screens Identify Vulnerabilities in GPCR Signaling and Cytoskeletal Organization in E-Cadherin-Deficient Cells. Molecular Cancer Therapeutics, v. 14, n. 5, p. 1213-1223, 2015.

TIAN, Y.; SCHREIBER, R.; KUNZELMANN, K. Anoctamins are a family of Ca2+activated Cl- channels. Journal of Cell Science, v. 125, n. 21, p. 4991-4998, 2012.

WANG, Q. et al. Vigilins Bind to Promiscuously A-to-I-Edited RNAs and Are Involved in the Formation of Heterochromatin. Current Biology, v. 15, p. 384-391, 2005.

WANITCHAKOOL, P. et al. Role of anoctamins in cancer and apoptosis. Philosophical Transactions of the Royal Society B: Biological Sciences, v. 369, n. 1638, 2014. 


\section{APÊNDICE G - Marcadores em possível desequilíbrio de ligação com o gene DMRT3}

Tabela S1 - Posição, porcentagem de variância genética aditiva explicada e MAF para os SNPs em algum nível de LD como o gene DMRT3 (Chr 23: 23:22378399-22392510).

\begin{tabular}{|c|c|c|c|}
\hline SNP posição (pb) & Chr. ${ }^{1}$ & Variância genética aditiva (\%) & MAF $^{2}$ \\
\hline 22.871 .873 & 23 & 0,00000 & 0,06 \\
\hline 22.886 .164 & 23 & 0,00000 & 0,05 \\
\hline 22.890 .741 & 23 & 0,00000 & 0,05 \\
\hline 22.891 .795 & 23 & 0,00000 & 0,05 \\
\hline 22.910 .150 & 23 & 0,00000 & 0,05 \\
\hline 22.911 .070 & 23 & 0,00000 & 0,05 \\
\hline 22.919 .002 & 23 & 0,00000 & 0,22 \\
\hline 22.920 .361 & 23 & 0,00001 & 0,22 \\
\hline 22.920 .480 & 23 & 0,00000 & 0,15 \\
\hline 22.921 .414 & 23 & 0,00000 & 0,04 \\
\hline 22.922 .059 & 23 & 0,00000 & 0,14 \\
\hline 22.924 .914 & 23 & 0,00000 & 0,04 \\
\hline 22.927 .015 & 23 & 0,01601 & 0,37 \\
\hline 22.946 .464 & 23 & 0,00000 & 0,01 \\
\hline 22.948 .065 & 23 & 0,00000 & 0,05 \\
\hline 22.948 .186 & 23 & 0,00000 & 0,03 \\
\hline 22.959 .925 & 23 & 0,00000 & 0,08 \\
\hline 22.972 .081 & 23 & 0,00000 & 0,04 \\
\hline 22.976 .199 & 23 & 0,00000 & 0,07 \\
\hline 23.018 .413 & 23 & 0,00000 & 0,22 \\
\hline 23.023 .859 & 23 & 0,00000 & 0,06 \\
\hline 23.026 .045 & 23 & 0,02608 & 0,39 \\
\hline 23.060 .877 & 23 & 0,00000 & 0,22 \\
\hline 23.060 .978 & 23 & 0,00000 & 0,13 \\
\hline 23.061 .231 & 23 & 0,00000 & 0,13 \\
\hline 23.063 .769 & 23 & 0,01833 & 0,34 \\
\hline 23.065 .806 & 23 & 0,00000 & 0,13 \\
\hline 23.068 .107 & 23 & 0,00001 & 0,36 \\
\hline 23.082 .209 & 23 & 0,00000 & 0,02 \\
\hline 23.087 .420 & 23 & 0,00000 & 0,06 \\
\hline 23.108 .192 & 23 & 0,00002 & 0,25 \\
\hline 23.116 .964 & 23 & 0,00000 & 0,06 \\
\hline
\end{tabular}

${ }^{1}$ Cromossomo;

${ }^{2}$ Frequência do alelo menor.

Fonte: Própria autoria. 


\section{APÊNDICE H - Interação entre as vias metabólicas encontradas}

Figura S1 - Visualização da interação entre as vias metabólicas, genes e metabolismos conforme discutido no item 5.4.3.

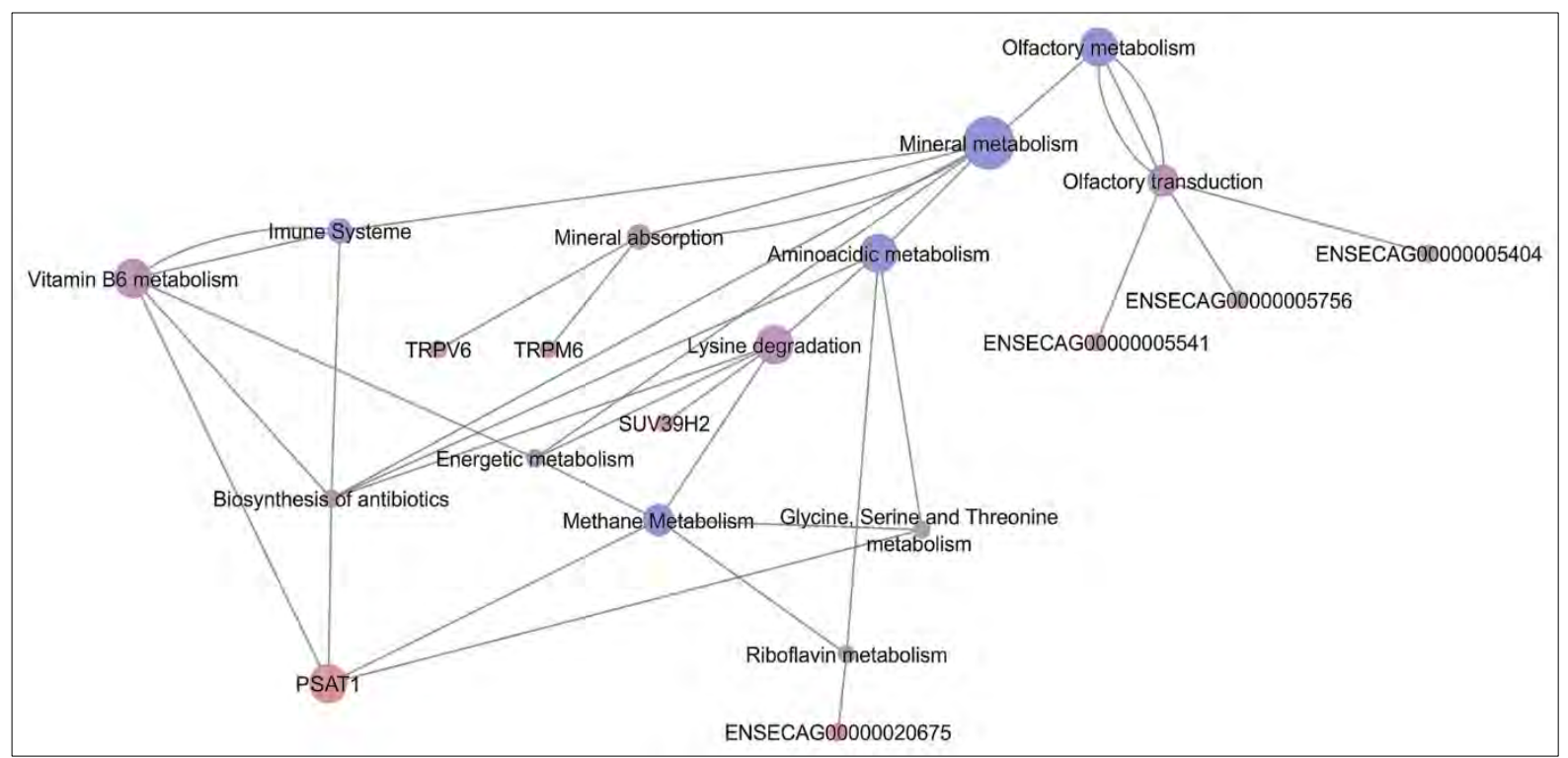

Fonte: Própria autoria. 


\section{APÊNDICE I - Haplótipos em torno dos SNPs que explicaram mais de $1 \%$ da variância genética aditiva}

Tabela S1 - Haplótipos preditos para os SNPs que explicaram mais de 1\% da variância genética aditiva.

\begin{tabular}{|c|c|c|c|c|c|c|}
\hline \multirow{2}{*}{$\begin{array}{l}\text { SNP posição } \\
(\mathrm{bp})^{1}\end{array}$} & \multirow{2}{*}{ Chr. $^{2}$} & \multirow{2}{*}{$\begin{array}{l}\text { Tamanho do } \\
\text { haplótipo }(\mathrm{kb})\end{array}$} & \multicolumn{2}{|c|}{ Posição do haplótipo ${ }^{3}$} & \multirow{2}{*}{$\begin{array}{l}\text { Número de } \\
\text { SNPs }\end{array}$} & \multirow{2}{*}{$\begin{array}{l}\text { Posição de } \\
\text { Cada SNP }\end{array}$} \\
\hline & & & Início & Fim & & \\
\hline \multirow{15}{*}{26.511 .708} & \multirow{15}{*}{6} & \multirow{15}{*}{89,985} & \multirow{15}{*}{26.433 .403} & \multirow{15}{*}{26.523 .387} & \multirow{15}{*}{15} & 26.433 .403 \\
\hline & & & & & & 26.438 .994 \\
\hline & & & & & & 26.447 .051 \\
\hline & & & & & & 26.450 .179 \\
\hline & & & & & & 26.453 .471 \\
\hline & & & & & & 26.454 .265 \\
\hline & & & & & & 26.478 .691 \\
\hline & & & & & & 26.488 .387 \\
\hline & & & & & & 26.492 .269 \\
\hline & & & & & & 26.504 .603 \\
\hline & & & & & & 26.505 .432 \\
\hline & & & & & & 26.508.977 \\
\hline & & & & & & 26.511 .708 \\
\hline & & & & & & 26.516 .744 \\
\hline & & & & & & 26.523 .387 \\
\hline \multirow{2}{*}{29.380 .920} & \multirow{2}{*}{16} & \multirow{2}{*}{3,462} & \multirow{2}{*}{29.380 .920} & \multirow{2}{*}{29.384 .381} & \multirow{2}{*}{2} & 29.380 .920 \\
\hline & & & & & & 29.384 .381 \\
\hline \multirow{2}{*}{18.598 .541} & \multirow{2}{*}{26} & \multirow{2}{*}{0,393} & \multirow{2}{*}{18.598 .149} & \multirow{2}{*}{18.598 .541} & \multirow{2}{*}{2} & 18.598 .149 \\
\hline & & & & & & 18.598 .541 \\
\hline
\end{tabular}

${ }^{1}$ SNPs que explicaram mais de $1 \%$ da variância genética aditiva;

${ }^{2}$ Cromossomo;

${ }^{3}$ Estes haplótipos foram preditos no software Plink, considerando uma janela de $1 \mathrm{Mb}$ e um mínimo de LD = 0,70.

Fonte: Própria autoria. 


\section{APÊNDICE J - Taxa de falso descobrimento e efeitos dos marcadores}

Figura S1 - Taxa de falso descobrimento para cada marcador no painel utilizado neste estudo, calculado de acordo com o procedimento de Benjamini-Hochberg.

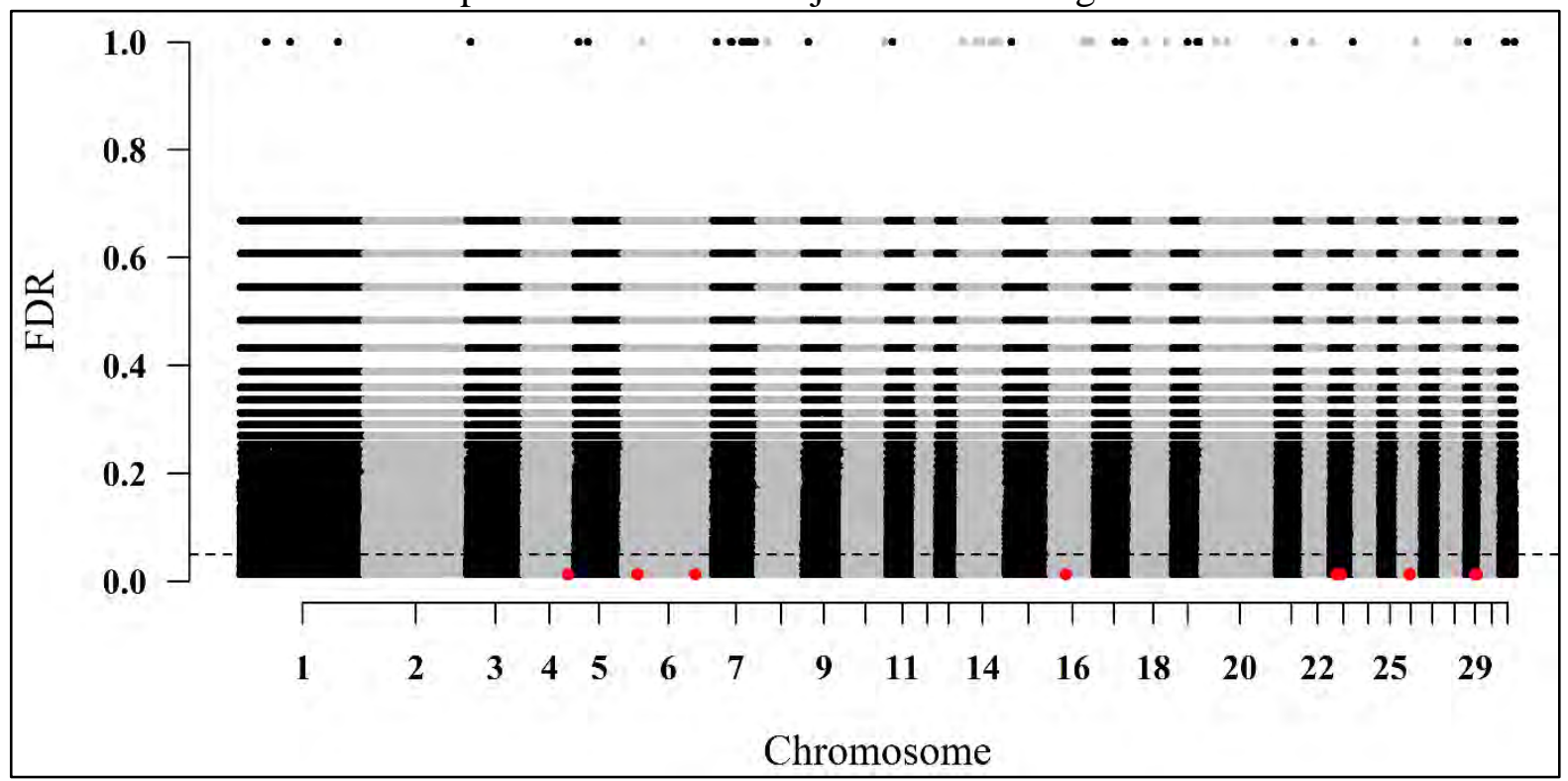

Fonte: Própria autoria. 
Tabela S1 - Erro padrão (SE), P-valor, taxa de falso descobrimento (FDR) e q-valor para os SNPs que explicaram mais de $1 \%$ da variância genética aditiva.

\begin{tabular}{|c|c|c|c|c|c|c|c|}
\hline Chr. ${ }^{1}$ & SNP & Position (pb) & $\begin{array}{l}\text { Additive genetic } \\
\text { variance }(\%)\end{array}$ & $\mathrm{SE}$ & P-value & FDR & q-value \\
\hline 4 & 95530303 44 & $95,530,303$ & 1.47 & 5.96 & 0.0244 & 0.0121 & 0.0584 \\
\hline 4 & 95541786_4 & $95,541,786$ & 1.26 & 5.51 & 0.0244 & 0.0121 & 0.0584 \\
\hline 4 & 95644265_4 & $95,644,265$ & 1.50 & 5.70 & 0.0246 & 0.0121 & 0.0584 \\
\hline 4 & 95704189_4 & $95,704,189$ & 1.77 & 5.99 & 0.0246 & 0.0121 & 0.0584 \\
\hline 4 & 95843696_4 & $95,843,696$ & 1.89 & 6.21 & 0.0261 & 0.0121 & 0.0584 \\
\hline 6 & 26511708_6 & $26,511,708$ & 3.26 & 7.41 & 0.0249 & 0.0121 & 0.0584 \\
\hline 6 & 73076296_6 & $73,076,296$ & 1.16 & 4.73 & 0.0249 & 0.0121 & 0.0584 \\
\hline 16 & 29380920_16 & $29,380,920$ & 2.22 & 6.33 & 0.0248 & 0.0121 & 0.0584 \\
\hline 23 & 13420227_23 & $13,420,227$ & 3.34 & 8.38 & 0.0244 & 0.0121 & 0.0584 \\
\hline 23 & 14986689_23 & $14,986,689$ & 4.30 & 9.43 & 0.0245 & 0.0121 & 0.0584 \\
\hline 23 & 16892410_23 & $16,892,410$ & 1.68 & 5.17 & 0.0244 & 0.0121 & 0.0584 \\
\hline 23 & 16892719_23 & $16,892,719$ & 1.68 & 5.17 & 0.0244 & 0.0121 & 0.0584 \\
\hline 23 & 17961772_23 & $17,961,772$ & 1.42 & 5.00 & 0.0249 & 0.0121 & 0.0584 \\
\hline 23 & 17982265_23 & $17,982,265$ & 1.04 & 4.40 & 0.0245 & 0.0121 & 0.0584 \\
\hline 23 & 17985802_23 & $17,985,802$ & 1.73 & 5.68 & 0.0245 & 0.0121 & 0.0584 \\
\hline 23 & 23143405_23 & $23,143,405$ & 1.50 & 4.86 & 0.0244 & 0.0121 & 0.0584 \\
\hline 23 & 23443921_23 & $23,443,921$ & 1.24 & 4.49 & 0.0244 & 0.0121 & 0.0584 \\
\hline 23 & 23494785_23 & $23,494,785$ & 1.39 & 4.81 & 0.0244 & 0.0121 & 0.0584 \\
\hline 23 & 23597542_23 & $23,597,542$ & 1.96 & 5.68 & 0.0244 & 0.0121 & 0.0584 \\
\hline 26 & 18598541_26 & $18,598,541$ & 2.28 & 6.63 & 0.0244 & 0.0121 & 0.0584 \\
\hline 29 & 17178229_29 & $17,178,229$ & 3.17 & 7.87 & 0.0248 & 0.0121 & 0.0584 \\
\hline 29 & 20239175_29 & $20,239,175$ & 1.17 & 4.95 & 0.0247 & 0.0121 & 0.0584 \\
\hline
\end{tabular}

${ }^{1}$ Cromossomo.

Fonte: Própria autoria. 
Figura S2 - Efeitos dos SNPs ( $3^{\text {a }}$ iteração) ao longo de cada cromossomo.

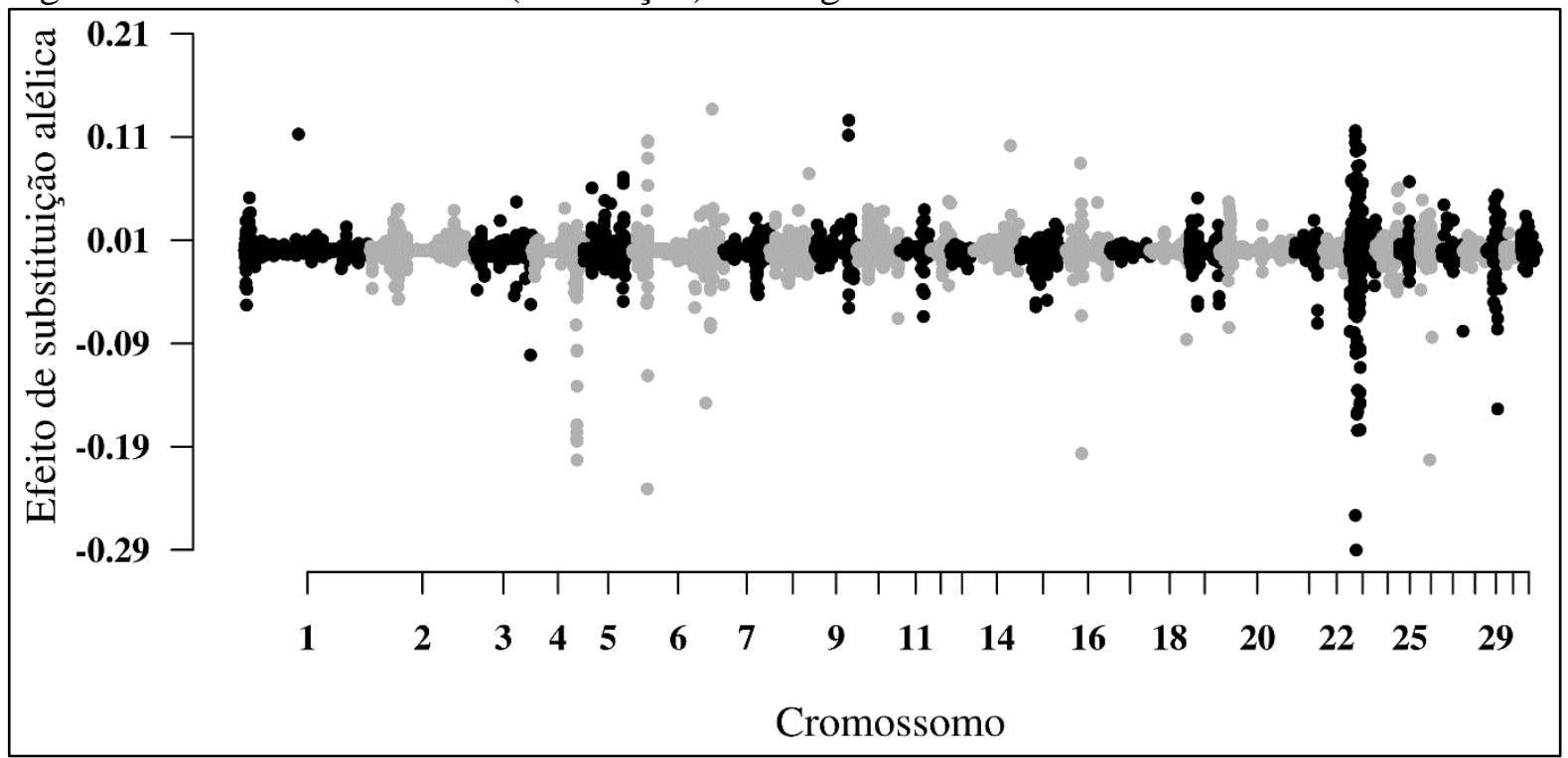

Fonte: Própria autoria.

Figura S3 - Distribuição dos efeitos dos marcadores.

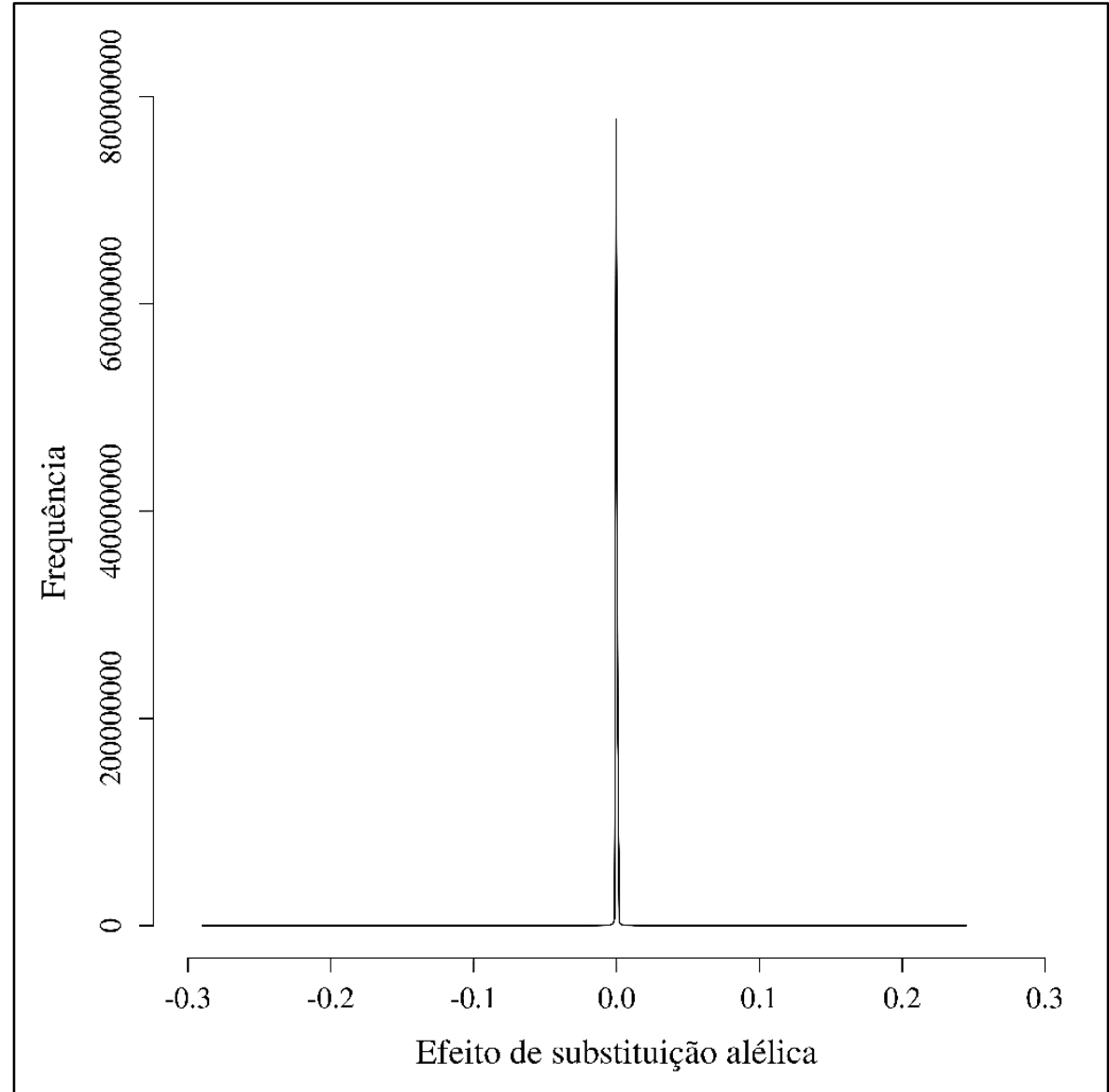

Fonte: Própria autoria. 